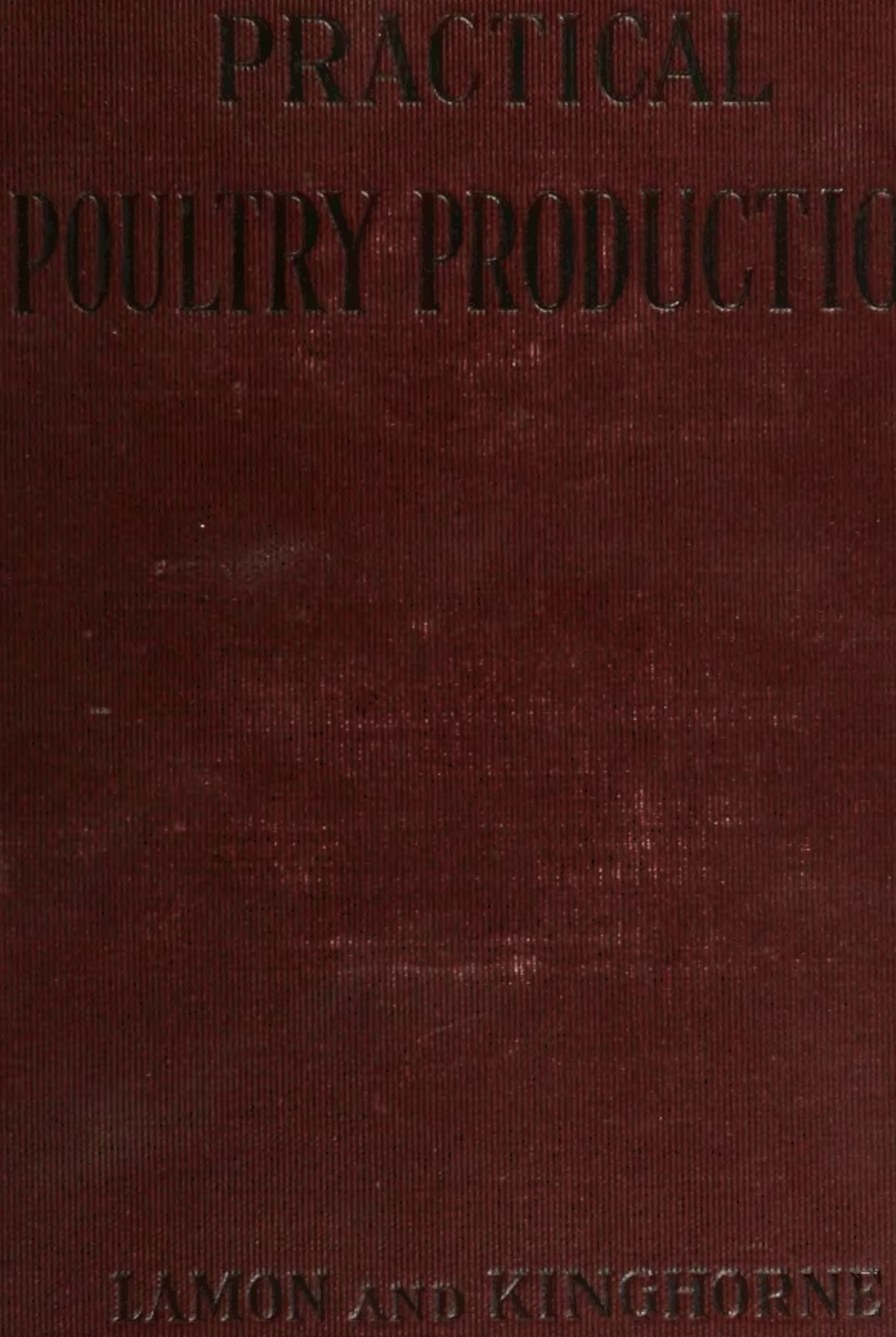




$$
\begin{gathered}
\text { SF } 497 \\
1.24
\end{gathered}
$$

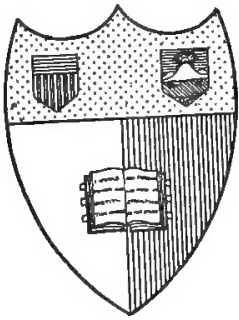

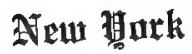

State Grallege af Aneitulture

\section{At U4nornell Atuinergity}

31thata, 於.

\section{Thithraxy}


SF 487 Cornell University Library

Practical poultry production,

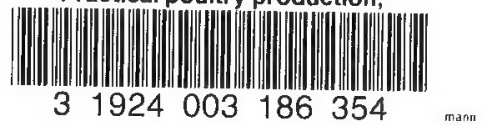




\section{Cornell University Library}

The original of this book is in the Cornell University Library.

There are no known copyright restrictions in the United States on the use of the text.

http://www.archive.org/details/cu31924003186354 



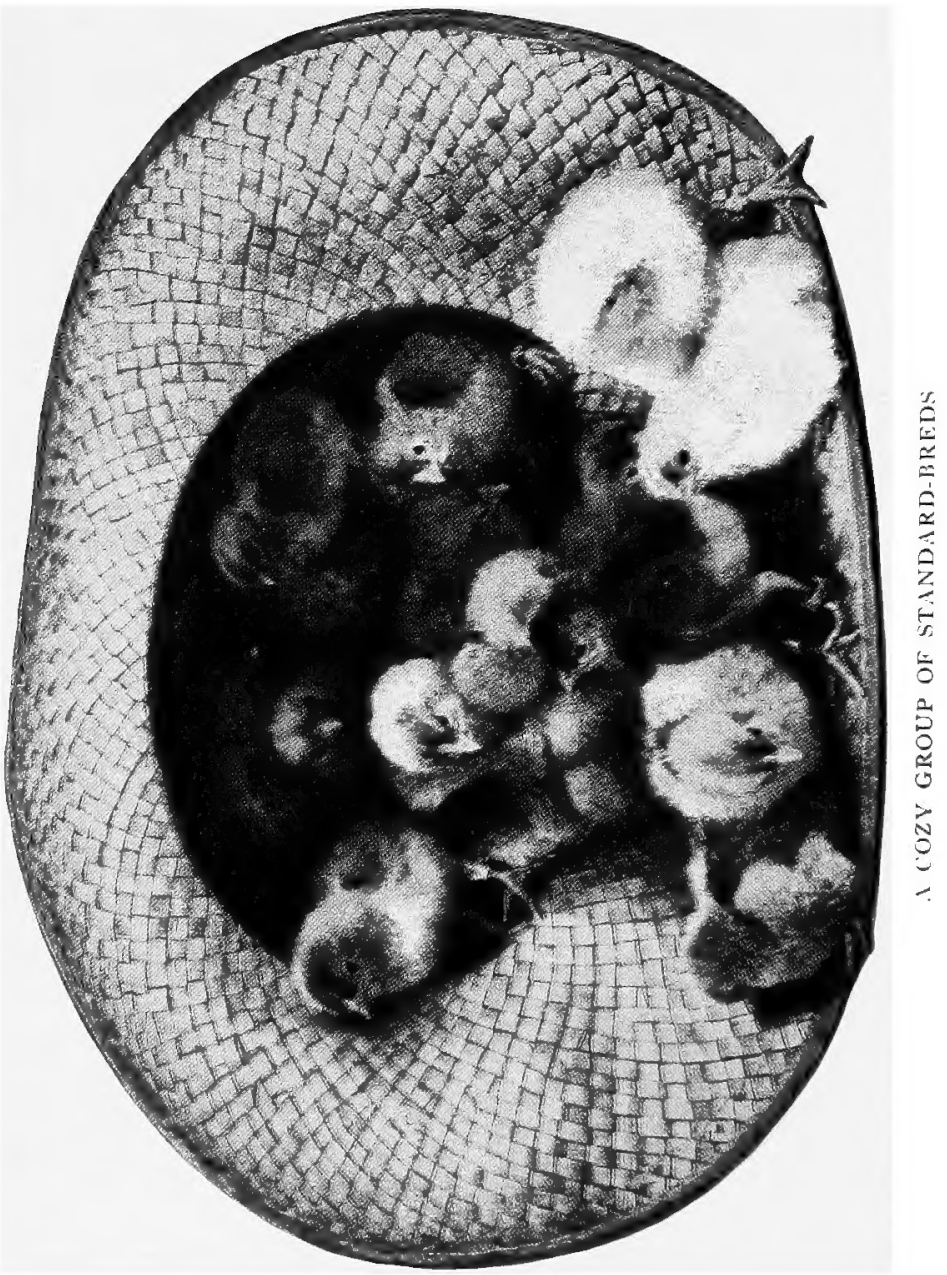




\section{PRACTICAL POULTRY PRODUCTION}

BY

HARRY M. LAMON

SENIOR POULTRYMAN, BUREAU OF ANIMAL INDUSTRY,

U. S. DEPARTMENT OF AGRICULTURE

AND

\section{JOS. WM. KINGHORNE}

JUNIOR POULTRYMAN, BUREAU OF ANIMAL INDUSTRY,

U. S. DEPARTMENT OF AGRICULTURE

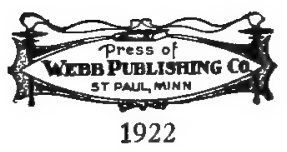


COPYRIGHTED， 1920-1922

WEBB PUBLISHING COMPANY

All Rights Reserved

W-3 


\section{DEDICATED}

TO THE

BOYS AND GIRLS

AND MEN AND WOMEN

WHO ARE DESIROUS OF SECURING DEFINITE INFORMATION THAT WILL HELP THEM TO SOLVE THEIR POULTRY PROBLEMS 



\section{PREFACE}

Many books have been written on general poultry keeping and the various branches of that industry. It seems, however, that no attempt has been made to present the fundamental principles and essentials in a manner and within a compass that will make a book both adequate and practical for student and poultry keeper alike.

It will be the effort of the authors to present the basic principles and practices of poultry keeping in such a way as to awaken interest, educate and develop purpose to undertake further work. It is natural and necessary, therefore, that some detail should be omitted. For example, some of the finer points of breeding, such as Mendel's Law, and elaborate points of judging are thought to be too extended and subordinate to the main object to be included.

While special chapters have been provided wherein such subjects as feeds, construction of equipment, etc., are discussed at length, it has been found advisable to treat special phases of these subjects under other chapter heads so as to clarify and complete the subject at hand. Thus, for example, while studying about chicks the student will find a complete discussion of the management, feeding, etc., of chicks without referring to other chapters. A clearer understanding of the subject can be obtained when treated this way, than if taken up at different times.

The general order of the chapters has been arranged with the thought that they will somewhat approximate the sequence of events both in the time of their occurrence in actual practice and classroom study.

It is believed that the subject of poultry keeping as herein presented will not only awaken interest among the boys and girls of graded and high schools, but that the brief and well illustrated nature of this work will suit it for farm- 
ers' short courses, movable schools, for special subject matter instruction to teachers, agricultural and home demonstration agents, and for any other courses or purpose where a general understanding of the subject is desired rather than specialization.

As ocular impression is an important educative factor, the various phases of poultry production have been elaborately illustrated. Under "Breeds and Varieties," for example, photographs are shown of the more popular breeds of each of the more important classes, so that the reader may have a graphic and complete idea of the appearance of the fowls, their class, and their economic usefulness. In like manner other phases of poultry keeping are illustrated and discussed.

Acknowledgment and appreciation are hereby extended the following men of the Animal Husbandry Division, Bureau of Animal Industry, U. S. Department of Agriculture, who through their helpful suggestions have aided in furthering this work: Alfred R. Lee, Rob R. Slocum, D. Lincoln Orr, D. M. Green, George W. Hackett and Jos. P. Quinn.

The authors further desire to acknowledge their appreciation to the officials of the U. S. Department of Agriculture for permission to publish this book. Credit is hereby given the U.S. Department of Agriculture for the illustrations contained herein, the use of which makes possible a clearer understanding of the fundamentals of poultry culture.

That a better understanding of the subject may be obtained, thereby affording the industry a continued and substantial growth in more efficient ways, is the desire and hope of the authors.

\footnotetext{
Harry M. Lamon Jos. Wm. Kinghorne Washington, D. C.
} 


\section{CONTENTS}

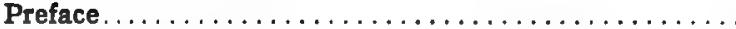

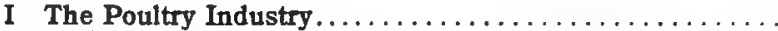
Size and extent.-Development.-Growth of incentives. -Poultry keeping on the farm.-Shows and education. - Intensive poultry sections.-Back-yard flocks.-The poultry breeder.

II Breeds and Varieties.........................

Origin and classification.-Selecting the breed.-Purpose, Standard-bred fowls vs. mongrels.-General-purpose Class: The Plymouth Rock, The Wyandotte, The Rhode Island Red, The Orpington.-The Egg Class: The Leghorn, The Ancona, The Minorea, The Blue Andalusian, The Campine.-The Meat Class: The Langshan, The Brahma, The Cochin, the Cornish.-The Game, Bantam, and Miscellaneous Classes.

III Breeding.

Importance.-Principles of breeding: Heredity, Variation, Sports or Mutations, Reversion or Atavism, Correlation, Regression, Progression, Prepotency, Fecundity, Inbreeding, Linebreeding, Outbreeding or outcrossing, Crossbreeding, Grading up.-Nomenclature of the fowl.-Essentials of poultry breeding: Health and vigor, Appearance and action. - Selection of the breeders: Size, Color, Head, Comb, Eyes, Neck, Body, Breast, Back, Wings, Tail, Legs and Toes, Skin.-Kind of fowls to reject.-Purpose of breeding.-Kinds of matings: Single mating, double mating, stud mating, flock or mass breeding.-Time to mate.-Size of mating.-Age of breeding stock.-Free range.-Management.-Feeding.

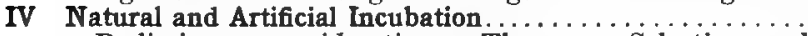

Preliminary considerations. - The egg.-Selection and care of eggs for hatching: Fertility, Freshness, Soiled eggs, Similar eggs, Sound shells, Normal eggs.-Method of packing eggs for hatching.-Period of incubation.-Proportion of males to females.-Time of year to hatch.When to hatch, When not to hatch.-Natural Incubation: How to set a hen, Indication of broodiness, Quarters, Dusting, Management of the sitting hen.-Artificial incubation: Incubators, Types of incubators, Selection of the incubator, Place to operate, Operation of the incubator, The Thermostat, The Thermometer, Operation, Correct temperature, Care of lamp, Turning the eggs, Cooling the eggs, Moisture and ventilation, Testing the eggs, Care of incubator at hatching time, Disinfecting and storing incubators.

v Natural and Artificial Brooding.

Natural Brooding: Brooding chicks with hens, Care of 
Chapter

Page

brood coop, Identifying chicks, Brood coops, Confine the mother hen.-Artificial brooding: Hovers, Brooders, Brooding systems, Individual hovers and brooders, Brooder stoves, Hot-water pipe brooders, Fireless brooders, 'Correct temperature for brooding, Care of purchased day-old chicks.

VI Care and Feeding of Chicks and Growing Stock.

Feeding and care of chicks: First feed, Green feed, Water.-Feeding and care of growing stock: Feeding: Grain feed, Dry mash, Sour milk, Green feed, Water. Care: Housing, Free range, Shade, Cleanliness.-General management.

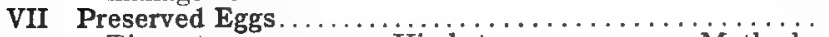

Time to preserve.-Kind to preserve--Methods: Waterglass, Lime Water-Disposition, Using, Selling.

VIII Poultry Houses and Appliances.................

Housing: Kind to build, Colony House and continuous house, Location, Time to build, Building Materials, Size and dimensions, Foundation and floors, Framework, Roof, Front, Walls, Partitions.-Interior arrangements: Roosts, Dropping board, Nests, Trap nests, Dust boxes, Broody coops, Drinking fountains, Ventilation.-Exterior arrangement: Yards, fences, gates, paint, whitewash.

IX Common Diseases and Treatment.

General prevention.-Common diseases, symptoms, and treatment: Roup, Canker, Cholera, Tuberculosis, Limberneck, Chickenpox, White comb, or favus, Blackhead, Frozen comb, Diarrhea in hens, White diarrhea in chicks, Intestinal worms, Gapes, Crop bound, Feather pulling, T'oe picking, Egg eating, Rheumatism, Scaly leg, Bumblefoot.

X Poultry Pests

Mites -Lice.-Head lice on chicks.-Stick-tight fleas.Poultry ticks, or blue bugs.--Chiggers.

$\mathrm{XI}$ Capons and Caponizing.

Capons: What is a capon? Advisability of caponizing, Most suitable breeds for capons.-Caponizing: Time to caponize, Caponizing instruments, The operation, Care after the operation, Subsequent management.-Feeding. -Killing and dressing.

XII Feeding for Egg Production.

Value of proper feeding.-Development of the egg.Poultry feeds and by-products: Grain feeds, Mash feeds, Commercial feeds, (Meat feeds, Green feeds, Charcoal, grit, and oyster shell, Water, Condiments and egg tonics.) Composition of feeds.-Balanced rations: Nutritive ratio, How to determine the nutritive ratio, Egg-laying rations.-Methods of feeding.-Quantity of grain to feed. -Artificial lighting: Kind of lights to use, Methods of feeding 
Object.-Culling the growing stock.-When to cull.Method: Sickness and lack of vigor, Molt, Shank color, Beak color, Vent color, Comb, Pelvic and keel bones, Flexibility of abdomen.-Kind to cull.-Kind to save.

XIV Turkeys, Ducks, Geese, Guinea Fowls, and Pigeons..... Turkeys.-Varieties: Bronze, White Holland, Bourbon Red, Black, Narragansett, Slate.-Management: Breeding, Mortality, Marketing.-Ducks.-Management.Breeds: The Meat Class: Pekin, Aylesbury, Muscovy, Rouen, Cayuga, Buff, Swedish.-The Egg Class: Indian Runner.-The Ornamental Class.-Geese.-Breeds: Toulouse, Emden, Chinese, African Wild, or Canadian, Egyptian.-Guineas.-Varieties; Pearl,White, Lavender. -Pigeons.-Varieties: Runts, White Kings, Carneaux, Homers, Maltese, Mondaine, Hungarians.

XV Preparing the Birds for Exhibition

Object and value of exhibiting poultry.-Kinds of poultry shows.-Preparing the birds for the show.-Selecttion, General disqualifications, Comb, Face, Back, Wings, Tail, Shanks and feet, Weight, Conditioning birds, Washing, Drying, Cleaning the head, feet and shanks.-Preparing ducks, geese, turkeys and pigeons for exhibition: Geese, Ducks, Turkeys, Pigeons.Shipping birds.- Show rules and regulations.

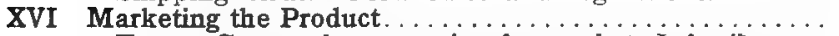

Eggs.-Care and preparation for market: Infertile eggs, Nests, Gathering eggs, Storing, Grading, Packing.Marketing: Precaution, By parcel post, By express, Packing, Weights. Table Fowls.-Broilers: Market classification, Time to market, Fattening.-Hens: Time to market, How to market-Capons: Killing, Best method of killing, Dry picking, Scalding, Drawing, Packing.-Turkeys.-Ducks.-Geese.-Guinea fowls.Squabs.-Shipping live poultry.

XVII Organization.

Junior clubs: Object of organization, Suggested constitution and by-laws, Plans for starting the actual work, Monthly meetings, Club exhibits, Awarding prizes on poultry work.-Adult community clubs: Advantages of such an organization, Selecting the community breed, Organization, Meetings, Development, Exhibits.

XVIII Business Management.

Hatching and brooding record.-Monthly statement sheet.-Yearly feed record.-Yearly egg record.-Yearly summary.- Yearly inventory.-Yearly balance sheet.Poultry club record.-Advertising: What and when to advertise, Methods of advertising, Answering inquiries.

Appendix........................ 335

Index.............................. 353 


$$
\text { - }
$$




\section{PRACTICAL POULTRY PRODUCTION}

\section{CHAPTER I \\ THE POULTRY INDUSTRY}

The production of poultry and eggs constitutes one of our most important branches of agriculture. To thoroughly appreciate this great source of food supply the magnitude of the poultry industry should be considered.

\section{SIZE AND EXTENT}

Size. It has been usual from the fact that most poultry is kept in comparatively small flocks on general farms, to regard the poultry industry as a little business. The relatively small size of these individual units has caused us to lose sight of the fact that flocks of fowls exist on practically every farm, and that in the aggregate they form an industry which is of great magnitude. Thus, for example, we find in the United States, according to the census of 1910, a total of over 5,500,000 farms reported as keeping poultry out of a total of a little over 6,300,000 farms. The value of the poultry and eggs produced in the United States during that year was somewhat in excess of $\$ 600,000,000.00$. This amount includes only the value of poultry products on farms and does not take into consideration a large amount which is produced by thousands of back-yard flocks in the villages and towns. Taking into consideration the great development and progress that has been made in poultry keeping since the 1910 census was taken, and since the further 

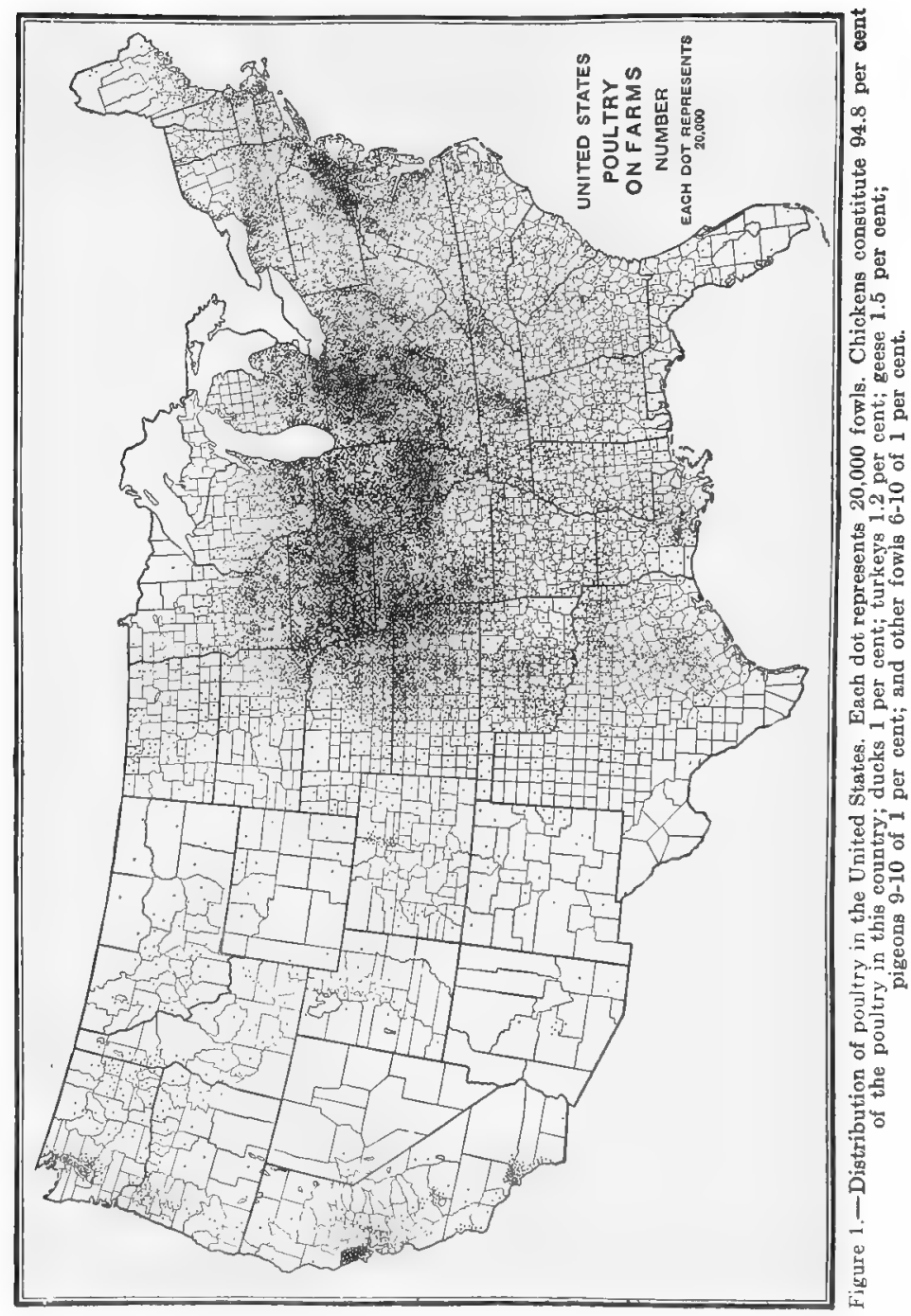
fact that back-yard flocks were not included in the 1910 census, it has been estimated that the poultry iudustry to-day totals a billion dollars annually.

As a measure of the importance of the poultry industry in the United States we find that, according to the 1910 census, it ranks seventh among the leading farm crops. The total value of poultry products is greater than the value of oats, is likewise greater than the combined value of timothy, clover, and alfalfa hay crop, as great as the combined value of all vegetables including potatoes, and greater than the

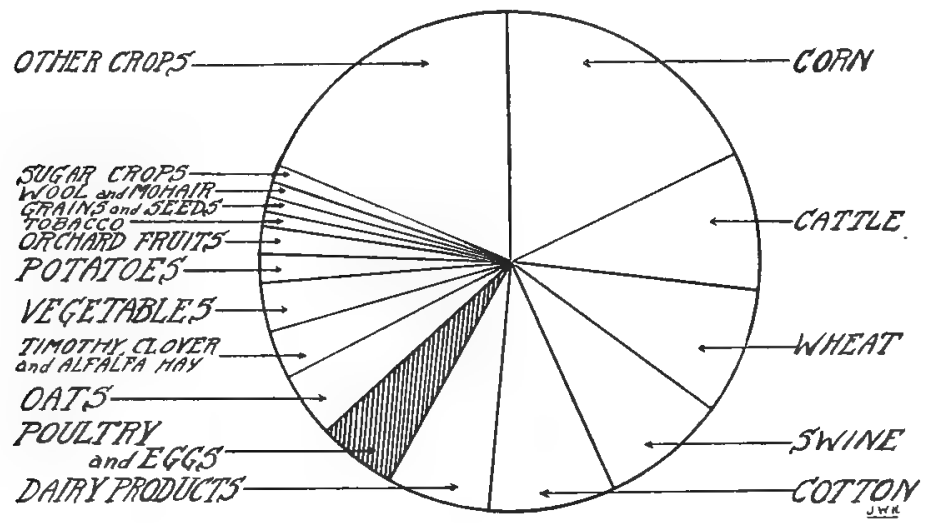

Figure 2.-Diagram showing relative value of poultry products sold as compared with other important farm crops.

combined values of orchard fruits, tobacco, seeds, and wool.

Extent. It is interesting to note in this connection that the leading agricultural states in the United States are also the largest poultry producing states, and, to pursue this subject still further, it appears that the leading agricultural counties in these states are likewise the leading poultry producing counties. From this fact it can be seen that general agricultural development and prosperity go hand in hand with poultry development. 


\section{DEVELOPMENT}

Growth of incentives. Judging from the nature of poultry keeping among our semicivilized races of recent times, it is probable that the domestication of fowls was first accomplished for the sport of cock fighting rather than for any economic reason. As the value of fowls as a source of food production became recognized, however, they were kept more and more for this purpose primarily. In consequence, from those early times until recent years the keeping of

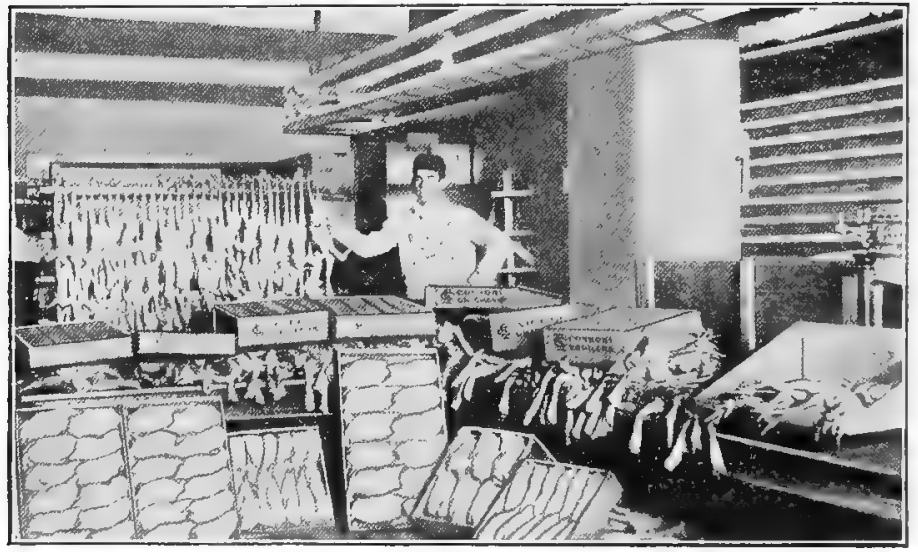

Figure 3.-Interior view of a modern cold-storage "plant.

poultry has been a matter of supplying food for the family. There was no incentive to keep a larger flock than would supply eggs and meat needed for the family, for the reason that transportation facilities were not such as to allow the surplus to be taken any considerable distance for disposal. When there was such a surplus it came to be largely a medium of barter or exchange with neighbors or with the merchants of near-by villages or towns. With the advent of steam railroads, however, and, more lately with the coming of cold storage, it has been possible to ship poultry and eggs long 
distances successfully. It has also been made possible through cold storage to conserve the surplus products in the natural breeding season, which is the spring of the year, until they can be disposed of during the season of scarcity in the fall and winter. During this period large quantities of poultry and eggs are placed in cold storage. This equalization of supply and demand has had a most profound effect on the poultry industry. It has made it possible for poultry keepers to dispose of surplus poultry and eggs during the season of greatest production at a price which is

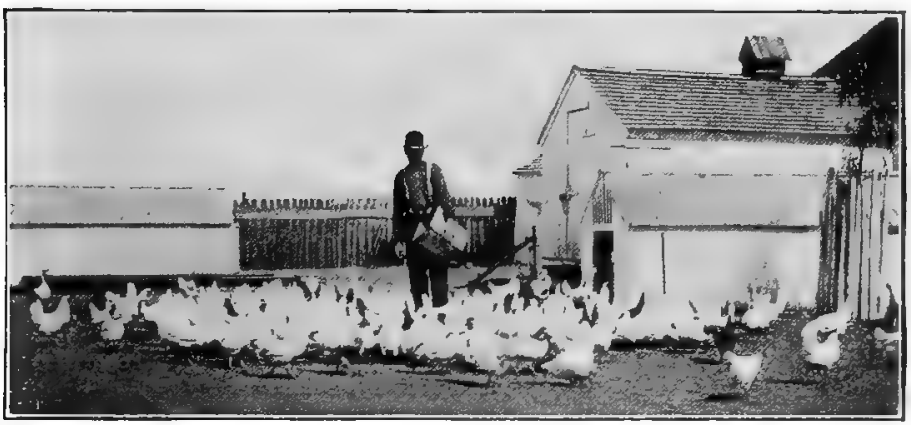

Figure 4.-The farm flock can be made a source of considerable revenue for practically the entire year.

profitable to them where previously they would have been unable to get prices which made it worth their while.

Poultry keeping on the farm. As a consequence of this condition, the development of poultry keeping has grown beyond the point where the farmer or poultryman has limited the size of his flock to meet approximately the needs of his own family, and has made poultry keeping one of the activities on the farm, from which an actual money income is received. In this connection it is worthy to note that the poultry flock on many farms, particularly of late years with the development of better methods, has proven to be 
a revenue producer practically all the year round. In many instances the amount of money received from poultry has been surprisingly large, often sufficient to buy the food and pay for the clothing of the family. The money from poultry and eggs, taken together with their other yearround revenue producers on the farm, such as butter, has, therefore, come to be a decided factor in providing for the physical welfare of the farmer and his family, and in many instances has gone still further and become one of the chief agencies in helping to pay off the farm mortgage or other indebtedness. It often happens that the care of the poultry flock becomes primarily the work of the farm women. Thus the women frequently have control of a part or all of the income derived from the poultry flock. In such instances it will be found that much of this money goes for purposes which tend to improve conditions of life on the farm and to provide conveniences and comforts in the home. The money is also often used to further the education of the children as well as to broaden the life and outlook of the farm communities.

A further development of the industry can be cited in the growth of special commercial poultry farms, where the keeping of poultry for the production of market eggs is the main activity. Sometimes these poultry farms have reached a point where from 1,000 to 20,000 or more head of fowls are kept.

Poultry shows and education. While this development of poultry keeping has been largely a matter of natural economic conditions, certain other agencies have played a part. Thus, fairs and poultry shows where poultry has been exhibited have had a considerable effcet in spreading interest in this activity and have, therefore, had a considerable influence on its development. The various governments, and, in the United States, the Federal Department 
of Agriculture, the state agricultural colleges and experiment stations have of late recognized the growing importance of the poultry industry, and by their experimental and educational work have done much to spread information on this subject.

Intensive poultry sections. Something of the present development in poultry keeping can be realized from the development of certain communities which depend almost

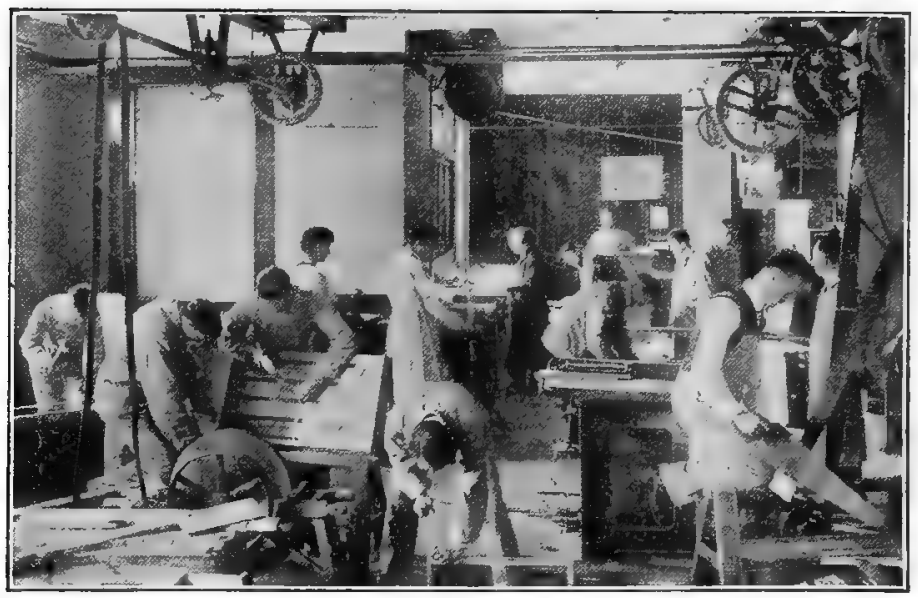

Figure 5.-Poultry students constructing poultry appliances. (Courtesy Cornell University)

entirely upon poultry activities for their prosperity. Thus, for example, in the United States there is the Petaluma district in California. This has an area with a radius of approximately sixteen miles where about a million and a half hens, principally Single Comb White Leghorns, are kept for laying purposes.

Another great poultry community in this country is the district known as Little Compton in Rhode Island. Here the fowls kept are principally Rhode Island Reds, and 


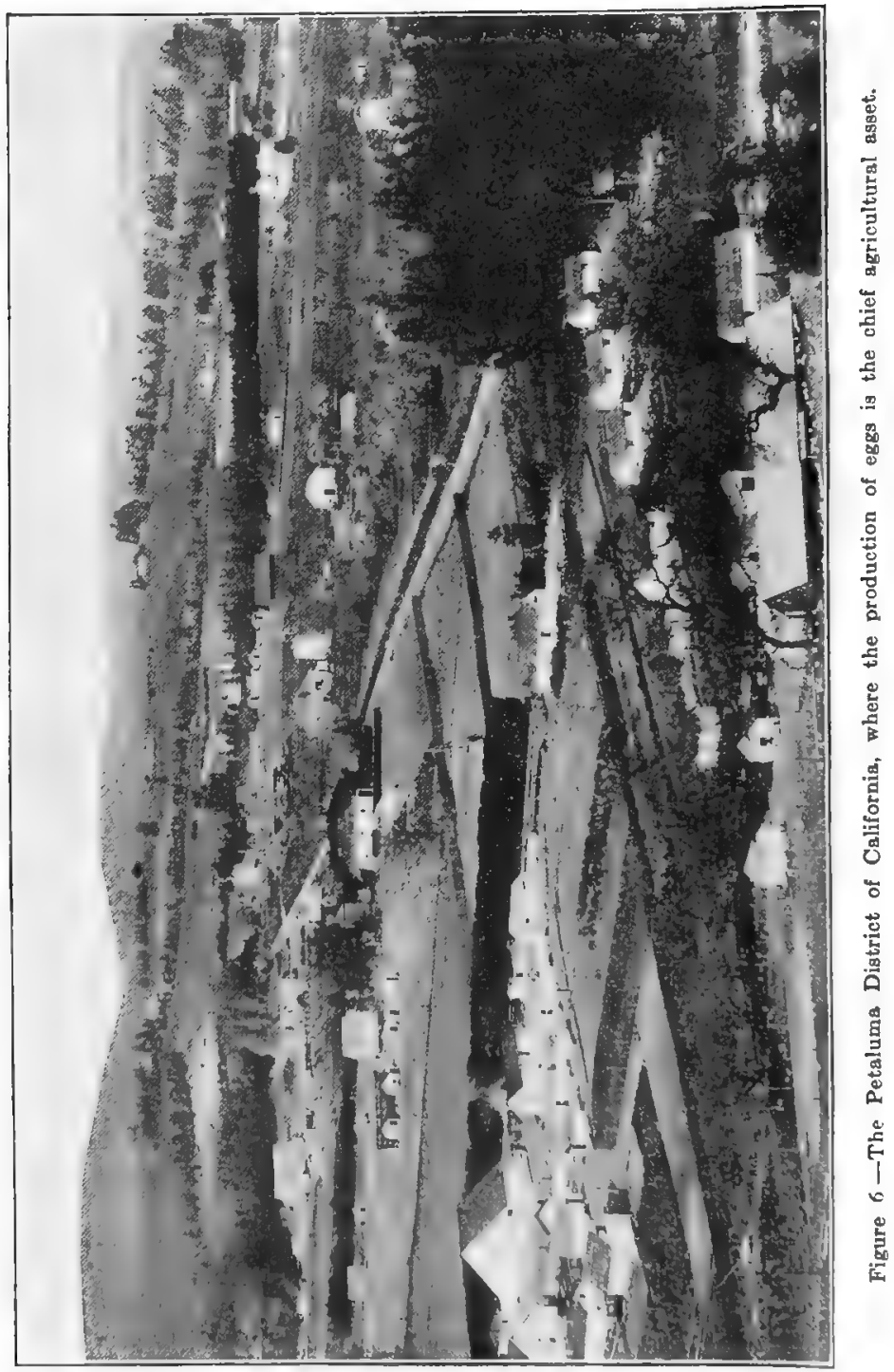


the farmers of this community depend upon poultry and eggs produced almost entirely for their income.

At the present time there is in the making a third poultry community located at Vineland, New Jersey. Here in the past few years the keeping of poultry has increased from a point where a few thousand fowls were kept until at the present time it is estimated that over three hundred thousand Single Comb White Leghorns are maintained principally

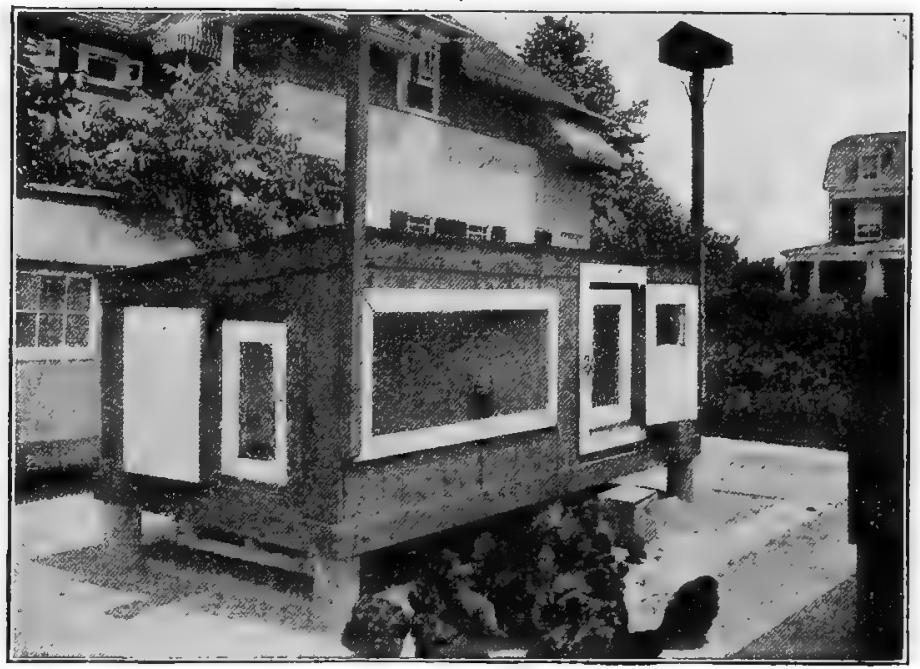

Figure 7.-A well-managed back-yard flock will aid considerably in reducing living expenses.

for the production of eggs for the New York markets.

Back-yard flocks. Another branch of the industry that has made wonderful strides in the past decade and which now plays an important part in food production is that of thousands of small flocks of fowls on town and village lots and in city back yards. Although as individual flocks their output is relatively small, at the same time their aggre- 
gate production during the year is great and of considerable value. In the main such flocks are kept for the production of eggs and an occasional fowl for home consumption. This phase of poultry production has developed as the result of its great economic value, for not only are fresh eggs available for home use, but in the production of such eggs much of the otherwise wasted table scraps can be utilized, when supplemented with suitable poultry feeds.

The poultry breeder. The growth and development of each of these three important branches of poultry keeping, that is, farm poultry, commercial poultry plants, and backyard flocks, have been made possible to a great extent by the persistent and untiring efforts of still another factor of the industry, namely, the poultry breeder. This class, while small as compared with those engaged in the other three branches, has been responsible for our present-day

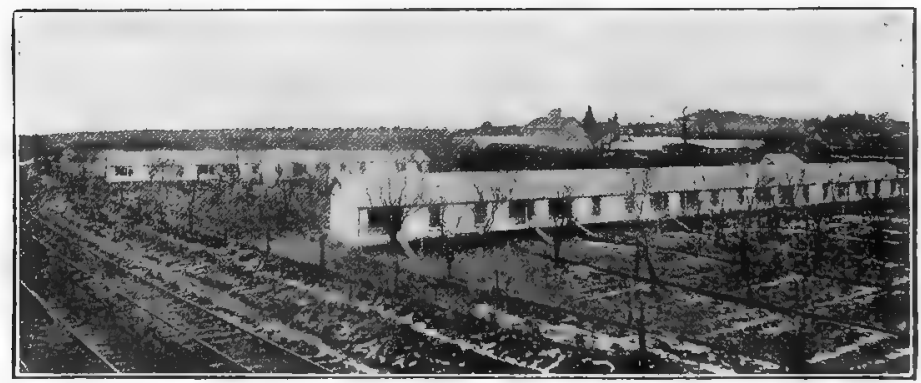

Figure 8.-An intensive poultry breeding plant.

standard-bred poultry, which is the foundation of the industry. In this phase of $r: \cdots 1+\cdots y$ keeping the principal source of revenue is derived from the sale of breeding stock and eggs for hatching.

\section{QUESTIONS}

1. What was the total value of poultry and eggs produced in the United States in 1910? 
2. How does the value of poultry production correspond according to the last census to oats, hay, vegetables, tobacco, orchard fruits, seeds, and wool?

3. To what was the domestication of fowls first attributed?

4. What factors have been largely responsible for the development of poultry keeping?

5. To what extent has the keeping of fowls on the farm developed?

6. Name three sections noted for exclusive commercial poultry farms?

7. Of what economic importance are back-yard poultry flocks?

8. Name the four principal branches of poultry keeping.

9. To what extent is the poultry breeder responsible for the development of the industry?

10. After carefully looking at the map on page 12, name ten of the most important poultry states in the Union.

\section{SUGGESTIONS}

1. As compared with other important agricultural products what is the extent of poultry production in your state? In your county? In your community?

2. From your own knowledge and observations, estimate the relative extent of farm poultry production as compared with that of commercial poultry plants in your state, county, and community.

3. If the production of poultry and eggs on general farms is in excess of that produced on commercial plants, what in your opinion is the reason?

4. To what extent are back-yard flocks kept in your town or city? Keep this question in mind for a week or so. Then, are there more back-yard flocks in your community than you at first supposed? If not, what seems to be the reason?

5. Endeavor to get the names and addresses of at least six men or women or both in your community who are poultry breeders. What breeds and varieties of poultry do they raise? If you do not already know these poultry breeders, get acquainted. They can be of assistance to you and will no doubt prove to be desirable acquaintances.

6 . Could you through your own efforts or with the help. of someone in your community organize a poultry club? Think the matter over and discuss it with your friends. For information on the organization of a poultry club see Chapter XVII.

\section{REFERENCES}

Principles and Practice of Poultry Culture, by John H. Robinson. Poultry Production, by W. A. Lippincott.

Illustrated Poultry Primer, U. S. Department of Agriculture Farmers' Bulletin 1040, by Harry M. Lamon and Jos. Wm. Kinghorne.

Hints to Poultry Raisers, U. S. Department of Agriculture Farmers' Bulletin 528, by Harry M. Lamon.

Poultry Management, U. S. Department of Agriculture Farmers' Bulletin 287, by Geo. A. Bell. 


\section{CHAPTER II}

\section{BREEDS AND VARIETIES}

With the development of poultry keeping on a sound economic basis we have come to realize the importance of considering the various breeds and varieties of poultry and the part that they play in the growth of this industry.

\section{ORIGIN AND CLASSIFICATION}

Origin. There is little definite knowledge as to the origin of the domesticated fowl, It is assumed that our present-day poultry is a direct descendent of one or more of the wild jungle fowls which are known to have existed in prehistoric times. Whatever may be its origin, our earliest historic records indicate that poultry has been under domestication for thousands of years.

Classification. It has been only of comparatively recent years, however, that we have had a variety of well defined types and breeds of fowls, referring to chickens, which can now be grouped according to their usefulness to man, as follows:-

1. The General-purpose Class.

2. The Egg Class.

3. The Meat Class.

4. The Game Class.

5. The Bantam Class.

6. The Miscellaneous Class.

In the discussion that is to follow we.will concern ourselves mainly with the first three classes on account of their economic value and the extent to which they are raised to produce food. The last three classes, that is, the Game, Bantams and Miscellaneous classes, are raised principally for show or pleasure, rather than for profit.

Before proceeding further, the factors which make up each of these classes should be considered. In any given class as grouped above there is a number of breeds of poultry, all of which usually perform the same general functions. 
These breeds of fowls in a given class differ from one another principally on account of their shape or conformation. In each of these breeds there are several varieties of the breed, all of which have the same general characteristic shape, but differ as the result of the color or marking of the feathers, or their type of comb. A still further distinction is frequently made within the variety as the result of some peculiar characteristic for which the variety has been bred, such as high egg production or desirable color of feathers, and which is known as a certain strain. To clarify this entire classification an example might be cited in a class, as follows:-

First. General-purpose class, which are noted for both egg and meat production.

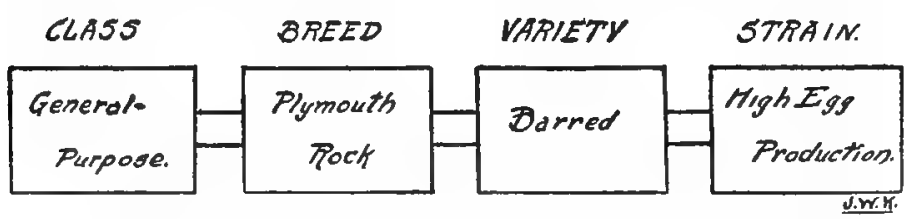

Figure 9.-Diagram showing classification of domestic poultry. Rock.

Second. As one of the breeds of this class, there is the Plymouth

Third. The members of this breed, or varieties of this Plymouth Rock breed, are the Barred Plymouth Rocks, White Plymouth Rocks, Buff Plymouth Rocks, Silver Penciled Plymouth Rocks, Partridge Plymouth Rocks, and Columbian Plymouth Rocks.

Fourth. In any one variety of a breed of a certain class we may find, as in the Barred Plymouth Rocks, a certain flock bred principally for high egg production and this is called an egg strain.

\section{SELECTING THE BREED}

Purpose. Beginners are urged to keep but one variety of a breed of fowls. The question is frequently asked, "Which is the best breed of fowls?" The answer is, "There is no best breed." Selection should be made of the breed that suits your purpose best, having in mind the object for which the fowls are to be kept. That is, eggs, or meat, 


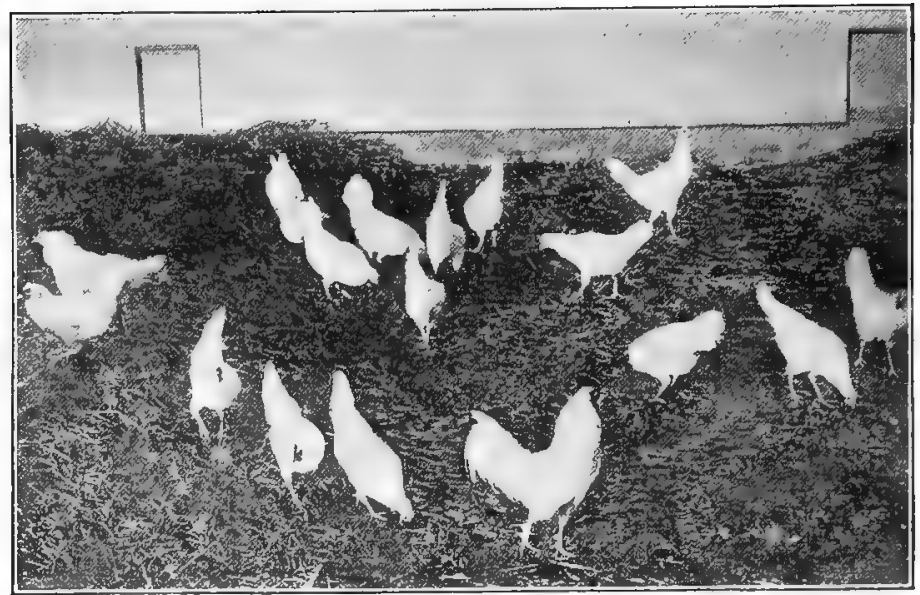

Figure 10.-A standard-bred fock.

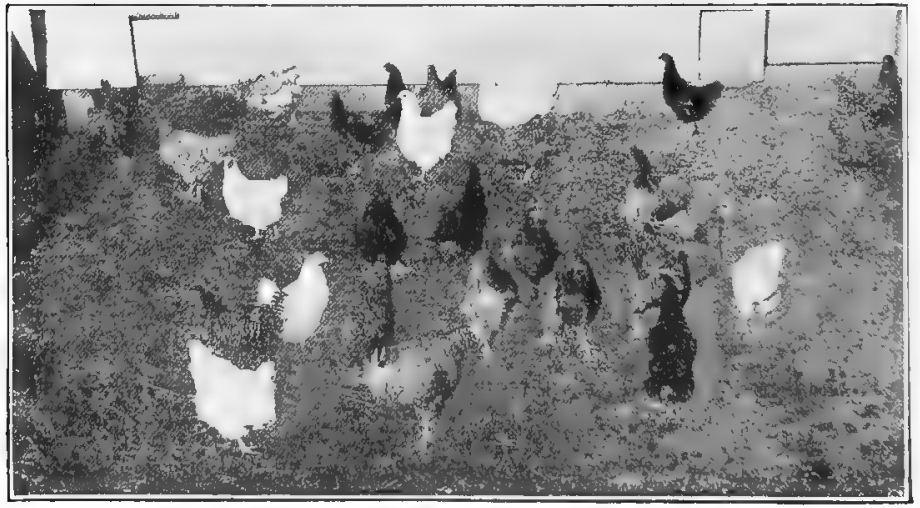

Figure 11.-A mixed flock. 
or both. As to the variety of the breed selected individual choice will have to be the governing factor. In the selection of a breed or variety of poultry, care should be taken to obtain healthy, vigorous stock.

Standard-bred fowls versus mongrels. The value of standard, or pure-bred, fowls over mongrels can not be overestimated. (By standard-bred poultry we mean fowls bred to conform with well established standards of form, color, markings, and weight as established for the various breeds

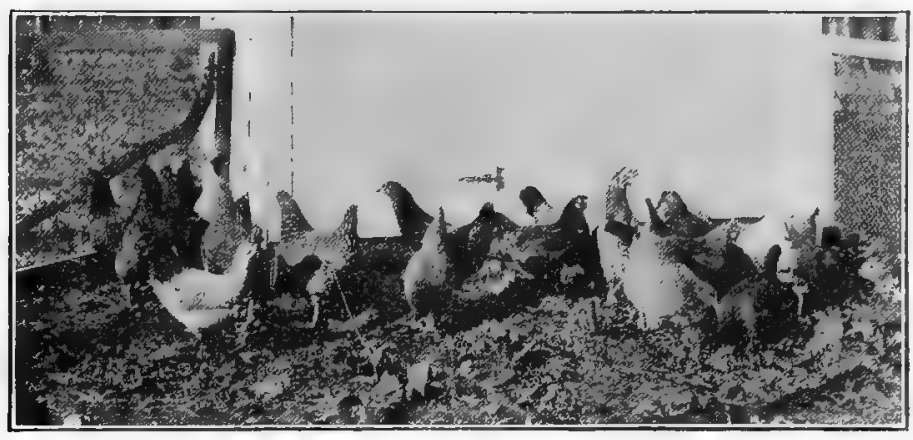

Figure 12,-A mongrel flock.

and varieties.) Given the same care, feed, and attention, standard-bred fowls will make a greater profit and afford greater interest and pleasure than mongrels or mixed fowls. The value of standard-bred fowls as compared with mongrels will be noted as follows:

Standard-bred fowls produce uniform products which bring higher prices.

Standard-bred stock and eggs sold for breeding purposes, bring higher prices than market quotations.

Standard-bred fowls can be exhibited and thus compete for prizes.

Standard-bred fowls create greater interest in poultry.

The products from mongrel and mixed fowls are not uniform and do not always bring the highest prices.

Eggs and stock from mongrel fowls are not sold for breeding purposes.

Mongrel fowls are not exhibited in poultry shows or exhibits.

Mongrel fowls do not inspire any great interest. 


\section{GENERAL-PURPOSE CLASS}

The breeds of this class are, as their name implies, of value for the production of both eggs and meat to such an extent as to make a general utility fowl. Such breeds as are included under this group are best suited to the general farmer, who desires a breed that is a profitable producer of eggs as well as one that is a suitable table fowl. These breeds are intermediate in size between the heavy

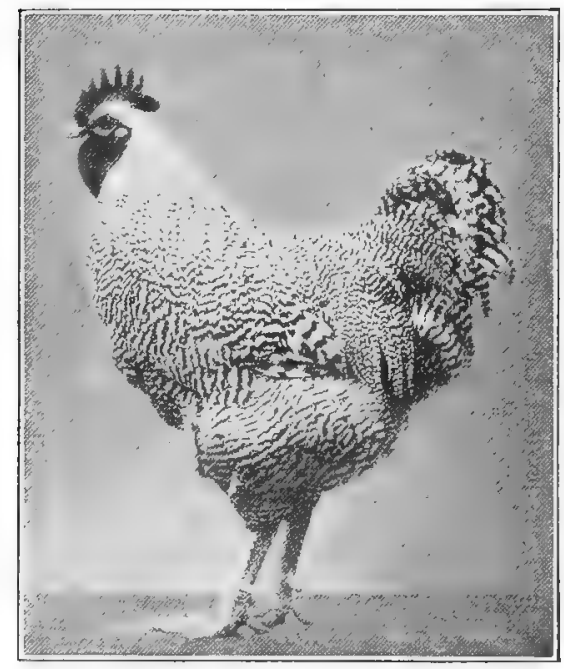

Figure 13.--Barred Plymouth Rock male. meat breeds and the smaller breeds of the egg class. This comparison may likewise be applied to their ability to mature and to their temperament. Thus, they mature more rapidly than the meat breeds, but are not as active and do not mature as quickly as the egg breeds. Almost without exception they are good sitters and mothers, and are good winter layers of brown-shelled eggs. Although classed as general-purpose fowls, considerable progress has been made in recent years in breeding several varieties of this group for high egg production. As the result it is not unusual to hear that representatives of this class produce 200 or more eggs per year. The four most popular breeds of this class are the Plymouth Rock, Wyandotte, Rhode Island Red, and Orpington. All these breeds with the excep- 
tion of the Orpington are of American origin. They have yellow skin and legs and lay brown-shelled eggs. The Orpington is of English origin, has a white skin, and lays brown-shelled eggs.

The Plymouth Rock. The standard varieties of this breed are as follows: Barred, Buff, White, Silver Penciled, Partridge, and Columbian Plymouth Rocks, of which the Barred variety is the most popular farm fowl. Aside from its desirable economic qualities this preference is due in part at least to the fact that it was one of the first early American

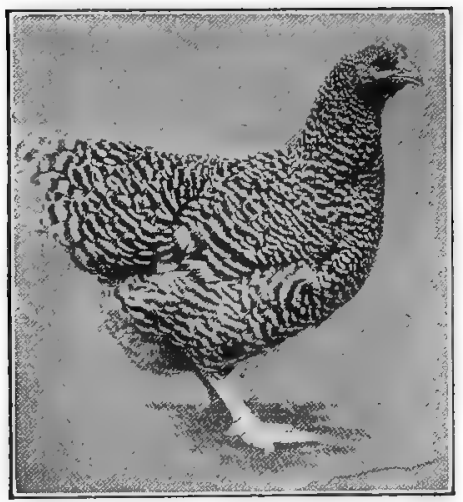

Figure 14.-Barred Ply mouth Rock female. varieties developed. The standard weights for the males and females of this breed are: cocks $91 / 2$ lbs., hens $71 / 2 \mathrm{lbs}$., cockerels 8 lbs., and pullets 6 lbs.

The Wyandotte. The standard varieties of the Wyandotte are as follows: Silver, Golden, White, Buff, Black, Partridge, Silver Penciled, and Columbian. The White Wyandotte is undoubtedly the most popular variety of this breed, and finds favor on many farms as a desirable producer of eggs and meat. White Wyandotte cockerels of from one to two and a half pounds make especially desirable broilers. The outstanding characteristic common to all varieties of this breed is the rose comb and the deep, short, blocky body. As will be noted, this breed is somewhat smaller than the Plymouth Rocks. The standard weight for cock is $81 / 2$ lbs., hen $61 / 2 \mathrm{lbs}$., cockerel $71 / 2 \mathrm{lbs}$., and pullet $51 / 2 \mathrm{lbs}$.

The Rhode Island Red. There are but two varieties 


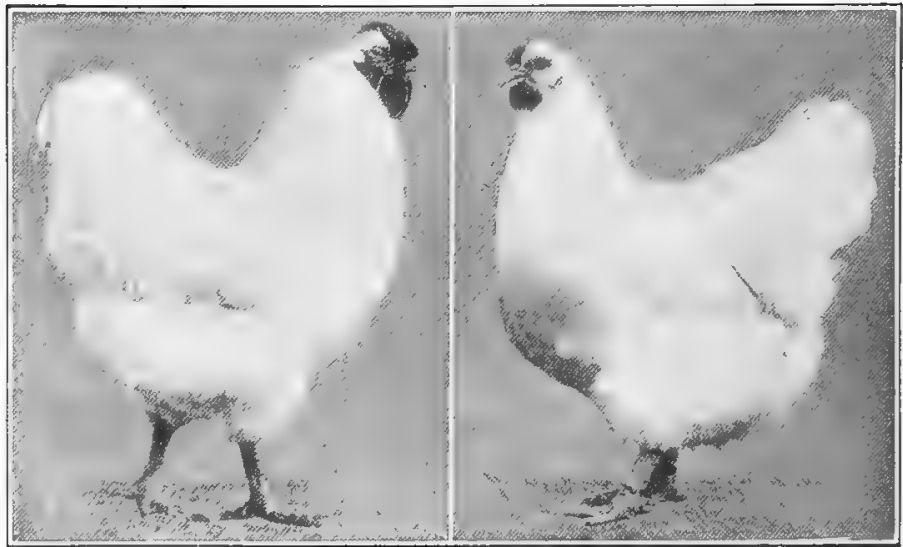

Figure 15.-White Wyandotte male. Figure 16.-White Wyandotte female.

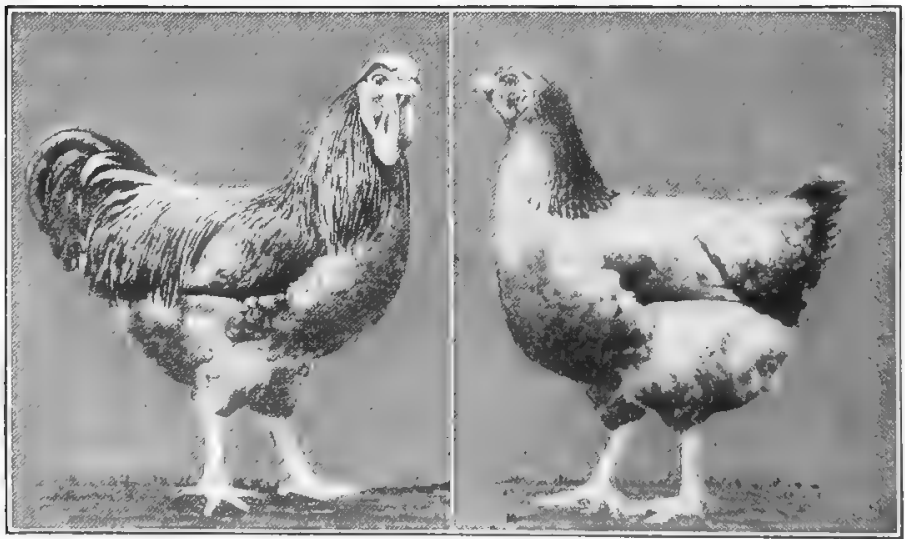

Figure 17.

Figure 18.

Rase Comb Rhode Island Red male. Rose Comb Rhode Island Red female. 
of this breed, both of which are of the same type and color, differing only in that one variety has a single comb and the other a rose comb. While this breed is one of comparatively recent origin, it has been widely adopted and is to-day one of the popular farm varieties. The standard weights of this breed are as follows: cock $81 / 2 \mathrm{lbs}$., hen $61 / 2 \mathrm{lbs}$., cockerel $7 \frac{1}{2} \mathrm{lbs}$., and pullet $5 \mathrm{lbs}$. From these weights it will be noted by comparison with the Wyandottes that they are practically the same with the exception of the pullet weight.

The Orpington. As previously noted, this breed is of English origin, but its place as a general-purpose fowl in this country has become firmly established. The standard varieties of this breed are: Buff, Black, White, and Blue. Unlike the American breeds the Orpington is characterized by having a white skin, which fact detracts somewhat from its value as a table fowl, as most

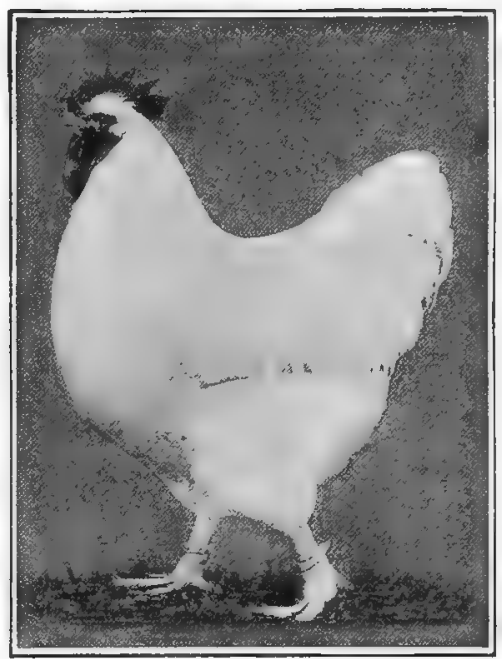

Figure 19.-White Orpington male.

markets in this country prefer yellow-skin breeds. The Buff and White Orpingtons have pinkish white shanks, while the Black Orpington has black shanks and those of the Blue Orpington are leaden blue in color. This breed is heavier in weight than either of the three above mentioned breeds. The standard weights are: cock $10 \mathrm{lbs}$, hen $8 \mathrm{lbs}$., cockerel $81 / 2 \mathrm{lbs}$., and pullet $7 \mathrm{lbs}$. 


\section{THE EGG CLASS}

The breeds of the Egg class, or, as they are frequently called, the Mediterranean and Continental classes, are of European origin. The outstanding characteristic of this class of fowls is their ability to produce white-shelled eggs economically. This fact has been largely responsible for

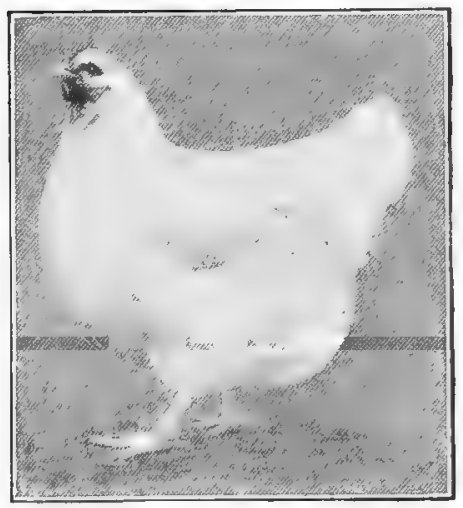

Figure 20.-White Orpington female. their adoption on commercial poultry plants where eggs are produced for sale in markets preferring whiteshelled eggs. With the exception of the Minorca the breeds included in this group are smaller in size than the general-purpose breeds, and, therefore, mature more quickly. They are very active and possessed of a decidedly nervous temperament. Several breeds of this class have been bred for increased egg production, so that at the present time we find individual fowls of this class producing 200 or more eggs a year. Being small in size detracts from their value as table fowls, although cockerels of these breeds are frequently sold as broilers. Another characteristic common to the egg breeds is the fact that they are classed as non-sitters. That is, as a rule they do not become broody or hatch their eggs. When fowls of this class are kept, artificial incubation and brooding are usually employed. Among the better known breeds of this class are the Leghorn, Ancona, Minorca, Blue Andalusian, and Campine.

The Leghorn. This breed, which originated in Italy, is made up of the following standard varieties: Single Comb 
Light and Dark Brown, Rose Comb Brown, Single and Rose Comb White, Single and Rose Comb Buff, Single Comb Black, Silver and Red Pyle. The Single Comb White Leghorn is not only the most popular variety, but the one generally found on commercial egg farms. Leghorns are neat appearing, alert and stylish in their bearing. All varieties of this breed have yellow skin and shanks. An indication of their size may be secured from the following standard weights: cock $51 / 2$ lbs., hen 4 lbs., cockerel $41 / 2 \mathrm{lbs}$, pullet $3 \frac{1}{2} \mathrm{lbs}$.

The Ancona. There are two varieties, both black in color with approximately on e feather in every five ending withaV-shaped white tip. These two varieties, the Single Comb and Rose Comb, are likewise identical in size and shape. This breed is similar to the Leghorns in that both originated in Italy;

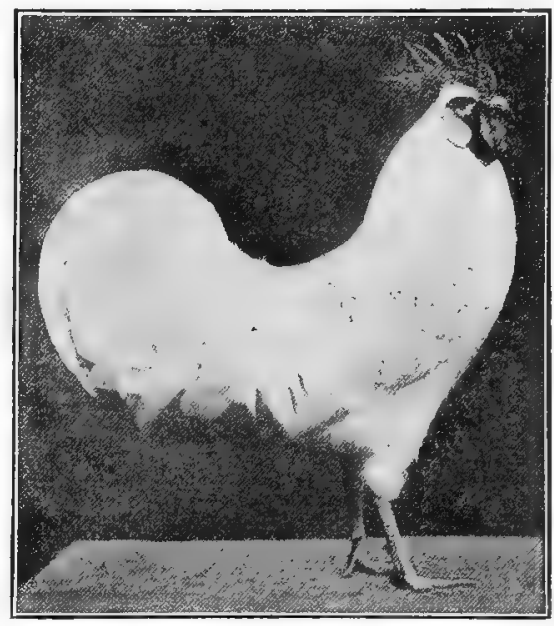

Figure 21.-.Single Comb White Leghorn male. in shape they are quite similar; and they both possess the same economic qualities. The standard weights for this breed are: cock $51 / 2$ lbs., hen $4 \frac{1}{2} \mathrm{lbs}$., cockerel $41 / 2 \mathrm{lbs}$., pullet $3 \frac{1}{2}$ lbs. How do these weights compare with those of the Leghorn?

The Minorca. The Minorca is of Spanish origin. The three varieties of this breed, that is, Single and Rose Comb Black, Single and Rose Comb White, and Single Comb Buff, 
are larger than any of the other breeds in the egg class. They have noticeably long bodies and in shape are more angular appearing than either the Leghorn or Ancona. The skin color of all the varieties of this breed is white. The exceptionally large white-shelled egg produced by the Minorca is typical of the breed. The standard weights are divided as follows: For the Single Comb Black, the

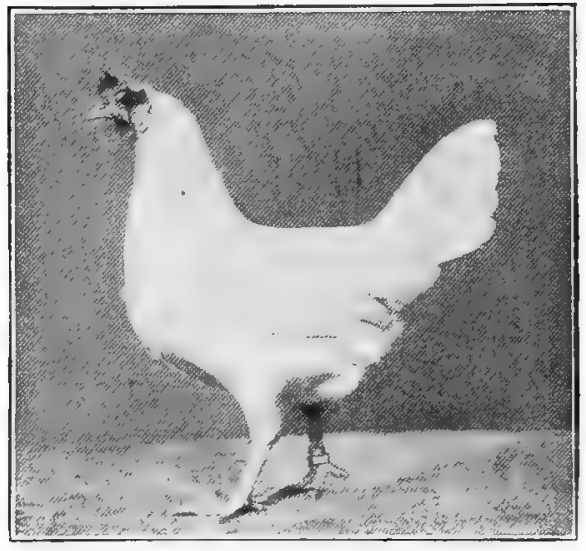

Figure 22.- Single Comb White Leghorn female. weights are: cock 9 lbs., hen $7 \frac{1}{2}$ lbs., cockerel $71 / 2$ lbs., pullet $61 / 2$ lbs. When compared with the breeds of the general-purpose class, it will be noted that the standard weights for the Single Comb Black Minorca are greater than for the Rhode Island Red and Wyandotte cock, hen, and pullet, the weights of the cockerel in each of these breeds being the same. For the other varieties, including the Rose Comb Black Minorcas, the weights are: cock $8 \mathrm{lbs}$., hen $61 / 2 \mathrm{lbs}$. cockerel $61 / 2 \mathrm{lbs}$., pullet $51 / 2$ lbs.

The Blue Andalusian. There is only one variety of this breed, it being, as its name implies, blue in color. This blue plumage is a characteristic that is peculiar to but few varieties of poultry, the Blue Andalusian and the Blue Orpington being the only two varieties found in the American Standard of Perfection.* As with the Minorca, the skin

*The American Standard of Perfection published by the American Poultry Association is the authorized guide for the selection and judging of standard-bred poultry. 
of the Andalusian is white. In shape and size it is between the Leghorn and the Minorca. The standard weights are: cock $6 \mathrm{lbs}$, , hen $5 \mathrm{lbs}$., cockerel $5 \mathrm{lbs}$, pullet $4 \mathrm{lbs}$.

The Campine. The Campine can best be remembered as the breed that originated in that country which we have come to know and respect so well, namely, Belgium. There are two varieties, the Silver and Golden Campine, each being identical in size and shape. Both varieties have white skins. Although they have been known in this country only during comparatively recent years, they have found considerable favor as egg producers. Their standard weights are: cock 6 lbs., hen 4 lbs., cockerel 5 lbs., pullet $31 / 2 \mathrm{lbs}$.

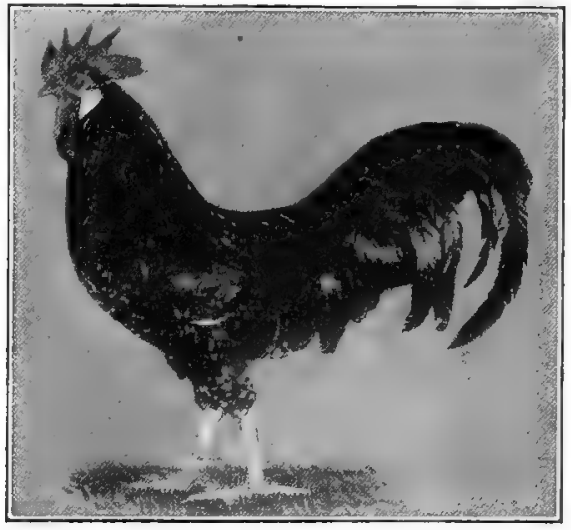

Figure 23.- Single Comb Ancona male.

\section{THE MEAT CLASS}

The breeds included in this class are primarily kept for the production of meat rather than for their egg-laying ability. The four most popular breeds representing this group are the Langshan, Brahma, Cochin, and Cornish, all of which are of Asiatic origin, except the Cornish, which came from England. Although classed as meat breeds, representatives of this group are sometimes kept as generalpurpose fowls. Each of these breeds is heavier and larger in size than the egg breeds or those of the general-purpose class. The Langshan, Brahma, and Cochin especially, are not as active as the breeds of the other two classes. They 
are easily confined, rather slow to mature, and lay large brown-shelled eggs. One of the most noticeable characteristics of each of these breeds, with the exception of the Cornish, is their feathered shanks. While persistent and dependable sitters, they are not as good mothers as the general-purpose breeds on account of their being more clumsy. All the breeds in this class have

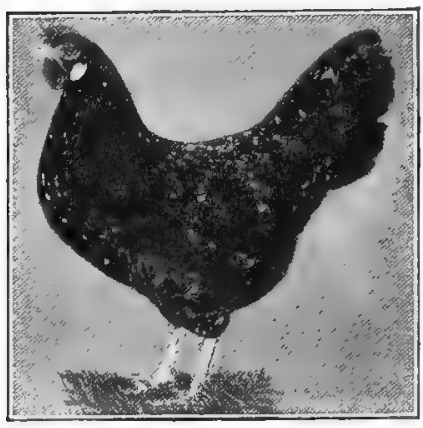

Figure 24.- Single Comb Ancona female. a yellow skin with the exception of the Langshan which has white skin. The large size of the breeds in this class makes them especially suitable for the production of large roasters in localities where suitable markets exist.

The Langshan. There are two varieties of this breed, the Black and White, the former being more generally raised. The Langshan is a tall, upright fowl, large in body but not so massive in appearance as the Brahma or Cochin. While classed with the meat breeds many poultrymen are getting good egg yields from the Langshan, the standard weights of which are: cock $91 / 2$ lbs., hen $71 / 2$ lbs., cockerel $8 \mathrm{lbs}$., pullet $6 \frac{1}{2}$ lbs.

The Brahma. The two varieties of the Brahma are the Light and Dark, the Light variety being the largest of our domestic fowls. The Brahma is sometimes kept on farms, as a general-purpose fowl and is a fair egg producer. As will be noted, the Light Brahma is heavier than the Dark variety. The standard weights of the former are: cock $12 \mathrm{lbs}$, hen $91 / 2 \mathrm{lbs}$, cockerel $10 \mathrm{lbs}$, pullet $8 \mathrm{lbs}$. The weights for the Dark variety are: cock $11 \mathrm{lbs}$., hen $81 / 2 \mathrm{lbs}$., cockerel $9 \mathrm{lbs}$., pullet $7 \mathrm{lbs}$. 


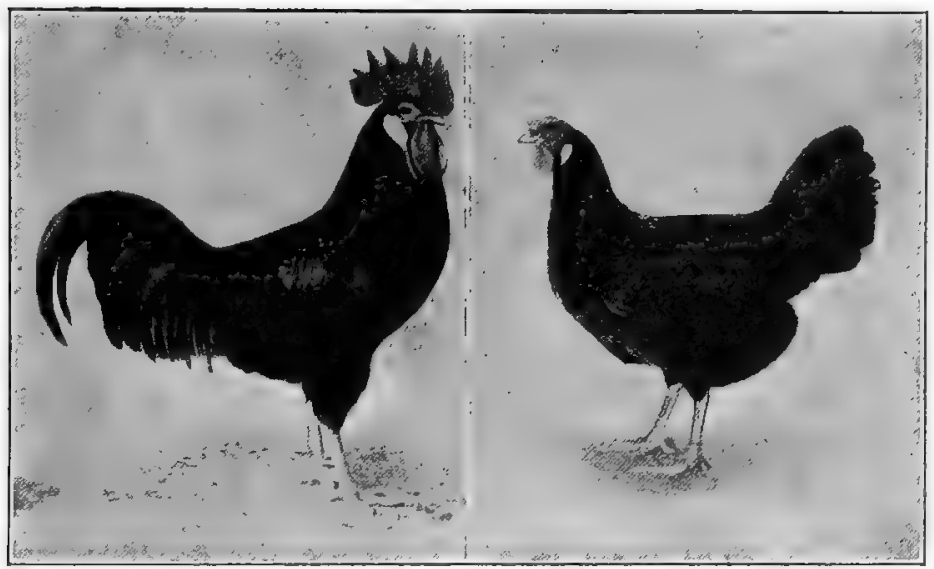

Figure 25.-Black Minorea male. Figure 26.-Black Minorea female.

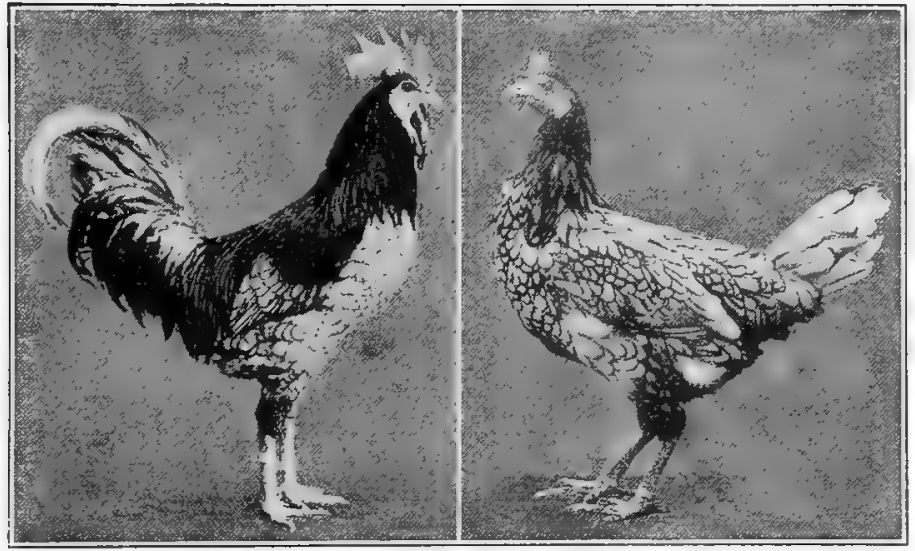

Figure 27.-Blue Andalusian male. Figure 28.-Blue Andalusian female. 


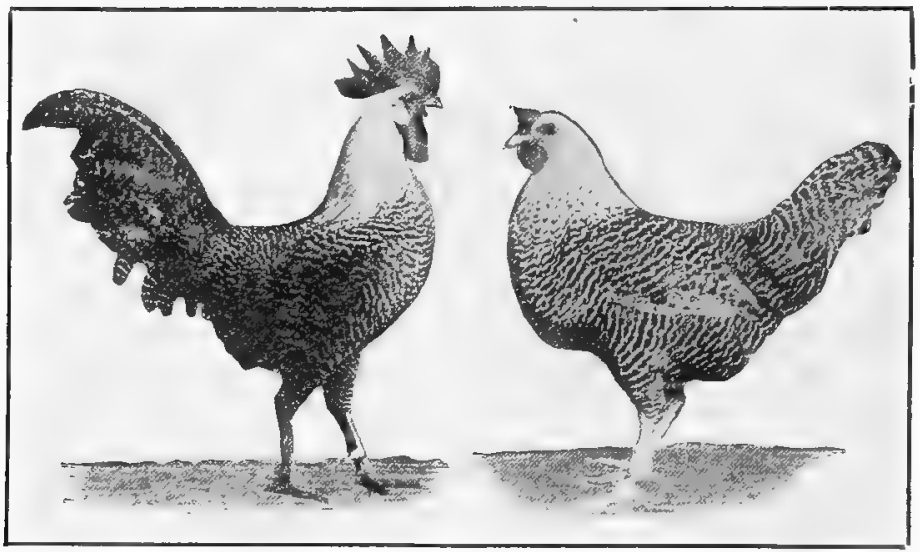

Figure 29.-Silver Campine male. Figure 30.-Silver Campine female.

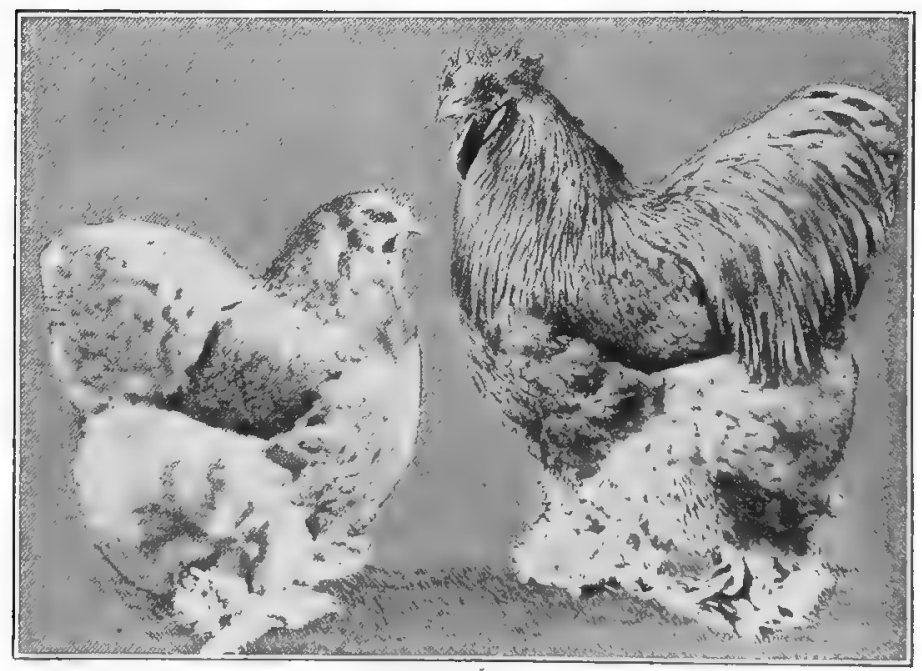

Figure 31,-Buff Cochin female. Figure 32,-Buff Cochin male. 


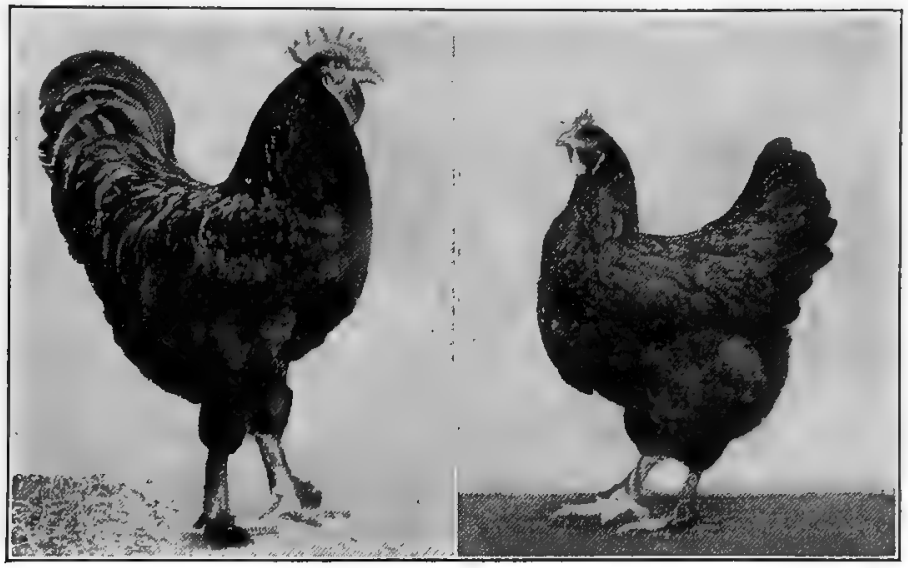

Figure 33.-Black Langshan male. Figure 34.-Black Langshan female.

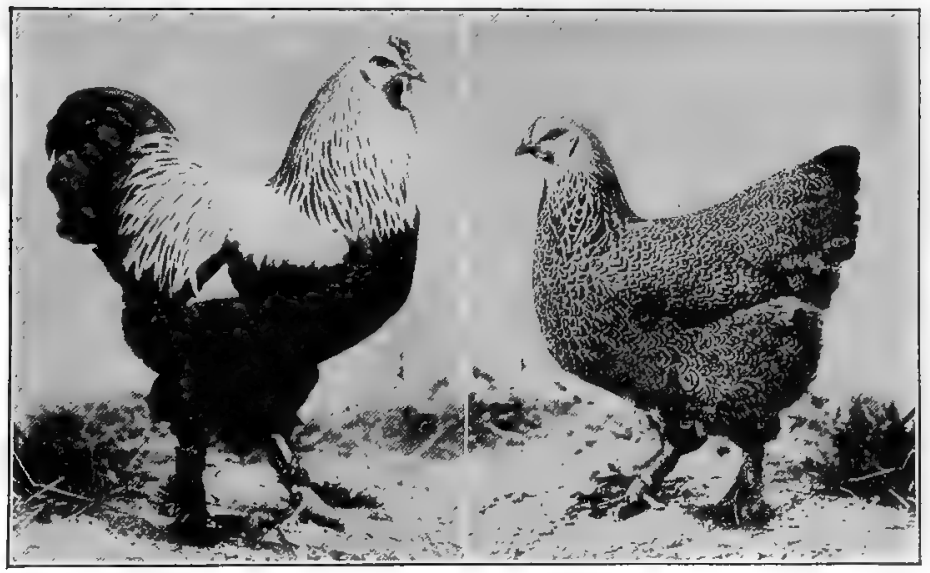

Figure 35.-Dark Brahma male.

Figure 36.-Dark Brahma female. 
The Cochin. This breed was formerly known as "The Cochin China," but of late years has been more correctly called "Cochin." There are four standard varieties: namely, Buff, Partridge, White, and Black, the Buff being the most generally raised. The outstanding and most noticeable characteristic of this breed is its profusion of long loose plumage which gives it the appearance of being a bird of greater weight than it is in reality. The fact

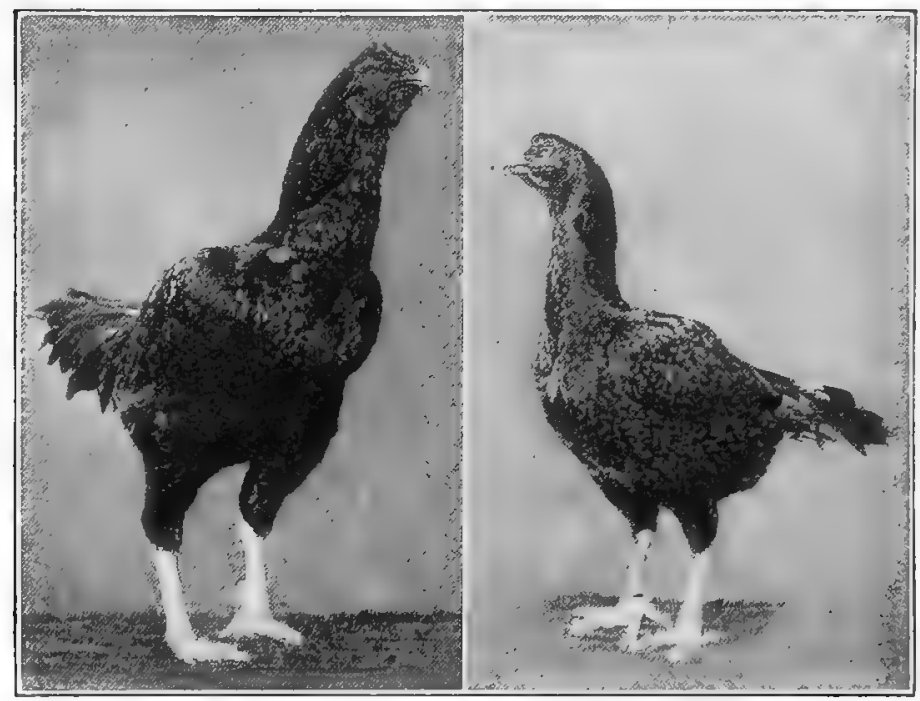

Figure 37.-Dark Cornish male.

Figure 38,-Dark Cornish female.

that the Cochin does not enjoy greater popularity even as a meat breed may be attributed largely to this excess feathering. The standard weights are: cock $11 \mathrm{lbs}$., hen $81 / 2 \mathrm{lbs}$., cockerel 9 lbs., pullet 7 lbs.

The Cornish. The Cornish is of English origin and was formerly called "The Cornish Game," later Cornish Indian Game, then Comish Indians, and now are known as Cornish. 
The three varieties are the Dark, White, and White Laced Red. As a meat breed the Dark Cornish especially have gained rapidly in popularity in this country. In appearance all varieties of the Cornish differ materially from the other breeds of this class. They are close-feathered, the shanks being free from feathers, the body very thick and compact, and the breast and shoulders very broad and well developed. The standard weights for the Dark and White Cornish are: cock 10 lbs., hen $7 \frac{1}{2}$ lbs., cockerel 8 lbs., pullet 6 lbs. For the White Laced Red Cornish the weights are: cock $8 \mathrm{lbs}$, hen $6 \mathrm{lbs}$., cockerel $7 \mathrm{lbs}$, pullet 5 lbs.

\section{THE GAME, BANTAM AND MISCELLANEOUS CLASSES}

The breeds found in these classes are not so well adapted nor are they so generally found on farms or on commercial poultry plants in this country as the breeds of the first three classes. It must not be supposed,

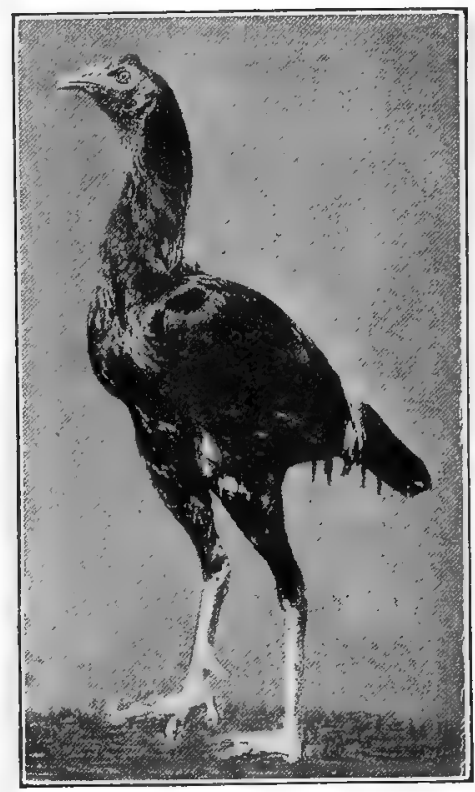

Figure 39.

Black-breasted Red Game cock. however, that they are without value as producers of eggs and meat, for such is not the case. Many justly claim that no finer quality of meat, and especially meat from the breast, can be obtained than that on a well finished Game.

The Game and Game Bantam Class. The Game and 


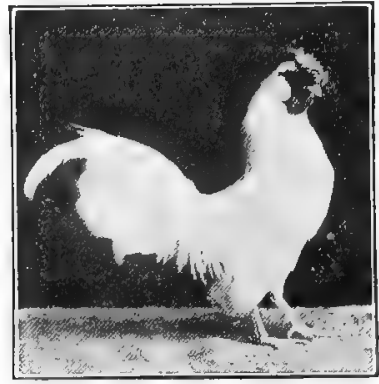

Figure 40

Rose Comb White Bantam cock.

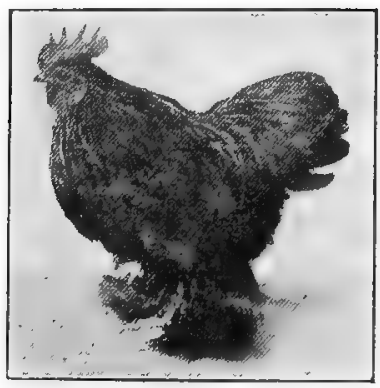

Figure 41.

Black Cochin Bantam cock.

Game Bantam both consist of the following varieties: Black-breasted Red, Brown Red, Golden Duckwing, Silver Duckwing, Birchen, Red Pyle, White and Black. A wellknown and typical representative of this class is the Blackbreasted Red Game.

The Bantam Class. The classification of Bantams as

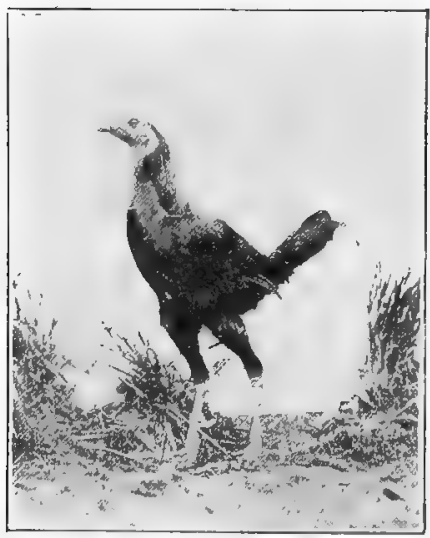

Figure 42.-Black-breasted Red Game Bantam cook.

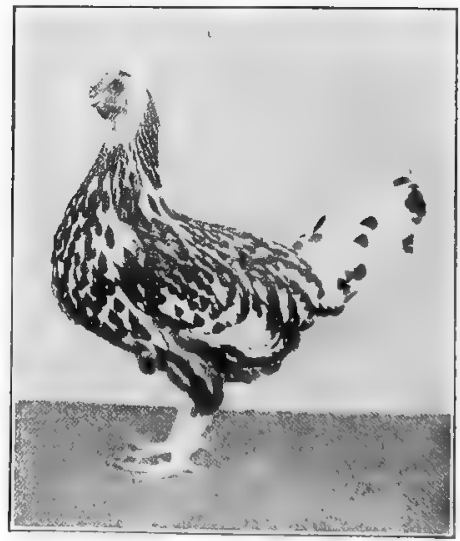

Figure 43.-Silver Spangled Hamburg hen. 
found in the American Standard of Perfection is grouped as the Game Bantams, embracing the same varieties as given above under the Games and the Ornamental Bantams which include thefollowing breeds: The Sebright, Rose Comb, Booted, Brahma, Cochin, Japanese, Polish, and Mille Fleur. As will be noted by their names, several of the breeds of Bantams are min-

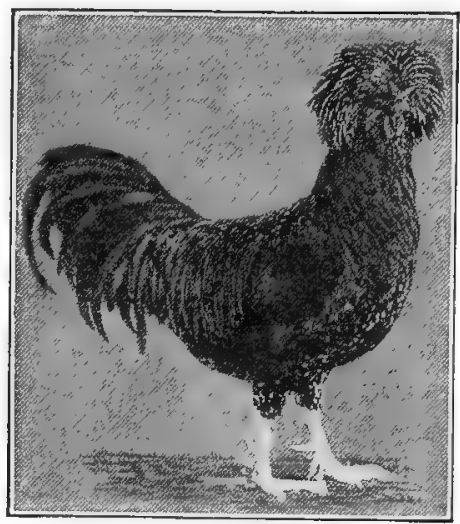

Figure 44.-Mottled Houdan cock. iature representatives of the larger breeds of the same name, such as in the case of the Games, Brahmas, Cochins, and Polish Bantams. The keeping of Bantams affords consid-

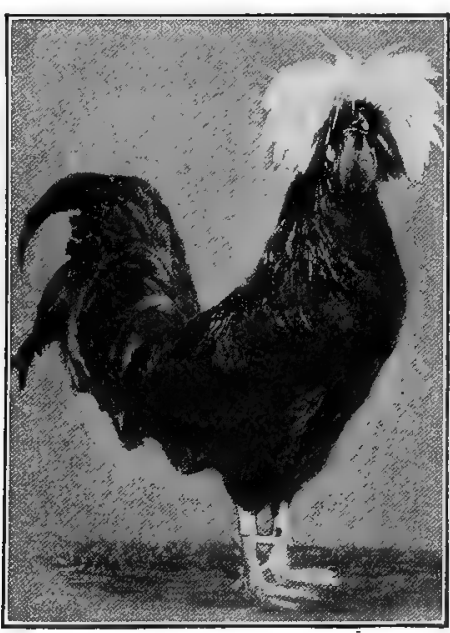

Figure 45.

White Crested Biack Polish cock. erablepleasureand frequently a substantial revenue can be secured, especially by selling stock for breeding and show purposes. The production of Bantams is especially suited for town and city back yards where the space is usually limited.

The Miscellaneous Class. The term applied to this class is of a general nature, for it includes the breeds from several of the classes as given, in the American Standard of Perfection, namely, the Polish, 
Hamburg, French and Ornamental classes. The breeds or varieties of these classes, while not generally raised in this country to a great extent, occupy a place of considerable economic importance in their respective native countries. For example, in France all the breeds of the French class which includes the Houdan, Crevecoeur, La Fleche, and Faverolles are most generally raised and are decidedly in favor as producers of both eggs and meat. To a certain extent the same principle holds true with both Polish and Hamburgs in some of the central European countries. The more popular breeds of this class as determined by their distribution in this country are the Houdan, Polish and Hamburg.

\section{QUESTIONS}

1. What are the six classes of fowls? Strain?

2. In a given class what constitutes a Breed? A Variety? A

3. Why are standard-bred fowls more desirable and profitable than mongrels?

4. Name the general-purpose breeds and state for what object they are raised.

5. Name four varieties of the Wyandotte.

6. If you wanted to keep fowls for the production of white-shelled eggs, what breed and variety would you select? Why? originate?

7. In what three countries did our most popular egg breeds

8. Which breeds of the meat class have feathered shanks and which have clean shanks? weight?

9. What two varieties of the meat breeds are the greatest in

10. Name two varieties of Games, three breeds and varieties of the Ornamental Bantams, and three French breeds.

\section{SUGGESTIONS}

1. After making observations for a period of a week, classify as many breeds and varieties as you have seen raised in your community, grouping them under their proper classes as given in the American Standard of Perfection.

2. When making these observations, list the number of flocks of standard-bred fowls and the number of mixed and mongrel flocks. Which list contains the greatest number of flocks?

3. If there are more standard-bred flocks than mongrel in your community, do you not think it would be an easy task to organize a club of breeders of standard-bred fowls and in that way interest those who raise mongrels? 
4. If mongrels predominate in your section, do you not think there is a great need for an organization that will have as one of its objects the improvement of stock in your community? Standardbred poultry means greater interest and increased revenue, both of which help to make a better community.

5. Should you organize a poultry club or should there be one already organized, do not limit it to townspeople, but invite the farmers and their wives to join as well as the boys and girls of the town and country. Everybody is interested in poultry.

\section{REFERENCES}

Races of Domestic Poultry, by Edward Brown.

American Standard of Perfection, published by the American Poultry Association.

Perfected Poultry of America, by T. F. MoGrew and G. E. Howard. Standard Varieties of Chickens. I. The American Class, U. S. Department of Agriculture, Farmers' Bulletin 806, by Rob R. Slocum. Standard Varieties of Chickens. II. The Mediterranean Class, U. S. Department of Agriculture, Farmers' Bulletin 898, by Rob R. Slocum.

Standard Varieties of Chickens. III. The Asiatic, English and French Classes, U. S. Department of Agriculture, Farmers' Bulletin 1052, by Rob R. Slocum. 


\section{CHAPTER III}

\section{BREEDING}

As in other branches of live stock production, the question of breeding poultry is all important where success is to be obtained.

\section{IMPORTANCE OF BREEDING}

There is no other phase of poultry production to which more importance can be attached than that of the principles and practice of breeding. The beginner may obtain stock from a good strain of standard-bred poultry, the birds may be housed in a thoroughly practical and well-planned building, and proper methods of feeding may be employed, but, should they be carelessly or indifferently bred, unsatisfactory results will surely follow. It has been of only.comparatively recent years that this fact has been so generally recognized as concerning poultry. It may be said that poultry breeders, or, as they are sometimes called, "fanciers," were the first to make any attempt to put into practice the principles of breeding in their effort to perfect the various breeds and varieties of poultry, as regarding type, color of plumage, and certain other characteristics. In the majority of such cases utility qualities, such as increased egg and meat production, were of little concern.

Of more recent years commercial poultrymen, or, as they are otherwise known, "utility poultrymen," have endeavored to put into practice such principles of breeding and selection as to increase egg-producing ability and meat qualities of fowls. In most instances but little attention being paid to markings, color of plumage, or other standard requirements, the sole idea is to increase production to meet market requirements, and to increase profits. It may thus 
be seen that the ultimate goal of each of these two classes of breeders was more or less extreme. Still more recently we find developing a class of poultrymen who through rigid selection and careful constructive breeding are combining the ideals of the fancier and utility poultryman by producing fowls that meet standard requirements and that are also profitable producers. That such a combination is not only possible but highly practicable and profitable is evidenced by the fact that many of our leading poultry breeders are now bending their efforts for the production of such stock.

A breeder of such stock as is shown in Figure 46 will not only establish a reputation and a profitable market for breeding stock, but will have eggs to sell for table purposes as well. Producers of purely utility stock, Figure 47, can hope to derive most of their revenue only from the sale of market eggs.

\section{PRINCIPLES OF BREEDING}

While the highest attainment and success can best be secured by a thorough understanding and systematic practice of the principles of breeding, at the same time considerable improvement in quantity of products and quality of stock can be secured by following the fundamentals of breeding practices as herein outlined.*

Heredity. This term, which is one of the most commonly used in breeding practices, refers to the transmission of the characters of the parents to the offspring. Such characters as are found in both the offspring as well as the parent stock are said to be inherited. For example, we can be reasonably sure when mating a White Plymouth Rock male and female together that generally speaking the offspring will be white in color, will be about the same type as the parents, and will have single combs.

*Those desiring additional and more complete information on the mating and breeding of poultry are referred to "Mating and Breeding of Poultry" by Harry M. Lamon and Rob R. Slocum, published by Orange Judd Co. 
Variation. By using the same example as given above under heredity we may find in the offspring of the mating of White Plymouth Rocks one or more birds that are superior to their parents in type, size, or production. On the other hand some of the offspring may be inferior to the parents in these qualities. This difference is called variation. It is by taking advantage of this law of breeding and selecting the birds which show improvement in appearance, performance, and size over the parent stock that progress is made.

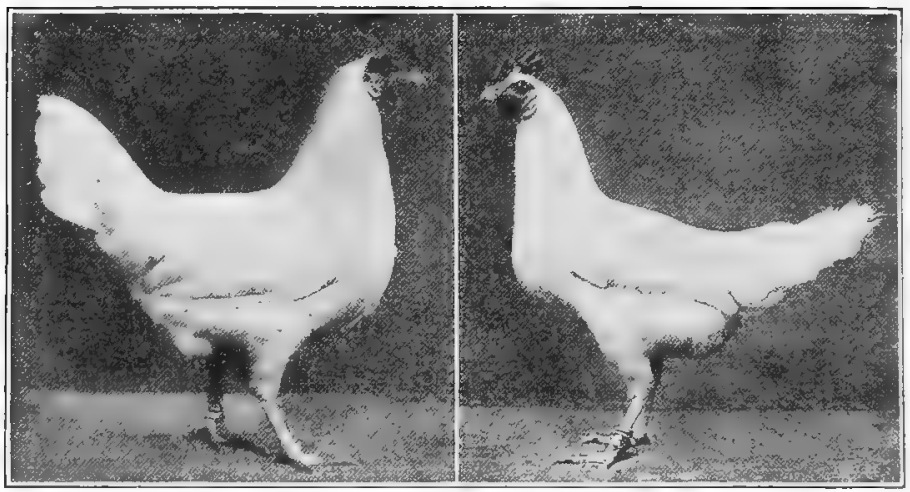

Figure 46.-This White Leghorn hen possesses the standard requirements of her breed and produced over 200 eggs in one year.

Figure 47-A White Leghorn her of poor standard qualities, which produced over 200 eggs in a year.

Sports, or mutations. By this term is meant the occurrence of individuals that are characterized by being radically different in type or color from their own ancestors. An example of a "sport" can be cited in the case of the White Minorca which is claimed to have been produced from a mating of Black Minorcas.

Reversion, or atavism, refers to the cropping out or appearance of characters in the offspring which are not found in the immediate parents but which were present in some of 
the remote ancestors. A common example of reversion or breeding back can be cited in the case of Columbian Wyandottes, by the presence of stubs or small feathers appearing on the shanks of some individuals of this variety. This is attributed to the feathered shanks of the Light Brahma which was one of the breeds used in originating the Columbian Wyandotte.

Correlation. By correlation is meant the close association of certain characters with other characters. For instance, there is a close correlation between red ear lobes and brown or tinted-shelled eggs in that one of these characteristics is rarely found without the other.

Regression refers to the factor in breeding which has to do with the inclination of the offspring to be nearer the average of the breed than were the parents. An example of this principle can be cited when a mating is made of a male and female which are larger than the average weight for the breed. The majority of the offspring from this mating are very apt to be smaller in size than were the parents. Likewise this principle is in evidence when the parents are smaller than the average for the breed, in which case a greater percentage of the offspring is apt to average larger in size than the parents. Regression is ordinarily not limited to one or a few individuals but appears in the mass or greater percentage of the offspring.

Progression. This term applies to the production of an occasional individual which is outstanding in quality or performance or both as compared to the breed in general. Progression applies to the individual rather than to the mass of the offspring. An illustration of this principle of breeding is as follows: A male and female of good quality may be mated and as the result one of the offspring may develop into a specimen that far surpasses not only the parent stock in every particular but is beyond that which is even occasionally 
produced or found in the breed. This individual is an example of progression.

Prepotency. The ability of an individual, either male or female, to stamp or fix a certain character or several characters on the offspring is called prepotency. Either parent, for instance, may be prepotent in transmitting to the progeny high egg production, size, desirable color of plumage, etc. On the other hand a parent may be prepotent in its ability to impress certain undesirable characters such as knock-knees, side sprigs, etc.

Fecundity is the ability to reproduce the species. In the case of fowls where eggs are the means of reproduction as well as a source of food, we speak of a hen as being fecund from the standpoint of her ability to reproduce her kind. Fecundity is measured by the number of eggs produced in a given period.

Inbreeding. Inbreeding involves the mating of closely related individuals. The purpose of inbreeding is to concentrate blood lines or intensify such characters as are desirable, in order to strengthen the established qualities. Care should be taken when inbreeding to avoid selecting a male or female, if possible, that possesses undesirable qualities, which are apt to be intensified as well as the desirable characters.

Line breeding. This system of breeding refers to limiting the selection and mating of individuals within a single family or strain, the purpose of which is to make a more rapid improvement of desirable characters or qualities. Line breeding necessarily is a form of inbreeding wherein, however, close inbreeding is avoided. In the strict interpretation of line breeding it should not involve the introduction of an individual that is unrelated or from a different family or strain.

Outbreeding, or outcrossing. It frequently happens in breeding practice that new blood is introduced into the 


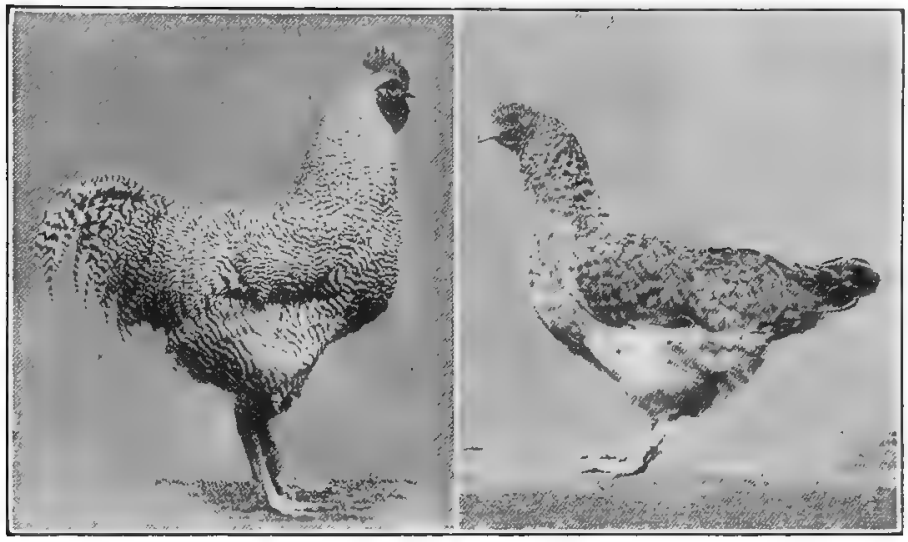

Figure 48.

Figure 49.

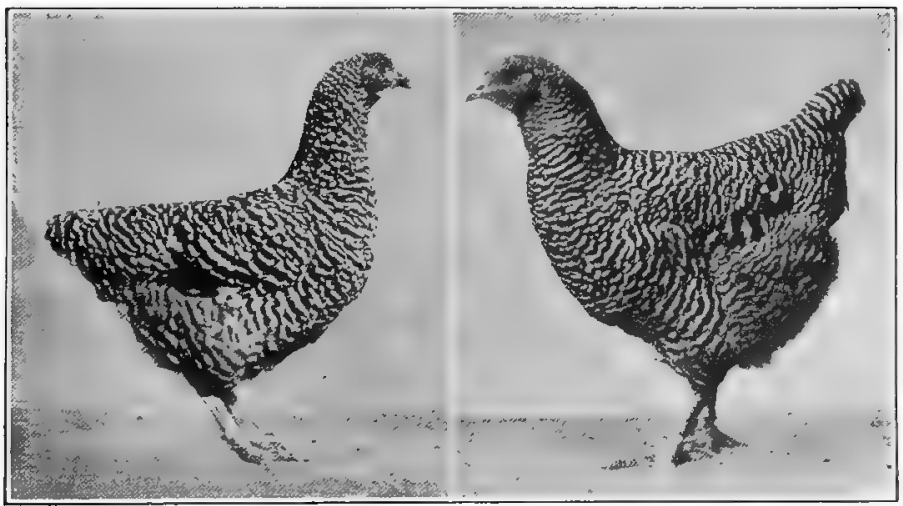

Figure 50.

Figure 51.

Result of using a pure-bred sire. The above pure-bred Barred Rock Cockerel (Figure 48), crossed with the mongrel hen (Figure 49), produced a half-blood pullet (Figure 50), weighing (average of the flock) 1.23 pounds more than the mother hen. Another pure-bred cross on this pullet produced a threequarters-blood pullet (Figure 51), weighing (average) 0.59 pounds more than her mother-An increase of nearly two pounds in two crosses. Note also the improvement in breed type. 
flock by breeding from an unrelated individual, which is, however, of the same breed and variety. This is known as outbreeding, or outcrossing, and is usually done to revive or introduce some character or factor such as vigor, in which the flock is deficient.

Crossbreeding. This form of breeding refers to the mating together of two distinct breeds or varieties. The object of crossbreeding is usually the effort to produce a

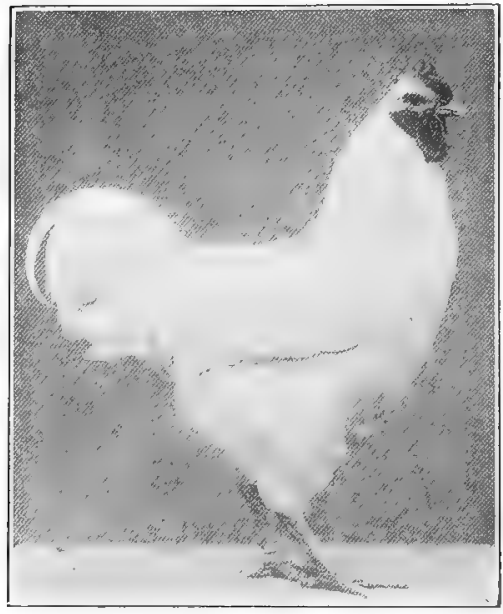

Figure 52.-A standard-bred male at the head of a mongrel flook will improve the quality of the flock materially. new breed by securing a new combination or blending of characters of the two original breeds. Sometimes the offspring of the first cross is mated to a third breed to further the blending or to introduce still other characters that may be desired in the new breed. Many of the American breeds and varieties originated as the result of crossbreeding.

GRADING UP

It sometimes happens that the improvement of the flock is desired wherein the birds are mongrels. In such a case, where the owner cannot afford to purchase a pen of standard-bred fowls, day-old chicks or hatching eggs from which to make a beginning, a standard-bred male may be secured. When such a bird is bred on a selected few of the best of the mongrel or grade females and this process continued for several years, a decided improvement will result. While such a practice is not generally recommended in 
preference to securing all standard-bred stock, and, while such grading up is a slow process in order to secure improved stock, it is decidedly more desirable than the practice of retaining a mongrel male as a breeder.

\section{NOMENCLATURE OF THE FOWL}

Before outlining the factors embracing the breeding of poultry it will be necessary to understand the location and position of the various parts of the fowl, as reference will be made to such parts in the discussion that follows.

The breed represented in Figure 54, is that of the Langshan and is shown so that the location of the feathers on the shank may be indicated as well as the name and location of other body parts. It will be recalled that this feathering of the shanks is a characteristic that is

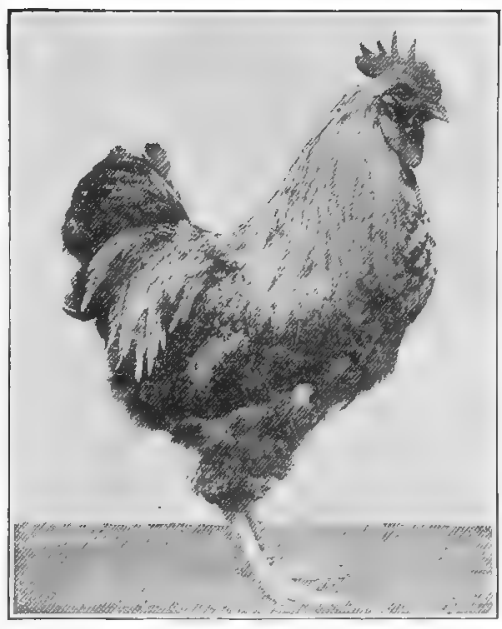

Figure 53,-A mongrel male will produce no improvement in quality.

found only on several of the meat breeds, the French and Ornamental breeds, and some of the Bantams. With this exception and those mentioned below the same body parts apply to all breeds and varieties of poultry.

The several types of combs as found in both male and female of the various breeds are clearly represented in Figure 55 and Figure 56.

Supplementary to the head of the crested fowl as shown in No. 7, Figure 55, a better idea can be obtained in Figure 57 as to the peculiar make-up of the head parts of the 


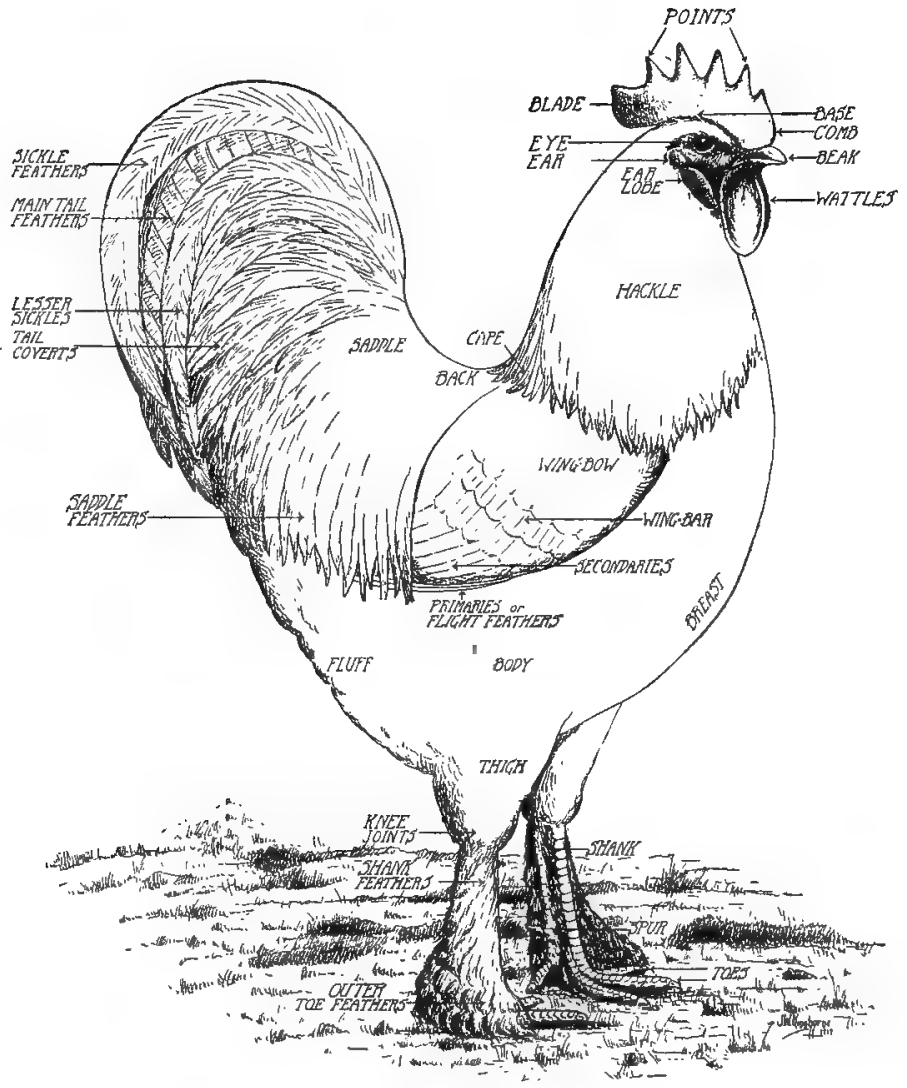

Figure 54,-Nomenclature chart giving the location of the various parts of the fowl. 


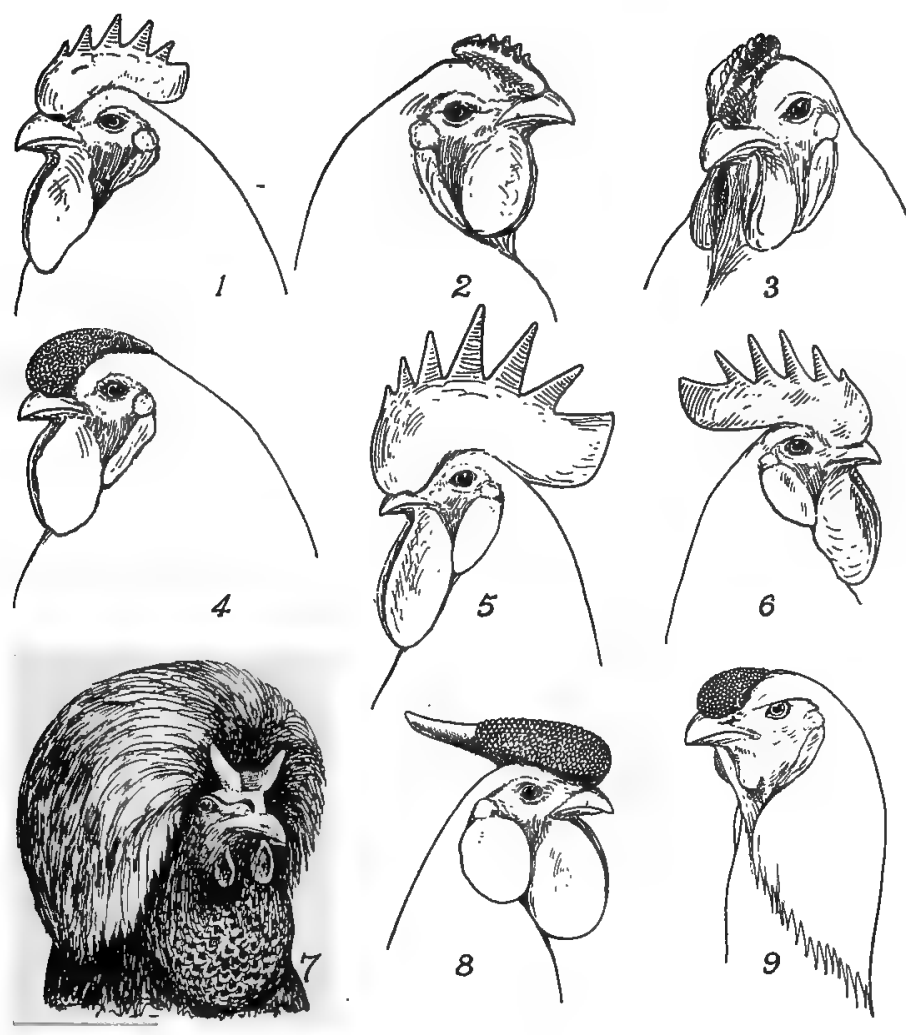

MALE HEADS SHOWING DIFFERENT TYPES OF COMBSS.
1. SINGLE.
2. PEA.
3. $P E A$
4. ROSE
5. SINGLE.
6. SINGLE
7 V-SHAPED.
8. ROSE.
9 STRAWBERRY

Figure 55.

crested breeds as found in the Miscellaneous class.

In some of the European breeds such as the English Dorking and the Faverolles and Houdan of France we find another peculiarity that is worthy of notice, that is, the fifth toe. The fifth toe of these breeds, as shown in Figure 
58, while an outstanding characteristic peculiar to these breeds, is purely a useless appendage.

ESSENTIALS OF POULTRY BREEDING

Health and vigor. In the selection of fowls for breeding the fact should be kept in mind that health and vigor in
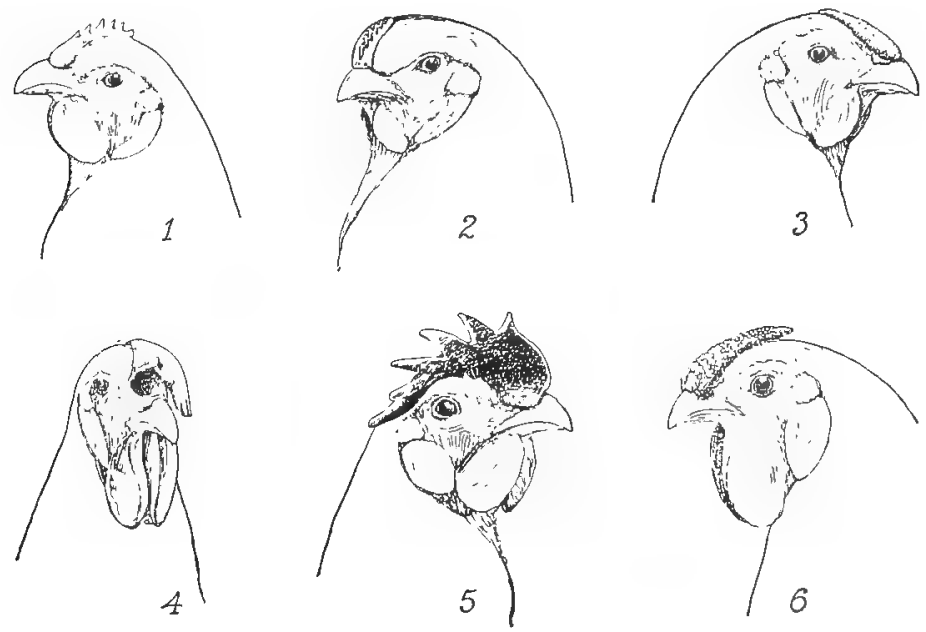

FEMALE HEADS SHOWING DIFFERENT TYPES OF COMBS.

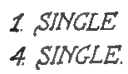

$2 P E A$

5 SINCLE:

3 ROSE

6 ROSE

Figure 56.

the parent stock are necessary for the production of strong healthy chicks. Frail weak chicks are usually the result of low vitality and vigor in one or both of the parents. The death rate among such chicks is usually great and those that do mature rarely if ever produce satisfactory results. Chicks from strong vigorous parents will develop ripidlly, under proper management, into well finished corkerels and pullets capable of producing desirable results. 
Appearance and action. The general appearance and action of fowls to be selected for the breeding pen as they appear on the range or in the yard should be considered. Select those with clean smooth plumage, for frequently soiled and roughened feathers are an indication of sickness or lack of condition. Fowls that are slow and sluggish in their action with little disposition to move about should not be selected for the breeding pen.

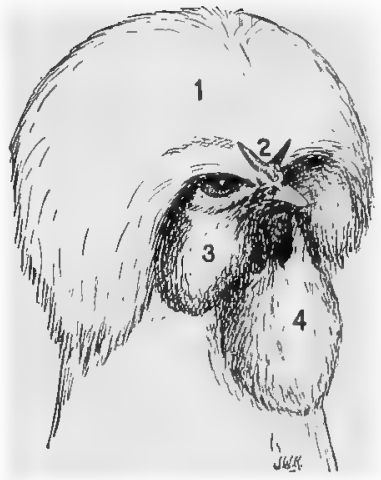

Figure 57.-The head of a crested fowl showing 1 crest, $2 \mathrm{~V}$-shaped comb, 3 muff, and 4 beard.

Sick fowls should never be used as breeders. Those that have been sick but have recovered should not be selected as breeders, if healthy fowls are obtainable. Male birds should be decidedly masculine in appearance, while females showing masculinity should be avoided as breeders.

\section{SELECTION OF THE BREEDERS}

- Having in mind the importance of health and vigor in the breeding stock, consideration should be given next to the desirable characteristics that good breeders should pos-

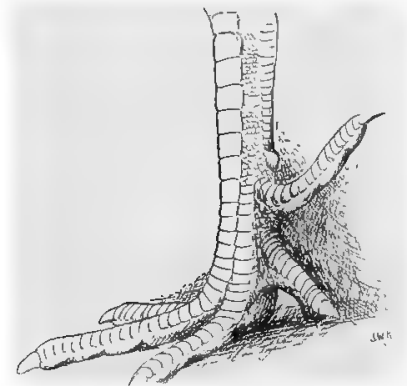

Figure 58.-The fifth toe that is characteristic of some of the English and French Breeds. sess. These general characteristics apply in a large measure to both the male and the female.

Size. Select fowls that are closest to the standard weight for the breed. Breeders that are considerably' above and below standard weight are not desirable for two reasons. First, oversized fowls are apt to be 
inactive and clumsy, most especially in the case of male birds in not being able to fertilize as properly as more active birds. Second, fowls that are below standard weight should not be selected, as there is a tendency for the offspring of some breeds to decrease in size rather than increase when such practice is followed.

Color. In choosing the birds for the breeding pen they should be so mated as to produce fowls that will conform

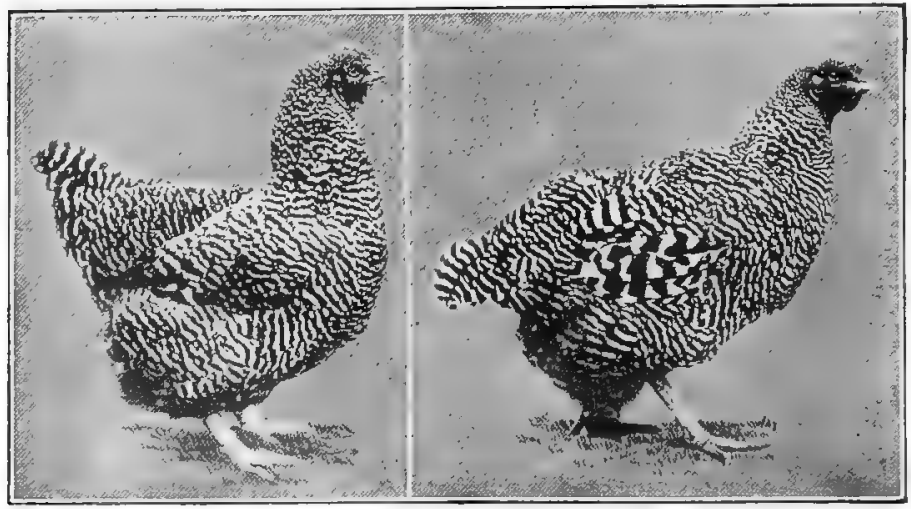

Figure 59.-Barred Plymouth Rock female showing high vitality.
Figure 60.-Barred Plymouth Rock female showing low vitality.

with the standard requirements for color and markings.

Head. The head is a good indication as to the health of the fowl. Good breeders should have a medium-sized head, broad between the eyes with a short stubby beak fairly well curved. A small refined head denotes an apparent lack of vigor. The distance between the eye and the base of the beak should not be great, as a long face is usually associated with a long crow head, which is undesirable. The face should have a good healthy color.

Comb. The comb should be well placed and should have a good bright red color. Avoid lopped combs in those breeds 
that are supposed to have upright combs. Defective combs such as shown in Figure 61 should be guarded against.

Eyes. The eyes should be of a good size, clear, bright, and fairly prominent. A dull sunken eye denotes lack of vigor and vitality.

Neck. The neck should not be long but fairly short and stout, indicating strength; and curved so that the head will be well back and over the breast.

Body. The body should have a well balanced appearance and should possess sufficient depth and length, keeping in mind the desirable type of the breed in question. The underline of the fowl is governed largely by the line of the back. In most cases the underline should not be straight or absolutely parallel with the line of the back, nor should the underline diverge sharply to the rear so as to give a baggy appearance. It should, however, be fairly straight and diverge slightly to the rear.

Breast. From the market point of view the breast is most important, owing to the quality and quantity of meat it carries in proportion to the rest of the body. It should be deep, round, broad and full. Avoid fowls having narrow or flat breasts. A fowl with a full crop must not be confused with one having a full breast.

Back. The back, which is a most important part of the fowl, should conform with the requirements of the breed in question as given in the American Standard of Perfection. A very common defect is the tendency for the back to become narrow as it approaches the tail. This is not a defect, however, in the Cornish or the Games.

Wings. The wings should be fairly short and held firmly in place. Fowls with twisted or slipped wings should not be used, as these are defects and are inherited.

Tail. The tail should conform with the requirements of the breed which usually call for one of medium length, 

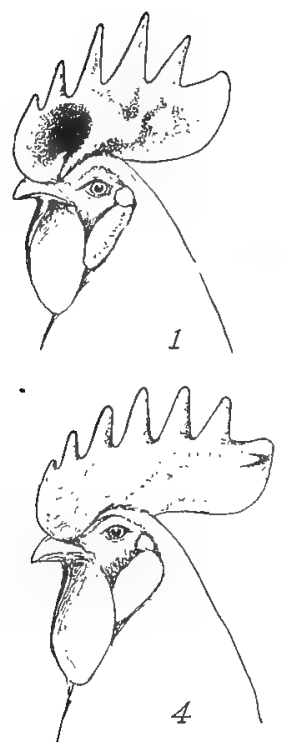
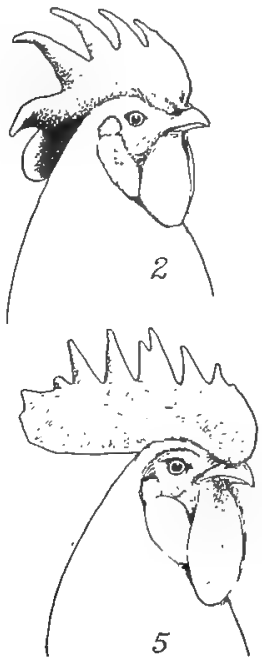
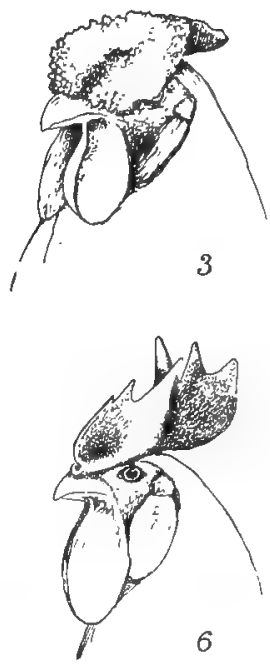

MALE HEADS SHOWING DEFECTIVE COMBS.

1 THUMB $M A R K$.

4 SIDE SPRIG
2. LOPPED (SINGLE).

5 UNEVEN SERRATTONSS.
3. HOLLOW CENTER

6. TWISTED.

Figure 61.

well spread and carried neither too high nor too low. A tail carried too high gives the bird the appearance of being short. An extremely high tail is known as a squirrel tail, as shown in No. 1, Figure 62. When carried too low it detracts considerably from the appearance of the bird. The proper angle at which the tail should be carried for each breed will be found in the American Standard of Perfection. Wry tail, No. 2, Figure 62, that is, a tail carried to one side, should be avoided in selecting the breeders.

Legs and toes. The legs should be of medium length, straight and set well apart. Such legs indicate sturdiness and vigor. The toes should be straight, strong, and well spread. 
Skin. The skin color is important especially in the meat breeds, as the best markets demand a yellow-skinned carcass. This point should be considered by the breeders of market poultry.

\section{KIND OF FOWLS TO REJECT}

The following defects should be guarded against when selecting fowls for the breeding pen: Crow, or snake, head; sunken and dull appearing eyes; wedge-shaped back; long, slim back; wry and squirrel tail; decidedly crooked breast-
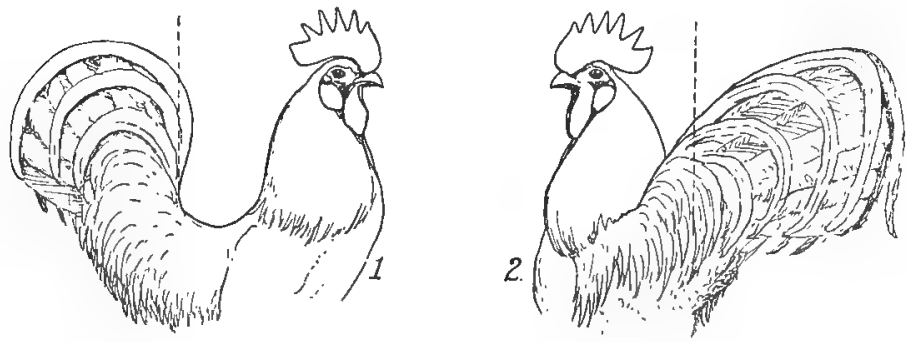

\section{MALES WITH DEFECTIVE TAIL CARRIAGE. \\ 2. WRY.}

1. SQUIRREL.

Figure 62.

bone; narrow breast; long slim legs and toes; knock-knee; shallow abdomen; and fowls that are deformed in any manner. Birds possessing these undesirable characteristics either inherit them or have been grown under unfavorable conditions.

\section{PURPOSE OF BREEDING}

In addition to the foregoing characters the purpose of breeding should be kept in mind when the fowls are selected. If the principal idea is to produce stock of exhibition quality, the fowls should be selected that approach nearest to the standard in type and markings, or that will combine these qualities so as to produce birds that will most nearly approach the standard. In addition to these standard requirements, if 
the purpose of mating be to produce table fowls, birds that possess a large frame well covered with an abundance of meat evenly distributed should be selected as breeders. (See Scale of Points in Appendix.) In the selection of breeders for the reproduction of stock for egg production birds should be chosen that are good producers of eggs or are the sons or

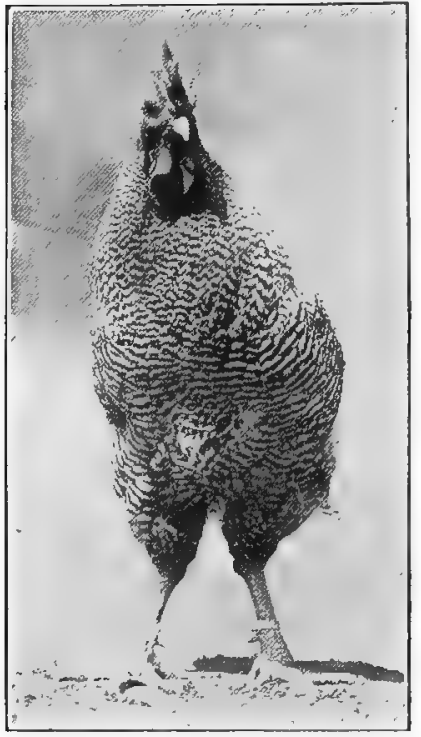

Figure 63.-A knock-kneed fowl, the kind to be avoided as a breeder.

daughters of good producers. Many suggestions relating to the selection of high producers will be found in Chapter XIII.

\section{KINDS OF MATINGS}

Single mating. Many varieties of fowls are single mated. That is, both males and females are secured which should conform to the standard requirements of the variety concerned from one mating. While the production of both males and females of standard quality is possible as the result of single mating, especially in the case of solid colored birds, many poultry breeders depart from this plan and resort to one mating to secure exhibition males and another mating for exhibition females. This system is known as double mating.

Double mating. As explained, this plan of breeding involves two separate matings in order to secure both exhibition males and females. A good example of double mating can be cited in the case of Barred Plymouth Rocks. To secure exhibition or standard males, that is, males having black and white barring of equal width, an exhibition male 
is mated to females that are darker in color than called for in the standard. This is known as the cockerel mating and produces exhibition cockerels and cockerel-bred pullets (those which are darker in color than exhibition pullets). To secure exhibition females a lighter colored male is mated to exhibition or standard females, that is, females having black and white barring of equal width. This is known as a pullet mating and produces exhibition pullets and light colored cockerels, or, as they are called, pullet-bred cockerels.

Stud mating. This system of mating is not as commonly used with fowls as those previously mentioned. As practiced the male or males are kept separate from the females and are only mated at certain periods. The object of stud mating is for the purpose of breeding individual females in one flock for instance to two or more males, having in mind a definite purpose of breeding. To carry on this plan successfully it is necessary to trapnest the females. (See page 149.) After each second or third egg produced the female is removed from the trap nest, taken to the male, and left with him until copulation takes place. It has been found that more frequent copulation is unnecessary to secure satisfactory fertility.

Flock, or mass, breeding. This form of breeding, as the name implies, refers to the mating of the entire flock, wherein there may be several males. This plan is not recommended unless all the individuals of the flock are selected for some definite purpose of breeding.

\section{TIME TO MATE}

The breeding pen should be mated at least two weeks before beginning to save eggs for hatching. When less time is allowed the greatest number of fertile eggs is not likely to be secured. When possible, the mating should be made far enough in advance so that a few eggs could be 
incubated for a week to see whether they are running fertile. If they are not fertile, the male should be removed and another male bird substituted. The lack of ability to fertilize eggs is not a very common defect among male birds. The mating should be done as early in the year as possible.

\section{SIZE OF MATING}

To a certain extent the breed influences the size of the mating. When fowls are yarded it is usually desirable to place from 12 to 15 females of the lighter type, such as the Leghorns, with a male bird. For birds of the general-purpose class, such as the Plymouth Rock, the proportion should be 1 male to 10 or 12 females, under yarded conditions, and from 8 to 10 females of the meat breeds, such as the Brahma, with 1 male. But, whenever the fowls have access to free range and the male is strong and vigorous, it is possible to obtain fertile eggs from a considerably larger flock of females. A vigorous Plymouth Rock or Wyandotte cockerel, for instance, on free range should be productive of good fertility when mated to 20 to 25 females. A male of the egg breeds, such as the Leghorn, under the same conditions, can be mated successfully to 25 to 35 females. When eggs for hatching are desired from a flock of hens that is too large for 1 male, 2 or more males can be placed with the flock, either at the same time or by alternating the males on successive days.

\section{AGE OF THE BREEDING STOCK}

As to the age of breeders, either pullets or hens, cockerels or cocks, can be used in the breeding flock. Hens, however, are preferable to pullets in that they lay larger eggs and seem to give better fertility and produce stronger chickens. Yearlings and two-year-old hens are more desirable than hens over two years old. An early hatched, well developed cockerel is oftentimes as desirable as a breeder 
as an older male bird. The fowls, either male or female, that have proven themselves to be especially valuable as breeders should be retained as long as they will breed.

FREE RANGE FOR BREEDING STOCK

Whenever possible, the breeding stock should have free range, especially during the early fall and winter before the breeding season. When this is not possible, free range just preceding and during the breeding season will be of great value in strengthening the fertility of the hatching eggs.

MANAGEMENT OF THE BREEDERS

After the fowls have been selected and mated, care should be taken to see that they are kept in good condition in order to insure the best results. Examine the fowls and houses at frequent intervals to see that they are not infested with lice and mites. When infested with either of these pests the fertility will be affected and sometimes totally destroyed. In cold weather care must be used to see that the male does not have his comb and wattles frosted or frozen. If injured in this way, his ability to fertilize eggs in most cases will be impaired, and he usually will not recover for several weeks. In very cold weather, males intended for breeding should be placed in a box or crate at night partly covered with a bag or cloth to prevent the freezing of the comb and wattles. Another means of preventing frosted comb and wattles is to grease these parts with vaseline. It frequently happens that the male is so gallant that he allows the hens to eat all the feed, with the result that he soon gets out of condition. It is well, therefore, to examine the male occasionally at night after he goes to roost to see that his crop is full and that he is not growing thin. If his gallantry is proving detrimental to himself, the male should be fed at least once a day separately from the hens. Sick fowls or those that show any signs of being out of condition should be removed from the breeding pen immediately. 


\section{FEEDING THE BREEDERS}

The feed for the breeding stock should be of such a nature as to keep the fowls in good condition and at the same time be conducive to the production of eggs. A good ration such as is fed to layers is suitable for this purpose provided it is not of a forcing nature. That is, it should not contain an extremely large amount of meat scrap or meat meal. The birds should be in good flesh and not allowed to become extremely fat. All grains should be fed in a litter so as to induce exercise by scratching for

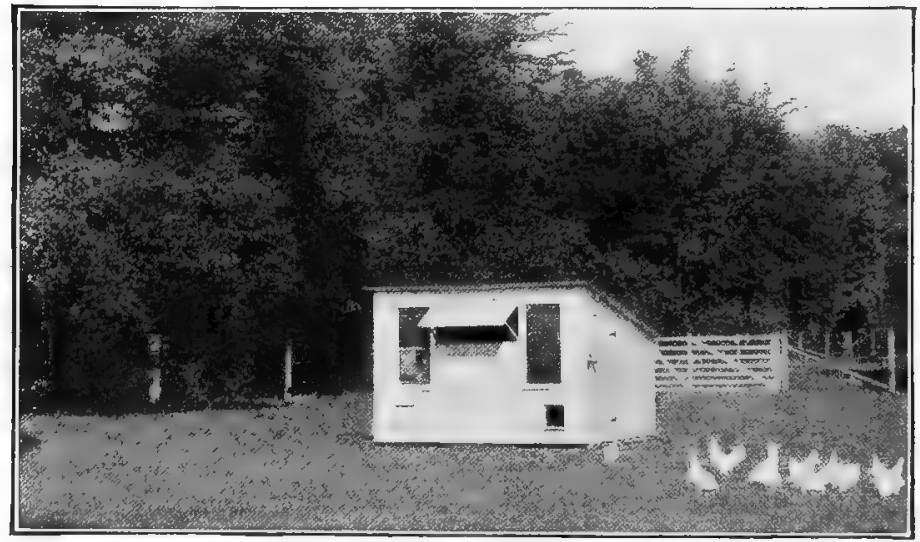

Figure 64.-Fowls on free range will give higher fertility and better hatches and stronger chickens than those confined.

them. When the flock does not have access to some natural supply of green feed, as is not likely during or preceding the breeding season, it is well to feed green feed in the form of sprouted oats, cabbage, mangels or cut alfalfa or clover. Care should be taken to see that the breeding pen is supplied with fresh clean water each day. In cold weather see that the ice is broken on top of the water pan at frequent intervals so as to enable the fowls to drink. A receptacle con- 
taining charcoal, grit, and oyster shell should always be available to the fowls.

\section{QUESTIONS}

1. Discuss the growth and progress that have been made in breeding poultry for standard requirements and high production.

2 . What is the advantage of breeding fowls for standard requirements and capable of high production?

3. Discuss heredity, variation, sports, reversion, correlation, regression, progression, prepotency and fecundity.

4. What is meant by inbreeding, line-breeding, outbreeding, crossbreeding?

5. Describe the process known as "Grading Up."

6. Name the various parts of the fowl.

7. Name the head parts found in the crested breeds.

8. What breeds are characterized by having a fifth toe.

9. What are two of the most important essentials in selecting breeders?

10. Discuss the general appearance and action of fowls that are to be considered as breeders.

11. When selecting the breeding pen, discuss the desirable characteristics that they should possess as concerning size, head, neck, wings, back, etc.

12. In general what are some of the outstanding defects that should be guarded against in selecting breeders?

13. What things should be kept in mind when breeders are selected for exhibition purposes primarily? For meat production? For egg production?

14. Describe single mating, double mating, stud mating, flock mating.

15. How long should the breeding pen be mated before eggs are saved for hatching?

16. When in confinement or yarded, how many Leghorn hens can be mated to a male bird? As concerning the general-purpose breeds, how many hens can be mated to a male bird, when confined? When given free range?

17. What is the advantage of free range over confinement for the breeding stock?

18. Discuss the management and feeding of the breeding pen.

\section{SUGGESTIONS}

1. Should you have a flock of fowls, would it not be to your advantage to so breed them as to combine standard requirements and production? What steps would you take to accomplish this end?

2. Could you not endeavor to have some one of the poultry breeders in your community give a talk on breeding poultry before a near-by farmers' club or grange? Could not such a talk be arranged also before the Boys' and Girls' Poultry Clubs in your community school? 
3. An interesting contest that can be arranged in connection with the school poultry club is to have a live bird on exhibit and to have the members name the various parts of the fowl, the object being to see what member can give the most complete list.

4. In company with other members of your poultry club or association, arrange to have a meeting at a near-by poultry plant some afternoon and hold a demonstration for the selection of the breeding pen. Keep in mind the object for which the mating is to be made as well as the desirable and undesirable characteristics to look for. Let each member make his or her own decision, placing on a piece of paper the leg band numbers of the birds selected. Have the members compare this selection with those of a competent breeder or the owner of the flock, who should state his reasons for such selection in detail.

5. If you have a flock of fowls at home, write an article or composition outlining in detail how you would select a pen of breeders from the flock, and how you would manage and feed them during the breeding season. After outlining such a plan endeavor to put it into operation.

\section{REFERENCES}

The Mating and Breeding of Poultry, by Harry M. Lamon \& Rob R. Slocum.

The Principles of Breeding, by E. Davenport.

Plymouth Rock Standard and Breed Book, published by the American Poultry Association. 


\section{CHAPTER IV}

\section{NATURAL AND ARTIFICIAL INCUBATION}

The incubation of eggs by artificial methods has made great progress within recent years. There is no question that artificial incubation as carried on with our present day incubators is thoroughly practical and possesses many advantages over hatching by natural means. A thorough understanding of the fundamentals of incubation and incubator operation as given herein, coupled with good management, will assist materially in securing satisfactory hatches.

\section{PRELIMINARY CONSIDERATIONS}

\section{THE EGG}

Before considering the subject of incubation a study of the construction of the egg will assist in understanding the suggestions as given for handling eggs that are to be incubated. The shell of the egg is porous, and consists of an outer and an inner layer, under which are two membranes. These membranes are separated at the large end of the egg and form the air cell. The air cell in a fresh egg is about as large as a ten cent piece and increases in size as the water in the egg evaporates. (See Figure 84.) Surrounding the yolk is the white of the egg, or albumen.

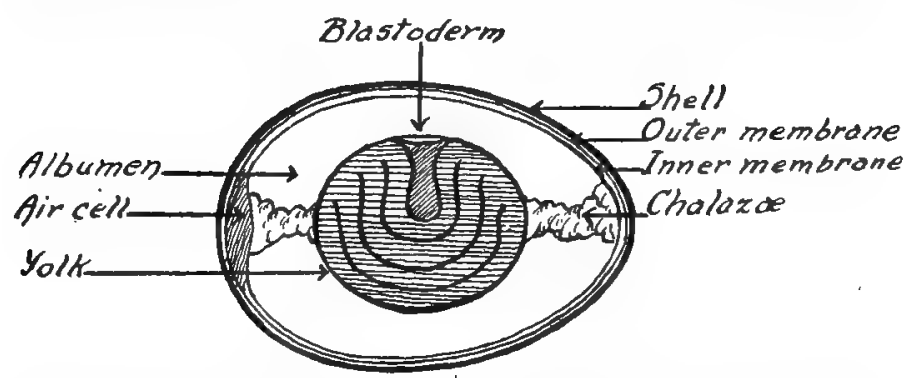

Figure 65.-Cross-section of an egg showing its structure and several parts. 
Two coiled membraneous cords or layers of thick albumen called chalazae are attached to the opposite ends of the yolk with each end of the shell. The purpose of the chalazae is to lessen the movement of the yolk so that its position will be maintained in the center of the egg. The germ spot, or blastoderm, is a small spot located on the upper surface of the yolk.

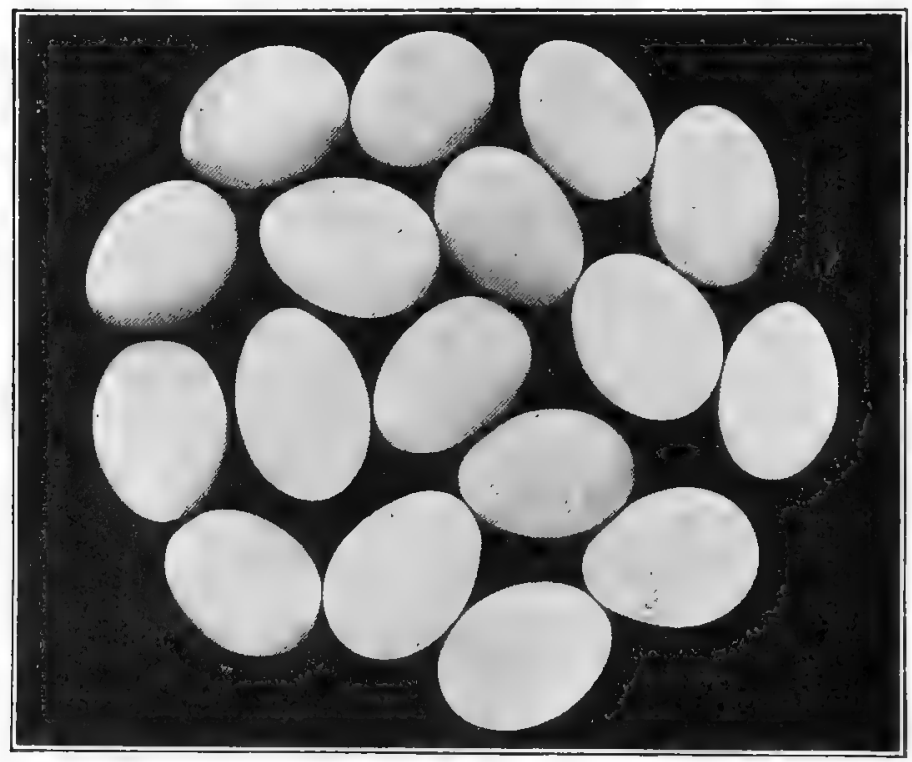

Figure 66.-Eggs showing variations in size and shape. Uniformity in size and shape should be the guide in selecting hatching eggs.

SELECTION AND CARE OF EGGS FOR HATCHING

Fertility. The most important factor necessary to produce a good hatch is fertile eggs, produced by healthy, vigorous stock properly mated and kept under the best possible conditions. The temperature at which eggs are kept previous to hatching has, therefore, a determining influence on 
the results of the hatch. They should be kept in a room or cellar where the temperature is from $50^{\circ}$ to $65^{\circ} \mathrm{F}$. They are generally kept in a cabinet or turning rack to keep the yolk from settling away from the center, but eggs that are to be kept less than a week need not be turned.

Commercial turning devices of various kinds are sold by poultry supply companies for this purpose. When such devices are not at hand, the eggs may be kept in a drawer or tray and turned with the hand each day.

Freshness. Eggs should naturally be as fresh as possible. They should be collected at least once a day in the summer and two or three times a day in the winter, to prevent their being chilled. It is not advisable to use eggs for hatching when they are over two weeks old.

Broody hens should not be allowed to sit on eggs all day, as the hatching qualities are apt to be impaired, and the germ of the egg is likely to start development before it is desired.

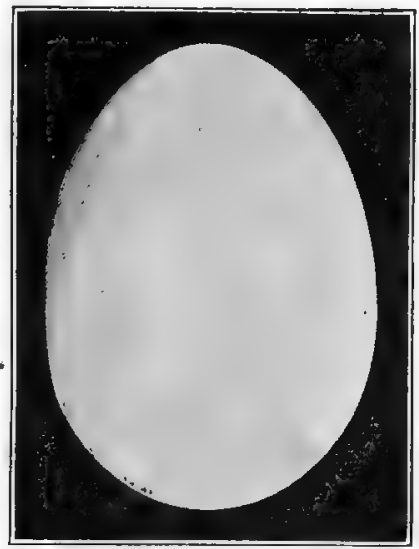

Soiled eggs. Do not set dirty or badly soiled eggs. If

Figure 67.-Selecting uniform eggs for hatching of good size that are of the same color is one of the quickest ways to secure uniformity in the offispring and increase the size of the eggs that they will produce. slightly soiled, they should be cleaned by rubbing them lightly with a damp cloth. Care should be taken not to rub off any more of the natural bloom of the egg than is absolutely necessary to remove the dirt. Duck eggs are usually soiled and, therefore, require washing, which does not apparently injure their hatching quality.

Similar eggs. One should not mix or set white-shelled 
eggs from the egg breeds, such as the Leghorn and Ancona, in the same incubator or under the same hen with brownshelled eggs of the heavier breeds, such as Plymouth Rocks or Wyandottes. The white-shelled eggs from the smaller breeds often hatch a little earlier than the brown-shelled eggs of the larger breeds. Eggs from different varieties of the same class of fowls may, however, be incubated together.

Sound shells. Only eggs of sound shells should be set. This precaution is evident if they are to be set under a hen, as they are apt to get broken during incubation. Eggs

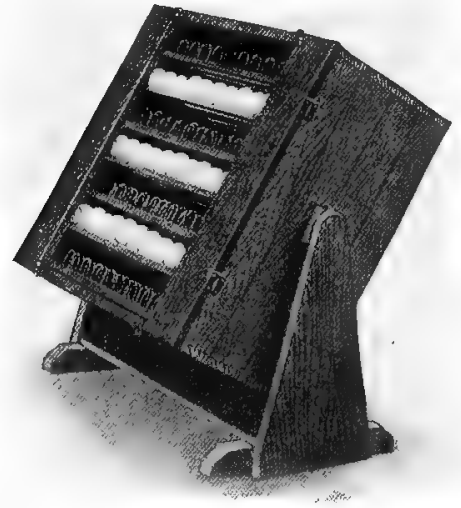

Figure 68. A turning crate for hatching eggs. of thin or porous shells are undesirable even for the incubator.

Abnormal eggs. Neither the hen nor the incubator will hatch strong chicks from eggs that are abnormal or small or poorly shaped.

PACKING HATCHING EGGS FOR SHIPMENT

Thousands of sittings of eggs for hatching are shipped each season and many are sent long distances, but in some instances rough handling in transit appears to affect the hatch from such eggs. A satisfactory method of shipping eggs for hatching is to use a common chip market basket, well lined on the inside with excelsior. Wrap each egg in a layer of paper, and put enough excelsior around the egg to make a ball of about three inches in diameter. Pack the eggs securely in the basket, covering them with a layer of excelsior. Then the basket should be covered with a strong piece of cotton cloth, 
which can be sewed on the basket or pushed up under the outside rim with a case knife. Stiff corrugated cardboard cartons made to hold from one to several sittings may be bought in which to ship eggs. It is advisable to allow eggs for hatching to remain in one position for about 12 hours after they are received, in order to allow the yolk to regain its normal position before the eggs are incubated.

$$
\text { PERIOD OF INCUBATION }
$$

The period of incubation of several of the different species of poultry is shown in the following table:

Table I. Period of Incubation for Poultry.

\begin{tabular}{|c|c|c|c|}
\hline $\begin{array}{l}\text { Kind of } \\
\text { Poultry }\end{array}$ & $\begin{array}{l}\text { Days of } \\
\text { Incubation }\end{array}$ & $\begin{array}{l}\text { Kind of } \\
\text { Poultry }\end{array}$ & $\begin{array}{l}\text { Days of } \\
\text { Incubation }\end{array}$ \\
\hline Hen... & $\ldots \ldots 21$ & \multirow{5}{*}{\multicolumn{2}{|c|}{ 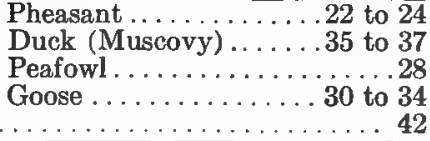 }} \\
\hline Duck. & & & \\
\hline Turkey & & & \\
\hline Guinea & 26 to 28 & & \\
\hline Ostrich & & & \\
\hline
\end{tabular}

Within a given class of poultry the period of incubation varies somewhat with conditions. For example, a hatch may run over one or two days in some instances, because the incubation temperature was too low throughout that period, while, on the other hand, the hatch may come off earlier than expected on account of a slightly higher temperature during the incubation period. If, as the result of an accident, the eggs are chilled or are overheated, the hatch should be continued and the eggs tested after a few days to determine the extent of the damage. There are instances known where chicks have been hatched from eggs left out of the incubator all night, as well as from eggs that have been subjected for a short time to a temperature considerably over $103^{\circ}$. Such practices, however, should be avoided, as the chicks from such eggs usually do not grow well.

\section{PROPORTION OF SEXES}

The average hatch will result in producing approximately 50 per cent of the chicks hatched as males and 50 


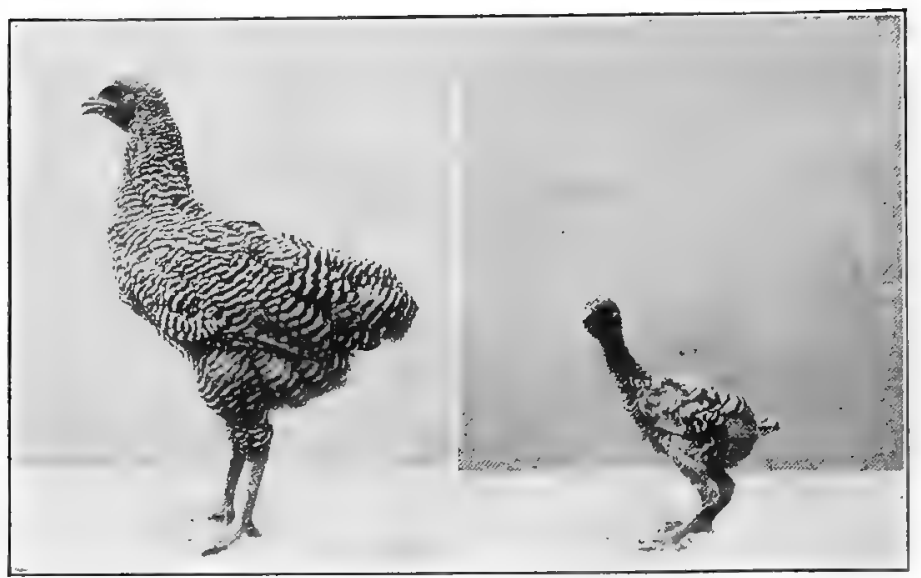

Figure 69.-Early hatched pullet, photographed June 26.

Figure 70.-Late hatched pullet, photographed June 26.

per cent as females. Some hatches will result in producing more of one sex than of the other; but, taking all the season's hatching and the per cent of each sex secured year

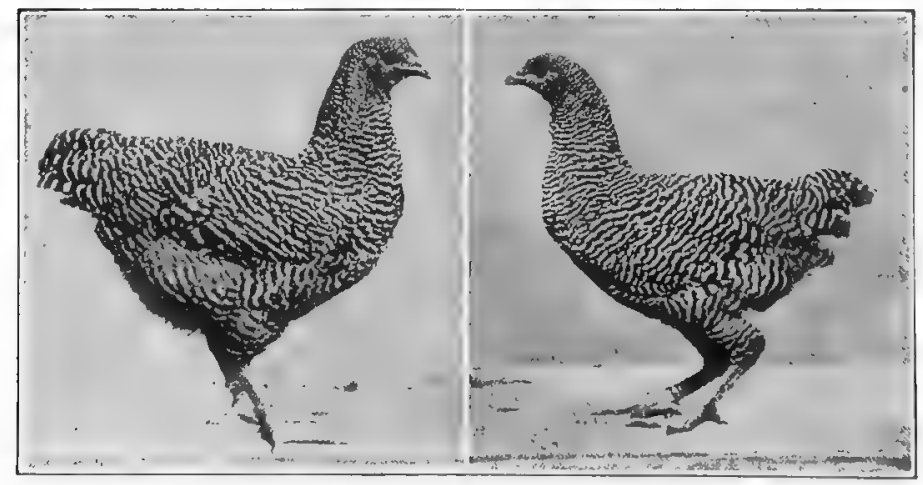

Figure 71.-Early hatched pullet, photographed September 26. Mature - Laying.
Figure 72.- Late hatched pullet, photographed September 26. Immature -Not laying 
after year, the general average will usually result as above mentioned. The problem of predetermining the sex still remains unsolved. In other words, up to the present time there is no satisfactory method of foretelling whether an egg will produce a male or a female.

\section{TIME OF THE YEAR TO HATCH}

When to hatch. The early spring is the best time for hatching, as it is nature's most favorable growing season. By hatching chickens early they have the advantage of this favorable growing season and a longer growing period than those hatched during the late spring or early summer.

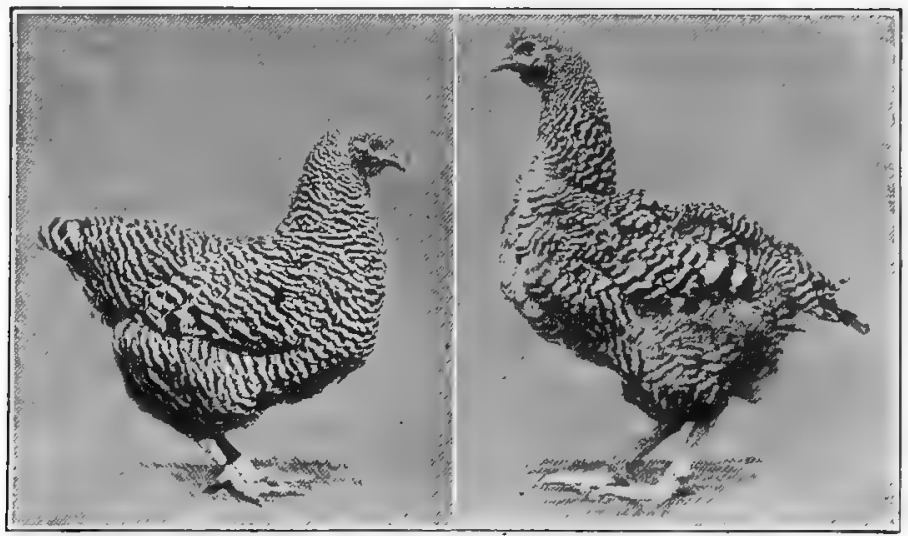

Figure 73--Early hatched pullet laying in the fall.

Figure 74.- Hen molting in the fall and not laying.

Given the same feed, care, and attention, chickens hatched the first of March weigh more when they are four months old than those hatched the first of May, when they are of the same age.

The rate of growth of a chick is greater during the first four weeks of its life than at any other period. Other conditions being equal, therefore the more favorable the period, 
the greater will be the rate of growth during that period. Consequently early hatched chicks having the advantage of a more favorable growing season make greater gains during the first four weeks of their lives than chicks hatched later in the spring.

February, March, and April are the best months for hatching in the North Atlantic, North Middle West and Northwestern states, while January, February, and March are the best months for hatching in the South and Southwestern states.

The smaller breeds, such as those of the egg class, can be hatched a little later than those of the heavier breeds, as they develop more rapidly and mature earlier. Chicks hatched early with proper care and attention should reach maturity and start laying in September, October, or November.

It is during the fall months that the hens are getting ready for winter by molting and growing new feathers and few hens grow feathers and produce eggs at the same time.

When hens are molting, eggs are scarce and when eggs - are scarce prices are high. The solution is to hatch early, so as to have early maturing pullets that will produce eggs when hens are molting.

When not to hatch. Great numbers of late-hatched chicks die each year as the result of being infested with lice, which are very prevalent in the summer. Then, too, hot weather retards the growth of chicks. Chicks hatched in early spring will get a good start before hot weather arrives and will not be so subject to lice as those hatched during the hot weather. Late-hatched chicks are usually the ones that become infected with roup in the fall, thereby endangering the rest of the flock.

With proper care and attention sitting hens will produce 
a large number of chickens at comparatively small expense. The hens of the general-purpose breeds such as the Plymouth Rocks, Wyandottes, etc., usually make very good mothers. The heavier breeds of the meat class, including the Brahmas and Langshans, make good sitters, but are inclined to be somewhat clumsy on the nest. The Leghorns and other

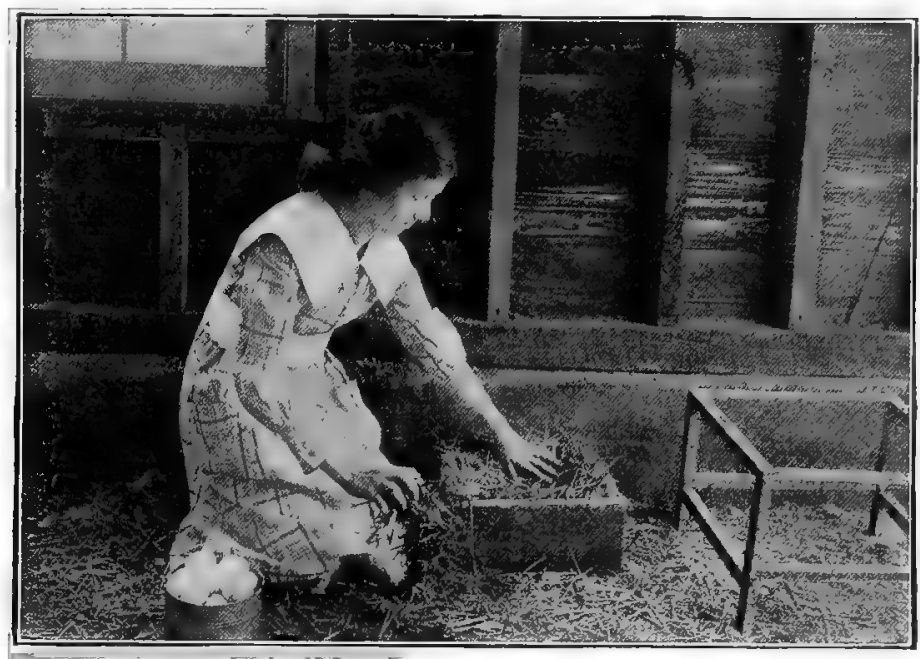

Figure 75.-Pack the hay or straw down firmly, shaping a circular nest slightly deeper in the center than at the edge to prevent the eggs from rolling out from under the hen and becoming chilled.

Egg breeds usually do not make very good mothers, even though they become broody and want to sit.

The normal temperature of the hen is from $106^{\circ}$ to $107^{\circ} \mathrm{F}$. This temperature varies little during the period of uncubation.

\section{HOW TO SET A HEN}

Indication of broodiness. When the hen becomes broody and wants to sit, it will be noticed that she will leave a few soft downy feathers in the nest. Then, too, such a hen sits 
longer on the nest when laying and on being approached will quite likely remain on the nest and cluck, ruffle her feathers and peck at the intruder. When a hen sits on the nest for two nights in succession and most of the feathers are gone from her breast, she is ready to be transferred to the nest where she is to hatch the eggs.

Quarters. When there are but a few hens to sit, special quarters are not necessary, but, where natural incubation is carried on to any considerable extent, a separate place or room should be provided for the sitting hens. It might be advisable to build a cheaply constructed shed or house for this purpose.

A most satisfactory nest for sitting hens can be built by using the following dimensions: 15 inches square, 12 inches high in back with a board 6 inches high in front to keep the nesting material in place. A wire-covered frame may be made to fit over the nest to confine the hen after setting her. (See Figure 77.) Before making the nest it is advisable to place 2 or 3 inches of damp earth or a piece of sod in the bottom of the nest box to provide moisture. The nest material is next put in and may consist of hay or straw.

In order that the hen will not be disturbed, it is best to place the nest in some quiet out-of-the-way place. When moving the broody hen from the laying nest to the one where she is to sit, the change should be made at night. Place a nest egg or two in the nest under the hen and cover the nest so that she will not get off. On the second evening go quietly in where she is sitting, leave some feed and water, and remove the covering from the nest so that she can come off when ready. When the hen returns to the nest after. eating, remove the nest eggs and put under her those that are to be hatched.

Dusting. Several days before the hen is set she should receive a thorough application of insect powder. When 
applying it hold the hen by the feet, as shown in Figure 76, with the head down, and work the powder well into the feathers, especially around the vent, through the fluff, and under the wings. Sprinkle some powder in the nest also.

MANAGEMENT OF THE SITTING HEN

When the eggs are hatching the hen should be confined and not disturbed until the hatch is complete. Should she become restless, however, the chicks that are

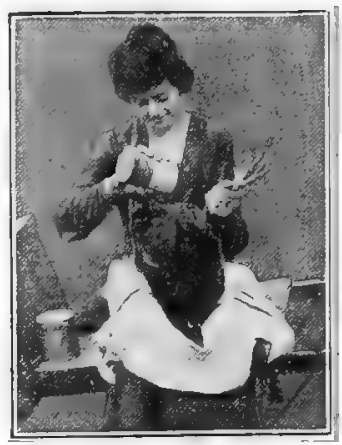

Figure 76.-Before setting the hen dust her thoroughly with insect powder. hatched first should be removed. When the weather is cool it is best not to put more than 10 eggs under a hen, while later in the spring, when the weather is warmer, from 12 to 15 can be placed in the nest, according to the size of the fowl.

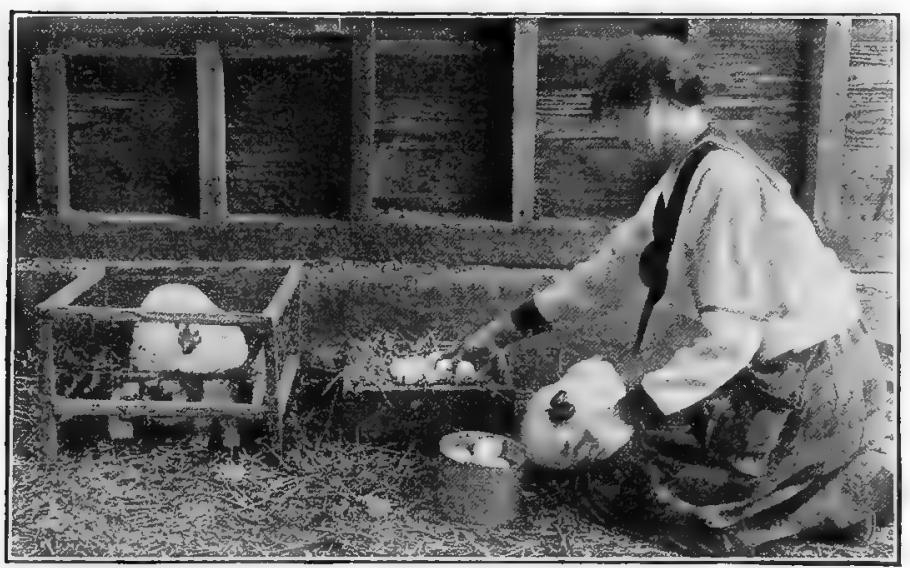

Figure 77.-Placing eggs in the nest for the sitting hen. 
When several hens are sitting in the same room, they should be confined to their nests, allowing them to come off only once a day to receive feed and water. A good feed for sitting hens is whole corn or wheat, or both. If there are any that are not inclined to come off for themselves, they should be removed from the nests for feed and water. Hens usually return to the nest before there is any danger of the eggs' becoming chilled; but, if they do not do so within a reasonable time, they should be put back on the nest. The eggs and nest should be examined each day and when soiled should be cleaned by removing all broken eggs, and those that are soiled should be cleaned with a damp cloth. When the nest material is soiled, it should be removed and clean straw or hay added.

Frequently eggs that are laid in the late winter and early spring are infertile. With this in mind it is advisable to set several hens at the same time and test the eggs after they have been incubated for 5 to 7 days. (See page 86 as to the method of testing eggs.) The infertile and dead-germ eggs should be removed and the fertile eggs put back under the hens. It is often possible then to put all the fertile eggs under fewer hens than were set originally and to reset the others. In this way a larger number of chicks can be hatched earlier than when the eggs are not tested.

\section{ARTIFICIAL INCUBATION \\ INCUBATORS}

Types of incubators. The various makes and kinds of incubators on the market are either of the hot-air or hotwater types. Both "moisture" and "non-moisture" incubators are made in these various styles of machines. The smaller incubators are usually heated by burning kerosene oil, gas or electricity. The source of heat for most of the mammoth machines is supplied by a coal stove, although gas and kerosene oil are used to some extent. In a few 
instances some of the mammoth machines are heated by electricity.

Hot-air and hot-water machines are both used successfully. The hot-water type of incubator will hold its heat longer than the hot-air machine in the event that the lamp goes out. The possibility of such an accident is, however, too slight to be worth considering when the incubator is attended to properly.

Mammoth machines are becoming quite popular and are used extensively both in the day-old chick business and

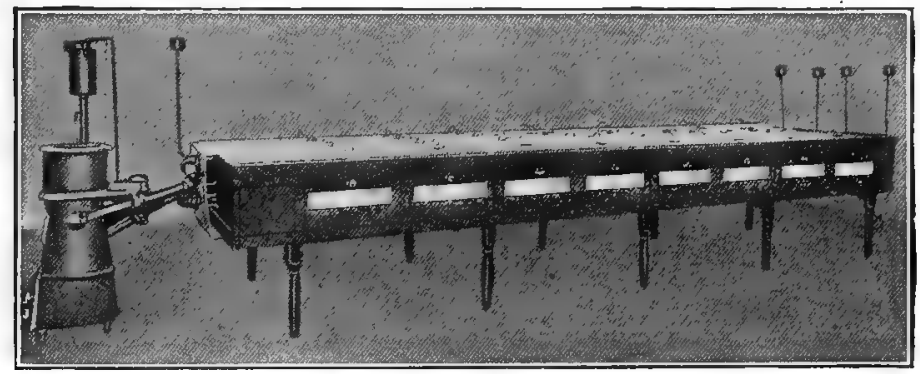

Figure 78.-A mammoth incubator with a capacity of 2,400 eggs.

in custom hatching. Their capacity runs from 1,500 to 10,000 or more eggs. These machines are built in sections, consisting of several compartments, each section holding about 2,000 eggs, the size varying in different makes. Small individual machines of from 150 to 400 eggs capacity are generally used when an incubator capacity of less than 2,000 eggs is desired.

Selection of the incubator. There is a large variety of reliable makes of incubators manufactured so that no one incubator can be recommended in preference to all others. Cheap machines are usually not economical to buy, as they are less reliable, require more attention and wear out more 


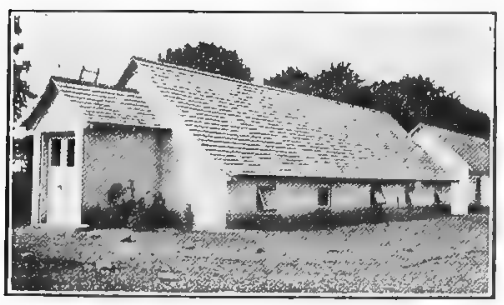

Figure 79.-An exterior view of an incubator cellar on a commercial poultry farm.

quickly than higher priced incubators. The value of the machine is small as compared to the value of the eggs used and the results produced. It is advisable, therefore, to invest in one that is absolutely reliable. It is best to purchase a make of incubator that is giving good results in your vicinity, so as to secure the benefit of the experience and advice of others.

Place to operate the incubator. Incubators are operated in a great variety of places with marked success. When but a few machines are used, they can be operated in a room or cellar of the house. A special incubator cellar or house should be provided where the hatching operations are extensive, or when mammoth machines are used.

The main essential in an incubator room or cellar is to

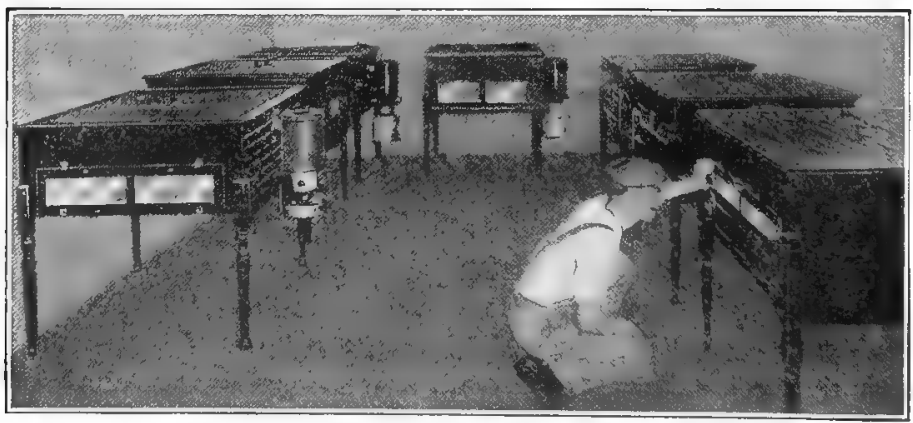

Figure 80.-The interior of a well arranged incubator cellar. The incubator room or cellar should be large enough to allow the attendant to work around the machines conveniently. Many incubator cellars have cement floors which are easier to keep clean and neat than board or earth floors. 
have it so arranged as not to subject it to any great variations in temperature and so that it will be well ventilated with fresh pure air. Muslin screens placed in the window frames provide good ventilation without draft and at the same time keep the sun from shining on the machines. Good results are secured in an incubator cellar as well as in incubator rooms which are entirely above the ground level. An incubator cellar, however, is more commonly used and usually better hatches can be secured. Incubators may be operated in buildings with single walls, especially in sections which have a mild climate. A building with a wall that is well insulated, however, is preferable.

\section{OPERATION OF THE INCUBATOR.}

Before beginning the actual operation of an incubator, attention should be directed to a thorough understanding of two very important parts of the machine, namely, the thermostat and the thermometer.

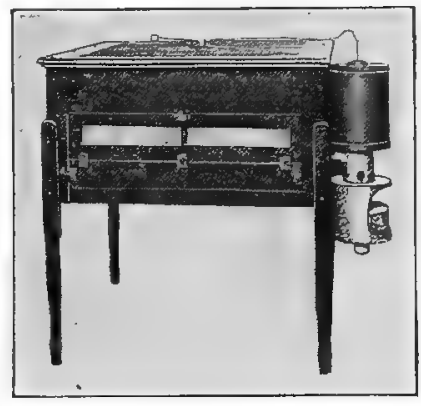

Figure 81. - A hot-air incubator showing the bar on the top of the machine that is controlled by the thermostat

The thermostat. The part of the incubator which controls the regulation of the heat is called the thermostat. This instrument acts on the principle of expansion and contraction caused by changes in temperature. It is fastened in the egg chamber and connected by a rod to a bar. This bar extends across the incubator to the lamp and has suspended from its other end a metal disk which covers the opening over the heater. As the temperature of the incubator increases the thermostat expands, which by means of the connecting rod raises the disk over the lamp and re- 
leases the heat from the heater. On the other hand, as the temperature of the incubator decreases the thermostat contracts, lowering the disk so as to close the heater, thereby retaining the heat.

The thermometer. There are two general styles of incubator thermometers, each of which gives satisfactory results. One is placed on the egg tray, usually in contact with the eggs and is known as the contact thermometer, while the other is hung above the eggs. In using the thermometer follow the manufacturers' directions unless there

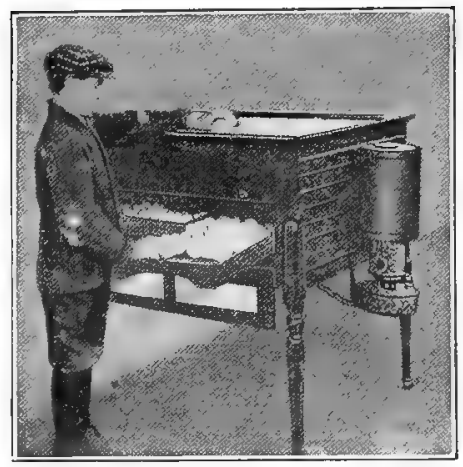

Figure 82.-It takes several hours for the machine to come back to its correct temperature after the eggs are first put in. Therefore, the regulator should not be changed during that time. is a very good reason for making changes. When the contact thermometer is used, some operators prefer to have the bulb touch two eggs so that it may record the temperature of at least one fertile egg. The thermometer is usually placed in the front of the egg tray, so that it can be easily read without opening the door of the machine.

Operating the incubator. The incubator should be set up according to the manufacturers' direction; and see that the machine is sitting perfectly level, thereby causing an even distribution of heat in the egg chamber. All parts of the incubator should be in their proper positions and the regulator should work freely. If the door of the machine sticks, do not plane it off until the machine has been heated up and thoroughly dried out. The machine should be run at about $102^{\circ} \mathrm{F}$. for a few days before putting in the eggs. 
Attend to the regulation of the temperature of the incubator before opening the door of the machine to attend to the eggs, but do not change the regulator any more than is absolutely necessary. The eggs will tend to throw off some heat as the embryo in the egg develops so that this fact may occasionally make it necessary to change the regulator slightly. The temperature in the egg chamber may likewise be regulated by lowering the flame of the lamp in the middle of the day when the room is warmer, owing to outside heat. Incubators require careful, regular, and systematic attention, which, though simple, is very exacting in order to secure good hatches.

The correct temperature. This depends upon the position of the thermometer in the egg chamber. The manufacturers' directions should be followed in this connection and changed only after experience shows that they can be improved. When the contact thermometer is used, the temperature should be held at $101 \frac{1}{2^{\circ}}$ to $102^{\circ} \mathrm{F}$. the first week; $102^{\circ}$ to $103^{\circ}$ the second week; and $103^{\circ}$ the third week. When a hanging thermometer is used, the temperature should be $102^{\circ}$ to $1021 / 2^{\circ} \mathrm{F}$. the first two weeks, and $103^{\circ} \mathrm{F}$., the last week. When the hatch is complete the thermometer will frequently run up to $104^{\circ}$ or $105^{\circ} \mathrm{F}$. without any injury to the chicks. This is due to the increased heat from the bodies of the chicks. It is not advisable to change the regulator at this time, provided the temperature does not run beyond $105^{\circ} \mathrm{F}$. With a good hatch the eggs will usually start to pip on the evening of the 19th day or the morning of the 20th and most of the chicks will be out of the shell on the morning of the 21st day. A high temperature during the incubation period may hatch the eggs too quickly and produce weak chicks, while a temperature that is too low throughout the hatch may delay the hatch somewhat. 
Care of the lamp. Use a good grade of oil. Clean and fill the lamp once daily, trimming the wick by scraping the charred portion off with a knife or by cutting the wick with scissors. The burner should be kept absolutely free from dirt and thoroughly cleaned after each hatch. A new wick is usually a good investment for each hatch, thereby eliminating any danger that the wick may give out during the hatch.

Turn the eggs before cleaning and refilling the lamp, so that there will be no possibility of getting oil on the eggs. The flame of the lamp is apt to increase in size after lighting. It is, therefore, advisable to return shortly after attending to the lamp to see that the flame is at a proper height.

Turning the eggs. The eggs are usually turned for the first time at the end of the second day of incubation and twice daily throughout the hatch up to the 18th or 19th day, or until the chicks commence to pip. After the eggs are turned, reverse the egg trays, end to end, and change the position of the trays from one side of the machine to the other, in a two-tray incubator. While turning the eggs keep the incubator doors closed unless the directions state otherwise. Eggs should be turned by removing a few from the center of the tray and working the others toward that point, placing those that have been taken out of the center to the sides of the tray.

Cooling of eggs. The length of time to cool eggs depends upon the temperature of the incubator room. As a rule it is safe to leave the eggs out of the machine until they feel slightly cool when placed against the face or eyelid.

Cool the eggs once each day after the 7th and up to the 18th day, inclusive. To cool properly, place the tray of eggs on top of the machine or on a table in such a position that they will not be in a draft. It is important that the egg tray should not project over the edge of its support, 
for part of the eggs would then be likely to cool much more quickly than the others.

Moisture and ventilation. Moisture and ventilation are closely related and closely associated factors in incubation, the amount of each depending upon the other. Moisture is one of the uncertain factors in incubation on which there are as yet no very satisfactory rules which will cover all conditions. Odd as it may seem, good hatches are secured both with and without using moisture under apparently the same conditions. An experienced incubator operator

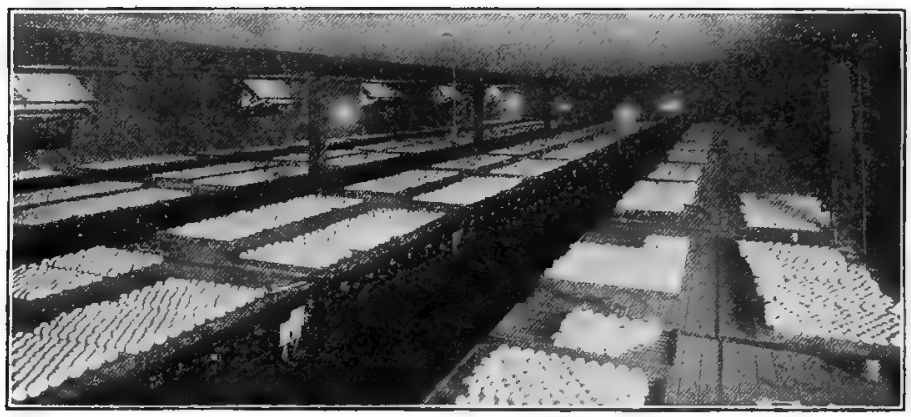

Figure 83.-Cooling eggs from a mammoth incubator.

usually works out, as the result of practice, the best amount of moisture to use under his conditions. When too much moisture is present, it may prevent the normal evaporation that is necessary to allow sufficient space for the chick to turn in the egg and break the shell. On the other hand, too little moisture may cause the chick to become dry and stick to the shell. Moisture is extensively used in hatching in high altitudes and in places where the incubator is run in a dry room. The following are the most common methods for supplying moisture in incubators: Sprinkling the eggs with warm water of about $100^{\circ} \mathrm{F}$., placing a pan of water or receptacle containing moist sand or a wet sponge inside of 
the machine below the egg tray, sprinkling or soaking the floor of the incubator room, or placing a pail of water under the lamp. There is considerably less danger of getting too much moisture in the incubator by the latter methods than by putting moisture directly into the egg chamber. When moisture is added to a non-moisture machine it should be removed before the chicks hatch. When an incubator is run in the room of a dwelling house, it is frequently necessary to add moisture even to a nonmoisture machine. Such machines run in a cellar in the same building might not need additional moisture. The

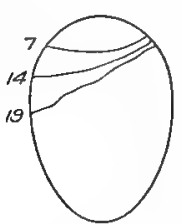

Diagram showing theair cell on the $7^{\text {th. }}$ 19', and 19 doy of incubation.

Figure 84.

presence of moisture on the glass in the door of the incubator during hatching time is the best indication of correct moisture conditions during incubation.

The increased size of the air cell during incubation is caused by the evaporation of the water in the egg. The air cell during incubation varies in size with the size of the egg, while the shape of the air cell varies greatly in different eggs.

Testing the eggs. An egg whether fertile or not has a grayish spot on the surface of the yolk known as the germ spot, or blastoderm. (See Figure 65). When a fertile egg is placed under a hen or in an incubator, the development of this germ begins.

White-shelled eggs can be tested on the 4th or 5th day, while the germ development in brown-shelled eggs often can not be seen plainly until the 7th day. Eggs with dead germs quickly decay and give off a bad odor, if allowed to remain in the incubator or in the nest. Infertile eggs make excellent feed for young chicks and should be used for 
this purpose. Most incubators come equipped with testing chimneys that fit on an incubator lamp. An electric light or a kerosene lamp may be used in a box with a hole slightly smaller than an egg cut in the side of the box and at the same level as the light.

A hole slightly larger than the chimney of the lamp should be cut in the top of the box to allow the heat to escape. (See Figure 86.)

The eggs, when tested, should be held with the large end up so that the size of the air cell may be seen as well as the condition of the embryo.

The testing should take place in a darkened room. The infertile egg when held before the hole of the tester will look perfectly clear, or the same as a fresh egg.

A fertile egg will show a small dark spot, known as the embryo, with a mass of little blood veins radiating in all directions, if the embryo is living.

If the germ of the egg is

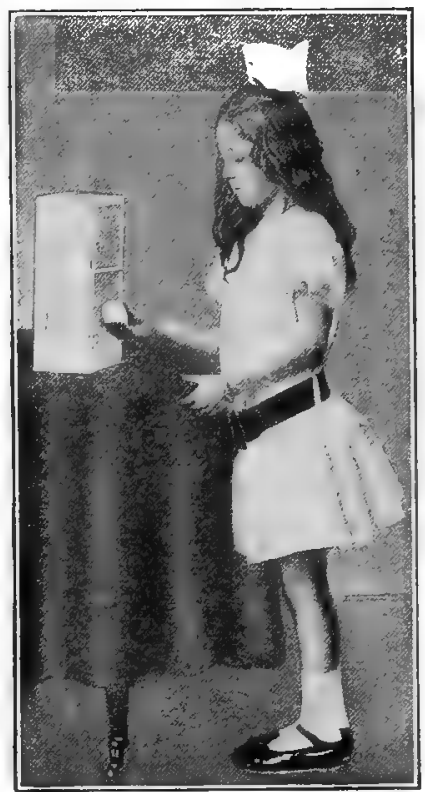

Figure 85.-The eggs should be tested at least twice during the period of incubation, preferably on the 7 th and 14th days, and all infertile eggs and those with dead germs removed. dead and it has been incubated for at least 46 hours, the blood settles away from the embryo toward the edge of the yolk, usually forming an irregular circle of blood, known as a blood ring. All infertile and dead-germ eggs should be removed at the first test.

Eggs containing living embryos are dark and well filled 


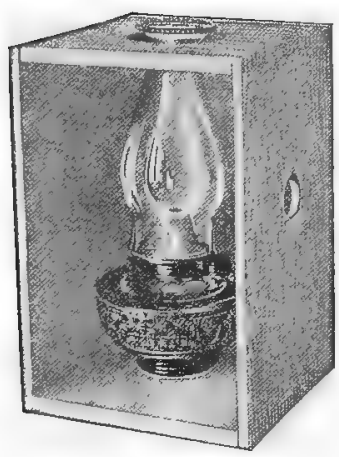

Figure 86.-Homemade egg candler. The hole for testing eggs should be directly opposite the flame of the lamp. up on the 14th day, showing a clear, distinct line between the air cell and the growing embryo.

Eggs with dead germs at the end of 14 days show only partial development and lack a clear distinct line of demarcation between the air cell and the rest of the egg.

Care of the incubator at hatching time. When the eggs begin to hatch do not disturb the machine until the hatch is over. The door should not be opened to see how the eggs are hatching, as the moisture, which is very essential at this time, will thus be allowed to escape. It is usually advisable to darken the incubator at hatching time by covering the glass in the door with a cloth, so that the chickens will not be attracted to the front part of the machine by the light. When the hatching is com-
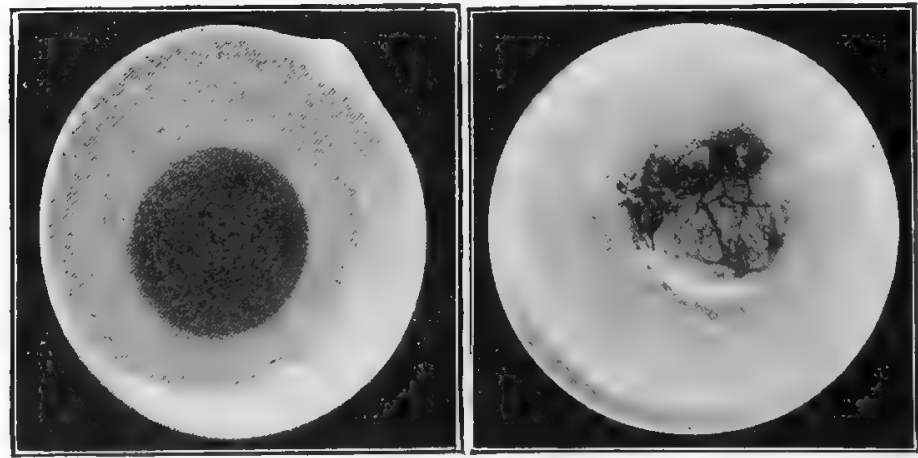

Figure 87.-An infertile egg at the end of 7 days' incubation broken out into a saucer to show the lack of germ development.
Figure 88.-A fertile egg after 7 days of incubation broken out into a saucer to show the blood veins and development. 
pleted, remove the egg tray and open the ventilators according to the directions furnished with the machine and retain the chicks in the incubator from 24 to 36 hours after the hatch is over before removing them to the brooders. Chicks that pip the shell but are unable to get out through their own efforts rarely amount to much if helped out.

\section{Disinfecting and storing}

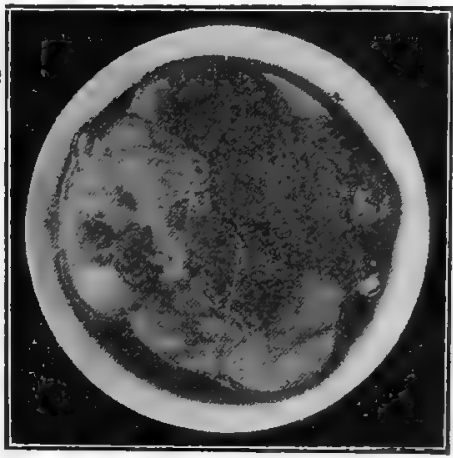

Figure 89.-Fertile egg at the end of 14 days incubation, showing the development of the embryo.

the incubators. When the hatching season is over, clean and disinfect the incubators. Empty and clean the lamps and store these parts in the machine. The incubator may be disinfected once a year or oftener, especially if any disease is present in the flock. Some poultrymen disinfect their machines before and after each hatch, as a preventive measure against disease. A ten per cent solution of a reliable coal-tar disinfectant and water may be used to

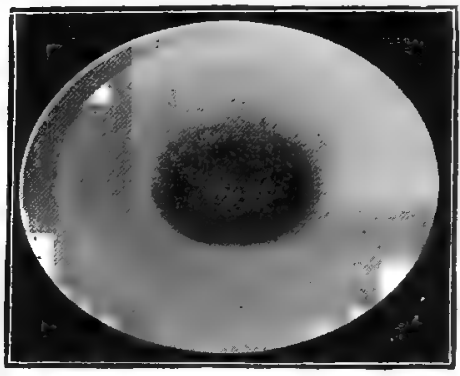

Figure 90.-An infertile egg at the end of 14 days. Such an egg appears somewhat clear before the egg tester wash out the machine and to disinfect the egg trays and nursery drawer. A 5 per cent solution of crude carbolic acid and water will also be found effective for disinfecting the incubator. If the burlap on the bottom of the incubator becomes dirty, it is advisable to renew it rather than to clean it. 


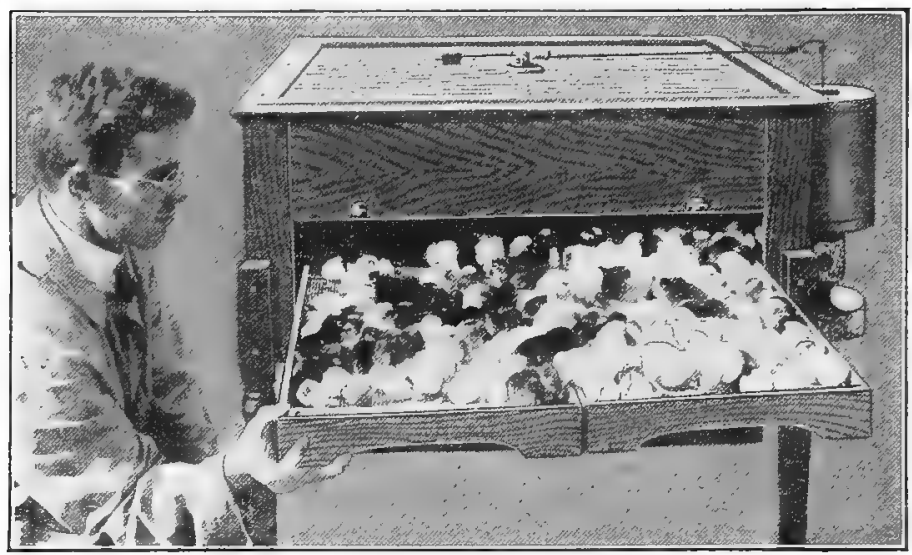

Figure 91.-A good hatch.

\section{QUESTIONS}

1. Name the several parts of the egg.

2. What are some of the essential features in the selection of eggs for hatching?

3. Describe a method for packing hatching eggs for shipment.

4. What is the period of incubation of eggs from the following: Hens? Ducks? Turkeys? Geese? Guineas?

5. Why should chicks be hatched early?

6. What is the best time of the year to hatch chickens in your community?

7. Describe the method of preparing the nest for the sitting hen. dusted?

8. Describe how to set a hen. Why and how should the hen be

9. What are the different types of incubators?

10. What is the object of a thermostat in an incubator? How does it control the temperature?

11. Describe two kinds of incubator thermometers and their correct position in the incubator.

12. Describe the essentials of a good incubator cellar.

13. Describe the method of starting an incubator.

14. At what temperature should an incubator be run throughout the hatch when the thermometer rests directly on the eggs? What is the correct temperature when a hanging thermometer is used throughout the hatch?

15. Describe the method of caring for the lamp of an incubator. When should the lamp be cleaned and filled, before or after handling the eggs?

16. Describe the method of turning and cooling eggs. 
17. Describe two methods of supplying moisture to eggs.

18. When testing eggs on the $7 \mathrm{th}$ and 14 th days, describe the appearance of an infertile egg. A dead-germ egg. A fertile egg.

19. What points should be kept in mind when the eggs begin to hatch in an incubator?

20. What should be done with the incubator when the season's hatching is complete?

\section{SUGGESTIONS}

1. In order to become familiar with selecting eggs for hatching, save all the eggs produced by your flock for several days and examine them carefully. How many would you select for hatching? In what respect are these superior to those not selected?

2 . Prove to your own satisfaction the many advantages of hatching early by carrying on the following simple experiment: Carry on your regular hatching operations as early in the spring as your climate and equipment will permit. About six weeks or two months later, hatch a few more chickens from the same stock as your early hatehed chickens, giving them the same care, feed and attention. On or about the middle of September, compare the early hatched stock with the late hatched for size, development, and health. Leg-band the pullets from both lots and see which begin to lay first. In carrying on this test, it should be remembered that, in order to make a fair comparison, all conditions should be the same with both lots of chickens, excepting the time they are hatched.

3. Do you not think it would be to the advantage of the members of your club or association and to other poultrymen and farmers in your section to know of the advantages of early hatching? If so, why not acquaint them with the facts in the case?

4. A most instructive demonstration can be carried on in connection with a group of poultrymen, farmers, boys and girls interested in poultry by studying and discussing the operation and construction of a hot-air and hot-water incubator. If they cannot be obtained in any other way, two incubators for this purpose may be borrowed from the local poultry supply dealer.

5. Another interesting demonstration can be arranged at the same time by showing the method of candling eggs during incubation. An egg candler should be provided, such as is shown on page 88, Figure 86 , together with eggs that have been incubated for 7 and 14 days. After those present pass judgment as to whether an egg is fertile, infertile, or is a dead-germ egg, break it out into a saucer to determine its true condition.

\section{REFERENCES}

Embryology of the Chick, by F. R. Lillie.

Natural and Artificial Incubation of Hens' Eggs, U. S. Department of Agriculture, Farmers' Bulletin 585, by Harry M. Lamon. 


\section{CHAPTER V.}

\section{NATURAL AND ARTIFICIAL BROODING}

The successful and proper brooding of chickens is rather a difficult operation, especially for the beginner. Comparatively speaking, it is not nearly so difficult to secure good egg yields and fair hatches as it is to successfully brood chicks. Such failure usually results either in raising only a small percentage of those hatched or in failing to raise strong, vigorous birds which develop into good stock. Methods of artificial brooding are being improved each year, but no one system has given perfect satisfaction.

The simplest and easiest way to raise a few chickens is with mother hens. This is the method that is used most extensively on the average farm and small poultry plant. Brooding chicks with artificial brooders is necessary where early chickens are raised, where chicks are raised in large numbers commercially, and where only Leghorns or nonsitting breeds of poultry are kept.

\section{NATURAL BROODING}

Brooding chickens with hens. As mentioned in the preceding chapter, sitting hens should be confined to slightly darkened nests at hatching time, and not disturbed unless they step on or pick the chicks. If for either of these reasons it should be necessary to remove the chicks, they should be put as soon as dry in a basket lined with warm material, and kept warm until all the eggs are hatched. Some hens begin to get restless after a part of the chicks are out, allowing the remaining eggs to become cool at the very time when heat is necessary. In such cases the eggs that are slow in hatching may be placed under other hens. As soon as possible after the eggs are hatched the hens should be fed, as they will then be likely to be contented. At this time, 
however, do not allow the chicks to have any feed. When the hatching is completed, the hen should be kept on the nest and brood the chicks for at least 24 hours before removing them to the brood coops.

Broody hens are sometimes used to raise incubatorhatched chicks and to take the place of the artificial brooder when there is only a small number of chicks to raise. In instances of this kind a few eggs should be put under a broody hen 4 or 5 days before the incubator is to hatch. When the hatch in the incubator is completed and after the chicks are thoroughly dry, one or two should be put under the hen, preferably at night. Should she mother them properly, the following evening add as many as she can take care of. In the spring hens will successfully brood 10 to 15 chicks and from 15 to 20 in warmer weather, depending upon the size of the hen.

When giving chicks to a hen to brood, it is best to add those of the same color and age as the ones already with her, for the reason that she will sometimes pick the strange chicks, if they are of a different color from the ones she is already brooding.

When transferring chicks from one hen to another, do so at night. Dust the hen with a good insect powder before moving her and the chicks to the brood coop, following the method given on page 77. The hen should be dusted every two weeks or oftener, if necessary, until the chicks are weaned. When lice appear on the chicks, or if they are troubled with "head lice," a little grease, such as lard or vaseline, should be applied on the head, neck, under the wings and around the vent, care being taken not to get too much grease on the chicks, as it will stop their growth, and in some cases prove fatal. For additional information on lice and mites see Chapter $\mathrm{X}$.

Care of the brood coop. Clean the brood coop at least 


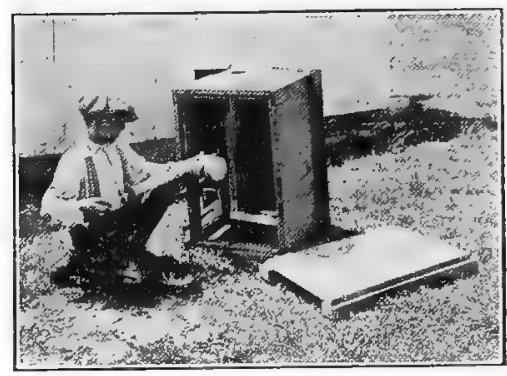

Figure 92, - The brood coop should be thoroughly cleaned and sprayed with kerosene or crude petroleum to preventlice and mites.

once a week, making every effort to keep it free from lice and mites.

From one to two inches of sand or shavings or a thin layer of fine straw or cut hay should be spread on the floor of the coop. The same should be done in brooder houses when artificial methods of brooding are used. Brood coops should be moved to fresh ground weekly, preferably where there is a grass range. Shade is very essential in rearing chickens, most especially during hot weather. A cornfield affords an excellent range for young chicks, as they secure many insects and worms, and have fresh ground to run on, due to the cultivation of the corn, and have abundant shade at the same time. These principles should be

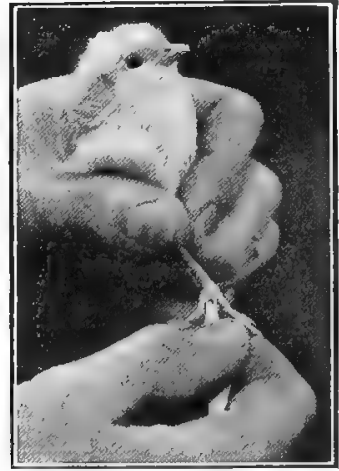

Figure 93.-Punching a hole in the web of a chick's foot with a toe-punching instrument. kept in mind at all times and put into $\mathrm{practice}$ whether the chicks are brooded by natural or artifici a l methods and the brood coop or the brooder located accordingly.

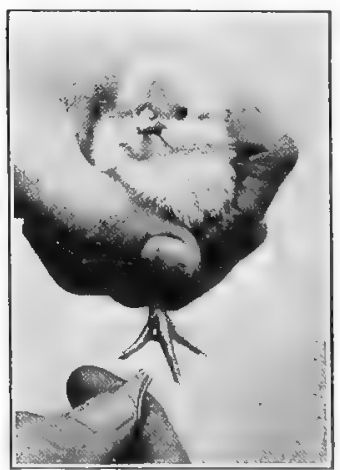

Figure 94.-The hole punched. Instruments for this purpose can be purchased from most poultry supply houses. 
Identifying chickens. All the chicks should be toe punched or marked before they are transferred to the brooder or brood coop. Such identification will enable one to tell their age and breeding after they are mature.

There has recently come into practice a system of permanently identifying chickens, that is known as wing banding. When this method is employed a small numbered band is placed on the leg of the chick soon after it is hatched. When about 4 weeks old, a slit is made with a knife in the web of the wing as shown in Figure 96. The band is then removed from the leg and inserted in this slit and closed, care being taken not to close the band so tight as to pinch the skin. Bands properly placed in the wings of chickens will in most cases remain there throughout the life of the birds. By keeping a record of the numbers of these bands a complete history, including time of hatching and breeding of the birds may be kept.

Brood coops. Brood coops for the hen and chicks should be made so that they can be closed at night to keep out cats, rats, and other animals. Such coops should be

/.
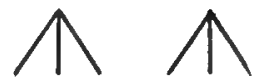

2.
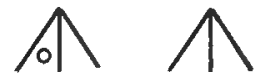

3.
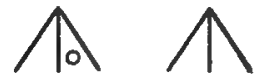

4.
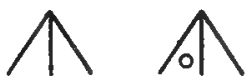

5.
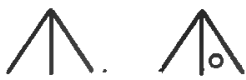

6.
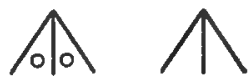

7.
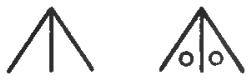

8.
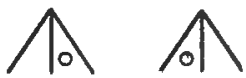

9.
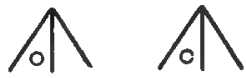

10.
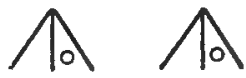

$1 /$.
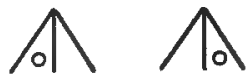

12.
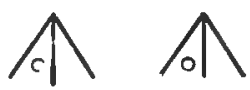

13.
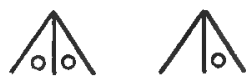

19.
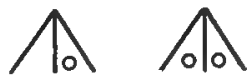

15.
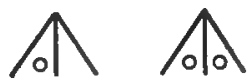

16.
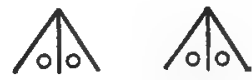

Figure 95.-Different combinations for toe marking. Each pair

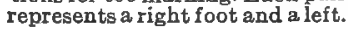




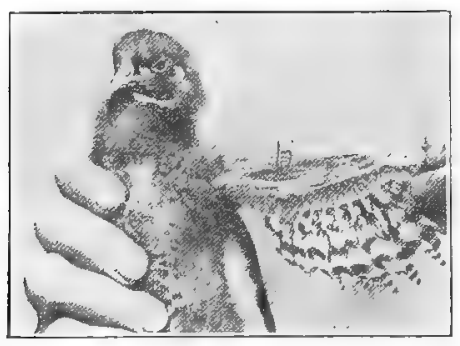

Figure 96.-The band fastened in the

constructed to provide sufficient ventilation and be rain-proof, so that the hen and chicks and the floor of the coop will be kept dry in inclement weather. The coop should also be constructed to enable it to be easily cleaned and sprayed. The style of construction of the coop matters but little so long as it is practical, comfortable and embodying the above features. The coop which is illustrated in the following figures has given good results.

The coop should not be nailed to the floor, but is left entirely free, so that it can be lifted completely off to facilitate cleaning. The sides of the coop sit over the edge of the floor in order that it can be kept tight and dry. The door of the coop is covered with a half inch wire netting and slides in back of the 3 slats in front in order to close the coop. To open the coop so that the chicks can come out, the door is pushed back of the boarded part in front. The holes covered with wire at both ends of the coopgive additional ventilation. These ventilators may be eliminated

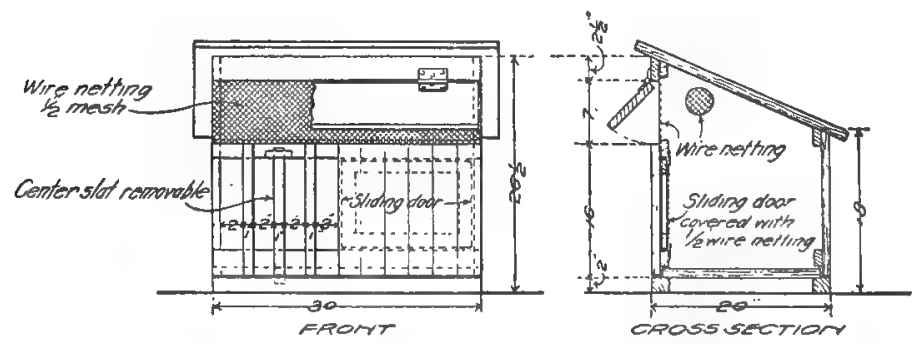

Figure 97.-The working plan of a box-shaped brood coop that can be easily constructed. 
in sections of the country that have extremely cool weather in the early spring.

The center slat in the front is removable, sliding into a small wire staple at the top and dropping into a square hole at the bottom. The slats are made of strips one inch square. The long narrow door at the top in the front of the coop is kept open for ventilation except in cool weather or on cool nights. This opening as well as the ventilators mentioned above should be covered with a $1 / 2$ in. mesh wire netting.

Confine the mother hen. The mother hen should be confined to the brood coop until the chicks are weaned, the

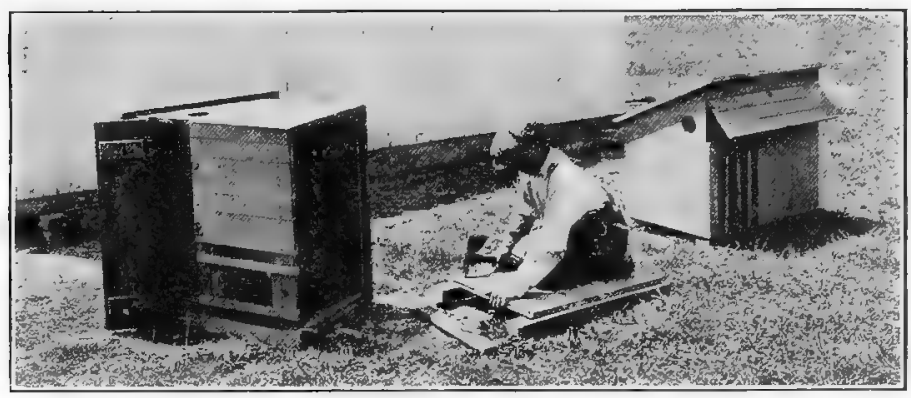

Figure 98.-New lumber need not necessarily be used in the construction of such coops for they can easily be made from dry-goods boxes or other available material.

chicks being allowed free range after they are a few days old. Hens that are allowed unlimited range and have to forage for feed for themselves and chicks often take them through wet grass where the chicks may get chilled and die or become lost.

Then, too, most of the feed the chicks secure when the mother hen is not confined goes to keep up heat of the body and to produce energy. The feed consumed by those that are with the hen that is confined to the coop produces 


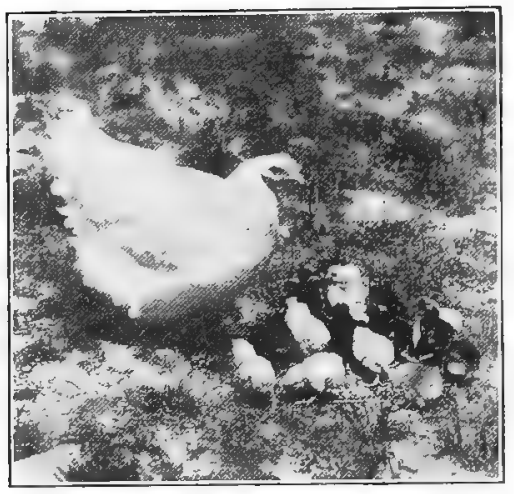

Figure 99.-Do not allow the mother hen to range with the chicks. Even when the mother hen is confined, the chickens frequently have to be caught and put into their coops during sudden storms, as they are apt to huddle in some place out of the way where they are liable to become chilled or drowned. Hens are usually left with the young chicks as long as they will brood them, which time is usually about 10 or 12 weeks.

\section{ARTIFICIAL BROODING}

Artificial brooding of chicks consists in supplying artificially the heat that is furnished by the hen under natural conditions. As mentioned in the previous chapter, the temperature of the hen is about $106^{\circ} \mathrm{F}$.,

more rapid growth, as the chicks do not have so much forced exercise.

In most broods there are sometimes one or two chicks that are not as strong as the others, so that, when the hen is confined, the weaker chicks can always find shelter and warmth under her and in a few days may develop into strong healthy chicks.

$$
\text { re usually left with the young }
$$

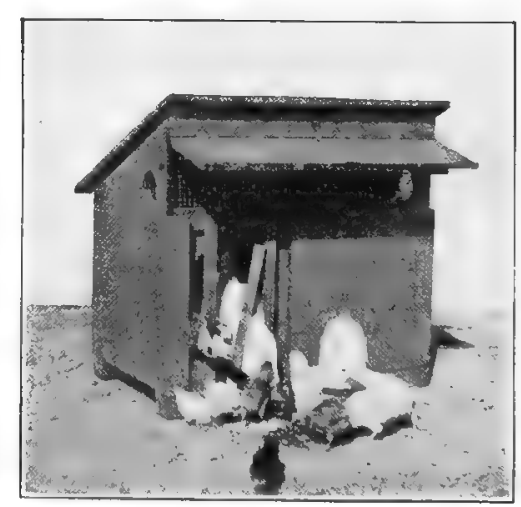

Figure 100.-Confine the mother hen to the brood coop until the chicks are weaned. 
but, as hens seldom sit closely on the chicks they do not receive this degree of heat. Hens naturally adapt their methods of brooding to conditions, such as outside temperature, size of the chicks, and conditions of the weather. In the successful operation of an artificial brooder these conditions must be met as closely as possible to secure the best results. The brooder should be so constructed as to supply the proper temperature, be readily adapted to meet changes in weather conditions, easy to clean, and well ventilated. Before the chicks are moved from the incubator to the brooder, it should have been in operation for a day or two at the proper temperature before receiving the chicks. After placing them in the brooder, they can be given feed and water as described in the next chapter. It is well to mention at this time that great care should be taken when moving chicks from the incubator to

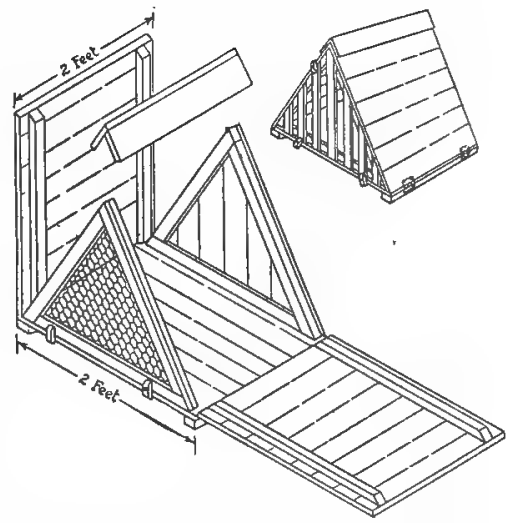

Figure 101.-An easily constructed A-shaped brood coop that can be folded up and stored when not in use. the brooder, as they may become chilled. They should be moved in a cloth-lined and covered basket or box.

Hovers, brooders, and brooding systems. There is perhaps a wider difference of opinion as to the value of various brooding systems than any other part of poultry equipment. We may thus infer that no system is ideal for all conditions, but that satisfactory results depend to a great extent upon individual handling and care. As previously mentioned, many failures in brooding are due to weak chicks which can 
usually be traced to faulty incubation or lack of health and vigor in the breeding stock. Brooding systems are classified according to their capacity as follows: Individual brooders or hovers holding from 25 to 100 chickens; coal and oil stove brooders with a capacity varying from 200 to 1,500 chicks and hot water pipe systems, the capacity of which is unlimited.

When possible, the beginner should thoroughly investigate brooding equipment such as is used by successful poultrymen or farmers in his community and which has been in operation for some time. Thus one can decide which system or kind of brooder is best for individual use.

Individual hovers and brooders. Small individual hov-

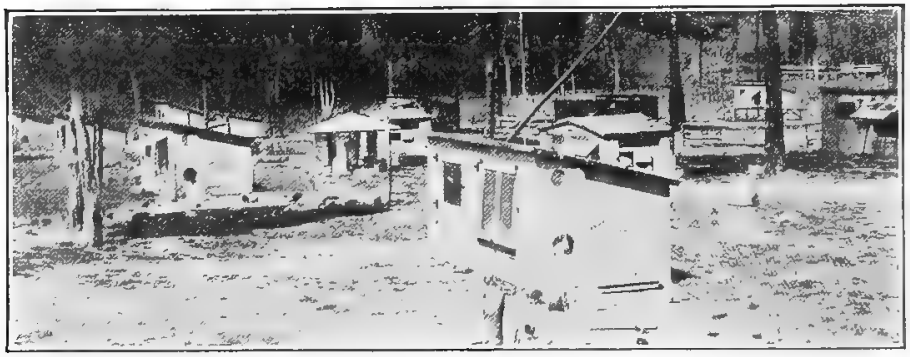

Figure 102,-Artificial brooding of chickens, showing the arrangement of kerosene heated outdoor brooders. Chickens which have access to a shaded range such as is here shown develop and thrive better in warm weather than those not having shade.

ers and brooders are heated by hot air or hot water with kerosene oil, and sometimes gasoline is used as the source of heat. Usually these small individual brooders are divided into two compartments of equal size. The hover is located in one compartment, which is artificially heated. In the other compartment, which is known as the cool, or exercising, room the chicks become accustomed to a cooler temperature before going out of doors. These two compartments are separated by a solid wooden partition, with the 
exception of a small door through which the chicks pass from one room to the other.

The small brooder of 50-chick capacity is gradually being replaced by larger brooder stoves of from 250 to 500 chick capacity.

Hovers are used either in continuous brooder houses or small colony houses. Outdoor brooders are used with satisfactory results under most weather conditions. Often the capacity of brooders and hovers is overestimated and experience has shown that from half to two thirds of the chicks estimated for the brooder or hover will usually do much better. Until one has had considerable experience, it is best not to brood over 250 chicks in one flock. When a lamp is used as the source of heat for

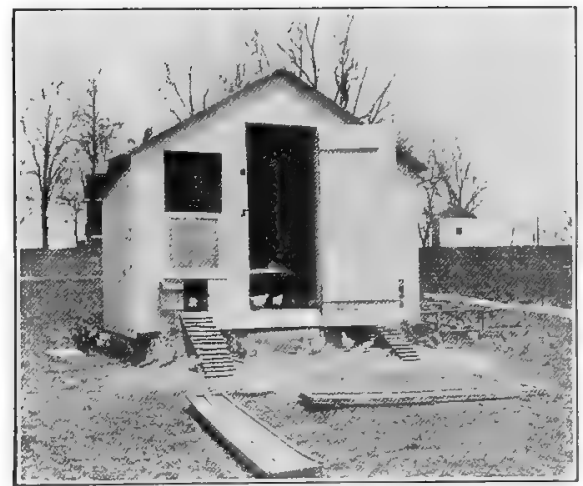

Figure 103.-A coal-heated colony stove brooder house, $12 \times 14$ feet with a capacity of 500 chicks. the brooder, care should be taken to keep the wick and burner perfectly clean or else trouble will result. A new wick for the brooder lamp after each second lot of chicks are brooded is a good investment. Brooder lamps and stoves should be inspected several times a day to see if they are in working order. The brooder lamp should not be filled too full of oil, as the heat of the lamp when lighted will expand the oil in the bowl and may cause it to overflow and catch fire.

Brooder stoves. Brooder stoves and separate individual hovers heated by coal, distillate oil and kerosene are coming 
into general use. Such brooder stoves have a capacity varying from 200 to 1,500 chicks.

These individual brooders are used in colony houses and frequently, when the chicks are weaned, the houses are used as growing quarters. Such a plan requires a smaller investment than the long hot-water-heated brooder house and likewise allows one to rear the chicks on range to good advantage. Brooder stoves of both oil and coal type are usually operated in houses that are from $12 \times 14$ feet to $14 \times 20$

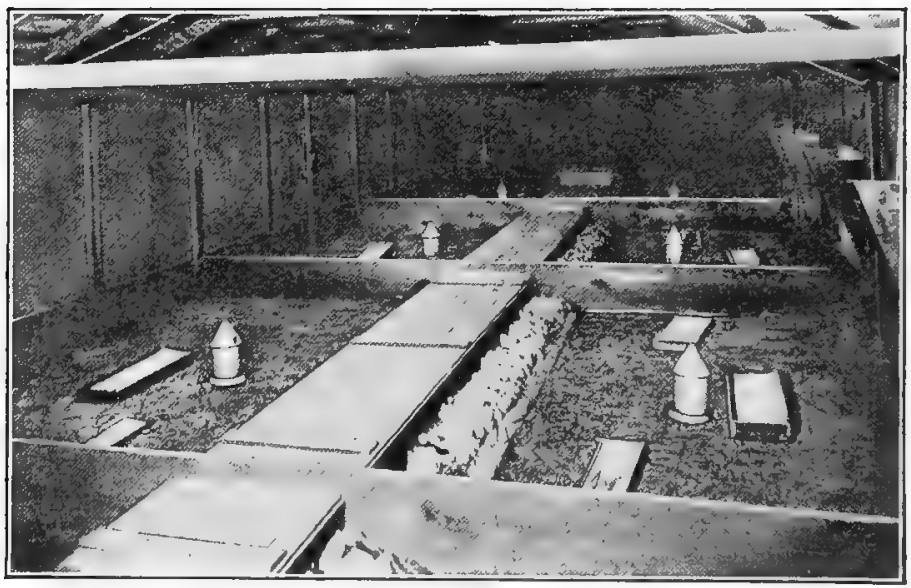

Figure 104.-A continuous hot-water-heated brooder house. Hot-water brooders are suitable for large poultry farms where most of the chickens are raised during the winter and early spring in large numbers.

feet and are also occasionally used in long continuous brooder houses, similar to the one shown in Figure 104.

It is advisable to have the colony brooder house wherein oil or coal-burning brooder stoves are used of an oblong shape rather than square. That is, the floor dimensions should be $12 \times 14$ feet rather than $12 \times 12$ feet. With a house so built it is possible by placing the stove back a 
little from the center of the floor to provide additional space in the front part of the house, where the temperature will be cooler.

Most of the oil brooders are equipped with a regulator that controls automatically the flow of oil that is fed from the tank. Such a system requires a minimum of care and at the same time supplies sufficient heat to keep the chicks from crowding. Coal-heated brooders are operated by self-feeding coal stoves.

Hot-water-pipe brooders. This system is used in long

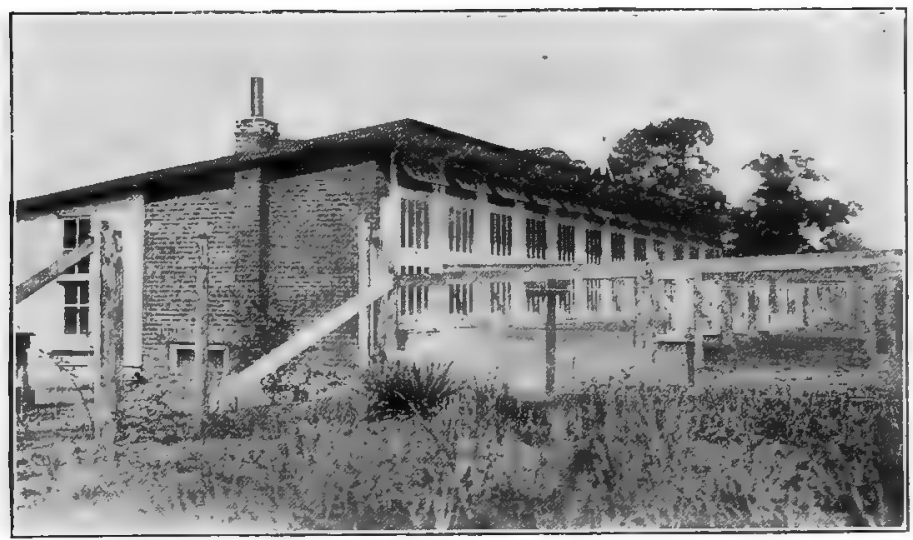

Figure 105,-Exterior view oi a continuous hot-water-heated brooder house.

continuous brooder houses which are heated with hot-water pipes, coal being used for fuel almost exclusively. This method of brooding is being used with good results, and, when employed, the labor of brooding a large number of chicks is less than where small individual hovers or brooders are operated.

Fireless brooders. Fireless brooders are used in a small way with good results and can be either purchased or built. 
Such brooders can usually be built at less cost than to buy them, as their construction is very simple. In this system of brooding the body heat of the chickens is the source of warmth. These brooders are equipped with adjustable covers composed of strips of cloth or feathers, which act on much the same principle as the feathers of the hen.

The position of the cover should be regulated according to the weather and the number of chicks in the brooder.

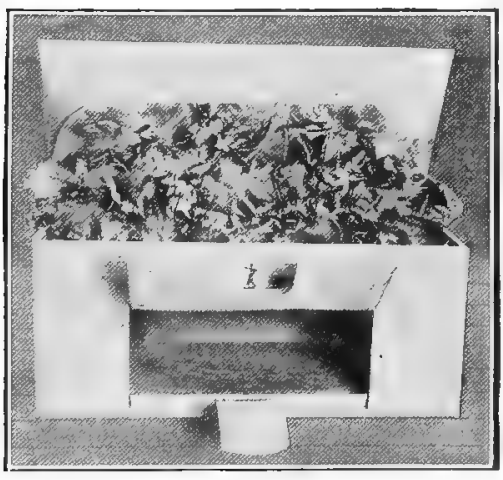

Figure 106.-An easily constructed fireless brooder.

In cold weather the cover should sag so as to be near the backs of the newly hatched chicks, while in warmer weather or with older chicks the cover is raised or removed depending on conditions. Usually from 12 to 40 chicks are placed in a fireless brooder, 25 being the average number. The use of fireless brooders is recommended only in a mild climate. In cold weather they should be operated in a heated room or building. Care must be given to keep the brooder clean by frequently changing the litter. Likewise the chicks must be watched carefully to see that they are comfortable and do not sweat. When first placed in the brooders the chicks may have to be put under the hover several times until they learn where to get warm.

Correct temperature for brooding. The correct temperature for the brooder or hover depends upon several conditions such as the position of the thermometer, style of the hover, age of the chicks, and the weather. In all 
cases aim to keep the chicks comfortable. When too cold, it will be noticed that they will crowd together and try to get near the center of the hover. When it is found in the morning that the droppings are well scattered under the hover, it is an indication that the chicks have had sufficient heat. When the chicks are comfortable, they will distribute themselves evenly at night. Too much heat will cause them to sweat and frequently results in their death.

It is impractical to state for each style of brooder at what temperature it should be kept to raise young chicks. In most cases it should be run at from $90^{\circ}$ to $100^{\circ} \mathrm{F}$., when the chicks are first put in and at an average of from $93^{\circ}$ to $95^{\circ} \mathrm{F}$., for the first ten days, the temperature being gradually reduced to about $85^{\circ} \mathrm{F}$., for the following 10 days and then lowered to $70^{\circ}$ to $75^{\circ} \mathrm{F}$., for as long as artificial heat is needed. In warmer weather and as the chicks grow larger the lamps may be used only at night and later only on cold nights. Care should be taken to prevent the chicks from becoming chilled or overheated, as either chilling or overheating. weakens them and may cause considerable trouble. From $1 / 2$ an inch to 2 inches of sand and cut clover or chaff litter should be spread over the entire floor of the brooder.

Management. Hovers and brooders must be cleaned frequently, as cleanliness is very essential, if chicks are to be raised successfully. When first put into the brooder, they should be confined under or around the hover by placing a cloth or wire frame 10 to 24 inches from the outside of the hover proper. This practice does not apply to the small indoor colony brooders. This guard should be moved gradually further away from the hover and removed entirely when the chicks are 3 or 4 days old, or after they have learned to return to the hover. When weather conditions are favorable, the chicks should be allowed to run on the ground, 
as they will do much better than when kept continuously indoors. Weak and crippled chicks should be killed as soon as noticed, because they rarely if ever develop into desirable stock. Brooders and brooder houses should be disinfected at least once a year and more frequently should disease occur in the flock.

Care of purchased day-old chicks. Whenever day-old chicks are purchased, provide a brooder of sufficient capacity for the number bought and have it in working order and regulated when the chicks arrive. Should the brooder not be ready, take the chicks from the shipping box into a warm room, feed and return them to the box, and repeat at intervals of about 5 hours until the brooder is ready. It sometimes happens that delay in the delivery of a brooder places one at a disadvantage as to what to do with the chicks. In such cases a fireless brooder may be constructed temporarily, such as is described on page 104. After the chicks have been placed in their brooder and made comfortable, they should be managed as described in the foregoing pages.

\section{QUESTIONS}

1. Discuss the advantages of natural as compared with artificial brooding.

2. Discuss the care of a sitting hen at the time of hatching.

3. Describe the method of treating lice on chickens.

4. Discuss the points to be kept in mind as concerning the care and location of the brood coop.

5. Describe the method of wing banding chicks.

6. What are the essential features to be kept in mind in the construction of a practical, comfortable brood coop?

7. Why should the mother hen be confined until the chicks are weaned?

8. What principles are necessary for the successful brooding of chicks by artificial methods?

9. Describe three systems of brooding chicks artificially.

10. Describe the construction of a fireless brooder.

11. At what temperature should a brooder be operated during the first twenty days?

12. When day-old chicks are purchased, what steps should be taken before they arrive? 


\section{SUGGESTIONS}

1. In an effort to learn all that you possibly can about artificial brooding investigate the various systems of brooding chicks in your community and determine, if possible, in each case the reasons for success and causes of failure in brooding.

2. After looking into the matter, which in your opinion is the most popular form of brooding chicks in your community, that is, by natural methods or artificial?

3. Should you have a flock of fowls, endeavor to put into practice a system of wing banding as described on page 95 , keeping a record of these numbers, including time of hatching and any other information that will be of value to you in the future.

4. Insofar as you can, make a working drawing of a good practical brood coop for hen and chicks, embodying such features as are outlined in this chapter. After your plan is completed, construct one coop or several such coops from your plan out of dry goods boxes or other available lumber.

5. If you are not entirely convinced as to the importance of confining the mother hen until the chicks are weaned, carry on a little experiment to prove this to your own satisfaction. Such a test should be made with two broods of chicks, both of which are hatched about the same time. With one brood of chicks confine the mother hen throughout the weaning period, being sure that the hen and chicks are provided with sufficient feed and water. The hen with the second brood of chicks should not be confined except during the night and should be allowed to run with the chicks at will. At the end of 8 weeks, weigh the chicks in both lots and compare them for size, weight, and development. Which lot has the greatest number of chicks living at the end of this period? Do you not think it would be advisable to impress upon your poultry friends and other poultrymen and farmers in your community the importance of confining the mother hen until the chicks are weaned?

6. Do you not think it would be interesting to construct a small fireless brooder such as is shown in Figure 106? Such a brooder might come in handy in case a mother hen should die or in any other emergency

\section{REFERENCES}

Natural and Artificial Brooding of Chickens, U. S. Department of Agriculture, Farmers' Bulletin 624, by Harry M. Lamon. 


\section{CHAPTER VI}

\section{FEEDING AND CARE OF CHICKS AND GROW- ING STOCK}

In addition to having the chicks hatched early, it is most important to keep the chicks growing, so that they will reach maturity and start laying before cold weather. Con-

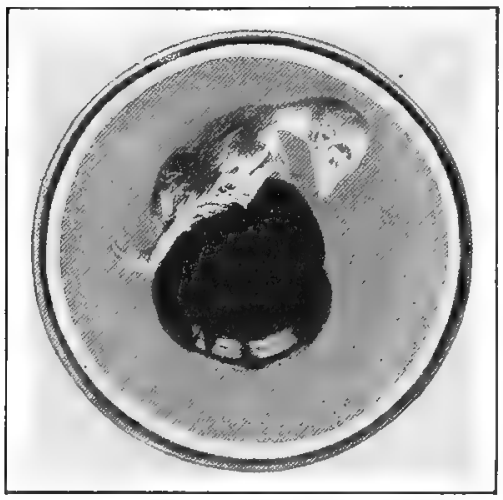

Figure 107-The yolk of the egg just before it is absorbed by the chick. sidering this fact, it is well, therefore, to keep in mind the factors that are essential for the proper growth and development of the young stock.

\section{FEEDING AND CARE OF YOUNG CHICKS}

The first feed. It is advised that the chicks should not be fed until they are 36 to 48 hours old. The yolk of the egg which is absorbed just before the chick is hatched furnishes all the nourishment required during this time.

It is very necessary that the yolk of the egg be thoroughly digested before the first feed is given. Many beginners, not understanding this fact, and who are anxious to feed the young chicks, give them feed before they are ready for it. Such practice frequently results in bowel trouble and very often in the death of the chick. It is this provision of nature for the first food of the chick that makes it possible to ship newly hatched chicks considerable clistances without feed or water. At the start it is advisable to feed five 
times a day, dividing the day into equal periods, and alternating a mash or soft feed with a grain or scratch feed.

A most practical method of feeding young chicks is that of keeping before them a pan or dish of sour milk for them to drink together with a pan or box of bran. This should be given them as their first feed and kept before them at all times in addition to the method of feeding suggested below. For the first feed in the morning and the feed at noon scatter in the litter or in a shallow trough as much johnnycake broken into small bits as the chickens will eat up in a short time. For the last feed in the evening they should be given as much as they want. It should be kept in mind, however, that more harm can be done by overfeeding young chicks than by underfeeding. Johnnnycake may be made as follows:

\section{Corn meal}

Eggs (infertile)

Baking soda

Mix with milk to a stiff batter and bake well.

5 pounds

6 pounds

2 tablespoonfuls

Note:- When infertile eggs are not available, use a double quantity of baking soda and add one half pound of sifted beef scrap.

The following may be used in the place of johnnycake where there is a considerable number of chicks to be fed and where the infertile eggs are available: 3 parts of dry bread crumbs and 1 part of hard-boiled infertile eggs mixed thoroughly together. Rolled oats may be used in the place of bread crumbs. The scratch feed to be fed after the first morning and noon feeds should consist of the following:

Finely cracked corn

Finely cracked wheat

Pinhead oat meal, hulled or rolled oats
5 pounds

3 pounds

2 pounds.

This mixture, when available, makes an ideal ration. In the absence of corn, cracked Kaffir corn, rolled or hulled barley may be substituted. As a substitute for this grain ration, a reliable brand of commercial chick grain may be fed. After the chicks are 10 days old, discontinue feeding 
the johnnycake or its substitute and feed a growing mash of which the following is a good example:

2 parts by weight of corn meal

2 parts by weight of middlings

1 part by weight of oat meal

2 parts by weight of wheat bran

$1 / 2$ part by weight of sifted beef scrap.

When the chicks are 8 to 10 weeks old, add 1 part of ground oats and increase the meat scrap to 1 part. This mash, when fed dry, should be placed in a hopper and left before the chicks continuously. When it is fed wet, add only enough milk or water so as to make the feed crumbly, but in no sense too moist or sloppy.

Whether or not it is desirable to purchase prepared chick grains or mashes, depends upon the cost of such feeds when purchased as compared with the cost and labor of mixing such feeds at home. Many successful poultry raisers find it economical and practical to feed ready-mixed commercial chick feeds, while still others prefer to purchase the feed ingredients and mix such feeds themselves. When purchasing commercial chick feeds, buy those that contain grains of good quality but only a small quantity of grit. Those raising chicks in a limited way will find it more economical to feed commercial chick feeds. As soon as the chicks will eat whole wheat, cracked corn, and other grains, the small chick grain can be eliminated. (See page 112.)

Green feed. Any tender green stuff may be fed with good results to young chicks. When a regular supply is desired, it is usually most convenient to use sprouted oats. (See page 204.) The necessity for green feed is of especial importance where the chicks are confined to small yards. The most desirable place to raise chicks successfully is on a good range where no extra green feed is required.

Other feeds. In addition to the above feeds, the chicks' growth can be hastened and they can be kept in good con- 
dition when given sour milk to drink. Oyster shell, small grit, and finely ground charcoal should be kept before them constantly.

Water. Little chicks should be supplied constantly with fresh water in either shallow pans or small drinking fountains. Such vessels should be frequently cleaned.

\section{FEEDING OF GROWING STOCK}

Proper feeding and care of growing stock during the spring and summer is of great importance. The chicks

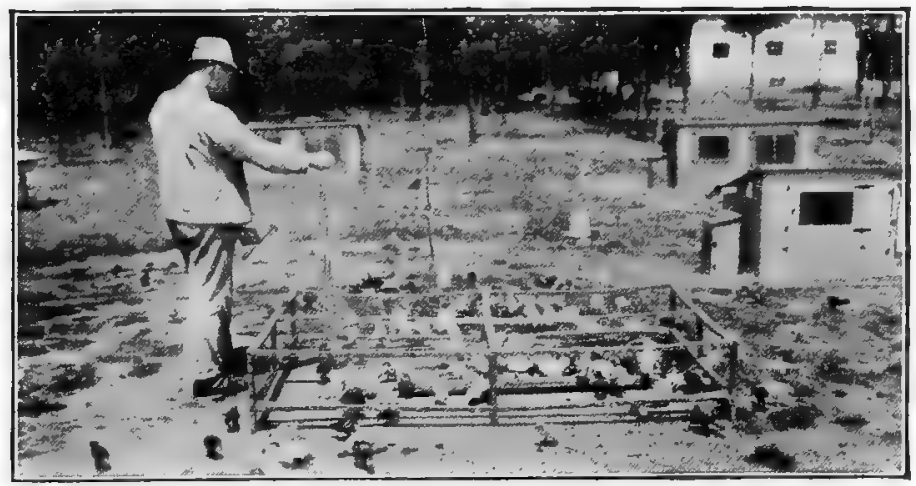

Figure 108.-Frame covered with wire netting to protect feed of young chicks from the older fowls. It will be noted that there is an open space five inches high around the lower edge of the frame to permit the chicks to walk under to get their feed.

may be hatched from strong, vigorous stock and carefully brooded; but, unless they receive the proper attention during the warm months, their growth will be retarded. In other words, the principal idea is to so feed and care for them that they will be kept steadily growing and mature into healthy well developed fowls.

The six essentials for proper growth are (1) proper houses; (2) feed and water; (3) free range; (4) shade; (5) cleanliness -freedom from lice and mites; (6) good management. 


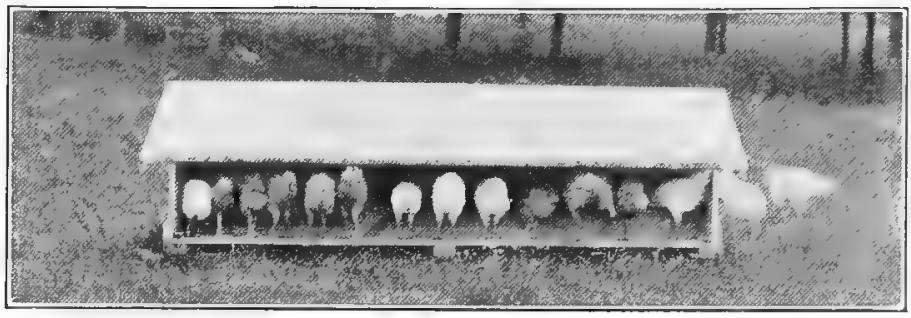

Figure 109.-Dry-mash hopper for the growing stock.

The food requirements for the growing chicks may be divided as follows: grain feed, dry mash, sour milk, green feed, and water.

Grain feed. In addition to such feed as chicks on free range are likely to find, the following mixture should either be scattered on the ground near their house or during rainy weather inside their house in the morning and evening. A satisfactory ration is as follows:

6 parts by weight of cracked corn

2 parts by weight of wheat

2 parts by weight of hulled oats

When available Kaffir corn or rolled or hulled barley may be substituted for hulled oats. In localities where hulled oats, Kaffir corn or rolled barley can not be obtained

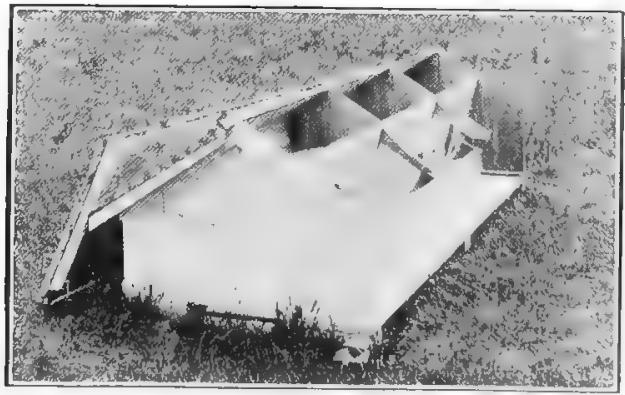
Figure 110 - Showing construation of the
dry-mash hopper. 
or is too high in price, a mixture of cracked corn and wheat may be fed until the chicks are old enough to eat whole oats at which time an equal part of whole oats may be added to the corn and wheat mixture.

Dry mash. In addition to the above feed, a dry mash should be fed in a hopper to which the chicks will always have access. Because growing stock is on range more than inside of the house, it is usually advisable to have the hoppers located out of doors. During continued rainy weather, however, when the birds are indoors, a supply should be available in the house.

The same dry mash as given on page 110 may be continued as their dry-mash feed during the growing period. As in the case of the young chicks, the growing stock as well should have access to the charcoal, grit, and oyster shell.

Sour milk. If a continuous

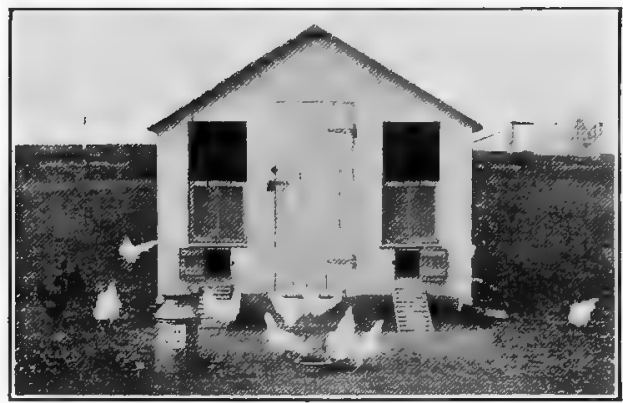

Figure 111.-In addition to promoting growth, the feeding of sour milk tends to keep the chickens in good condition.

supply of buttermilk or sour skim milk can be readily obtained, it may be fed separately in a pan provided for the purpose and the beef scrap in the dry mash reduced one half. When whole milk is available, it should be allowed to become sour before feeding.

Green feed. Whenever possible, the growing chicks should be allowed free range, so that they may obtain as much natural green feed as they need. Green feed is an excellent tonic for chicks and, when it can not be obtained 


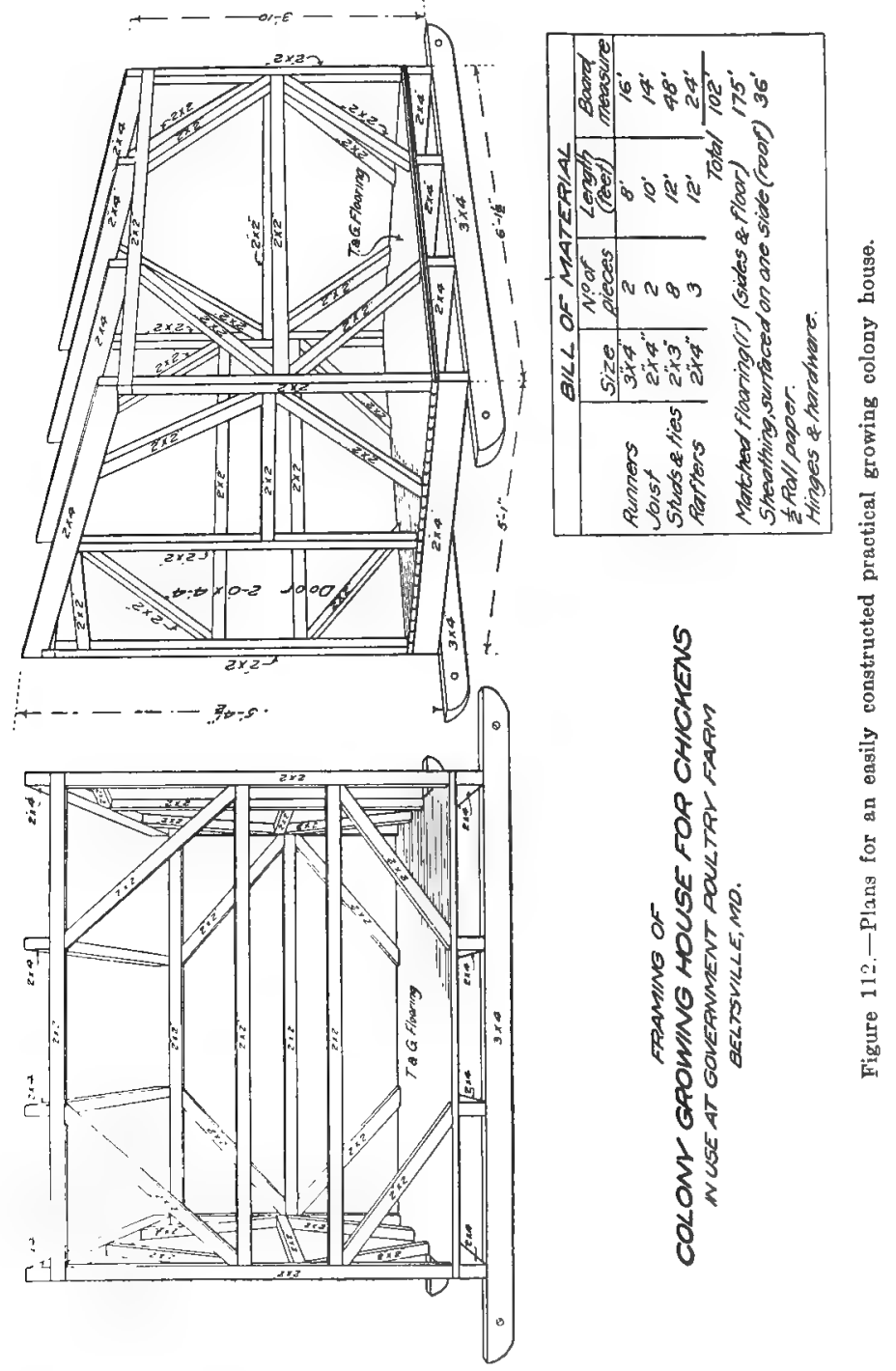


on range, such feed as sprouted oats, cut clover, alfalfa, mangel beets or cabbage should be fed daily.

Water. The importance of clean fresh water can not be overestimated. In very hot weather, fresh water should be furnished twice daily. Whenever possible the pan of water should be placed in the shade to keep cool. The water pan should be cleaned each day before fresh water is added.

\section{CARE OF GROWING STOCK}

Housing. Growing chicks should be provided with a house that will give them a place to stay in bad weather and

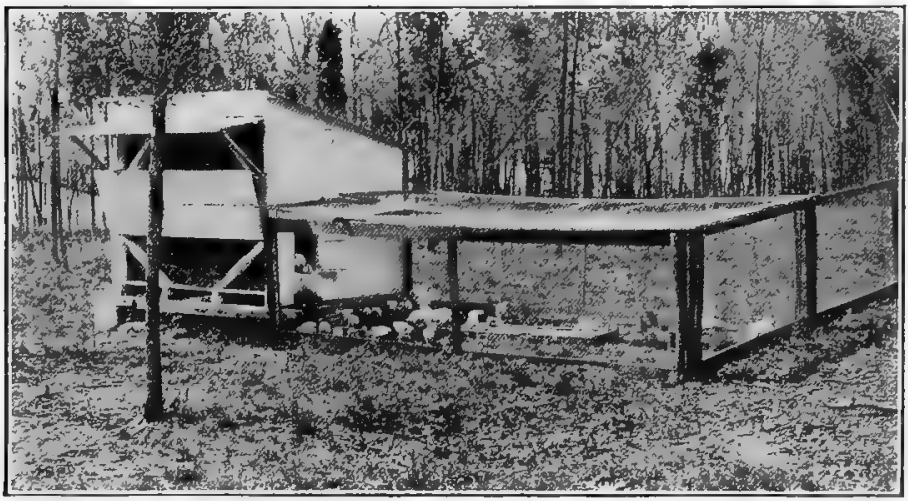

Figure 113.-Growing colony house built from the aboye plang. The wire runway is removed after 5 or 6 days when the chicks learn where to return when given free range.

at nights. No definite style of house is recommended, but one should be built that will provide the chicks with ample ventilation without draughts, dryness, plenty of sunshine, and so arranged that it can be easily and frequently cleaned. The lumber from piano and dry-goods boxes can often be used in building such a house, and, when covered with ordinary roofing paper so as to keep out the rain, will make desirable quarters. It is recommended that such houses be 
built on the colony plan so they can be moved from place to place, thus providing fresh ground for the chicks to range over. A type of growing house such as has been used successfully will be found in Figure 115.

In placing the chicks in their growing house for the first time it is best to confine them for several days, erecting a temporary yard so that they will know where to return after allowed free range. Care should be taken not to crowd the chicks by placing too many in any one house. As the chicks increase in size they should be thinned out and placed in other houses, so as to avoid crowding. Colony brooders can be used for the growing stock after there is no longer

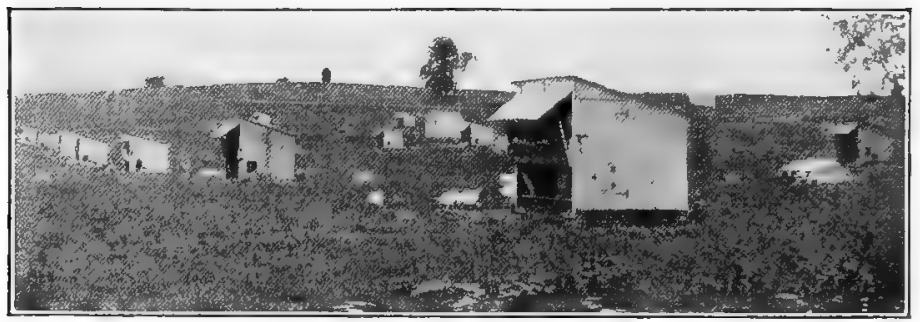

Figure 114.- Chicks on free range obtain considerable food such as worms, bugs, ete., that helps considerably to reduce the cost of feeding.

need for artificial heat. In such cases, however, it is usually advisable to provide additional growing quarters to prevent crowding.

Free range. Plenty of free range should be provided, if the chicks are to make rapid, vigorous growth. Confining the chicks to a limited range not only increases the tendency to disease and slowness of growth, but tends to increase the cost of feeding.

Shade. Plenty of shade should be provided for growing chicks in order that they may thrive and grow in hot weather.

Chicks allowed to range in an orchard will not only find 
ample shade and green feed, but will benefit the trees as well as themselves by destroying insects and worms. When an orchard or woodlot can not be used for this purpose, the growing of corn or sunflowers will help to provide the necessary shade. Artificial protection against the sun's rays may be obtained by supporting frames covered with burlap a few feet above the ground.

Cleanliness. Every effort should be made to keep the

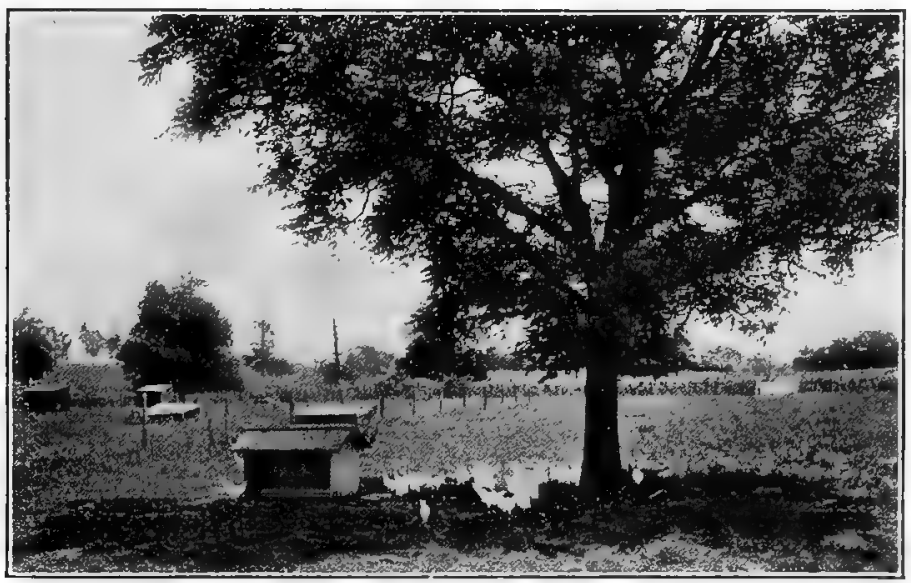

Figure 115.--Shade provided by growing plants or trees is much cuoler than that afforded by buildings or other artificial means.

coops or house clean and sanitary. Disease most frequently starts in unclean quarters. The house should be cleaned at least once a week and twice a week, if the weather has been such that the birds have been confined to the house during the greater part of the time. Clean sand and straw litter should be scattered over the floor of the houses so as to assist in keeping them clean. When the chicks are confined to a limited range, the ground should be spaded up or plowed at frequent intervals, so as to provide fresh ground in which 
they may scratch. Chicks should be examined frequently to see if they are infested with lice or mites. When these are found, every effort should be made to exterminate them by following the methods suggested in Chapter X.

General management. As soon as the chicks develop sufficiently so that the cockerels want to mate with the pullets, they should be separated from the pullets in order to assist the proper growth of both pullets and cockerels.

As soon as the cockerels are of sufficient size, those not intended to be kept for breeders the following year should be marketed (See Chapter XVI) or caponized. When chicks become 2 or 3 months old, it is often advisable to teach them to roost; for, when they are allowed to remain on the floor, it is difficult to keep them clean and to keep them from crowding. Such roosts should be from 3 to 4 inches wide, as this width tends to eliminate the danger of forming crooked breastbones, which are the result of chicks' roosting on narrow roosts. The chicks can usually be induced to roost by placing the perches near the floor. If it is found that only a few of them take to roosting, the others can be made to roost, if placed on the roosts after dark for a few nights in succession. In the late summer and early fall the pullets that mature and begin to lay should be removed from the growing houses to their permanent winter quarters. When possible, this change should be made before they begin to lay, so as not to disturb them. When the stock has been wing-banded, it is well to note at this time the numbers of those pullets that started laying first. Other things being equal, these pullets may make desirable breeders the following spring.

\section{QUESTIONS}

1. Why is it so necessary that the chicks should not be fed until they are 36 or 48 hours old?

2. Discuss the method of feeding chicks up until they are 10 days old. 
3. Describe a good growing mash for the chicks after they are 10 days old.

4. What are the points to be kept in mind when commercial chick feeds are purchased? stock?

5. What are the six essentials for the proper growth of growing

6. Describe a good grain ration for the growing stock. ens?

7. Of what value are free range and shade for the growing chick-

8. What practice should be followed in order to insure cleanliness and freedom from disease of the growing stock? pullets?

9. At what time should the cockerels be separated from the

10. What should be done when the pullets start laying?

\section{SUGGESTIONS}

1. A demonstration that will be of value to any group of people or community interested in poultry is that of actually mixing desirable feeds for chicks and growing stock. In order to arrange for such a demonstration before a poultry club or an association, a talk should be given by some one that is acquainted with the subject of feeding the young stock, calling attention to the facts as stated in this chapter. Such a talk can be supplemented with the actual mixing together of the various feeds as outlined herein.

2. Should there be a poultry farm located in the community, a visit should be made with the idea of determining the methods employed in the management of the growing stock. Observations should be made to see how elosely such management conforms with the six essentials for proper growth. In making such an observation particular attention should be "given to the kind of houses used for the young stock, how they are fed and watered, the kind of feed that is used, what provisions are made for free range and shade, and the methods of management employed.

3. In order to become entirely familiar with this phase of poultry keeping, a visit should likewise be made to a general farm where several hundred fowls are kept. Observation and a comparison should be made of the methods employed on this farm as contrasted with the methods used on the poultry farm and those given in this chapter.

\section{REFERENCES}

"Natural and Artificial Brooding of Chickens" by Harry M. Lamon, U. S. Department of Agriculture, Farmers' Bulletin No. 624. 


\section{CHAPTER VII \\ PRESERVED EGGS}

During the spring and early summer, when eggs are abundant and reasonable in price, attention should be given to preserving them for winter use. It frequently happens that farmers and poultrymen as well as those having small flocks dispose of all their eggs in the spring when they are plentiful and cheap in price without preserving a supply for fall and winter use. When such practice is followed, it becomes necessary during the season of low production to use for home consumption fresh eggs which at that time bring a much higher price on the market than eggs produced in the spring. When a supply of preserved eggs is available for use in the fall and winter, these can be used at home and practically all the fresh eggs sold. Fresh eggs properly preserved may be kept from eight to ten months in excellent condition and used with good results.

\section{TIME AND KIND}

Time to preserve. Eggs produced during the hot weather ordinarily do not possess the keeping qualities of those produced in the spring, unless they are handled under the most favorable conditions. Again eggs are more plentiful in April and May than they are in July and August. It has been found that eggs laid in April, May and early June keep better than those laid later in the season. It is recommended, therefore, that only eggs produced at this season be preserved.

Kind to preserve. Careful attention should be given to the condition of eggs preserved, as one or two dirty-shelled eggs or bad eggs may spoil the entire lot. It is also important to see that no cracked eggs are preserved. If satisfac- 
tory results are to be obtained, the eggs should be fresh and clean. It is highly desirable also to preserve only infertile eggs, that is, eggs produced by a flock wherein there is no male bird. When possible, it will be advisable to purchase eggs for preservation direct from a farmer or poultryman who can insure their freshness and also the fact that they are infertile. Eggs purchased from the stores or on the market may not be so desirable for this purpose, owing to the frequency with which they are handled, the range conditions under which they are kept, and their condition. Germ development or blood rings will not be found in infertile eggs and consequently they possess better keeping qualities. See page

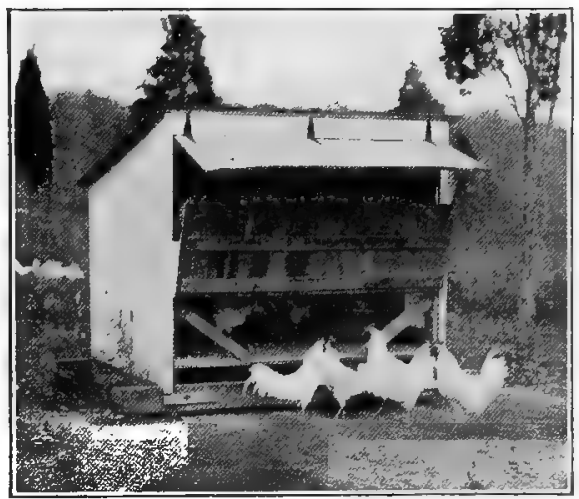

Figure 116.-Cockerels that have been separated from the pullets.

280 in regard to infertile eggs. Eggs that float when placed in the solution are not fresh and, therefore, can not be preserved. When the shell of the egg is only slightly soiled, a cloth dampened with vinegar may be used to remove such stains.

When soiled eggs are put into the jar they are apt to spoil and washing removes a protective coating which helps to prevent spoiling. When eggs are purchased, or, if there is any doubt as to their freshness, they should be candled as described on page 86 , in order to determine their true condition before preserving them. 


\section{METHODS}

Water glass method. One of the most satisfactory methods for preserving eggs is by the use of sodium silicate, or, as it is commonly called, water glass. The present price of sodium silicate is from twenty-five to thirty cents a quart and at this price eggs may be preserved at a cost of approximately three cents a dozen. On account of the low cost of preserving eggs it is not desirable to use water glass solution a second time, as its keeping quality deteriorates with age.

Use one quart of sodium silicate to nine quarts of water boiled and cooled. Place in a five-gallon crock or jar. This

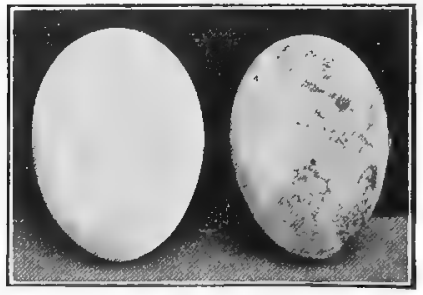

Figure 117.-A desirable and undesirable egg for preservation. A soiled egg as shown on the right should not be preserved. will be sufficient to preserve fifteen dozen eggs and will be a guide as to the quantity needed for a larger amount of eggs.

First, select a five-gallon crock or galvanized can and clean it thoroughly, scald it, and allow it to dry.

Second, heat about 10 to 12 quarts of water to the boiling point and allow it to cool.

Third, when cool, measure out 9 quarts of water, place it in the crock, and add 1 quart of sodium silicate, or water glass, stirring the mixture thoroughly.

Fourth, the eggs can now be placed in the solution, being very careful to allow at least 2 inches of the solution to cover the top layer of the eggs.

Fifth, place the crock containing the preserved eggs in a cool dry place well covered to prevent evaporation. Two or three shects of waxed paper covered over and tied around the top of the crock will answer this purpose. Should only a few dozen eggs be available at any one time for preserving, additional eggs can be added at later periods until the crock 
is nearly full, being sure at all times, however, to have at least 2 inches of the solution covering the top layer of eggs. When it is found that the solution is evaporating, additional solution should be added.

Limewater method. Whenever water glass can not be obtained, the following method may be used in its stead. Many regard this method entirely satisfactory, although instances are known where eggs so preserved have tasted slightly of lime, a probable result of the fact that the eggs

\section{PRESEAVING EGGS WATEP-GLASS METHOD}

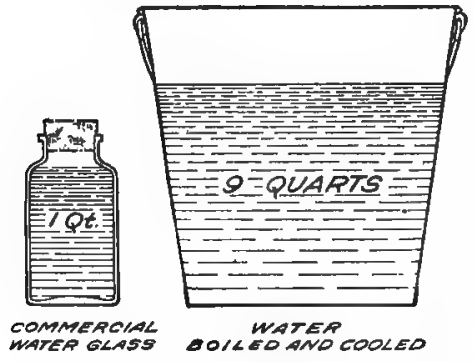

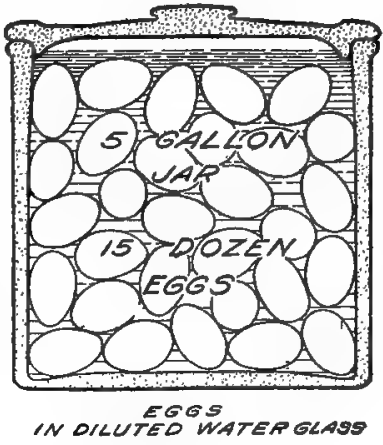

Figure 118.

have thin shells. Slake 2 pounds of unslaked lime with a little water and add 5 gallons of water that has previously been boiled and allowed to cool. The mixture should be allowed to stand until the lime settles and the liquid is clear. Place clean fresh eggs in a clean earthenware jar and dip out the clear lime water, pouring it into the vessel until the eggs are covered. This quantity of solution will be sufficient to preserve from 25 to 30 dozens of eggs. At least 2 inches of the solution should cover the top layer of eggs. Some prefer to add a pound of salt with the lime water mixture, but for good results it is not necessary to do so. 


\section{DISPOSITION}

Using preserved eggs. Fresh clean eggs properly preserved by either of these methods can be used satisfactorily for all purposes in cooking and for the table. Eggs preserved in the summer should be used first, as their keeping qualities are not so good as those preserved in the spring.

Before boiling

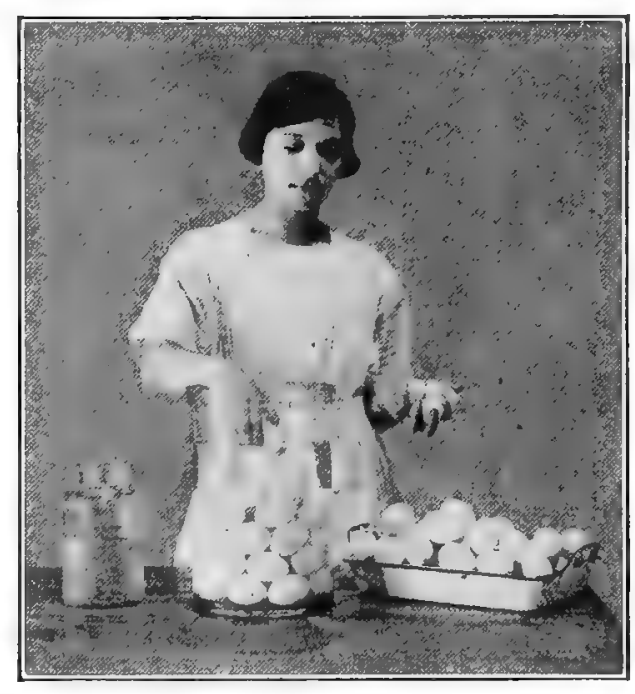

Figure 119.-The glass jar shown in this cut illustrated more clearly the eggs in solution. preserved eggs, a small hole should be made in the large end of the egg with a pin, to allow the air in the egg to escape, when heated, so as to prevent cracking the shell. (See Figure 120.) In preserved eggs the yolk or white does not possess the firmness that characterizes the fresh eggs. This condition is brought about by the fact that the tissues of the egg are weakened by age. This condition, however, does not detract in any way from the food value of the egg. At times difficulty is experienced in attempting to poach preserved eggs, especially those which have been preserved for over six months, because the yolk has a tendency to mix with the white. This tendency is not found to such a great extent when perfectly fresh clean eggs are properly preserved. 
Selling preserved eggs. Ordinarily the methods of preserving eggs as described herein are intended primarily for home use and should not be construed as a method that can take the place of keeping eggs in cold storage. Should it so happen that it is desired to sell preserved eggs, it should be thoroughly understood by the party purchasing them that they are

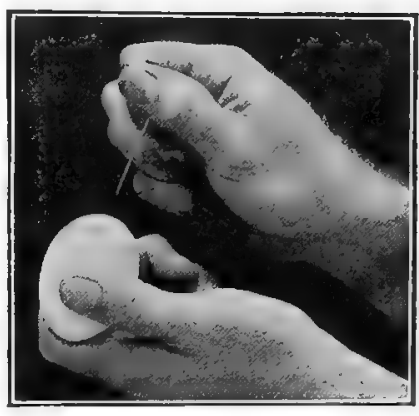

Figure 120.-Punching a hole in the egg with a pin before boiling. preserved, no attempt being made to represent them as fresh eggs. In several states it is against the law to misrepresent a preserved product as a fresh article.

\section{QUESTIONS}

1. What is the economic importance of preserving eggs for home use?

2. At what time of the year should eggs be preserved? Why?

3. Describe in detail the kind of eggs to preserve. removed?

4. When eggs are only slightly soiled how can such stains be

5. Why is it so important that only fresh, clean, and infertile eggs be preserved?

6. Deseribe in detail the method of preserving eggs by the water glass method. of lime.

7. Describe in detail the method of preserving eggs by the use

8. When boiling preserved eggs why is it essential to punch a hole in the large end of the egg? fresh egg?

9. How do the yolk and white of a preserved egg differ from a

10. What measures should be adopted when selling preserved eggs?

\section{SUGGESTIONS}

1. The preserving of eggs for home use is of great economic value and its practice is spreading rapidly. There are still many, however, who are not acquainted with the value and simplicity of the methods described herein. It is suggested that those interested in poultry and poultry products should endeavor to interest others and especially housewives as to these methods of preserving eggs. 
2. There is hardly a demonstration that can be more effectively carried out or that creates more interest than that of preserving eggs by the water glass method. In carrying on the demonstration the method should be explained as discussed herein and the actual operation take place, following the five steps as outlined. An interesting additional feature for such a demonstration is that of showing how an old egg in which considerable evaporation has taken place can not be preserved. In order to prove this point, fill a quart fruit jar about three fourths full of the water glass solution. Place in this solution an egg that has quite a large air cell. It will be noted that the egg will settle to the bottom of the jar and then slowly rise to the top and float on the surface. This action can be easily observed and is most effective in showing that an old egg can not be preserved.

3 . Should you or your club desire to encourage the home preservation of eggs, you no doubt can obtain considerable co-operation from the local druggists or grocers, who, having sodium silicate for sale, will gladly arrange for a window display showing the method of preserving eggs.

\section{REFERENCES}

“Preserving Eggs," U. S. Department of Agriculture Farmers' Bulletin No. 1109 by J. W. Kinghorne. 


\section{CHAPTER VIII}

\section{POULTRY HOUSES AND APPLIANCES}

Supplying poultry with a suitable environment is one of the essential features of poultry management. There was a time when the trees of the orchard and the wagon shed afforded practically the only means of shelter for the farm flock. But that period is passing, for those who keep poultry appreciate that, in order to secure desirable results, the fowls must be comfortably housed.

From the extreme just cited we find, on the other hand, poultry houses that have been constructed along most elaborate lines and the expense of building has been so great in many cases that it was impossible for the fowls to produce such returns as would pay a reasonable interest on the money invested. It can be seen, therefore, that there is a happy medium and that

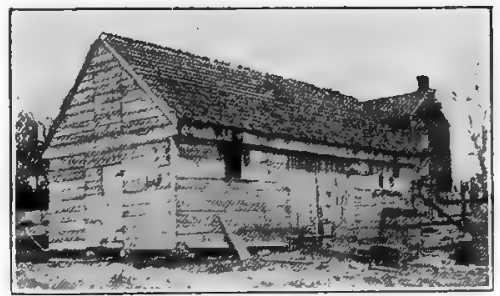

Figure 121. - An inadequate farm poultry house. This building does not provide the essentials of a suitable house for fowls.

a house in order to be comfortable and practical need not be expensive or elaborate. The essential features of a suitable poultry house are:

(1) Economy in construction. (2) Convenience from the standpoint of both the fowls and the attendant. An abundance of sunlight. (4) Freedom from moisture. (5) Ventilation without drafts. (6) Sufficient space for the fowls. (7) Protection from excessive heat and cold. Proof against rats and mice. (9) Sanitation. 
HOUSING

Kind of house to build. As with other phases of poultry keeping, the question is often asked "What is the best style of house?" In a general way the answer may be given that the most satisfactory style or plan of a house should enbody the above mentioned essentials, taking into consideration the part of the country where the house will be located. With a few modifications a house embodying these essentials will give satisfactory results in Maine as well as in

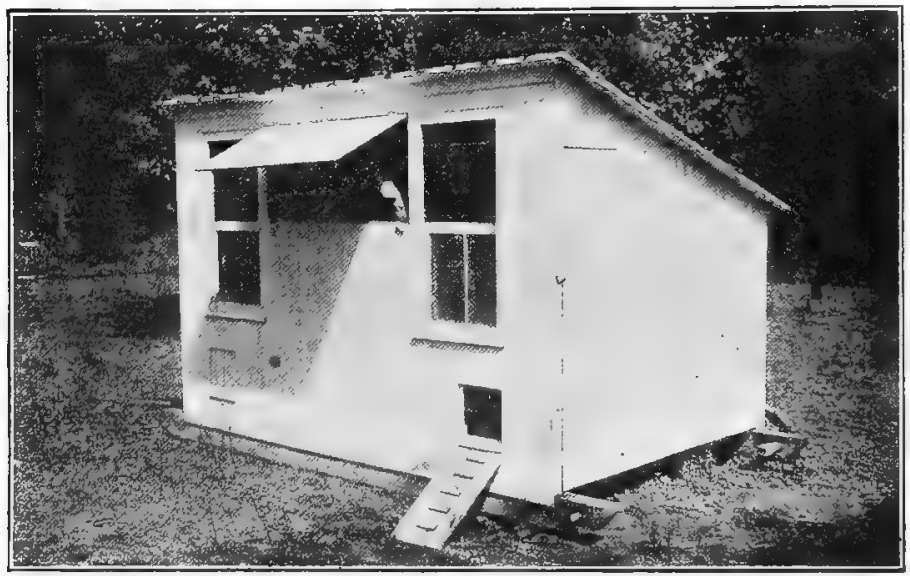

Figure 122.-A practical easily constructed colony house that will accommodate a flock of 25 fowls.

California. The house in the South or the Southwest, however, may be built more open, that is, with a more open front and at a less expense than one suitable for a colder climate.

Colony house and continuous house. The housing of fowls consists of two systems, each differing considerably from the other. The first system is called the colony plan, or extensive system. 
The houses used in this plan consist of small buildings, usually built so that they can be moved from place to place on the farm, and so placed as to eliminate the necessity of fences, thereby giving the flock free range. The advantages of the colony system are: (1) The fowls so housed are usually on free range. (2) The fact that the fowls are on range enables them to pick up considerable feed during the summer months. (3) The expense of fences is eliminated.

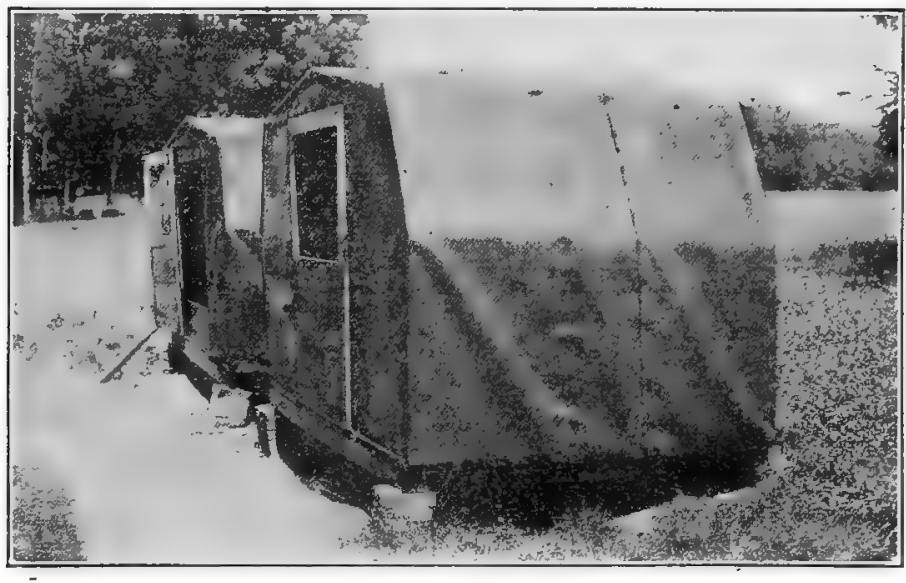

Figure 123.-Colony house built out of piano boxes and covered with roofing paper. Such houses are practical, easy to construct, and cost but little to build.

(4) The danger of spreading disease throughout the flock is reduced to a minimum, owing to the fact that the flock is divided into small units.

The disadvantages of the colony plan are as follows: (1) The extra labor in caring for the fowls in stormy weather and the difficulty in feeding and caring for the fowls at such a time. Colony houses can, however, be drawn together at some central point on the farm for the winter, thereby cutting down the amount of labor in caring for the fowls. 
(2) The cost of construction of such houses is greater than the continuous house plan in that each colony house must necessarily be a complete house in itself, and (3) More ground is necessary than when the continuous house system is used, as the houses would have to be scattered if the various flocks are kept separate.

The second plan, known as the continuous house system, is, as its name implies, a long continuous house under one roof which may or may not be separated into pens.

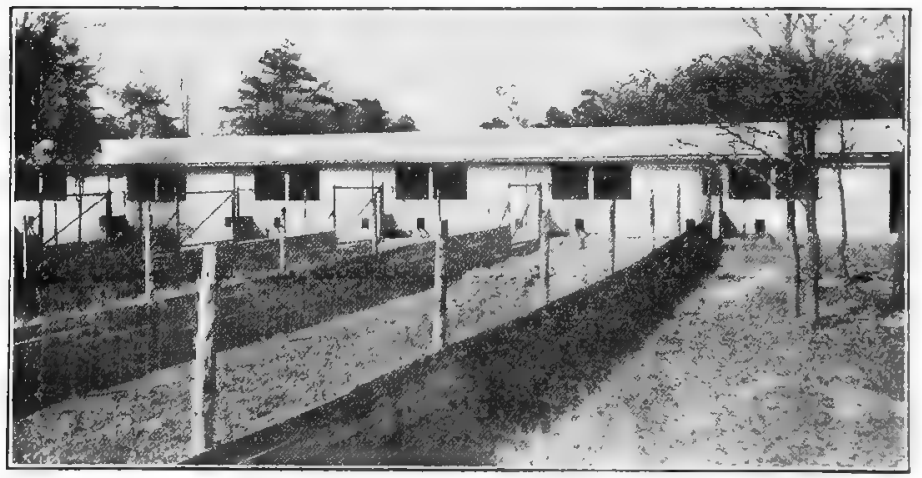

Figure 124.-A good example of a long continuous poultry house. When such a house is used for the layers separate yards are not necessary.

While continuous houses usually consist of but one story, two-story houses are occasionally found. In this style of construction the upper story is either a duplicate of the lower one in its interior arrangement or the upper floor is used principally for roosting quarters and the lower floor as a scratching shed.

The advantages of the continuous house system are: (1) The cost of construction of such a house is less per bird capacity than the colony plan. (2) The cost of labor in attending to and feeding the fowls is less than with the first system. (3) The convenience in caring for the fowls 
in one house is greater. (4) A greater number of birds can be housed on a smaller area of land in this system, when fences are used to keep them confined, than with the colony house system.

The disadvantages of this system are: (1) The added cost for fences, if the fowls are to be confined within a given area. (2) The added cost of feed due to the fact that the fowls, if yarded, have to be supplied with practically all the feed required. (3) The danger of spreading disease throughout the entire flock is greater than when the flock is divided

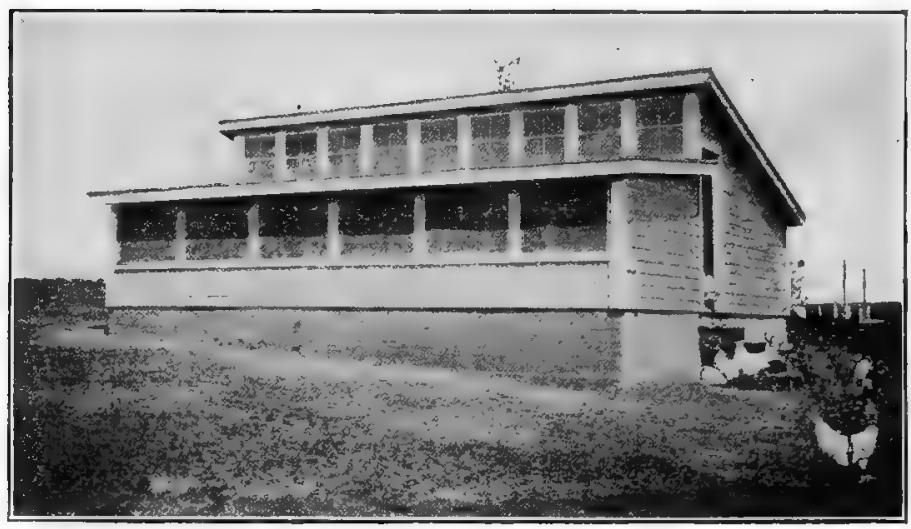

Figure 125. - A semi-monitor continuous poultry house suitable for a small farm flock, in sections where the winters are severe. It will be noticed that this house has a concrete foundation.

into smaller units. (4) The possibility of the yards' becoming polluted through continued usage.

For the general farm the colony house system is usually recommended in that the houses may be moved about from place to place, thereby giving the fowls free range and other natural advantages.

The continuous house system is usually found on commercial poultry farms or on general farms with large flocks. 


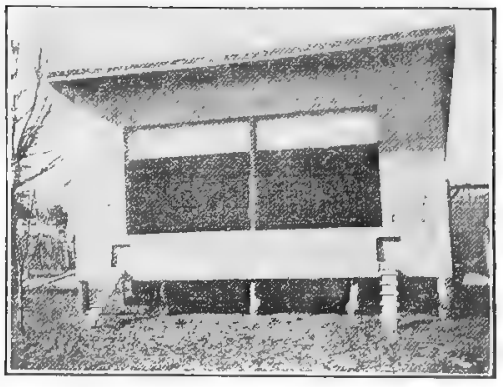

Figure 126.-A small open front house suitable for a small flock in the suburbs or on the farm. This house has a wooden floor and is built on posts. In rainy weather the opening beneath the house provides additional seratching space for the hens.

LOCATION AND CONSTRUCTION OF HOUSE

Location. The ideal location for a poultry house is on a gradual slope facing the south or southeast, so that there will be a natural drainage away from the building. As a matter of fact, however, fowls can be raised successfully on any well-drained soil. A dry porous soil such as a sand or gravelly loam is preferable to a clay soil, as the former drains more rapidly and can be kept in a more sanitary condition.

Time to build. The most desirable time to build the poultry house is during the spring or early summer. When the house is constructed of new lumber, sufficient time will elapse before cool weather to allow

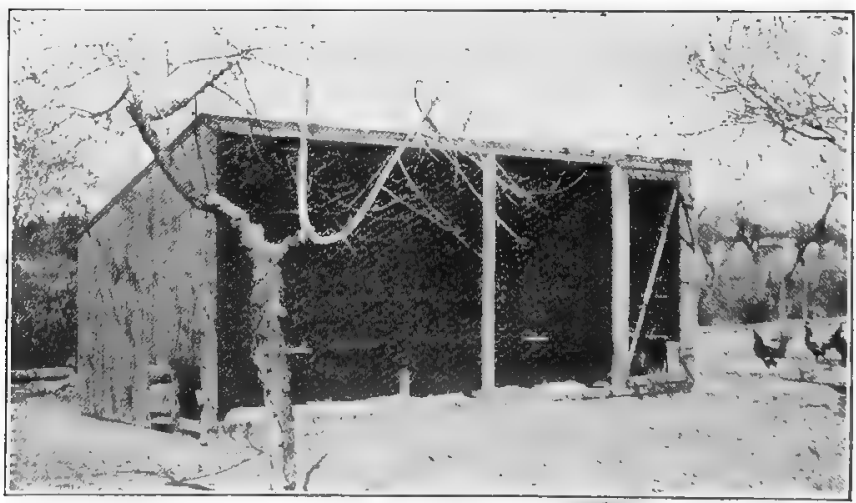

Figure 127.-A complete open front house suitable for the South where the winters are mild. 


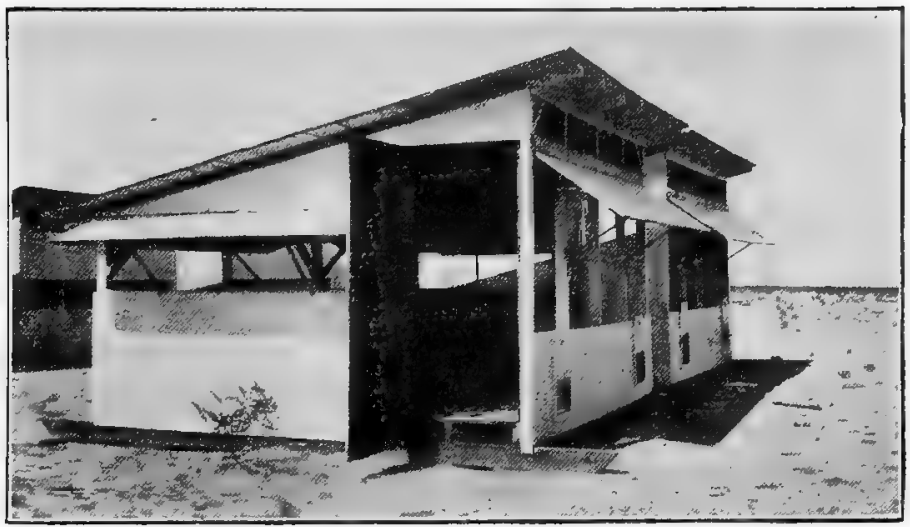

Figure 128.- Type of house suitable for a hot climate. Note the openings in the front, sides, and back to provide ample ventilation.

the house to thoroughly dry out. This fact should be kept in mind when the floor and foundation of the house are constructed of concrete.

Building materials. The most satisfactory, practical, and economical material to use in the construction of the house proper, exclusive of the foundation and floor, is lum-

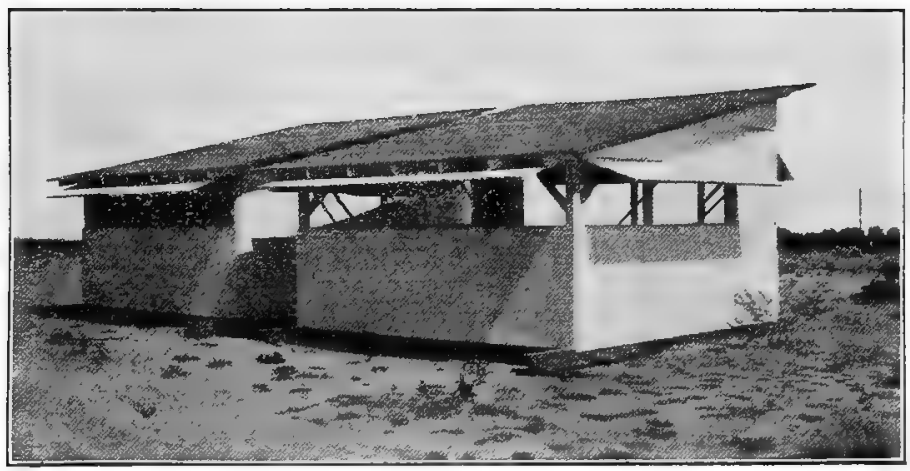

Figure 129.-Rear view of houses shown in Figure 128. 
ber. Hollow tile, brick, cement, and even stone, are occasionally used in building poultry houses, but in most instances such material not only proves to be too costly but likewise is not as satisfactory ás lumber. The most common fault found in houses built of hollow tile, brick, and cement is that they retain the dampness, which is detrimental to the health of fowls. In the extreme northern sections of the country, where the thermometer registers as low as $40^{\circ}$ below zero during the winter months, houses properly constructed of lumber have given mostsatisfactory results. (See page 142.) Even in such parts of the country where, owing to the scarcity of timber, other building materials can be purchased as cheaply as lumber, it is advisable to use lumber.

Size and dimensions of the house. The size of the poultry house will depend on the number of fowls to be kept. The amount of floor space per bird is dependent somewhat on the system of housing used. When colony houses are used in a mild climate and hens have free range throughout most of the year, 2 to 3 square feet per bird should be allowed. With such a system and in sections where the birds are confined to the house during most of the winter months at least 4 to 5 square feet per bird should be provided. From 3 to 5 square feet per bird should also be allowed in a continuous house, depending on the number of fowls. Small houses should provide more space per bird than large houses. In larger houses there is a greater area in which the birds can exercise. The house should not be so deep that the sunlight will not reach the rear portion of the building at some time during the day. As to the height, a low house is more easily kept warm in the winter than one with a high roof. The roof, however, should not be so low as to make it inconvenient for the attendant.

Foundation and floors. When a permanent continuous house is built, the most satisfactory foundation is con- 


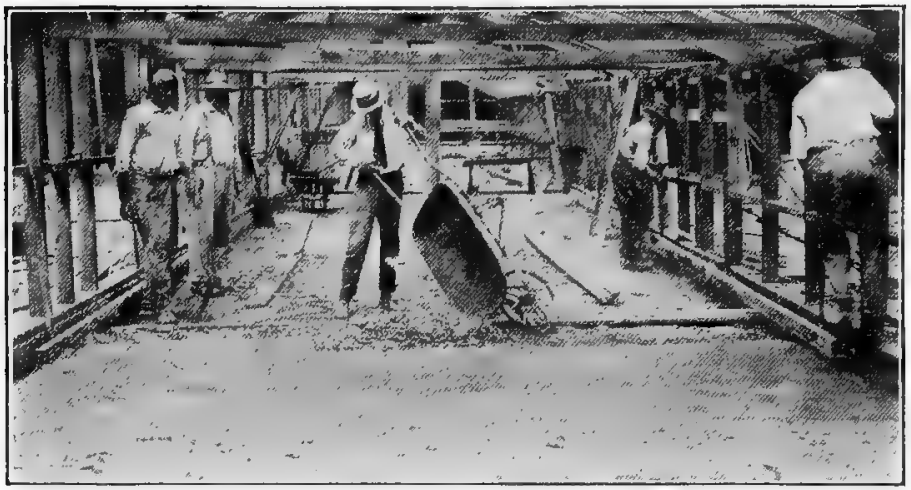

Figure 130.-Laying a concrete floor in a continuous house.

crete. Such a foundation should be built deep enough not to be affected by frost, to hold the buildings substantially, and of sufficient height above the ground level to prevent the entrance of water. An average height of 8 to 12 inches above the level of the ground should be sufficient to insure a dry floor. When a concrete foundation is used, the floor of the house should likewise be made of concrete.

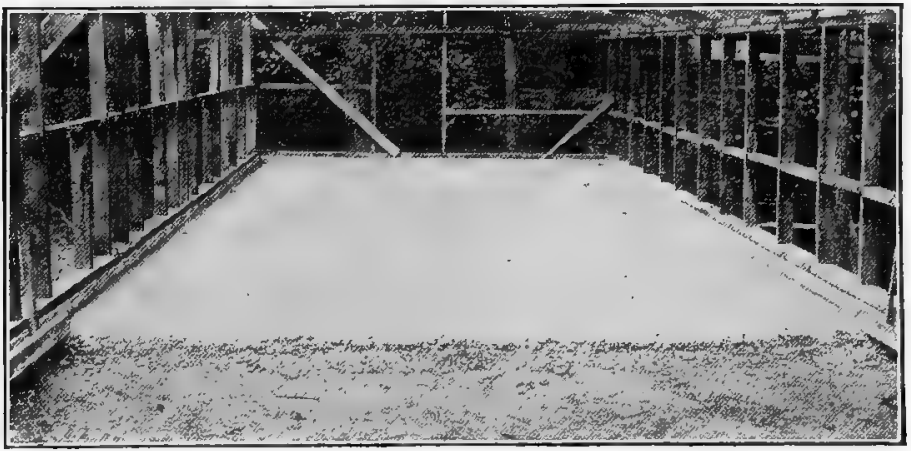

Figure 131,-Part of the concrete floor completed. Such a floor is permanent and easily kept clean. 
Such a floor is easily kept clean, practically makes the house rat-proof, and, if properly constructed, can be kept dry. In laying the foundation of a concrete floor, broken stone or gravel should be first laid as a foundation and from $2 \frac{1}{2}$ to 3 inches of concrete placed on top. Befcre finishing the top surface of the floor, a layer of tar paper such as is used for building that is lapped and cemented with tar at the seams should be placed on top of the rough concrete to help keep the floor dry and warm. The top layer of cement is then put on top of the paper. When concrete is not used for the foundation, the building may be erected on brick piers or posts. A board floor is mostly used with such a foundation and in cold climates should be laid double, with building paper between the boards. An earth floor gives good results, if it can be kept dry. It should be 3 to 6 inches higher than the level of the ground outside. An objection to such a floor is the difficulty in keeping it clean. As a sanitary measure remove from 3 to 4 inches of the top soil each year and replace it with fresh clean soil.

In the colony house the floor and foundation are usually constructed of lumber, the foundation timbers being constructed in the form of skids so that the house can be easily moved from place to place.

The framework of the building. The framework of the house should be constructed of lumber of sufficient size and dimensions to make it secure, depending upon the size and construction of the building.

With small continuous houses or colony houses most of the frame can be constructed of $2 \times 4$ inch lumber. In larger buildings, especially of the continuous house type, the uprights can be made of $2 \times 4$ inch scantlings and the rafters and floor joists of $2 \times 4$ or $2 \times 6$ inch lumber when the depth of the house and the span of the roof are over 16 feet deep. The sills can be made of $2 \times 4$ inch timber 


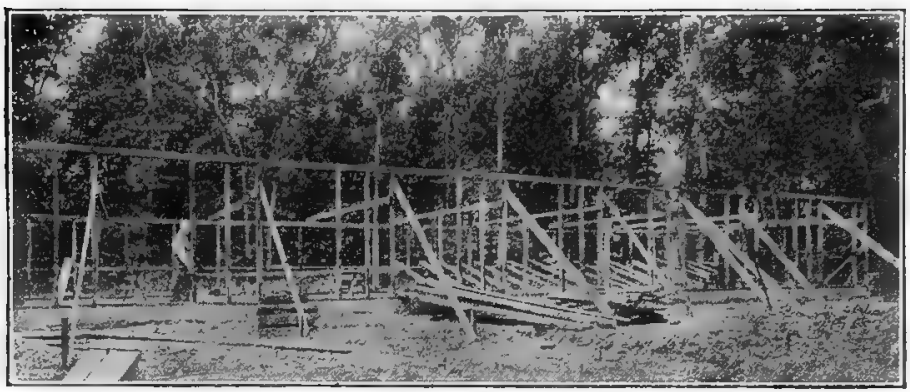

Figure 132.-The method of erecting the uprights of the framework of a continuous house.

when laid on a cement wall and $4 \times 4$ inch when the foundation is of brick piers or posts.

Floor joists, of course, are necessary only in houses having a wooden floor. When constructing colony houses, especially those that are to be moved from place to place, the framework should be well braced to prevent the houses from racking when moved. The runners, or skids, of the colony

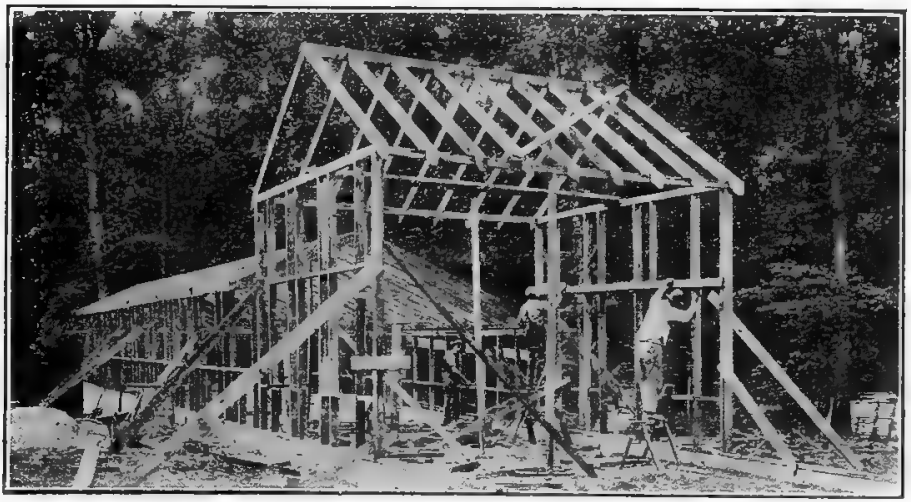

Figure 133.-Close up showing uprights in position and the framework of the roof completed. The second story section of this house will be used as a feed room and for supplies. 


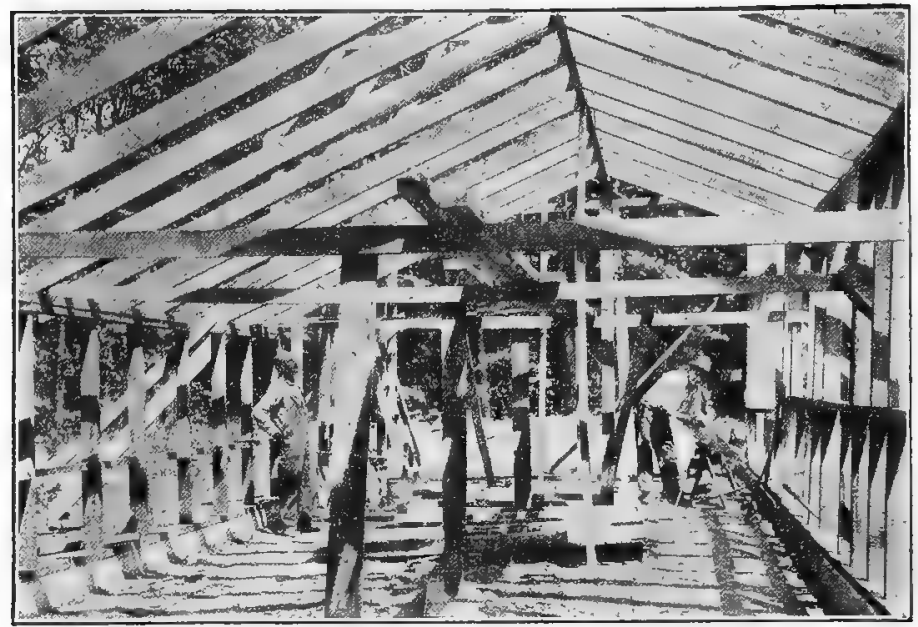

Figure 134.- Showing the method of placing the rafters for a two-thirds pitch roof. The crosspieces and uprights in the middle as shown in the picture are but temporary braces and will be removed.

house, depending upon its size, are usually built of $3 \times 4$ or $4 \times 6$ or $6 \times 6$ inch lumber.

The roof. There are six different styles of roof as shown in Figure 135.
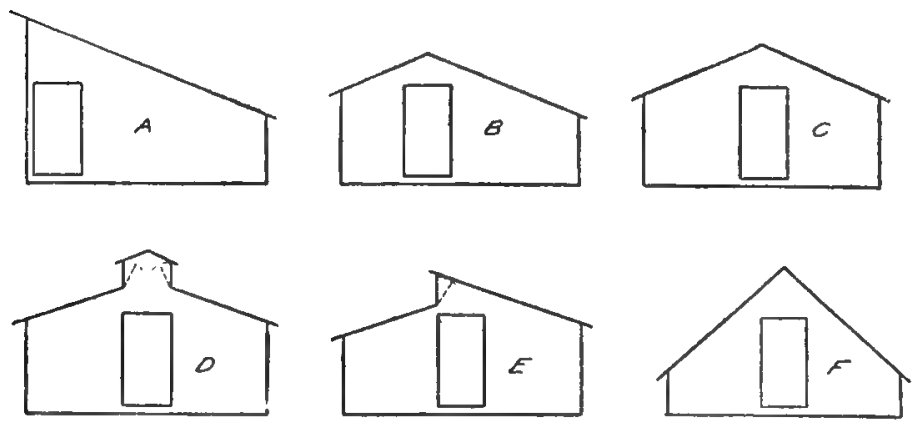

Figure 135.-Types of roofs for poultry houses. (a) Shed roof or single-pitch type. (b) Combination or two-thirds pitch. (c) Gable or double pitch.
(d) Monitor.
(e) Semi-monitor.
(f) A-shaped. 
Of these various styles the shed roof, or single-pitch, (Figure 135) is the easiest to construct. A roof of this type provides sufficient height in front to allow the sun's rays to reach the rear of the house, provided it is not too deep, and likewise all the rain water drains to the rear of the house. A good grade of roofing paper properly put on will be a lasting and satisfactory material for this purpose. These facts should determine the type of roof to build.

The roof should have sufficient pitch to allow the water to drain quickly.

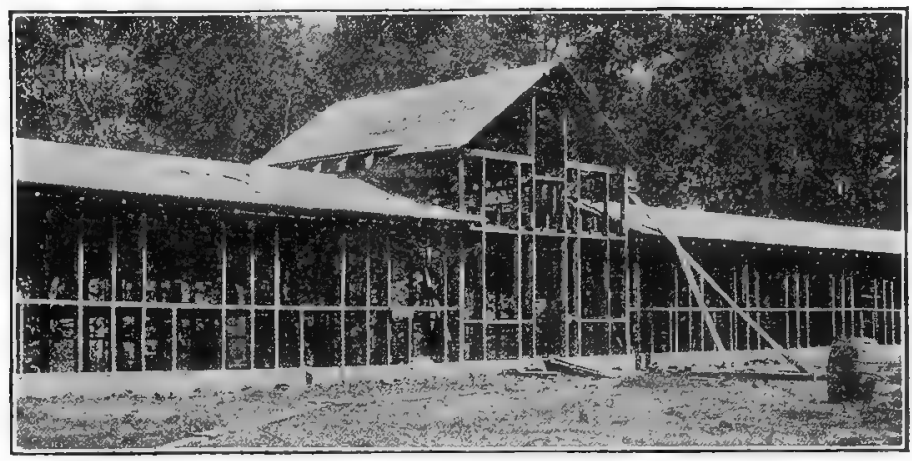

Figure 136.-After the framework of the building is completed the sheathing is nailed to the rafters prior to putting on the roofing.

The shed, or single-pitch, roof is most satisfactory for houses up to 16 feet deep.

The combination, or two-thirds, pitch roof and the semimonitor roof are best adapted for buildings over 16 and up to 24 feet deep. The former style of roof reduces the amount of surplus air space and makes a neater appearance than the single-pitch, or shed-roof, type.

The monitor and gable roof are usually used for buildings that are more than 20 feet deep and houses that have a central alley, especially brooder houses. The gable roof 


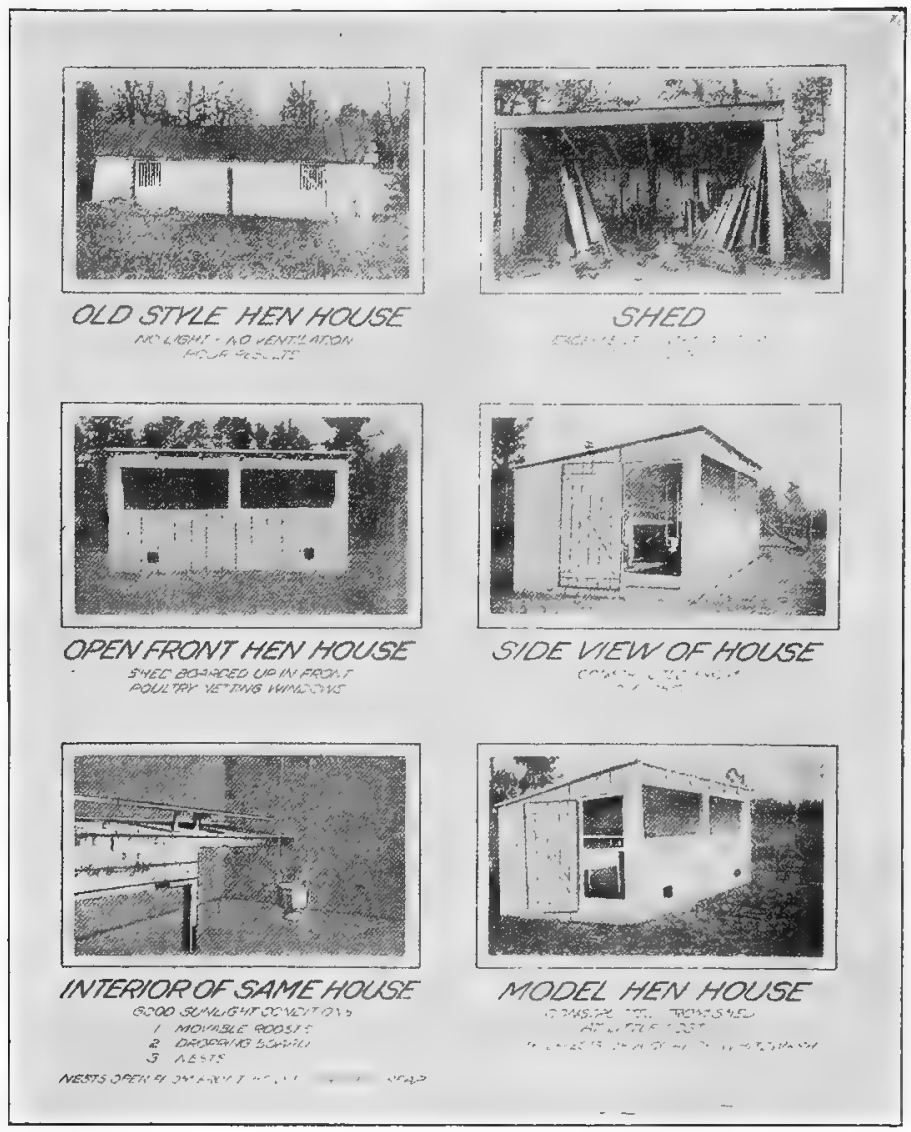

Figure 137.-Remodeling the poultry house out of old lumber at small expense. is mostly used for two-story buildings and incubator cellars. The A-shaped roof is sometimes used for colony and growing houses, although not so extensively as the singlepitch, or shed, roof.

The two-thirds pitch and double-pitch styles of roof are 
particularly suited to houses in cold climates where the gables may be filled with straw, which absorbs the moisture and assists in keeping the houses dry and warm.

The front of the house. Too many glass windows in the front of the house usually increase the temperature during the day; but, as glass radiates heat very quickly, the house will become cold at night. In sections of the country
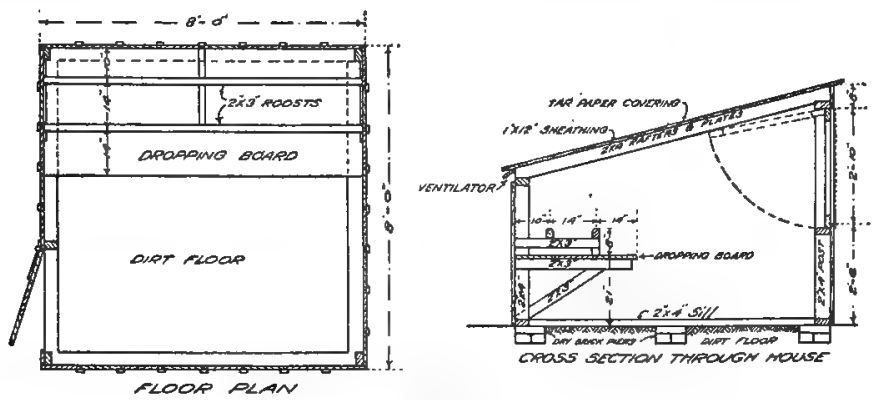

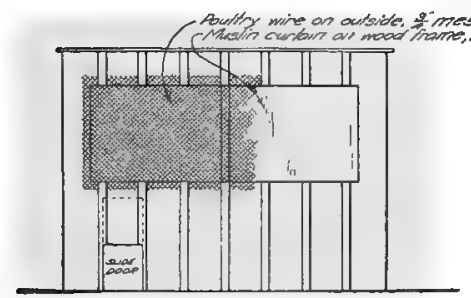

PAONT ELEATION

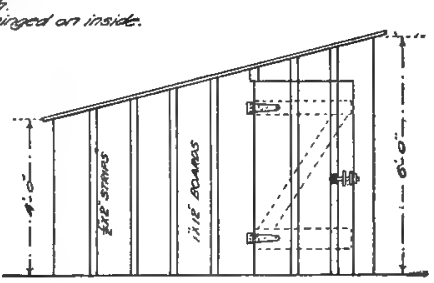

END ELENTION

Figure 138,-Plans for an easily constructed practical back-yard poultry house that will accommodate about 20 fowls.

where the climate is unusually cold in the winter a third of the open space in the front of the house should consist of windows, the balance of the openings to be covered with unbleached muslin or burlap, which keeps out the wind but permits a slow circulation of air without draft. In sections of the country having a more temperate climate glass windows can be entirely eliminated and two thirds of the front of the house left open and covered with muslin 
or burlap in eold weather. (See Figure 126.) In the South more open space may be given to the front of the house and a curtain provided where necessary for cool nights. (See Figure 128.) The front of the house should be high enough so that the opening or windows will permit the sun to shine well back into the house during the winter.

The walls of the house may consist of one or two thicknesses of boards, depending upon the climate. In an extremely cold section the rear wall of the house may be built of either two thicknesses of boards covered on the inside with building or roofing paper, or built with double walls with a dead air space between, the inside wall being covered

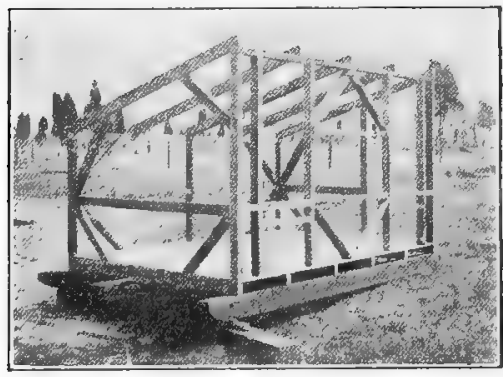

Figure 139-The framework of a colony house shown in Figure 122. Note how the framework is braced to prevent racking when the house is moved. with roofing paper. In sections of moderate climate one thickness of boards will suffice and, when built of unmatehed lumber, the cracks should be covered with narrow strips to prevent drafts.

Partitions. In long continuous houses, whether they are divided into pens or not, there should be a solid partition from the back of the house to the front part of the dropping board and extending to the ceiling at intervals of from 20 to 30 feet. (See Figure 144.) This arrangement eliminates the possibility of drafts' affecting the birds at night while on the roost. When the house is divided into pens, the lower 3 feet of the partition should be solid to prevent the males in the different pens from fighting and the other part composed of wire netting. Solid partitions should be built across the entire house at a distance of every 

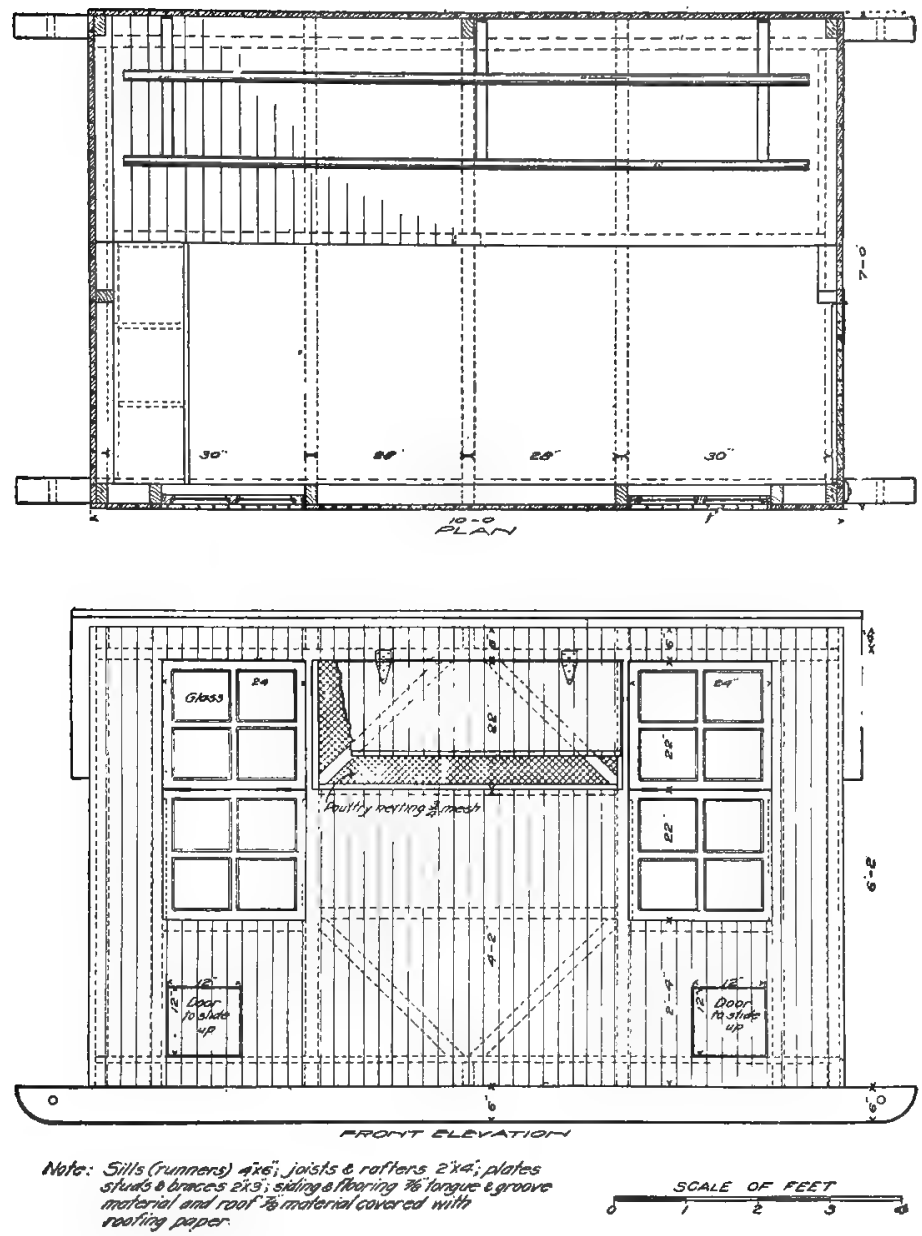

Figure 140.-Floor plan and front elevation showing the construction of a colony house as shown in Figure 122. 
40 to 50 feet, depending on the length of the building, in order to prevent drafts. Such partitions closer than this will interfere with the circulation of the

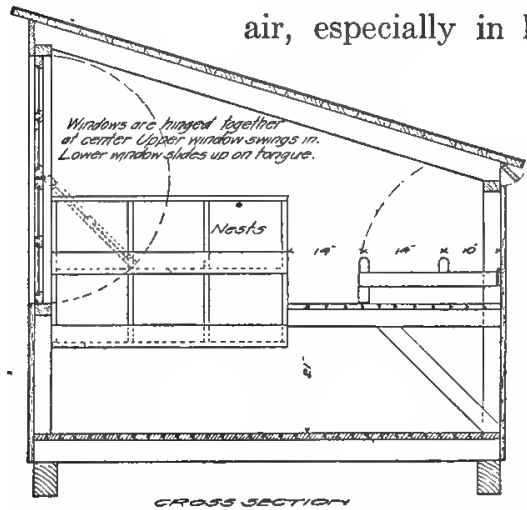

Figure 141. Crose-section of Colony House shown in Figure 122. This house has a capacity of 25 hens.

INTERIOR

ARRANGEMENTS

The interior fixtures should in most instances be built so that they can be readily removed and cleaned, and be also inexpensive and simple in construction.

Roosts. The roosts are placed in the rear of the building and all the roosts should be on the same level, so that the birds will not crowd and fight to get on the highest roost at night. The roosts should be from 5 to 8 inches above the dropping board and so constructed that they can be lifted up in one section to facilitate cleanin (See Figure 147.) Satisfactory roosts can be made from 2 $\mathrm{x} 2$ or $2 \times 4$ inch scantlings with the upper edge slightly rounded

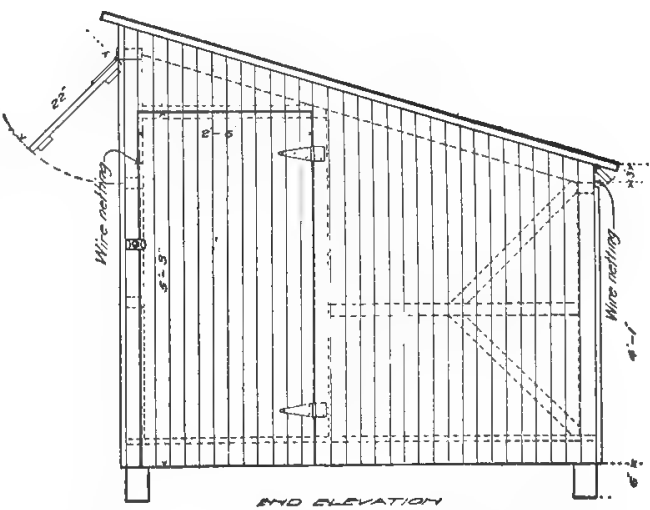

Figure 142,-End elevation of colony house shown in Figure 141 

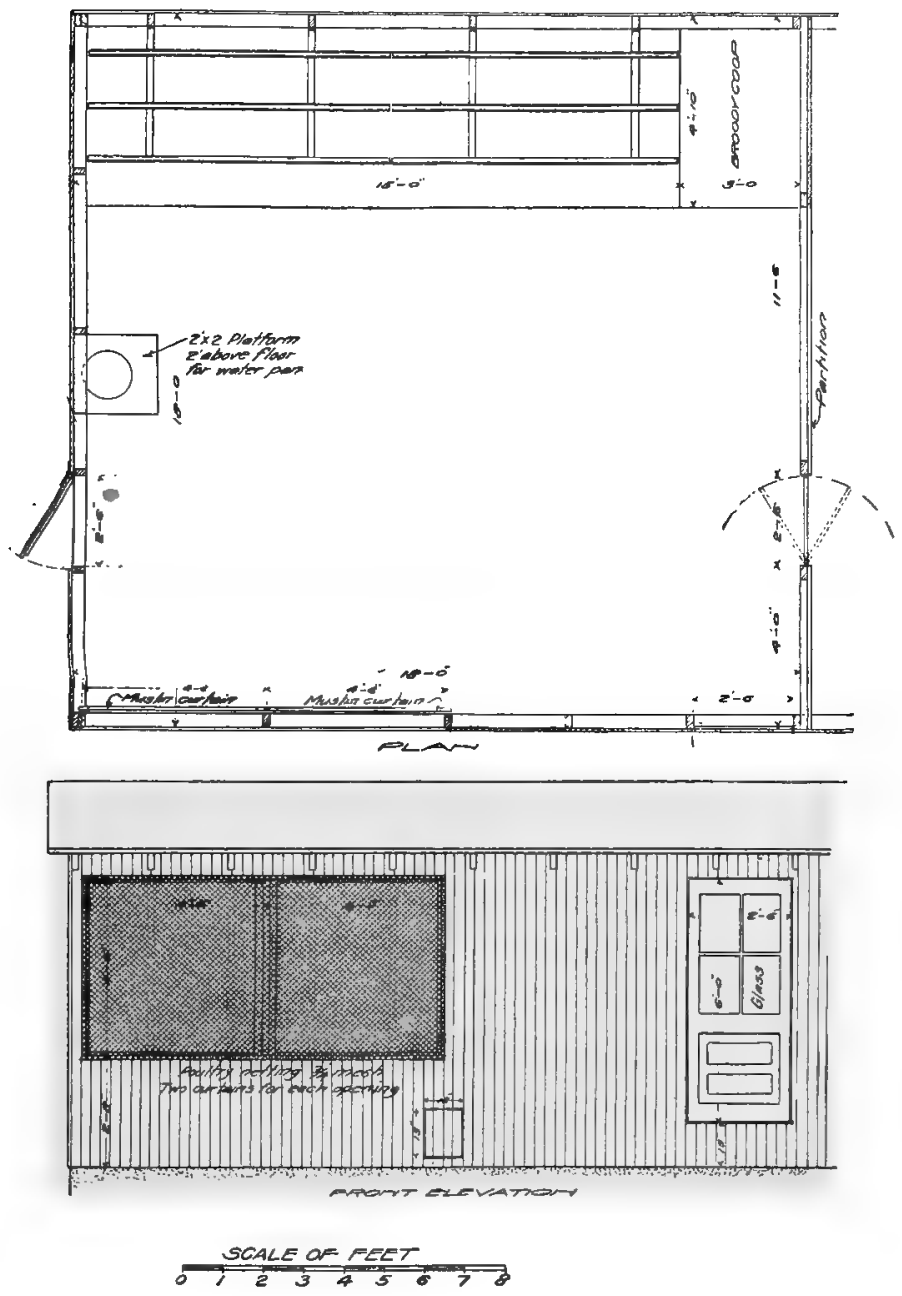

Figure 143.-Floor plan and front elevation of a continuous house as shown in Figure 124. Each pen of this house is $18 \times 18$ feet square, having a capacity of 80 to 100 hens. 

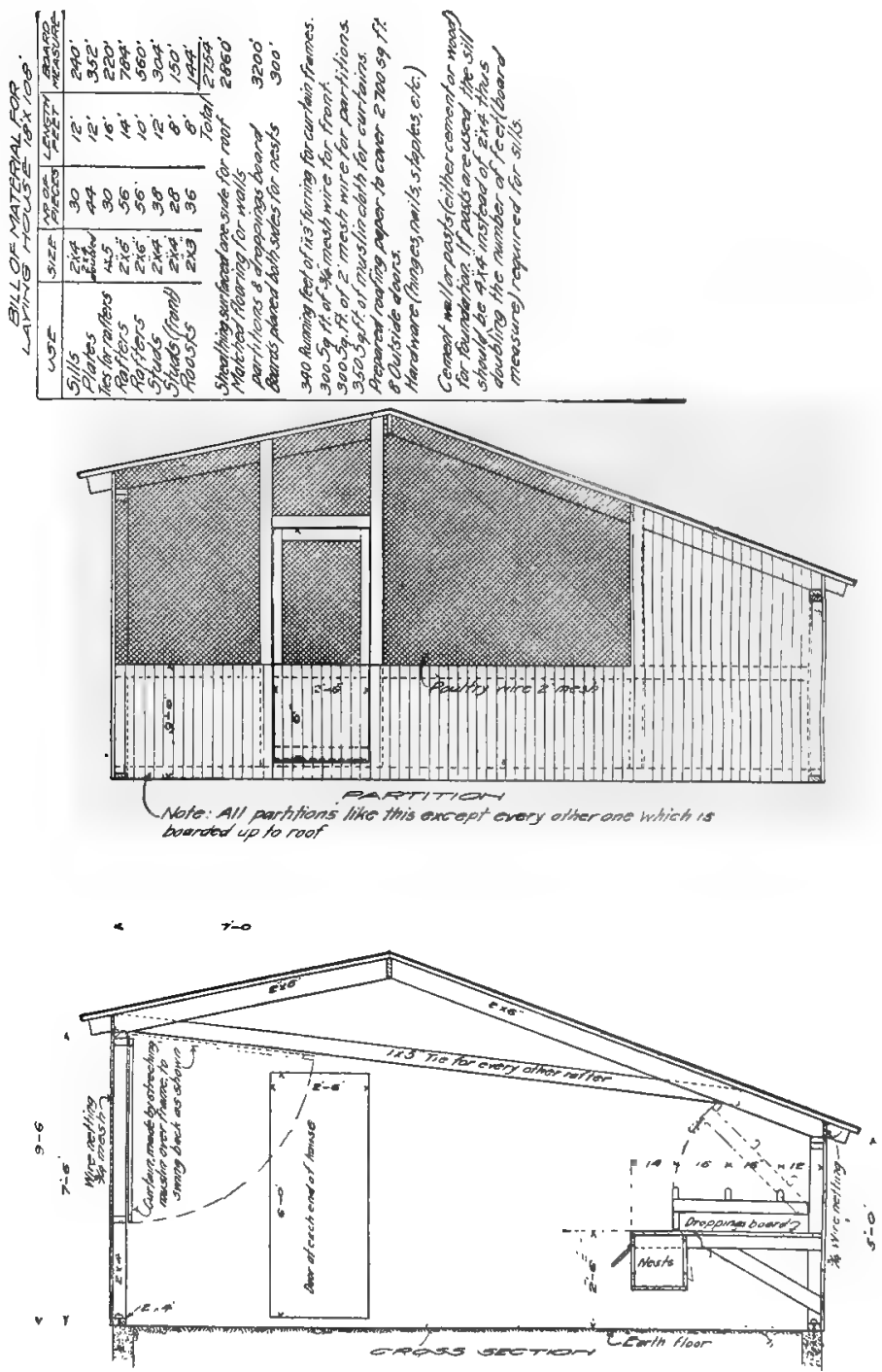

Figure 144,-Partition and cross-section of laying bouse as shown in Figure 124. 


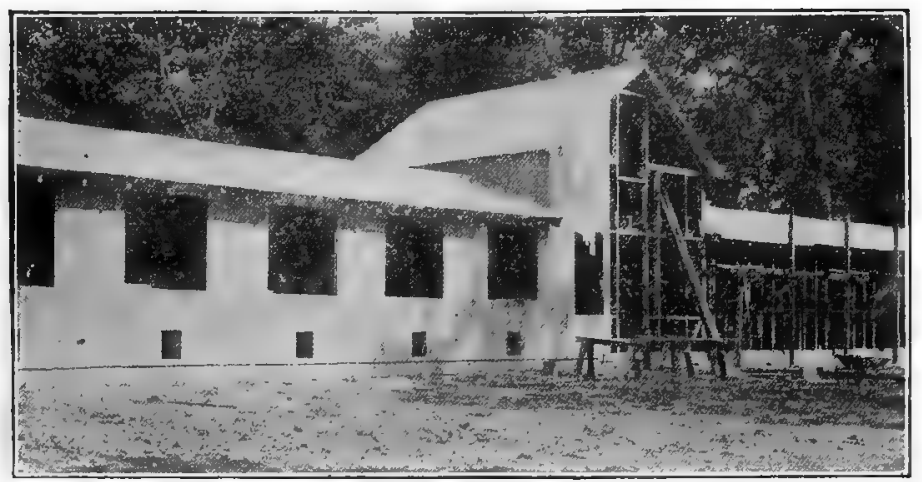

Figure 145.-Showing the front of a continuous house partially completed. and placed about 15 inches apart. Allow from 10 to 15 inches of roost space for each bird according to their size.

Dropping board. The dropping board should be from $21 / 2$ to 3 feet above the floor and extending back to the rear wall. The front edge of the dropping board should extend about 10 inches out from the first roost.

Nests. The nests may be placed under the dropping board or on the side wall, as shown in Figure 148. The nests should be 15 inches square and 12 inches high, with a

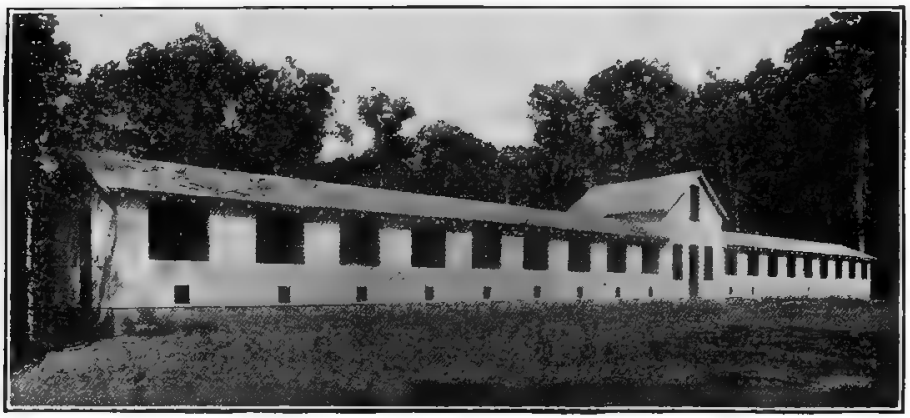

Figure 146,-The oontinuous house completed. 


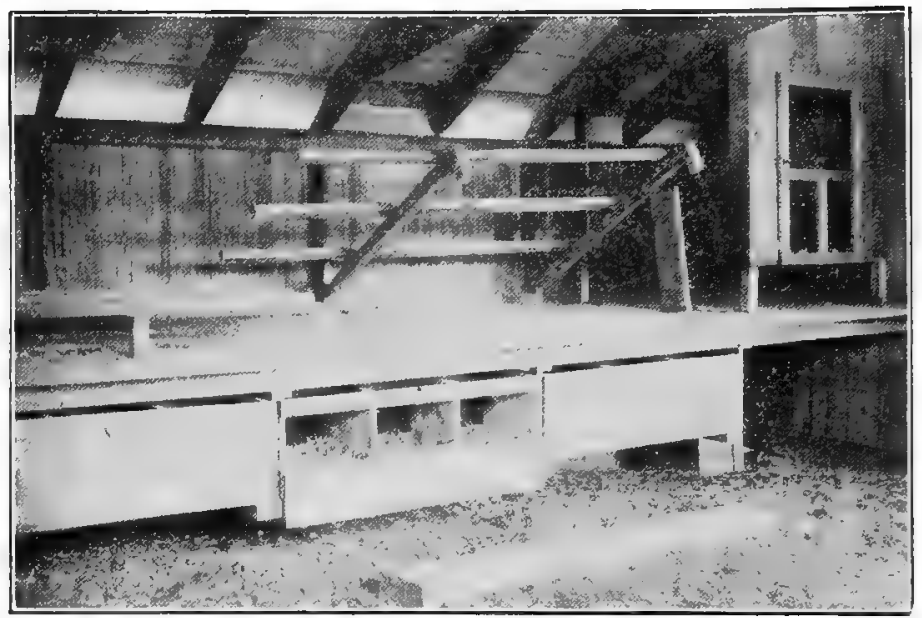

Figure 147.-A good interior arrangement of a long laying house, showing roosts, dropping boards, nest.s underneath and wire coop at end for confining broody hens. One section of the roost is shown elevated to facilitate cleaning the dropping boards. The nests allow the hen to enter from the rear, the front being opened to permit cleaning the nests and gathering the eggs. Note ventilators in the back of house and the abundance of sunlight which insures a dry house and healthy fowls.

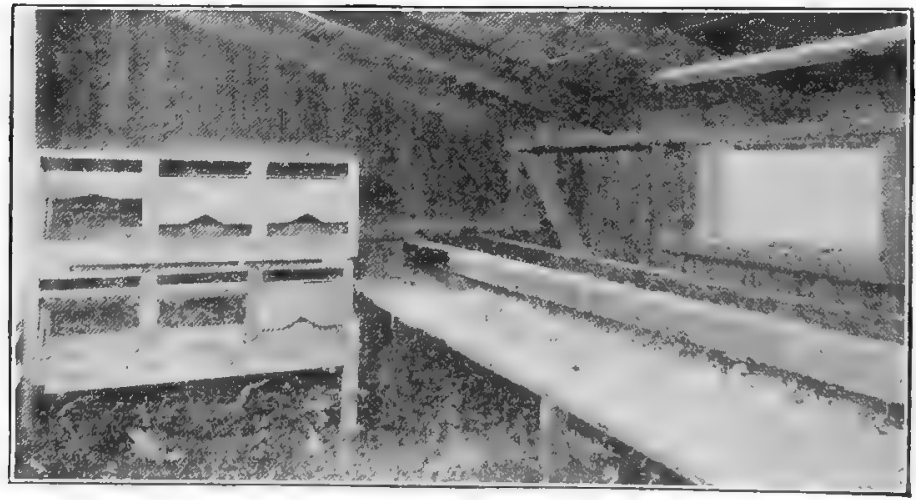

Figure 148. - Interior view of colony house as shown in Figure 122, with trap nests placed at the end of the building. A ventilator such as is shown in the rear of the house should be provided and kept open in hot weather. 


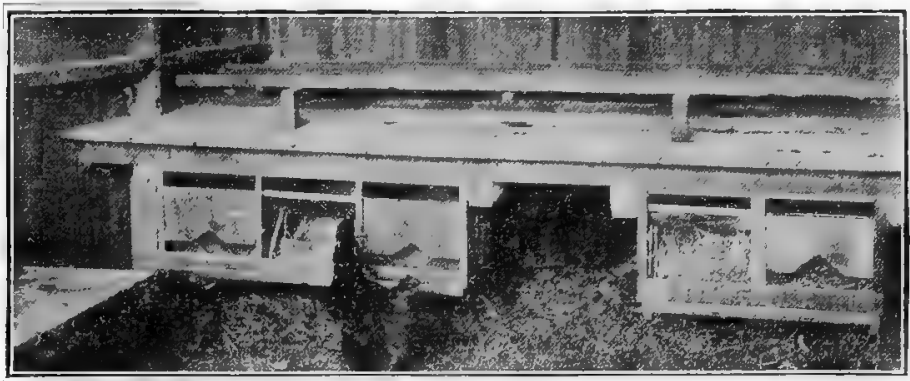

Figure 149.-Trap nests arranged under the dropping board and showing the hen about to enter an open nest. Hens have already entered the nests that are closed.

4 inch strip at the bottom of the entrance to keep in the nest material. Provide one nest for every 4 to 5 hens. When the nests are placed under the dropping board, the opening should be from the rear, as hens prefer a dark place in which to lay. A door in the front of the nest should be provided to enable the attendant to collect the eggs and clean the nests. (See Figure 147.)

Trap nests. A trap nest is so arranged that after a hen enters it she is confined until released by the attendant. Such nests are essential in any careful systematic breeding work such as pedigree breeding or the breeding of exhibition poultry. On account of the amount of extra labor necessary in attending to trap nests they are not entirely practical for the commercial poultryman or farmer. The advan-
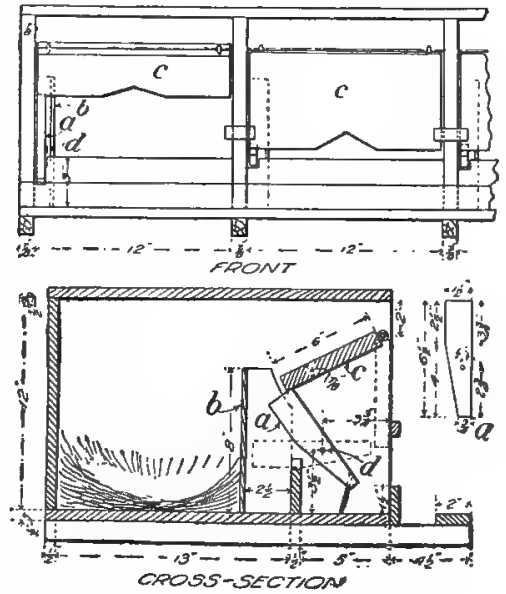

Figure 150,-Working plans of a trap nest as shown above. 
tages of trapnesting the layers are as follows:-(1) To tame the birds, thereby tending toward increased egg production. (2) To furnish definite knowledge concerning the traits and habits of individuals. (3) To furnish the only satisfactory basis for systematic breeding. (4) To eliminate the non-productive hens.

Dust boxes. Fowls clean themselves of insects by wallowing in the soil. In addition to this method of keeping themselves clean from insects other measures should be employed to keep down these pests by cleaning the houses thoroughly at intervals and spraying as described in Chapter

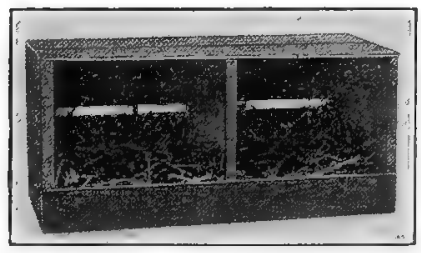
Figure 151. A simple nest built out the house will be found large of an orange crate. for a dust box in houses having concrete or board floors, especi.lly in continuous houses and where the birds are yarded. A box $4 \times 4$ feet square and one foot high built in the corner of

$X$. Provision should be made enough for a flock of from 50 to 75 hens. Fine, light, dry dust or sandy loam is excellent material for this purpose. When possible, wood ashes should be mixed with the soil.

Broody coops. A broody coop should be provided and used to break up broody hens. Such a coop can be constructed on the inside of the house, as shown in Figure 147. In the spring and summer months it is advisable to place the broody coop outside, as shown in Figure 152. When out in the open there is more to attract the hen's attention and it is cooler than when placed inside of the house. These conditions tend to break up broodiness.

Drinking fountains. As will be brought out in the chapter on feeding, the importance of providing plenty of fresh, clean water for the fowls can not be overestimated. 
To provide this a receptacle large enough to hold a day's supply of water should be placed on a platform or shelf elevated about a foot from the floor to prevent the scratching material or litter from getting into the water. (See Figure 153.) Water pans or drinking vessels should be carefully cleaned each day before fresh water is added.

\section{VENTILATION}

The keynote of proper ventilation is fresh air without drafts. A cloth or burlap curtain over the opening in

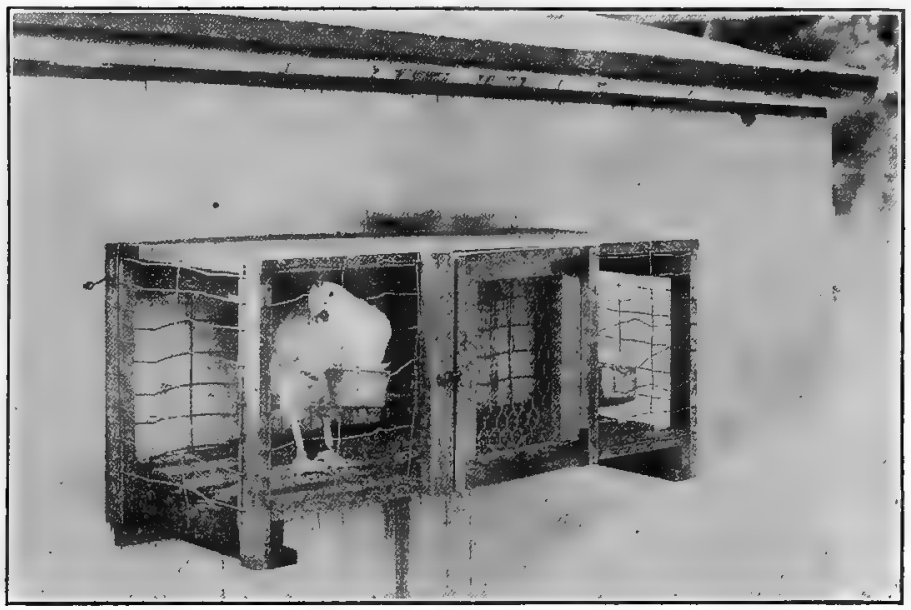

Figure 152.-A broody coop hung on the back of the house.

the front of the house that can be closed on cold nights and in stormy weather is one of the most successful methods for ventilating. In mild weather such glass windows as are in the front of the house should be opened or removed so as to provide plenty of ventilation.

In extremely hot weather provision should be made in the rear of the house for an opening to allow a complete circulation of air, so that the building will not be too warm 
for the birds. In the winter such an opening should be sealed tight to prevent drafts. There is, however, less chance of a bird's catching cold in a cold, dry house than in a warm, damp one. Proper ventilation will prevent the accumulation of dampness.

\section{YARDS AND FENCES}

Yards. In most instances yards are of course unnecessary when the colony houses system is used. Yards are never advisable except when it is absolutely necessary to

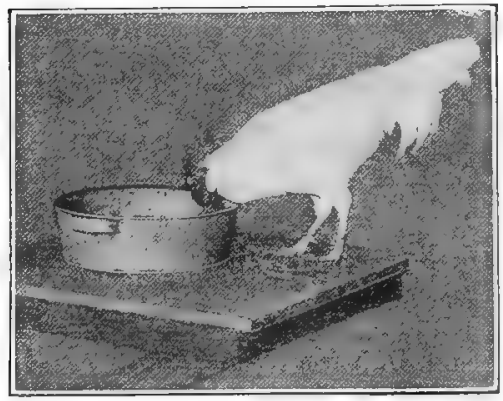

Figure 153. - A water pan placed on an elevated platform to prevent the litter from getting into the water. keep the birds confined to a limited area. When it is necessary to so confine the birds, double yards should be provided, one in the front and one in the rear of the house. With this arrangement the birds may be alternated from one to the other. With such a system and with proper management a green crop can always be available for the fowls throughout most of the year, by growing such a crop in one yard while the fowls have access to the other yard. (See page 203.) When yards can be constructed on only one side of the house, they should be on the south side. If it is desired to keep the yard in permanent sod, at least 100 square feet of yard space should be allowed for each fowl. When green feed such as sprouted oats, mangel beets, etc., are supplied and the yards used principally for exercise, provide at least 35 square feet for each fowl.

Fences. Two-inch wire mesh is probably the cheapest and one of the most suitable materials for fencing fowls. 
When such wire is used it will be found to last longer by nailing the bottom edge of it to a four-inch board extending from post to post. The top of the fencing may be kept rigid by fastening it to a heavy wire stretched at the tops of the posts. Where two or more yards are adjoining, the fences should be boarded at the bottom to a height of 3 feet to prevent the male birds from fighting between the fences (See Figure 124.), or an extra strip of wire fencing

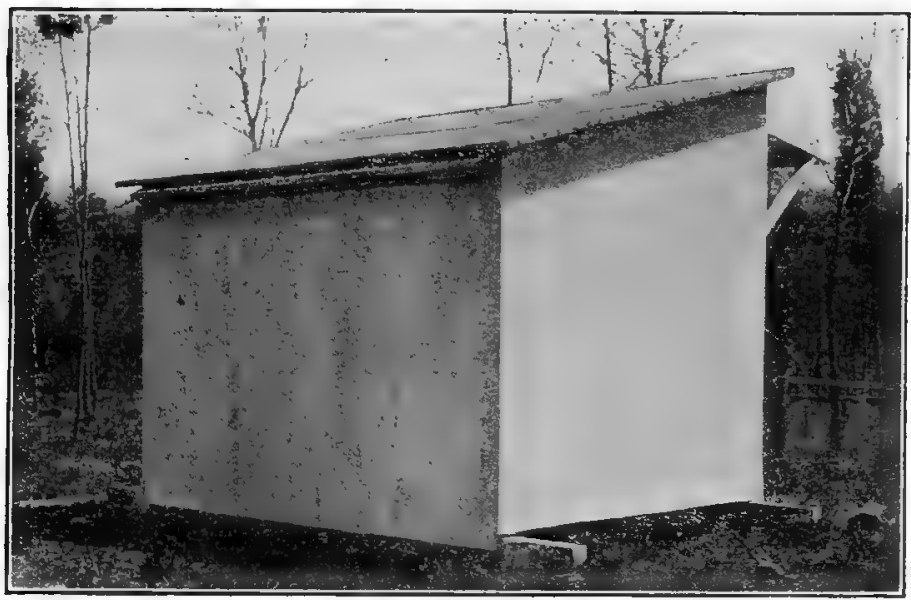

Figure 154,-A ventilator as shown here or in Figure 148 should be opened in warm weather.

3 feet wide can be attached on the other side of the post for this purpose in the place of boards.

The height of the fence is governed by the variety of fowls kept. The smaller breeds, such as the Leghorns, need a fence from 6 to 8 feet high in order to keep them confined. A 6-foot fence can be used where Leghorns are raised, provided the flight feathers of one wing of the fowl are clipped. For the heavier breeds a 5 -foot fence will be found satisfactory. Where the general-purpose breeds, such as 


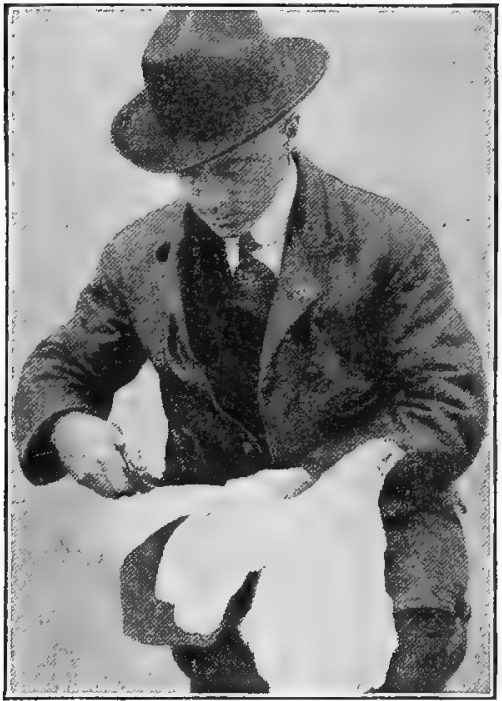

Figure 155.-Clipping the flight feathers of the wing. the Barred Plymouth Rock and Wyandotte, are kept, it is sometimes advisable to clip one wing of each bird in order to prevent their flying over the fence, when it is only 5 feet in height.

Clipping the wing. In many instances it will be found necessary to clip the wings of the birds to prevent their flying over the fence, especially in the case of Leghorns and other breeds of this type. In no instance should both wings of the fowl beclipped.

By clipping the feathers of but one wing the fowl's balance is lost when it attempts to fly, due to the fact that one wing is shorter than the other. Hold the fowl with the wing spread as shown in

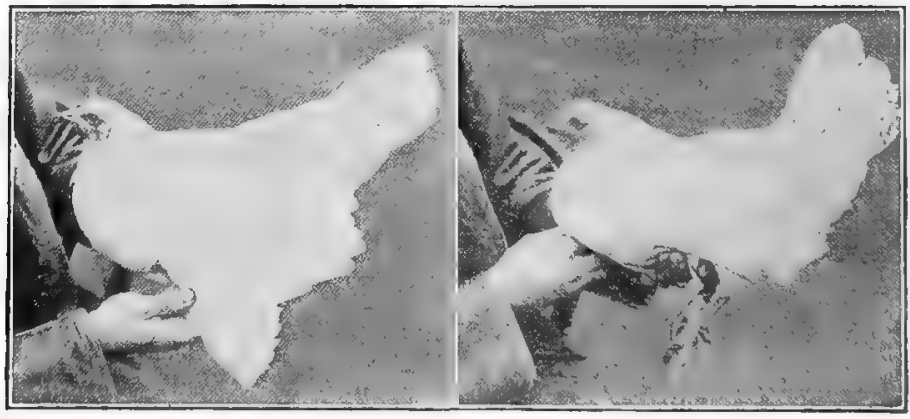

Figure 156,-The flight feathers clipped.

Figure 157.-Wing folded after feathers have been clipped. 
Figure 155 and with a sharp pair of scissors clip the flight feathers only. With these feathers cut, the wing will then have the appearance as shown in Figure 156. Furthermore, the clipping of the flight feathers is hardly apparent when the wing is folded in its natural position, as shown in Figure 157.

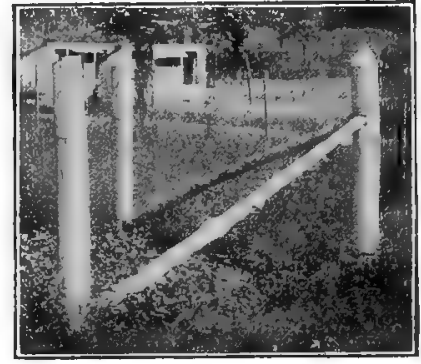

Figure 158.-The corner posts of the fence should be well braced.

Gates. In all cases at least one gate should be provided for each yard and, where several yards adjoin, a gate should be made between each yard and the one next to it.

When the yard is of considerable size, a double gate should be provided, so as to admit a wagon to remove the litter from the house or a team of horses in the event it is desired to plow the yard.

\section{PAINT AND WHITEWASH}

It is always advisable either to paint or whitewash the poultry buildings not only from the standpoint of appearance,

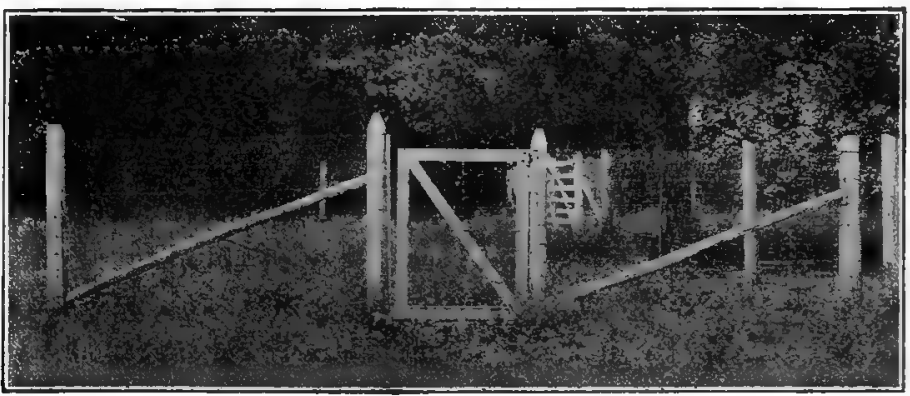

Figure 159.-The gate should be well made and hung on strong hinges in order for it to be serviceable. 
but likewise to protect the lumber. Suitable ready mixed paints can be purchased and will in most cases answer the purpose. Whitewash is the most inexpensive finish that can be applied and can be used either for the exterior or interior of the house. Satisfactory weather-proof whitewash for the outside of the building can be made as follows:

1. Slake 1 bushel of quick lime in 12 gallons of hot water.

2. Dissolve 2 pounds of common salt and 1 pound of

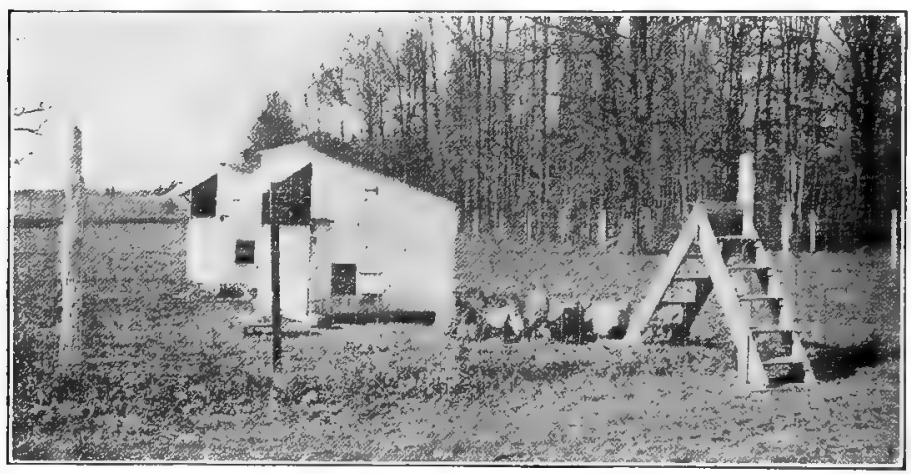

Figure 160.-When colony houses are only temporarily placed in a field or lot and a gate is not close by, a stile as shown can be erected. Ordinarily the fowls will not attempt to fly out from the top step of the stile.

sulphate of zine in 2 gallons of boiling water. When mixed, pour this into the slaked lime. Stir well and add 2 gallons of skim milk.

\section{QUESTIONS}

1. What are the nine essential factors for a suitable poultry house?

2. What are the advantages and disadvantages of a colony house system?

3. What are the advantages and disadvantages of a continuous house system?

4. Describr an ideal location for the poultry house.

5. What factors should be considered in planning the size and dimensions of the house? 
6. Describe three styles of floors for the poultry house and the merits of each style.

7. Discuss the factors to be considered when erecting the framework of the house.

8. Name the six styles of poultry house roofs. Which is the most easily constructed?

9. Describe three methods of constructing the front of the house. What kind of openings would you provide for a house in your section of the country?

10. Deseribe the method of building the walls of the house.

11. Discuss the construction of partitions in a long, continuous house.

12. Where should the roosts be placed?

13. Describe the position and purpose of the dropping board?

14. Describe the size of a suitable nest and the number that should be provided for a flock of 50 hens.

15. What are trap nests and when should they be used?

16. Discuss the value of a dust box for the hens.

17. Where should the water pan be placed in the house? Why?

18. What is the keynote of proper ventilation for the poultry house? How can proper ventilation be provided?

19. When should yards be used and how should they be constructed?

20. Describe a satisfactory method of building fences.

21. Describe the correct method of clipping the wing.

22. What factors should be considered when constructing gates?

23. Discuss the advantages of painting or whitewashing the poultry buildings.

\section{SUGGESTIONS}

1. As noted in this chapter, a poultry house should consist of various essential features in order to make it practical and convenient. As will also be noted, no one type or style of poultry house is recommended, or, in other words, there is no best type of poultry house suitable for all conditions and circumstances. With this fact in mind, draw the plans for a poultry house built on either the colony or continuous house plan, incorporating the essentials as given. In planning such a house the climate in the section of the country in which you are located should be kept in mind.

2. After you have perfected your plans for such a house, show it to several of your friends who are familiar with the construction of poultry houses for their suggestions and criticism. After you are convinced that these plans are satisfactory, if you are contemplating building a house, it is suggested that the house be built following such plans.

3. If you already have a poultry house and are not entirely satisfied with its arrangement, why not remodel it, embracing some of the suggestions as given in this chapter. Figure 137 on page 140 will show you what can be done in this connection.

4. In order to become familiar with the kinds of houses and systems of housing in your community, make a survey, the object of which should be to obtain a list of the various kinds of poultry houses in your 
section. Such a trip as this will also enable you to observe the satisfactory and unsatisfactory features in other poultrymen's or farmers' poultry houses.

5. If your house has an earth floor, why not consider removing this floor and in its stead build a concrete floor, which will be more permanent and more easily kept clean.

6. Does your poultry house or the majority of those in your community have too much glass in the front? If such is the case, why not consider removing or suggesting to others that some of the glass be removed and the openings covered with curtains in cold weather?

7. Does your house contain sufficient roosting space, nests, and other interior arrangements as mentioned herein? If not, such improvement as can be made will, no doubt, prove to be most desirable.

8. Before the arrival of winter be sure that all cracks in the rear and sides of the house are tightly sealed in order to prevent drafts. Before warm weather comes also make sure that the house is sufficiently ventilated to keep the building from becoming too hot during the summer.

\section{REFERENCES}

Poultry House Construction,U. S. Department of Agriculture Farmers' Bulletin 574, by Alired R. Lee.

A Simple Trap Nest for Poultry, U. S. Department of Agriculture Farmers' Bulletin 682, by Alfred R. Lee.

Poultry Management, U. S. Department of Agriculture Farmers' Bulletin 287, by George A. Bell. 


\section{CHAPTER IX}

\section{COMMON DISEASES AND TREATMENT}

The prevention of poultry diseases and infection is largely a matter of management. The most successful poultrymen endeavor to manage their flocks in a way to prevent disease rather than to be continually doctoring. While it is found possible to prevent diseases to a great extent by keeping the fowls as well as the houses and surroundings clean and sanitary, in many flocks, nevertheless, fowls from time to time come in contact with some disease or disorder that interferes with their growth or production. In most instances it is not practical to attempt to cure one or two sick fowls; for, even though they are apparently cured, their value as producers or breeders will be lessened. Again, the disease may reappear and endanger other fowls. Every effort should be made to prevent disease from becoming prevalent throughout the flock; for, unless a known cure is possible and the flock can be treated as a whole, it may become necessary to kill off a large number of the fowls.

\section{GENERAL PREVENTION}

Other than by keeping the poultry house, drinking fountains, hoppers, and surroundings clean and sanitary the healthy fowls in the flock may be prevented from getting diseases by immediately removing those that show signs of infection. The contagious or infectious diseases like roup, canker, chicken pox, cholera, etc., are caused by germs, which not only develop rapidly within a fowl so affected, but are subject to spread among the rest of the flock. The drinking fountain is most frequently the means of spreading disease and thus endangering other birds. In less severe forms of disease, as, for example, roup, canker, chicken pox, it is possible to prevent the contamination of the whole 
flock by adding to the drinking water an antiseptic that has the power to kill such germs as may be present.

In such instances it is well to give the flock an antiseptic, such as potassium permanganate in the drinking water, as described under roup, and to spray and clean the house and buildings thoroughly with a $5 \%$ solution of crude carbolic acid or some coal-tar product in water. Usually the fowl that is not well can be told by the fact that it is

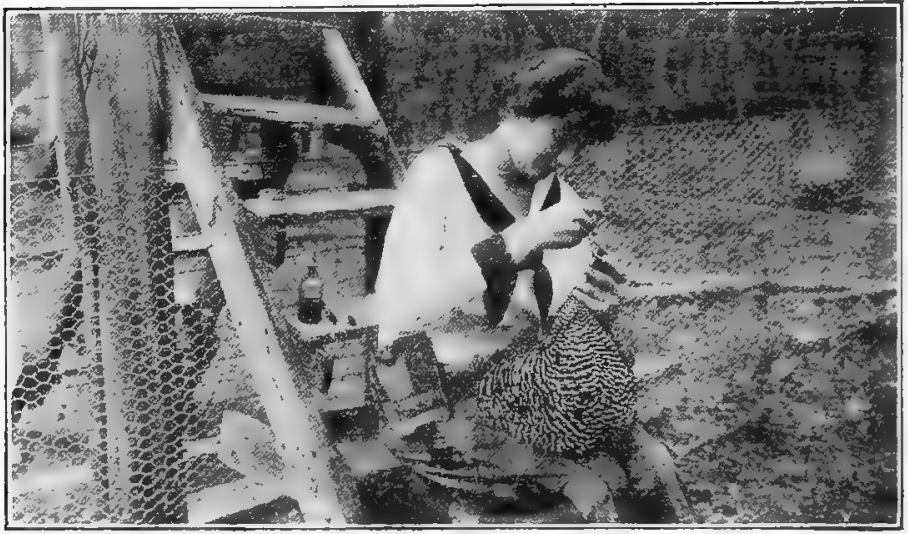

Figure 161.-Doctoring a sick hen.

not as active as the others, stands around in an out-ofthe-way place, and shows little disposition to eat. Such a fowl should be immediately removed from the flock and, if seriously sick, should be killed and the carcass burned or deeply buried.

COMMON DISEASES, SYMPTOMS AND TREATMENT

Roup. Roup is a highly contagious disease, spreading from one bird to another rapidly. The disease is quite common in the fall, especially in poorly ventilated damp houses. Late-hatched and poorly developed stock is usually very 
susceptible to roup, especially if all conditions such as proper housing, etc., are not favorable. The prevention in this case would, of course, be to hatch early, so as to have the stock well grown by fall. Likewise undersized or poorly developed birds should be culled from the flock sometime during the summer, as described in Chapter XIII.

Symptoms. The first symptoms of roup are watery and swollen eyes, loss of appetite, and a thin watery discharge from the nostrils. It will sometimes be noticed that a fowl so affected will stand around with its head under the wing most of the time. On examining the plumage under the wing it will be found discolored or dirty. There is usually a rather offensive odor accompanying roup, which, when once detected, can always be recognized when roup is present. As the disease develops, the discharge becomes thick and inter-

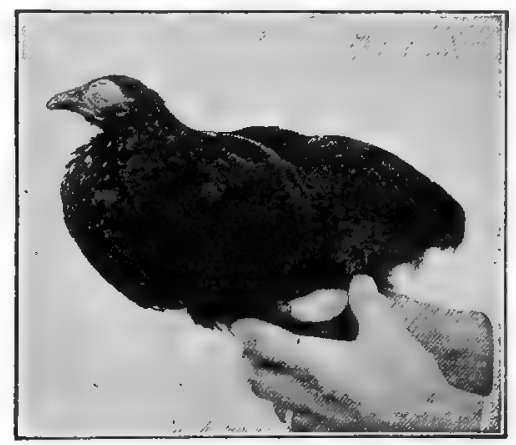

Figure 162.-A fowl with roup. feres with the bird's breathing. In severe cases the bird's head becomes inflamed and the eye badly swollen, so that it protrudes.

Treatment. Remove the sick birds to a warm, dry, well-ventilated room that is free from drafts. Syringe the nostrils by means of a medicine dropper with a solution of one teaspoonful of common salt in a quart of water. The eyes may be bathed gently with the same solution. Grease around the nostrils and eyes with pure or carbolated vaseline. After cleaning the nostrils and eyes with the saltwater solution birds may be individually treated by syring- 
ing the nostrils with either of the following solutions by means of a medicine dropper (Figure 161) or by immersing the head of the bird in a basin containing the mixture and holding it there for a few seconds, care being taken not to hold the bird long enough to cause suffocation. Suitable remedies for such treatment are boric acid 1 oz., water 1 quart, or potassium permanganate $1 \mathrm{dram}$, water 1 pint; or boric acid 11/4 oz., borax $1 / 2 \mathrm{oz}$, and 1 quart water. Hydrogen peroxide used in the proportion of $1 \mathrm{oz}$. to $3 \mathrm{ozs}$. of water is sometimes effective. As a general treatment and preventive, dissolve in one gallon of drinking water as much potassium permanganate as will remain on the surface of a dime. The flock should be given no other drinking water than that containing the potassium permanganate. It is good practice to use potassium permanganate in the drinking water as a preventive as soon as cool weather begins in the fall.

Canker. This disease is somewhat akin to roup and is also known as diphtheretic roup.

Symptoms. This disease is characterized by cheeselike patches that form on the membrane of the mouth, throat, and tongue.

Treatment. Sprinkle a little sulphur or chlorate of potash in the mouth and throat of the bird. Another effective treatment consists of washing the sore patches with a mixture of equal parts of hydrogen peroxide and water.

Cholera. This is probably one of the worst discases that affects poultry, for it spreads rapidly and in most instances the cure is unsatisfactory. Fortunately, however, this disease is very rare and is frequently mistaken for other troubles that are less serious.

Symptoms. The usual symptoms of cholera are as follows: The fowl is troubled with diarrhea, the droppings become watery and yellow or green in color, the fowl is 
depressed, the feathers ruffled, and the comb is usually either very pale or very dark. Fowls so infected usually have a great thirst but poor appetite. Fortunately many so-called cases of cholera are simply diarrhea. Fowls having cholera usually die within 36 hours.

Treatment. The most satisfactory method of combating this disease is to kill and burn all fowls that are really affected. Clean and spray all water fountains and the houses thoroughly with a $10 \%$ solution of carbolic acid and water, or one of the coal-tar products, such as creolin, creosote, etc., and water. The droppings should be buried deep. burned, or sprayed with the above solution. The drinking water may be made antiseptic by adding as much potassium permanganate as will remain on the surface of a dime to each gallon of water. This serves to prevent the spread of the infection through water and is also a means of administering a general preventive to the flock as a whole.

Recent experiments at the *Rhode Island Experiment Station show that attempts to immunize fowls against cholera infection by inoculation have not proven entirely satisfactory. Such inoculations, however, produce an increased resistance against infection but not complete immunization.

Tuberculosis. Tuberculosis of poultry is a highly contagious disease that usually affects the liver, spleen, and intestines.

Symptoms. From the outward appearance the symptoms of this disease are usually not noticeable until it has reached an advanced stage of development. The fowls gradually lose weight, their combs turn pale, and, as the disease continues, the birds become listless and seem to be affected with diarrhea. Not infrequently the disease affects their joints, either by creating a swelling or by causing the fowl to become lame. (See Figure 163.)

*Rhode Island Experiment Station Bulletin 179 by Dr. Philip Hadley. 


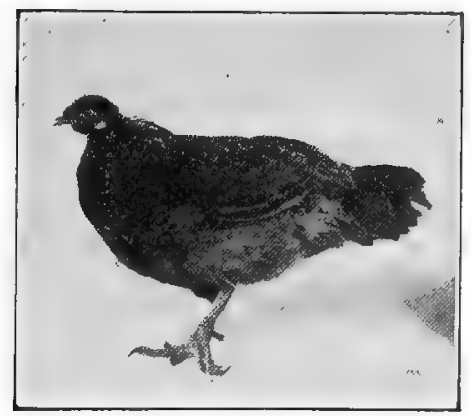

Figure 163. A fowl infected with tuberculosis. (Courtesy of Dr. W. W. Dimock, Ames, Iowa.)
Treatment. There is really no satisfactory treatment for this trouble. When the disease is discovered in a wide-spread form, that is, throughout most of the birds, they should be immediately killed and burned or buried, and the houseand yards thoroughly cleaned and disinfected. As an extra precaution all the litter and droppings from the house should likewise be burned. Under ordinary circumstances it is not advisable to retain any of the fowls that have been exposed to this infection, as it is highly probable that sooner or later the disease will manifest itself in them.

Limberneck. This disease, so-called, is really a condition or symptom of several diseases.

Symptoms. It is characterized by the fact that the fowl's neck becomes paralyzed and limber so that the head can not be held erect and is twisted to one side. The cause is usually a form of food poisoning as the result of the bird's feeding on decomposed animal flesh.

Treatment. Two teaspoonfuls of castor oil giv-

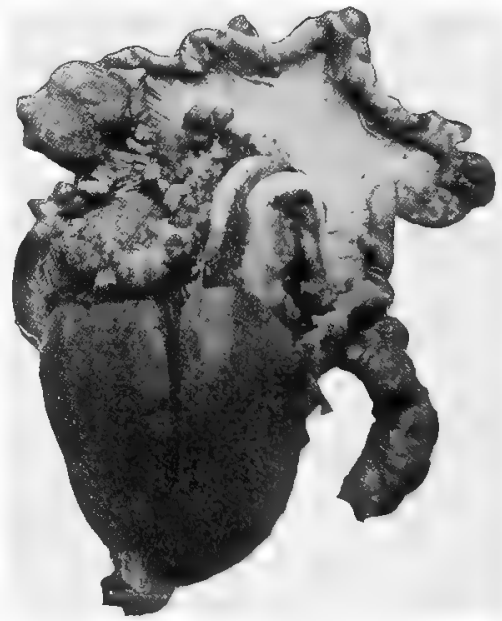

Figure 164,-Liver and intestines of a tubercular fowl shdwing tubercles in wall of intestines and tubercular lesions on the liver. (Courtesy of Dr. W. W. Dimock, Ames, Ia.) 
en to the fowls will sometimes effect a cure. In all cases an effort should be made to find the cause of the disease, which is usually a dead animal or fowl that is decomposed and is being eaten by the birds. The carcasses of birds that

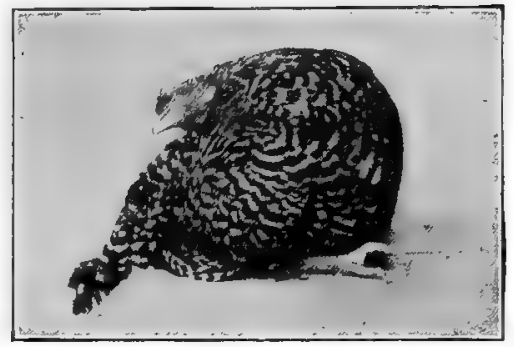

Figure 165.-A bad case of limberneck. die as the result of limberneck should be deeply buried or burned when found.

Chicken pox, or sore head. This is a very contagious disease that occurs in practically all classes of poultry, particularly in the South.

Symptoms. It may be told by the formation of yellow patches or nodules that appear at the base of the beak, on the face, comb, and wattles. In severe cases these patches or nodules increase in number to the extent that the bird has difficulty in opening its eyes and beak.

Treatment. Cover the sore patches with carbolated vaseline, which will cause the crust to soften and drop off. The tissue beneath the crust or scab should then be painted with tincture of iodine. As an additional remedy add 5

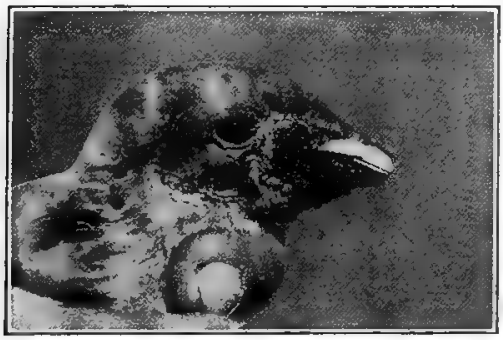

Figure 166.-A young chick with sore head. pounds of powdered sulphur to 100 pounds of dry mash, placing this mixture before the birds affected. The general suggestions as already given concerning spraying the house and coops with a disinfectant applies equally as well to thisinfection. 
White comb, or favus. This is a very contagious disease, spreading quickly from one bird to another.

Symptoms. The general symptoms of this disease are white or grayish spots that form on the comb, wattles, ear lobes, and other parts of the body.

Treatment. Birds so affected should immediately be removed from the flock. When the disease affects only the bare parts of the head and face it can sometimes be cured

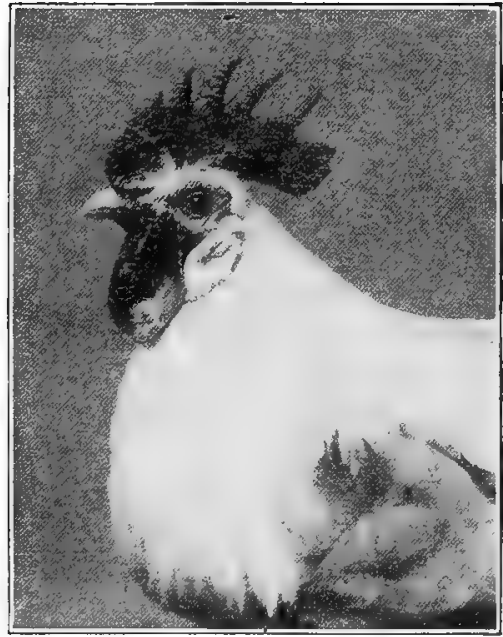

Figure 167.-White Leghorn cockerel with favus, or white comb. by applying iodine. Another effective remedy is that of applying ointment composed of 1 part of powdered sulphur mixed with 9 parts of carbolated vaseline. In applying this the affected parts should be merely greased and not rubbed, as rubbing tends to spread the disease. Repeated applications should be made every three days until the affection disappears. If the feathered portions of the body are affected, it is better to kill the fowl, as it usually requires considerable time to effect a cure.

Blackhead. The most troublesome and infectious disease that affects turkeys is blackhead, an affection of the intestines and liver. It is noticeable that, whenever the climate and range conditions are such as to permit turkeys to forage for the greater part of their feed, cases of blackhead are infrequent. Again, blackhead rarely occurs in flocks 
possessing good constitutional vigor and vitality and which are properly managed.

Symptoms. The comb and skin of the head and neck turn very dark purple.

Trealment. No successful cure for this disease has been found; but free range and care not to overfeed are very important factors in keeping the flock free from this disease.

Frozen comb. Frozen or frost-bitten combs frequently occur in cold weather, especially with birds having large single combs. Fowls having lopped single combs or rose combs are not so susceptible, principally due to the comb's being closer to the head.

Symptoms. The points or parts of a comb that have been frozen will turn black soon after the comb thaws out. Unless timely treatment is applied,

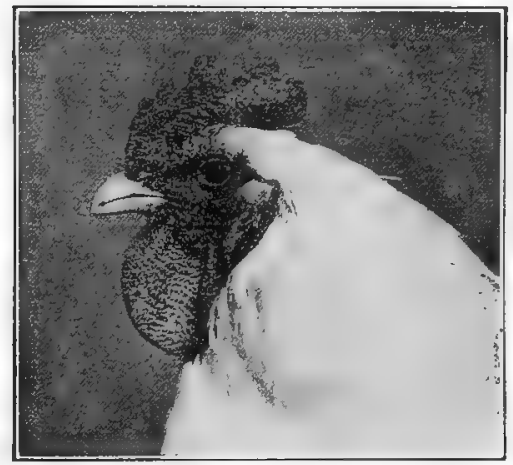

Figure 168.--The points and part of the blade of the comb of this male bird have been frosted.

the frozen parts will shrivel and drop off.

Treatment. Applying snow or cold water to frozen combs before they thaw out will frequently save them. After being thawed by this method, vaseline should be applied to the frozen parts at least once a day for several days.

Diarrhea in hens. Diarrhea, while not a serious affliction, should be checked as soon as possible, as it causes quite a strain on the fowl and interferes with production.

Symptoms. Diarrhea can readily be recognized by the extreme watery condition of the droppings and the 
frequency of operation. It is usually caused by a change in the quality or quantity of feed, excessive green or meat feed, and very hot weather.

Trealment. One of the best cures is to deprive the fowl of all green or meat feeds and wet mash and feed a dry mash and grain feed. A teaspoonful of castor oil or sweet oil with 5 drops of oil of turpentine added will frequently check the trouble.

White diarrhea in chicks. This is probably the most dreaded of chick diseases, it being very contagious and fatal in its results.

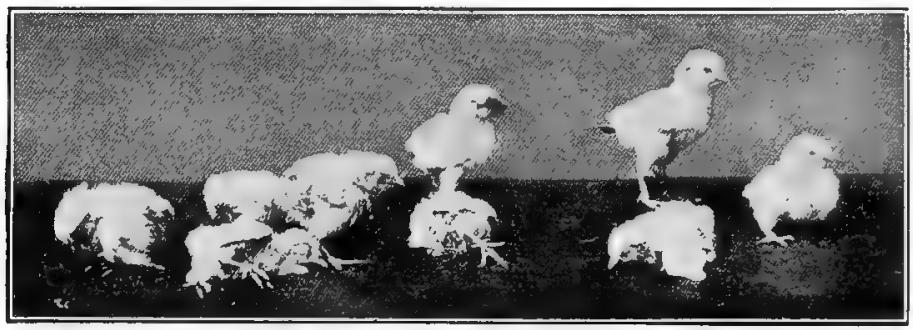

Figure 169.-Chickens with white diarrhea.

Symploms. It can easily be told by the fact that the chicks tend to droop their wings, are sleepy in appearance, show little or no desire to eat, assume almost a ball shape, and the whitish brown droppings adhering to the vent and fluff cause them to become "pasted up."

Prevention. The development of this disease can be prevented to a great extent by selecting strong vigorous breeding stock and putting into practice proper methods of brooding and management of the chicks. For instance, it is seldom that this disease will manifest itself if the chicks are properly brooded and every effort is made to keep them from becoming chilled or too warm or overfed. Once the vitality of the chicks is lowered, it is difficult for them to 
resist this disease or other diseases. As a general means of preventing this trouble, care should be taken to see that purchased eggs used for hatching are from flocks that are free from it.

It has been found that chicks which have white diarrhea but which have recovered from its effects become carriers of this disease. On reaching maturity the disease becomes centralized in the ovary or egg-producing organs and thus the disease is transmitted by the hen through the egg to the chick hatched from the egg. When it is apparent that the disease is present in the flock of hens, it can be eliminated by what is known as the agglutination test. This method has been perfected by the Connecticut Agricultural Experiment Station. The manner of carrying on this test is as follows: *A blood sample is taken from the hen and a numbered band placed on the bird, a corresponding number being placed on the sample. A bacteriological test is then made of this blood sample by a bacteriologist in an effort to find out whether the hen is a carrier of this disease or not. Many agricultural colleges are now in a position to carry on such tests. "The test is practically accurate, though in some cases depending on the stage to which the disease has advanced, the test may not locate an infected bird, but if the test is carried on through several generations the disease can be eliminated." "The birds to be tested should have laid practically a year before the testing takes place; for, if tested sooner than this, they may not react to the test, because the disease will not have progressed sufficiently. Those birds which show that they are carriers of the disease should be eliminated from the breeding pen and eggs for hatching should be saved only from those which do not react to this test."

Trealment. Chickens that have reached the advanced * New Hampshire College Extension Circular 44 by A. W. Richardson. 
stages of this disease should be removed, killed and burned. Ten grains of potassium permanganate or as much as will remain on the surface of a dime should be added to each gallon of drinking water and kept before the chicks until they are at least 4 weeks old.

Intestinal worms. Many chickens are infected with one or more kinds of intestinal worms. It is only, however, when the growing conditions are not favorable, as when the brooders or growing houses are very crowded, that this trouble manifests itself. The worms so infecting chickens are usually from $3 / 8$ of an inch to $4 \frac{1}{2}$ inches in length.

Symptoms. When worms are present, the bird becomes thin and listless, the comb loses its color, turning purple, and the eyes have a staring look. In general, the bird appears unhealthy. Often intestinal worms prove their presence by being found in the droppings.

Prevention. As a general prevention transfer the birds to a range to which fowls have not had access previously. The old range should be well plowed and sown in some crop before allowing the birds to return.

Treatment. The following remedy has proven effective in treating chickens for this trouble. On the basis of 100 birds to be treated, soak 1 pound of finely chopped tobacco stems in water for 2 hours. Mix this liquid with half of the usual amount of mash feed that is usually fed for the day. All feed should be withheld from the fowls so treated for 24 hours previous to the treatment. Two or three hours after feeding this mash mix one fourth of the usual dry mash that is fed during the day with water in which 11 ozs. of epsom salts has been dissolved. It should be remembered that this treatment and the amounts given are on the basis of 100 birds. This treatment, as described, should be repeated 10 days later.

Gapes. This trouble is due to the presence of small 
worms that have attached themselves to the inside of the chicken's windpipe.

Symptoms. The characteristic symptom is the frequent gaping of the bird in its effort to expel the worms.

Treatment. As the gape-worms are usually found on the ground that has been used for some time as a range for poultry, the best remedy is to move the chickens to a new range. The ground so infected should be thoroughly limed and plowed, and not used for young chicks for at least two seasons. As an individual treatment the worms can often-times be removed by inserting a looped horsehair down the windpipe of the chick. After so inserting it, turn it two or three times. When withdrawn it will usually bring out several of the worms. Make sure that the hair is injected in the windpipe and not down the bird's throat. The worms so removed should be shaken from the hair into a receptacle and scalded or burned. Frequently such worms can be removed by adding 15 grains

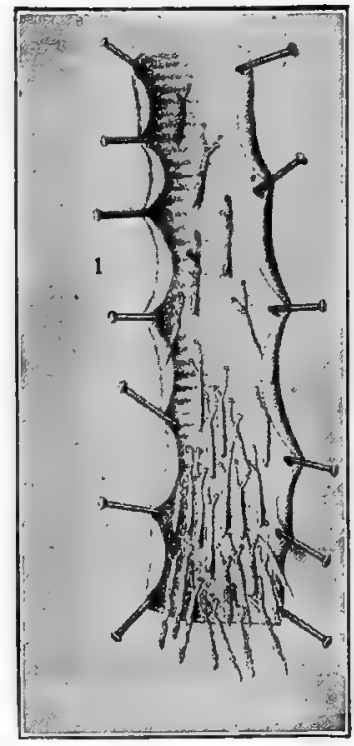

Figure 170.-The windpipe of a chick cut open showing the gape-worms attached of salicylic acid to each quart of drinking water.

Crop bound. This disorder is caused by the crop's becoming overloaded with feed to such an extent that the muscular walls become partially paralyzed and thus unable to work off the accumulated food.

Symptoms. The trouble can be discovered by the fact that the crop is hard, firm, and protrudes noticeably. Again, birds so affected will be frequently noticed trying to move 
the crop from side to side in an effort to cause additional action or movement, so as to expel the contents.

Treatment. Ordinarily this trouble can be overcome by pouring half an ounce of melted lard or sweet oil down the throat and working the crop with the hand so as to

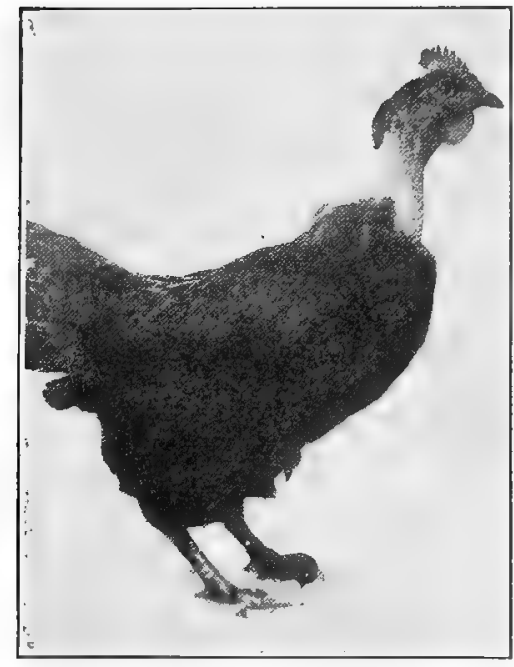

Figure 171.-A result of feather pulling. allow the oil or lard to mix with the feed. The food will then usually pass away in a few hours.

Feather pulling. This habit, most frequently acquired during the molting period or in the spring, is noticeable in that the fowls pick their own feathers and eat them, or the feathers of the other fowls.

Treatment. When it is noticed that birds have contracted this habit, they should be given additional exercise by scattering their grain in deep litter. Likewise plenty of exereise by giving them increased range, if possible, together with the addition of plenty of green feed and animal feed such as meat scrap, fish scrap or milk, will help to overcome this trouble. A piece of salt pork hung in the house where the fowls can pick at it will frequently counteract the trouble. When this habit is limited to a few birds, they should be removed from the flock.

Toe picking. This trouble may likewise be called a habit and is usually found in young chickens that are closely confined. 
Treatment. An additional quantity of meat scrap mixed with the dry mash, green feed and range will frequently overcome this trouble. The brooder should also be slightly darkened when this habit is present.

Egg eating. This habit, when once contracted by a fowl is difficult to correct. It is usually caused by the hen's stepping on a thin-shelled egg and breaking it, after which it is eaten.

Trealment. Provide plenty of oyster shells as a preventive to insure the production of eggs with normal shells, which are less easily broken. Darkening the nest tends to discourage the habit. Increasing the amount of beef scrap in the mash also tends to break it. Free range also helps to overcome this unnatural habit.

Rheumatism. Fortu-

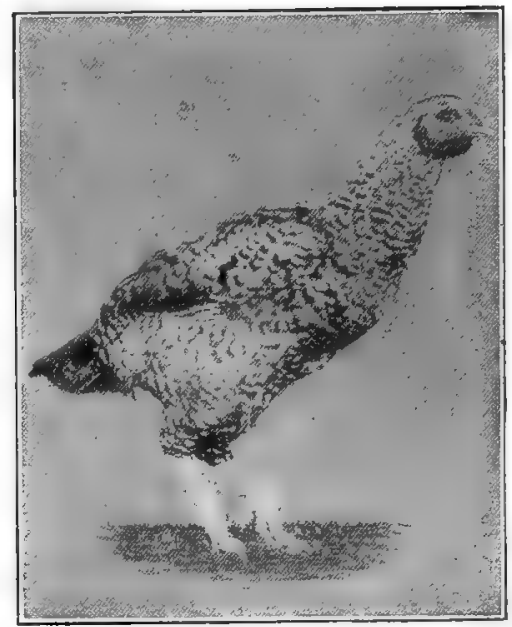

Figure 172.-A fowl afflicted with rheumatism. nately this affliction is not commonly found in fowls.

Symptoms. The disease is usually characterized by lameness or stiffness of the joints and is usually caused by continued exposure to cold or dampness.

Treatment. The most effective treatment for this disease is to see that the houses are well ventilated and dry. Fowls so affected will usually respond to treatment when kept dry and warm and when supplied with a good ration supplemented with green feed.

Scaly leg. This diseased condition is most frequently 


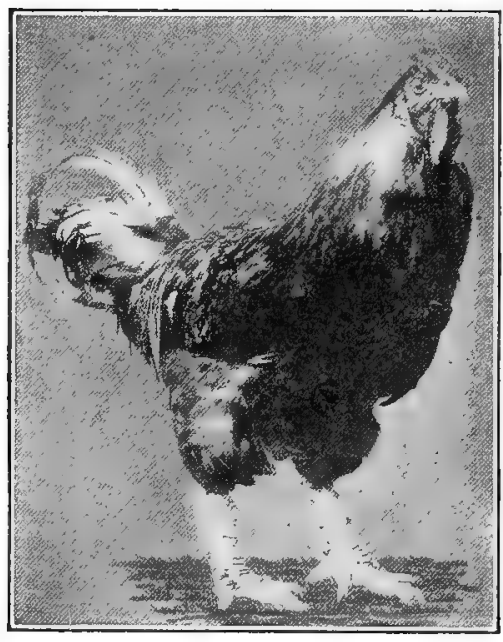

Figure 172,-A male bird affected with scaly leg.

found among older fowls and is caused by small mites that burrow under the scales of the shanks and the feet, and there multiply in number.

Symptoms. The disease is easily recognized by the enlarged condition and rough appearance of the feet and legs.

Treatment. Wash the bird's legs well with soap and warm water, removing all the loose scales. Rub well with a mixture of equal parts of kerosene and linseed oil. Vaseline may be substituted for the linseed oil. Pure kerosene applied to the fowl's legs and feet has likewise been found to be an effective remedy. When kerosene is applied care should be taken that none of the kerosene comes in contact with the feathers or skin of the fowl.

Bumble foot. Bumble foot is caused by bruises formed on the bottom of the fect, usually caused by the fowl's jumping from high roosts to the hard floor.

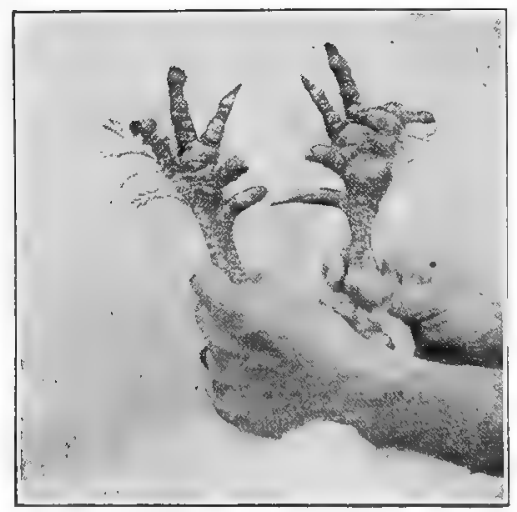

Figure 174.-A case of bumble foot. 
Symptoms. In this condition the fowl is likely to walk with seeming difficulty or limp.

Treatment. To remove the cause lower the roosts or provide plenty of litter on the floor. When the foot is badly swollen, a small cut should be made with a clcan sharp knife and the pus removed. Wash the wound out with equal parts of hydrogen peroxide and water. Grease with vaseline and bandage with a strip of cloth.

\section{QUESTIONS}

1. What general preventives should be practiced in order to prevent poultry diseases?

2. Describe the symptoms for roup, together with an effective treatment. Why is it so necessary to remove fowls that are affected with such a disease as cholera, chicken pox, favus, roup, etc., from the flock?

3. Deseribe the method of treating chicken pox.

4. What prevention and treatment should be practiced for white diarrhea in chickens?

5. Describe a method for treating chickens with gapes.

6. How can feather pulling be overcome in a flock?

7. Describe the method of treating fowls for scaly leg.

8. What is usually the cause of rheumatism in poultry?

9. Describe the cause and treatment for bumble foot.

10. Describe the method of preparing a good internal antiseptic that may be used in the drinking water to prevent such contagious diseases as roup, white diarrhea, and cholera.

\section{SUGGESTIONS}

1. Form the habit of carefully observing the growing stock as well as the producers at all times and remove immediately all birds that appear to be listless or not inclined to be as active as the rest of the flock. This practice is very important and can not be emphasized too greatly.

2. Keep in mind at all times that it is ordinarily not practical to attempt to treat individual fowls that are sick. Such fowls, even though they recover, ordinarily do not produce such results as will pay for their feed, and under no circumstances should they be used in the breeding pen.

3. Should a disease or infection break out in your flock or those of your neighbor's and you are unable to determine the nature or cause of it, send a fowl or two so affected to your state college of agriculture for diagnosis.

\section{REFERENCES}

Diseases of Poultry, by Pearl, Surface, Curtiss.

Important Poultry Diseases, U. S. Department of Agriculture, Farmers' Bulletin 957 , by D. E. Salmon. 


\section{CHAPTER X \\ POULTRY PESTS}

The presence of mites and lice on poultry has a very marked effect on the number of chickens raised and the number of eggs produced by the laying hens. Thousands of chickens die every spring and summer as the result of lice and in most cases such a loss could have been prevented. It is a familiar sight, that of the hen wallowing in a hole of dust, scratching, and fluttering her feathers in an effort to get rid of these insect pests. It is possible and thoroughly practical to keep the poultry flock reasonably free from lice and mites. Such a practice should be the aim of every one who is endeavoring to establish a successful flock of poultry.

\section{MITES}

Chicken mites, or, as they are sometimes called, "gray," or "red," mites are very small and gray in color. After they have been on the fowl, however, and filled themselves with blood they become reddish in appearance. Hence they are sometimes called "red" mites and at other times, when they are hungry, again "gray" mites.

In the daytime mites usually stay in the cracks of the hen houses and under the roosts, where they lay their eggs. At night, when the fowls go to roost, the mites come out of their hiding places, attach themselves to the fowls and feed by sucking blood from the birds. This annoyance causes the fowls to become very uncomfortable and consequently they do not thrive as they should.

Remedy. Knowing the habits and hiding places of mites, an effort should be made to get rid of them. The chicken house, nests, and dropping board should be thoroughly cleaned and sprayed. Especial attention should 
be given to spraying the under side of the dropping boards and roosts, especially where the roost joins the support (See Figure 176.), as these are favorite hiding places for mites. The poultry house that is kept clean and has plenty of sunlight and ventilation is usually free from mites. A very good way to eradicate this pest is to spray the inside of the house or to whitewash it.

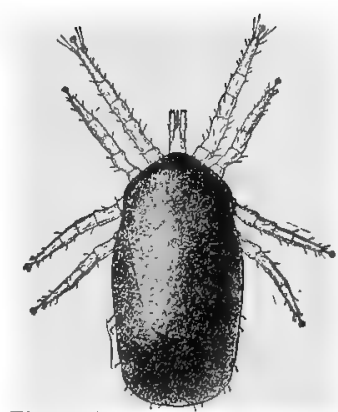

Figure 175.-A female chicken mite after feeding. Greatly enlarged.

Whitewash. An effective whitewash that has been used for this purpose is made as follows: Slake half a peck of lime and dilute it with 20 gallons of water. Add 1 pound of salt previously dissolved in water. To this mixture add 2 quarts of crude carbolic acid or 1 gallon of stock dip and apply with a spray pump or brush.

$A$ good spray. Another very effective method that can be used to kill mites is to spray the roosts, nests, and all cracks or crevices with kerosene, crude oil, or some wood preservative manufactured from coal tar, such as creolin, creosote, etc.

If possible, the spraying should be done with crude oil

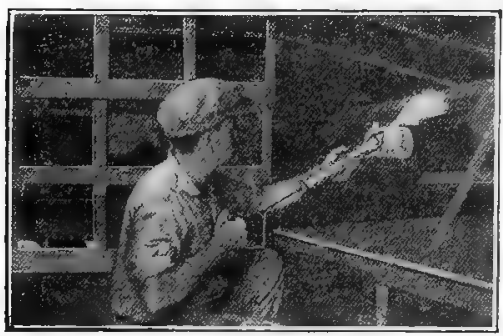

Figure 176.-A small hand pump may be used for spraying the inside of the house. or wood preservative rather than kerosene, inasmuch as it is necessary, when kerosene is used, to continue to spray every 10 days or 2 weeks throughout the warm weather, once the mites have gotten started. The effect of crude oil or a coal-tar product is 


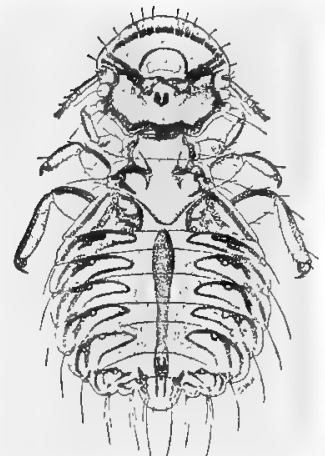

Figure 177,-A İrge common hen louse. Greatly enlarged.

much more lasting. The time to use either of these methods is early in the spring before the mites have a chance to increase in number and annoy the fowls. Should mites appear later in the summer, the spraying should be repeated.

\section{LICE}

The common chicken louse is larger than a mite and is pale yellow in color. It differs from the mite also in that it spends most of its time on the body of the fowl, although sometimes it is found in the nests. The louse lays its eggs at the base of the fluffy feathers on the fowl, especially around the vent. From 6 to 10 days are required for these eggs to hatch.

Lice do not suck the blood from the fowls as do the mites, but annoy the birds by feeding on scales and secretions of the skin, and parts of the feathers.

Remedy. Owing to the fact that lice spend the greater part of their time on the fowls the most effective treatment is that which is applied directly to the birds. The cleanliness of the hen house is equally as

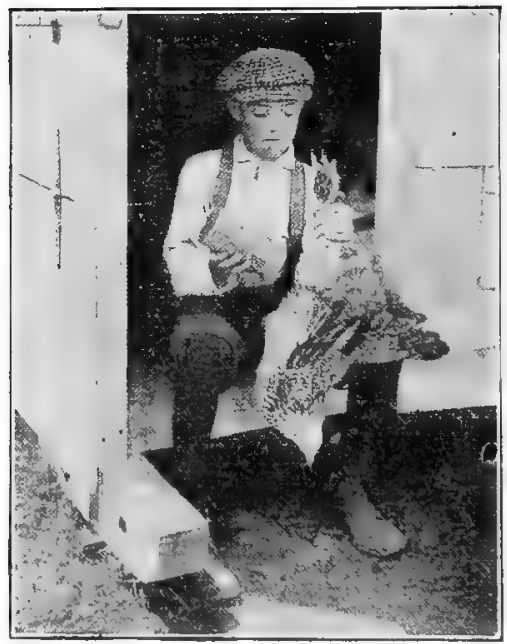

Figure 178.-Dusting forls by hand is especially recommended for sitting hens and fowls that are very much infested with lice. 
important, however, if lice are to be gotten rid of entirely. The two most practical methods of fighting lice are dusting and using a paste or an ointment.

Dusting. Dusting can be done in two ways:

1. Providing a good dust box as described on page 150 , containing a mixture of road dust and wood ashes, and allowing the hens to dust themselves.

2. Applying dust directly to the fowls.

When applying the dust or lice powder directly it should be worked well into the feathers with the hand, especially around the vent and under the wings. Fowls dusted in this manner should be treatedasecond time in about a week or ten days. A good homemade lice powder can be made as follows: Mix $11 / 2$ pints of gasoline and half a pint of crude carbolic acid. Stir this mixture thoroughly into

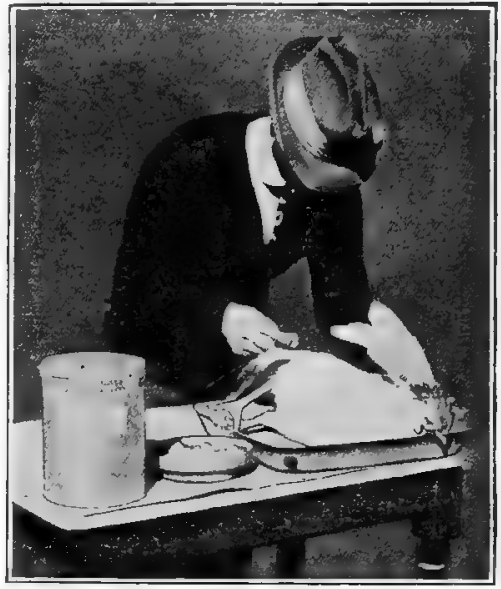

Figure 179.-Applying sodium fluoride to a fowl.

4 quarts of plaster of Paris and land plaster. Allow it to dry and apply as suggested above It has recently been found that sodium fluoride is very effective in getting rid of lice on fowls. Sodium fluoride comes in powdered form and can be purchased at most drug stores.

Inasmuch as a little of this powder goes a long way in accomplishing results, a pound is sufficient to treat a large number of fowls. The method of applying sodium fluoride is by taking a small pinch between the fingers and placing 
it down near the base of the feathers, below the vent, at the base of the tail, under the wings, around the breast, and in the back of the neck. Care should be taken not to inhale the sodium fluoride powder, as it irritates the nose and throat. A damp handkerchief tied over the nose and mouth can be used by those applying the powder.

Ointment. One of the most effective ointments used to destroy lice on fowls is commerical blue ointment or mercurial ointment. When the latter is used it should be thoroughly mixed with an equal part of vaseline or lard.

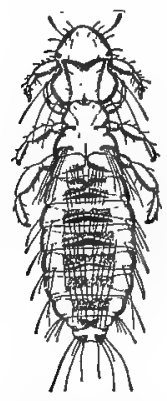

Figure 180,-A head louse greatly enlarged, such as is found on chickens. Commercial blue ointment may be used undiluted. When using either of these apply a small portion (a piece about the size of a pea) with the fingers around the vent of the fowl, but not on the body or under the wings. Care should also be taken to see that none of the ointment gets into the vent, as it is injurious.

\section{HEAD LICE ON CHICKS}

Very frequently chicks that are hatched by a hen that is infested with lice likewise become infested and frequently die when they are not properly treated.

Remedy. Head lice may be prevented or exterminated by one or more of the following methods.

Ointment. As a treatment for lice on chickens a small portion of lard or vaseline should be applied to the top of the head, under the wings, and around the vent. As previously suggested in the chapter on brooding, care should be taken not to get too much grease on the chickens, as it may prove fatal.

Dusting. As a preventive it is suggested that steps be taken to keep the chickens free from lice by dusting the mother hen thoroughly before the chicks are hatched and at intervals of a week or ten days after the chicks are hatched. 
The use of sodium fluoride as described herein will be found most effective for sitting hens.

Sprays. Either of the sprays previously mentioned on page 177 or the whitewash recommended to prevent the spread of lice will also help to keep down lice when applied to the poultry house.

\section{"STICK-TIGHT" FLEAS}

In many of the southern states fowls and chicks are often infested with what are commonly called "stick-tight" fleas. They are so named owing to their habit of sticking to one place on a fowl instead of moving about as lice do.

Usually they are found in groups or clusters on the comb, wattles, and around the eyes. Chicks, when infested with this species of flea, often die very quickly. Hens, however, being stronger, will usually stop laying, but not infrequently die when infested for any length of time. The most common breeding places of these fleas, as of mites, are in

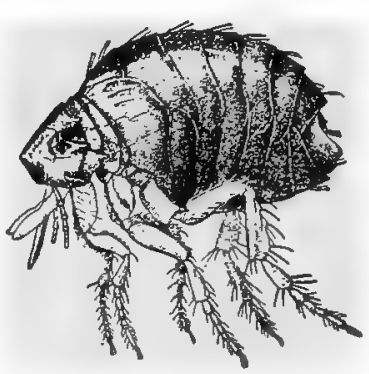

Figure 181 - Stick-tight flea. Adult female. (Much enlarged.) the cracks and crevices of the brood coops and poultry houses and also in dry matter and vegetable refuse.

Remedy. The most satisfactory method of exterminating these pests is to clean and spray the house and equipment thoroughly in addition to treating the birds.

Spray. The same spray recommended under the head of mites may be used effectively.

Ointment. To treat the birds individually, grease the comb and wattles with a preparation of 1 part of kerosene and 3 parts of lard, care being taken not to get too much of the mixture on the body or in their eyes. It is well also, when stickstight fleas are prevalent, to spray the yards and 
runs, especially an earth floor in the poultry house or the ground beneath the poultry house, when the floor is raised above the ground, with a solution of salt and water. This keeps the ground moist and prevents the fleas from breeding.

POULTRY TICKS, OR BLUE BUGS

These insect pests are likewise common in some of the southwestern and southern states and are extremely harmful to poultry and pigeons. The habits of these insects are much the same as those of red, or gray mites, as the adult insect feeds on the body of the birds at night and during
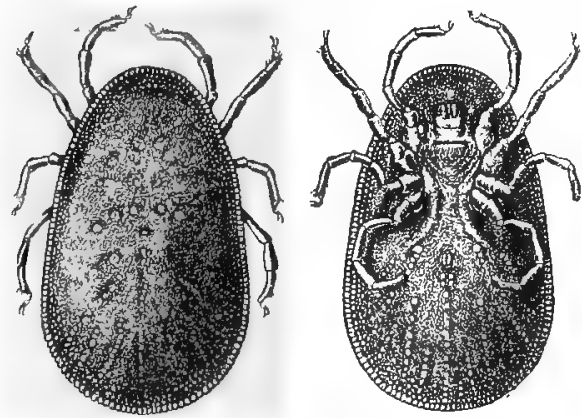

Figure 182.-Blue Bug. the day hides in the cracks and crevices of the house.

The eggs of the blue bug are laid in the cracks and crevices of the poultry house and after hatching the young bugs crawl out and attach themselves to the fowl where they remain until they become full of blood. They then drop off and develop to adult size, after which they attack the fowls only at night, spending the day in the cracks and other hiding places about the house. "Blue bugs" are about the size of a bed bug and are much more harmful and more difficult to kill than either lice or mites.

Remedy. Various means may be employed in the extermination of this pest.

Change of quarters. When the poultry house or coops become infested, move the birds to other quarters for a week or ten days. During this period the young bugs on the birds become filled with blood and fall off. The fowls should then be returned to their former house. 
Spray. Meantime the poultry house should be thoroughly cleaned by removing all nests, nesting material, roosts and other interior fixtures and spraying thoroughly with crude petroleum, kerosene, or one of the coal-tar products.

Scalding. Equipment, such as brood coops and shipping crates, when infested, can be treated by scalding thoroughly with boiling water. When there is every indication that the blue bugs have been eradicated, the birds may be returned to the house.

CHIGGERS (RED BUGSOR HARVEST MITES)

Chiggers are found and are quite troublesome in the southern and likewise the central western states. The chigger, or red bug, before it develops to the adult stage, is microscopic in size, red in color, and has six legs. After developing, or reaching the adult size, they become larger and visible to the eye, although still very small in size. Chiggers breed in tall grass and are particularly abundant in low marshy land.

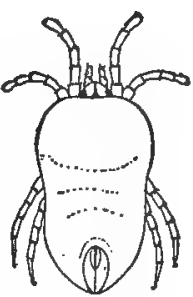

Figure 183. - Adult chigger, or "red bug." Greatly enlarged. (From Banks.)

They attack the fowls and the chicks while they are on range, biting and penetrating the skin, usually under the wings, on the breast and neck, causing annoyance and itching. Soon after the chiggers penetrate the skin, an abscess is formed and becomes inflamed. The presence of these mites, especially on chickens, results in the birds' becoming weak, with little disposition to eat, and they finally die from hunger.

Remedy. The remedy is either one of prevention or application.

Keep the grass down. The most satisfactory method of exterminating chiggers is by keeping the grass cut or grazed short on ground where the fowls range.

Ointment. To treat the birds individually, apply 
sulphur ointment or a mixture of 1 part of kerosene to 3 parts of melted lard to portions of the skin of the fowl where the chiggers have entered. When pus has formed in the sore, remove the scab and wash it with a $4 \%$ solution of carbolic acid and water.

\section{QUESTIONS}

1. Why should every measure be taken to keep the fowls and chicks free from insect pests?

2. Describe the appearance of chicken mites, both before and after they have fed from the body of the fowl. What are the habits of the chicken mite?

3. Describe two effective remedies to eradicate chicken mites.

4. How does the common chicken louse differ from the chicken mite, both in appearance and habits? be applied?

5. Describe a good homemade louse powder. How should this

6. Describe a method of treating individual birds with sodium fluoride. With blue ointment.

7. Describe an effective treatment for head lice on chickens.

8. Describe the habits and treatment of stick-tight fleas.

9. What measures should be taken to exterminate blue bugs from the poultry houses and buildings?

10. Where are chiggers, or red bugs, found, and how can they be prevented?

\section{SUGGESTIONS}

1. As discussed in the chapter on incubation, one of the most effective ways to prevent the loss of chickens as the result of lice and mites is by hatching early in the spring, so that the chickens will grow to be of good size before the warm weather, when the lice and mites are so troublesome.

2. As a matter of good management, endeavor to put into practice the suggestions as contained in this chapter, in order to exterminate such insect pests as may be troubling your flock.

3. Should you be a member of a poultry club or an association, endeavor to interest the members as to the importance of eliminating lice and mites from the flock. Such an effort on your part may result in the saving of hundreds of birds.

4. Impress upon your acquaintances and members of your poultry club the reason and advantages of spraying for lice and mites in the early spring before these insects have a chance to increase in number.

5. Should you find any of the insect pests mentioned herein troubling your flock, try each of the remedies mentioned under each insect pest, and see which is the most satisfactory. Do you not think it would be a good idea to acquaint your friends and club members with the results of your experience in this connection?

\section{REFERENCES}

Mites and Lice on Poultry, U. S. Department of Agriculture Farmers' Bulletin 801, by F. C. Bishop and H. P. Wood. 


\section{CHAPTER XI}

\section{CAPONS AND CAPONIZING}

What is a capon? The word capon is the name applied to the unsexed male chicken and caponizing is the process of unsexing by the removal of the testicles. A true capon is quite different from a cock or cockerel both in his disposition and appearance. In disposition he is quiet and docile, shows no disposition to fight, is easy to confine, and seldom if ever crows. The comb and wattles develop little or not at all, making the head appear small and feminine.

The purpose of caponizing. Cockerels are caponized for two reasons, first, to secure an increased growth and a better quality of flesh, and, second, to secure a higher price that is paid for capons as compared with cockerels and cocks. The flesh of a cockerel as it matures becomes tough and stringy, while the flesh of the capon retains the softness and tenderness of young birds and is, therefore, more desirable

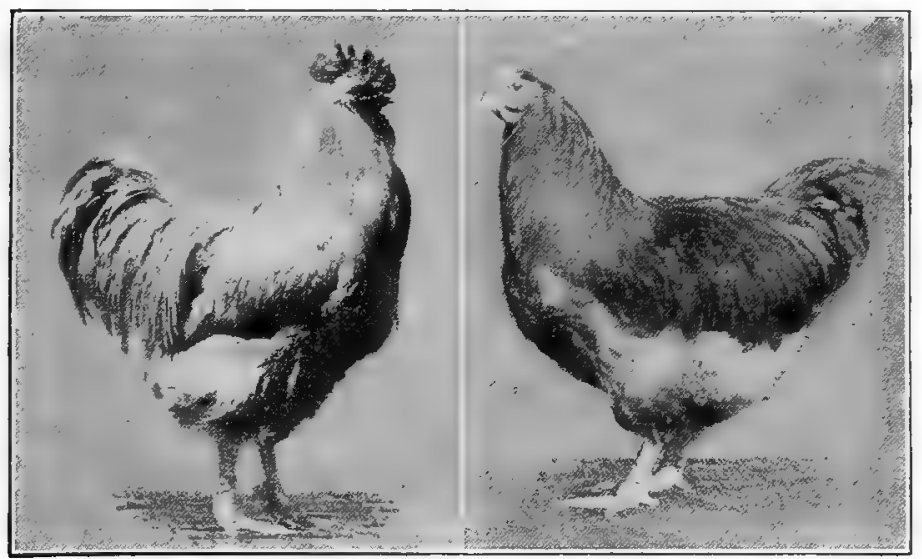

Figure 184.-A Buff Orpington cock. Figure 185.-A Buff Orpington capon. 
as a table fowl. For this reason the price received for capons is usually greater than that received for cocks. The capon continues to grow longer than a cockerel and fattens more readily, consequently reaching a larger size.

The advisability of caponizing. The production of capons for market is a specialized branch of the poultry industry. The center of this industry will be found principally in the East in the states of Massachusetts, New Jersey, and eastern Pennsylvania, where capons are produced for the markets of the larger eastern cities. "Soft roasters" which have been for years produced in large numbers on the south shore of Massachusetts are in most instances capons, the males being caponized so they will attain an increased size and have a superior quality of flesh. The advisability of caponizing surplus cockerels rather than to sell them as broilers depends largely upon local market conditions. That is, the local or near-by markets should show a demand for capons and the price paid should be such as to make the venture profitable. In any event it is more profitable to caponize the cockerels than to keep them without caponizing and allow them to develop into cocks, as these bring a lower price than any class of market poultry. If, therefore, conditions are not favorable for the production of capons, the surplus cockerels should be marketed as broilers. When possible, a few cockerels should be caponized for home use in the winter. It is not generally advisable to raise capons on a limited range or where they have to be fed all that they require to eat. As the object of caponizing is to produce flesh, the capon's appetite and desire for feed is greater than that of other fowls. It is, therefore, advisable that they be given plenty of range, when possible, so that they can forage for part of their feed and thereby help to reduce the cost of production. Other conditions being favorable, the general farm is an ideal place for the production of capons. 
Most suitable breeds for capons. Owing to the fact that large capons bring the best prices, it does not pay to caponize males of the smaller breeds, such as the Leghorn. Breeds with yellow legs and skin, such as the Plymouth Rock, Cornish, Brahma, Langshan, and Wyandotte, as in other classes of table poultry, are the most desirable for this purpose. Of these the Light Brahma and Barred Plymouth Rock and other American breeds are most generally used.

Time to caponize. Cockerels should be caponized when they weigh from $1 \frac{1}{2}$ to 3 pounds, or when they are from 2 to 4 months old. The general-purpose breeds can be caponized when a pound and a half in weight or when 2 months old, while cockerels of the meat breeds should be about 3 or 4 months old or about 3 pounds in weight.

Ordinarily cockerels should

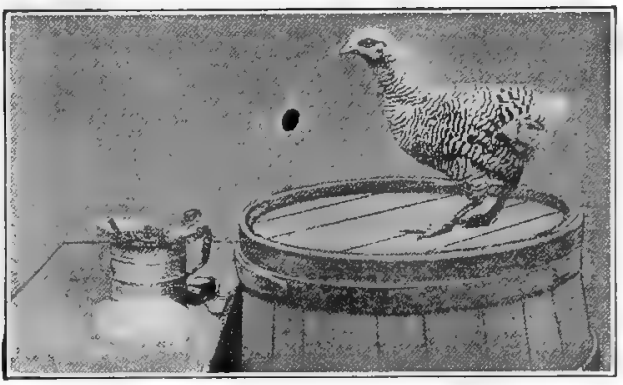

Figure 186.-Barred Plymouth Rock cockerel of suitable size to caponize.

not be caponized when larger or older than just stated, as there is considerable danger in losing the birds by pricking the arteries which lie near the testicles and thereby causing them to bleed to death. Capons are in the greatest demand beginning with the Thanksgiving season and until the end of March. Considering this fact and remembering that it takes about ten months to produce a well-finished capon, it will be evident that it is important to hatch early in the spring in order to have cockerels of suitable size to caponize in June and July.

Preliminary requirements. Cockerels that are to be 
caponized must be confined and deprived of all feed and water for 24 to 36 hours prior to the operation, in order that the intestines will be empty and enable the operator to locate and remove the testicles easily. Depriving the cockerels of water before the operation lessens the blood flow when the incision is made.

Caponizing instruments. To perform this operation successfully, a set of special caponizing instruments is nec-

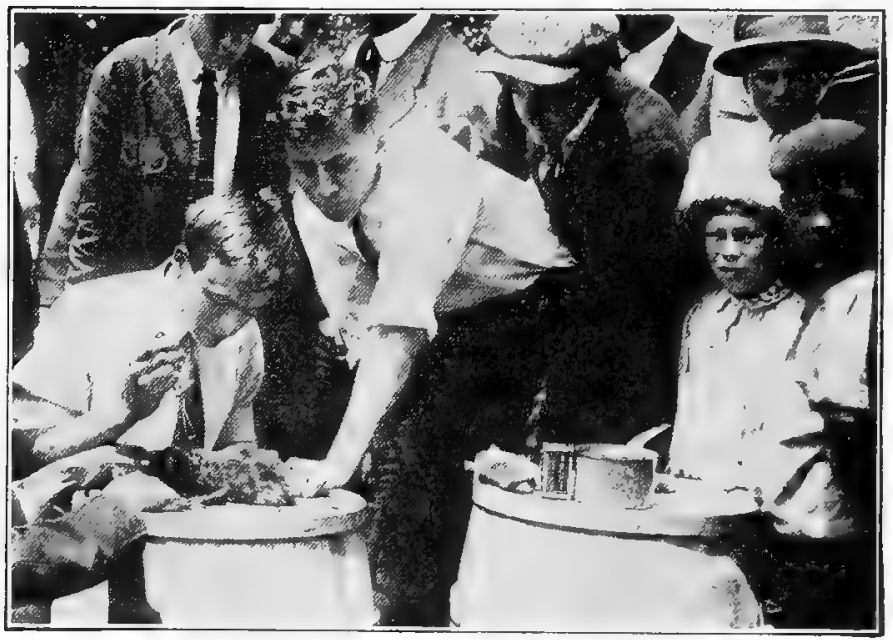

Figure 187.-Members of a poultry club caponizing a cockerel.

essary and can be bought from practically any poultry supply house.

The necessary instruments are a sharp-pointed knife to make the incision, (Figure 188c), a spreader, used to spread the ribs apart (Figure 188d and e), a sharp-pointed hook to tear the membrane beneath the skin (Figure 188h), and the testicle remover of which there are six different types, (Figure $188 \mathrm{a}, \mathrm{b}, \mathrm{i}, \mathrm{k}, \mathrm{l}$, and $\mathrm{m}$ ). Of these instruments either 
$\mathrm{i}, \mathrm{l}$, or $\mathrm{m}$ are the most practical. A probe such as shown (Figure 188g) may likewise be used to push the intestines aside as well as a small pair of tweezers (Figure 188f) which may be used in removing any foreign matter from the body. The operation. The instruments, together with a pan

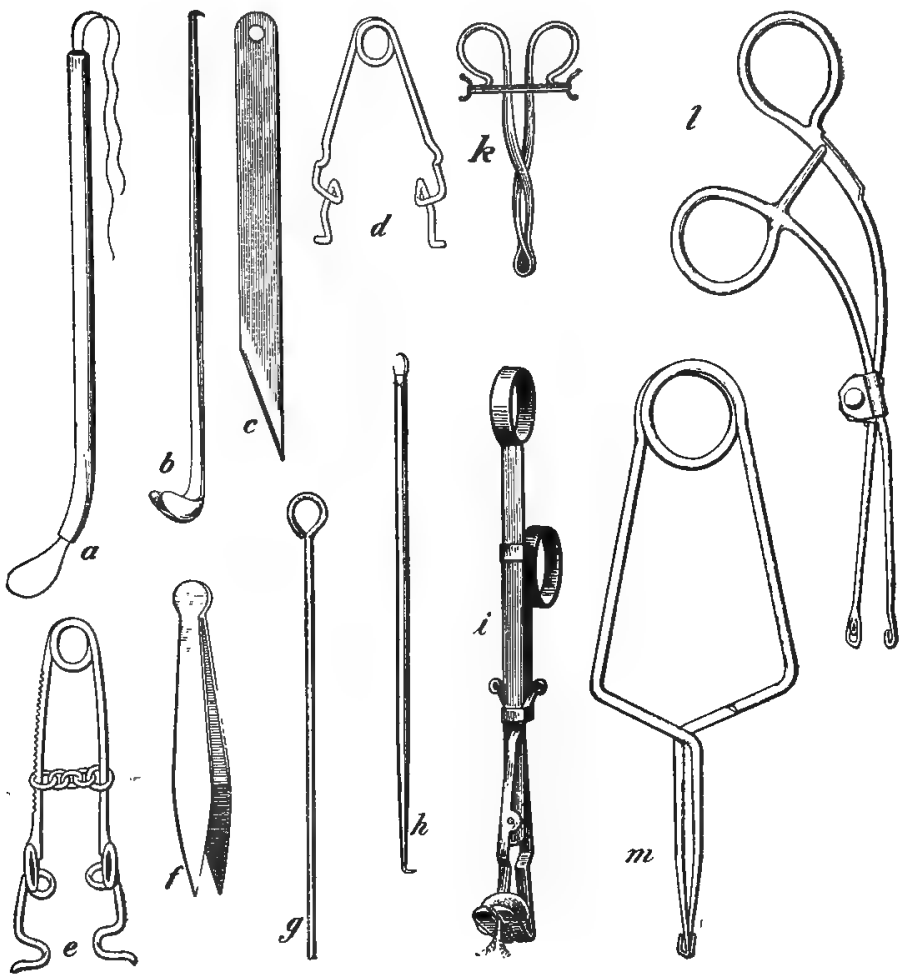

Figure 188.-Instruments used in caponizing.

of water and a sponge, should be placed on a box adjacent to a barrel or table where the operation is to be performed. The bird is then placed on its side on the head of a barrel or on a table of convenient height and held stretched out 


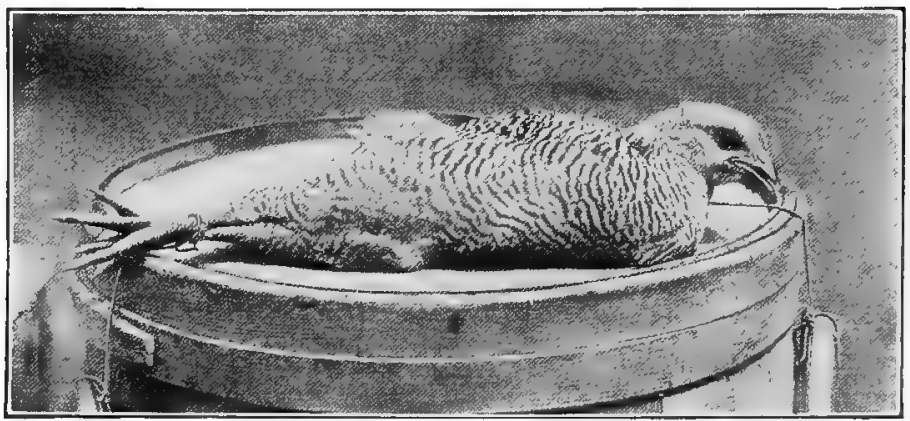

Figure 189.- Method of holding the cockerel in position for the operation.

by means of a cord passed under both wings and another cord around both legs, each being weighted down with weights sufficient to hold the bird in place comfortably. The operation should be performed out of doors, preferably in the sunlight or else artificial light may be used by reflecting it into the body cavity, so that the testicle can be seen and removed.

Moisten and remove the feathers around and over the last two ribs which can be felt just in front of the thigh.

Before making the cut, pull the skin down toward the thigh. While holding the skin in this position make the

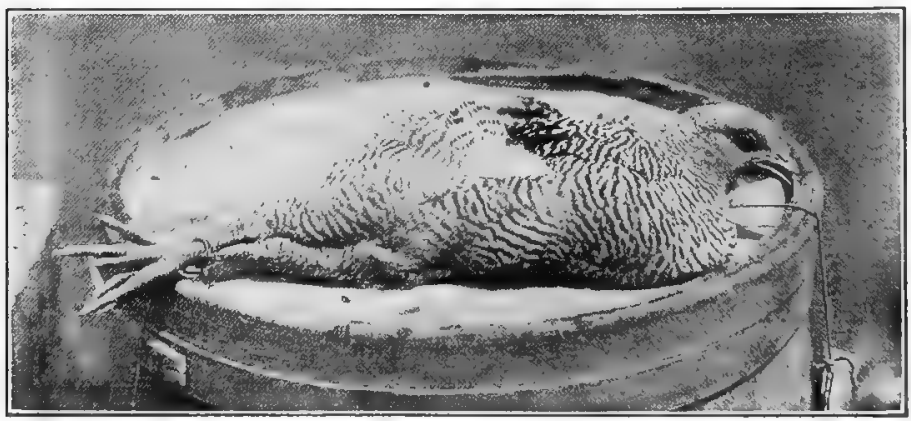

Figure 190.-Feathers removed to make ready for the incision. 


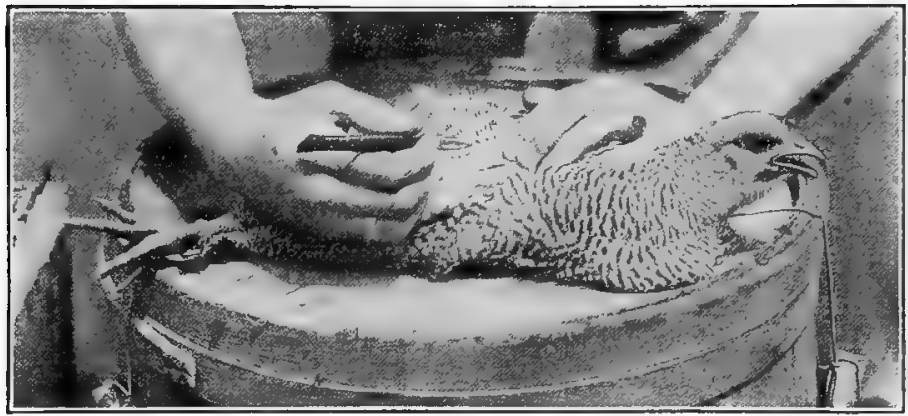

Figure 191.-Making the incison.

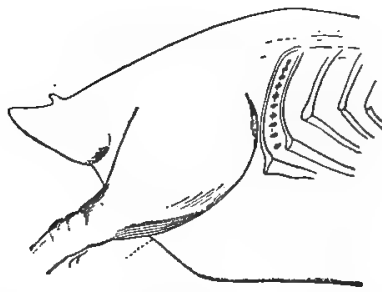

Figure 192,-Diagram showing where incision should be made between last two ribs.

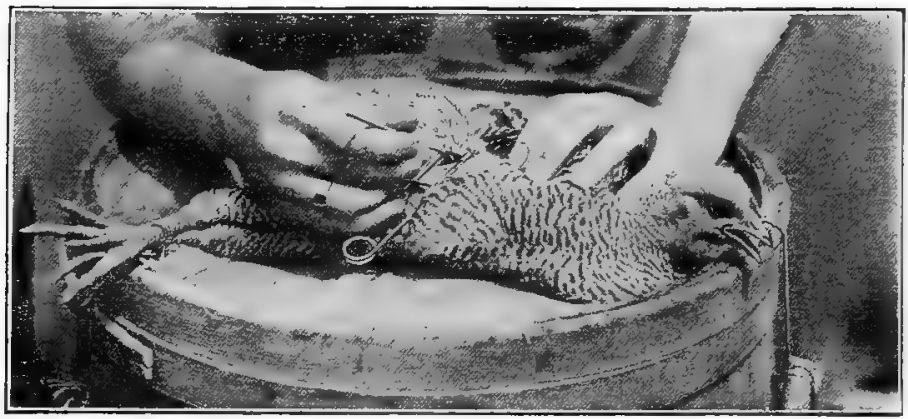

Figure 193.-The spreader in place and the membrane belng torn with a sharp pointed hock. 


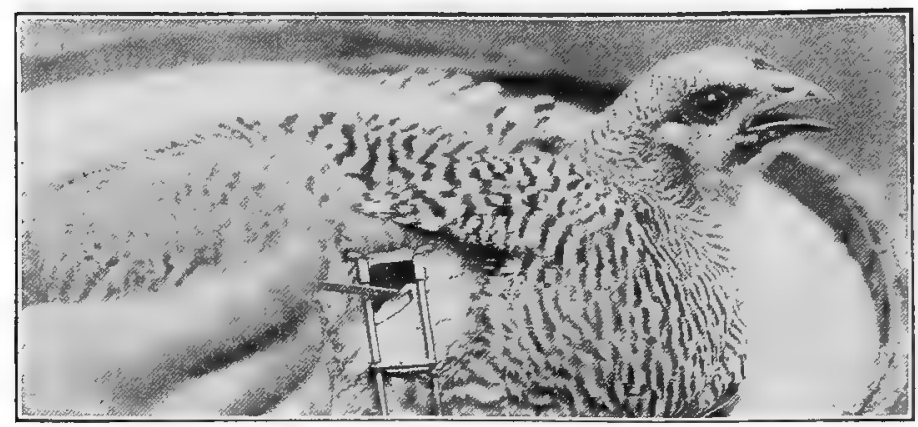

Figure 194.-The spreader in place. One testicle can be seen lying between the jaws of the spreader.

incision between the last two ribs. Then when the operation is over and the bird is released, the skin slips back over the wound and closes it. (See Figure 196.)

Insert the spreader (Figure 1881 or $\mathrm{d}$ ) and enlarge the cut so as to allow the introduction of the testicle remover (Figure $188 \mathrm{i}, \mathrm{l}$ or $\mathrm{m}$ ) but do not cut too close to the backbone, as to do so might cause considerable bleeding.

After the incision is made and the spreader inserted, a thin membrane will be observed covering the intestines.

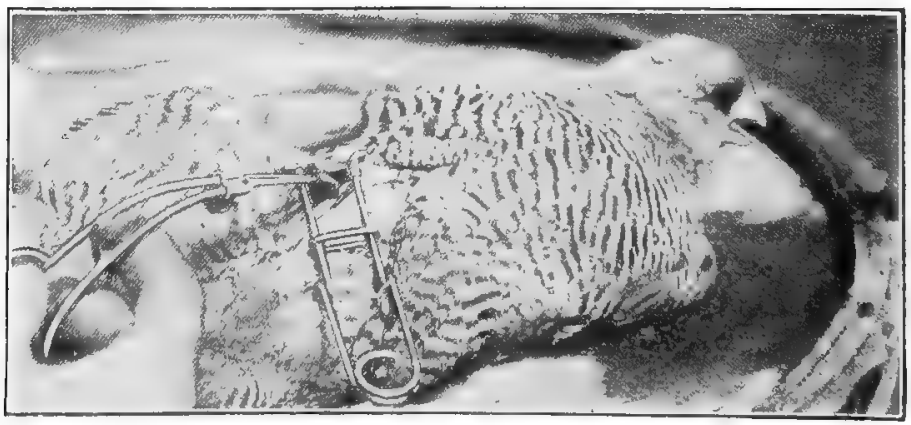

Figure 195.-Removing the testiole. 
This must be torn with a sharp pointed hook (Figure 188h). The intestines will now be seen and, when pushed aside with the probe, (Figure 188g) two small cream-colored or sometimes dark-colored testicles will be observed, one on each side and close to the backbone.

These should now be removed with the testicle remover and, if possible, the lower one should be removed first. Those not experienced in caponizing often find it difficult to locate the lower testicle. When such is the case the upper

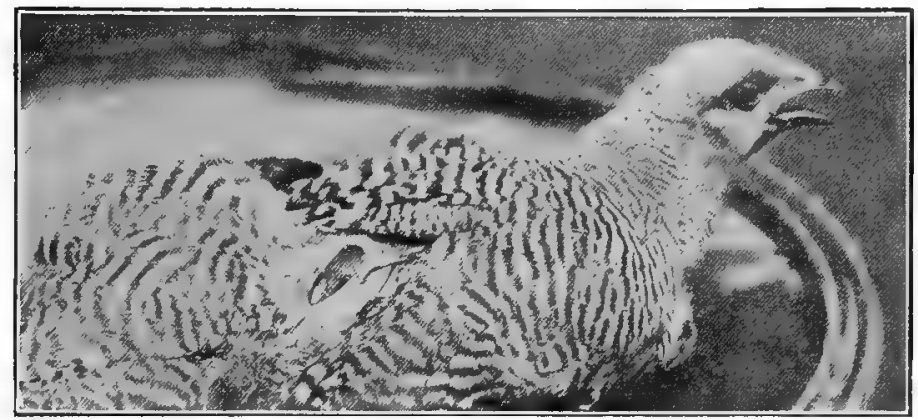

Figure 196.-After the spreader is removed and the weights taken off the wings, it will be noticed that the skin slips back over the incision so as to close it.

one can be removed, the bird turned over and the other testicle removed by repeating the operation on the other side of the fowl. Practice, however, should make this second operation unnecessary.

Care must be taken when removing the testicle so as not to break or rupture the arteries which lie close to them. Should they be cut, the bird will bleed to death within a few minutes. Such birds that may be killed during the operation are suitable for eating and are not, therefore, a loss. Observe closely and be sure that the entire testicle is removed. If even a small portion is left, the bird will not develop into a true capon but will look like a cockerel 
instead and can not be sold at capon prices. Such a bird is known as a "slip." In order to become perfectly familiar with the location of the testicles and the procedure as described herein, it is advisable for the beginner to practice this operation on a dead cockerel or one that is intended to be killed. Thus the place to make the incision, the location of the testicles, etc., can be definitely learned and confidence secured. While the operation is not a difficult one, practice is necessary to enable one to caponize quickly. Even expert caponizers make mistakes and some birds will be lost, but this loss should not be more than two or three per cent of the number operated on.

Care after the operation. Caponizing apparently does not inconvenience or hurt the birds at all. From appearances it would seem that the first step in the operation, namely the removal of the feathers, is the most painful and this can be lessened to a great extent by soaking the feathers over the ribs with water before they are removed. After the capons are released from the operating table they should be confined to a yard or pen by themselves where they can be kept quiet for several days. Remove all roosts from their house for the first two weeks after the operation, as the less jumping or flying they do, the sooner the wound will heal. Capons may be fed as usual, but, if preferred, a wet mash composed of equal parts of corn meal, bran, middlings, and $10 \%$ beef scrap can be given for a day or two after the operation. During the first week or ten days the capons should be carefully observed to see whether or not "wind puffs" have formed. This condition is caused by air gathering under and puffing out the skin near the wound. To relieve this trouble make a small cut in the skin with the point of a knife and press out the air.

Feeding capons. In addition to such feeding as the birds pick up on range, they should be fed a grain ration, 
such as is fed the rest of the flock each morning and evening until about two weeks before it is desired to market them. They should then be given a fattening ration, as discussed on page 293. During the process of fattening they can be fed either in a small pen or by confining them in feeding coops or crates.

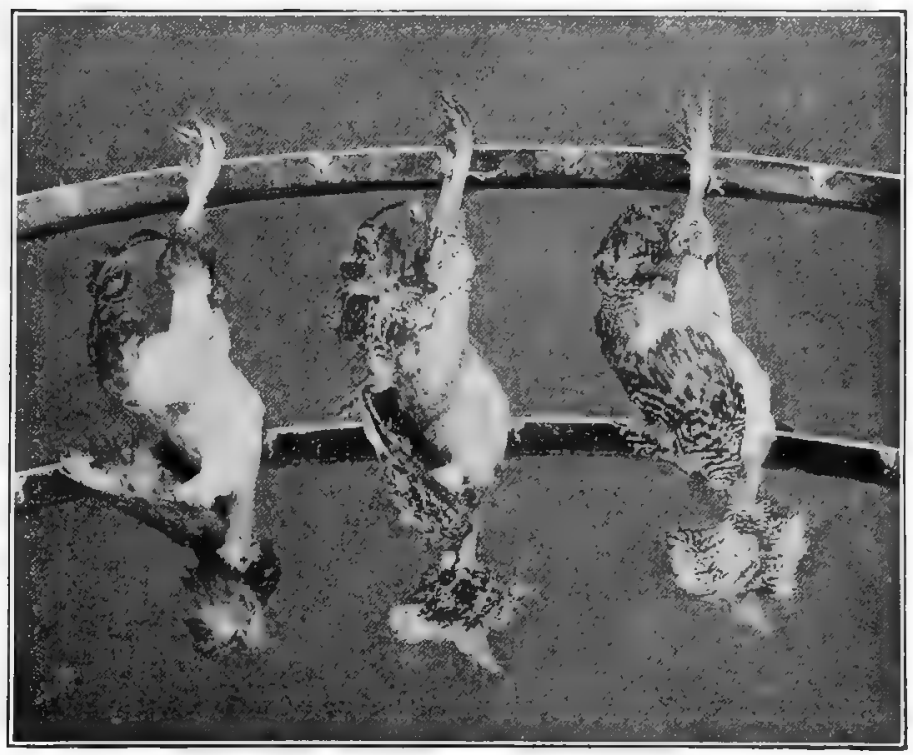

Figure 197.-Capons dressed for market.

Killing and dressing. In killing capons, the method as described on page 297 should be followed. Capons should always be dry-picked. Do not, however, pick the feathers off the neck and head, the tail feathers, those at the base of the tail, the feathers of the last two joints of the wing, and those on the lower part of the leg. These feathers, together with the true capon head, are the characteristic signs by which the capon is known. 
Cutting off the head in killing the capon or picking the feathers clean is likely to result in not securing capon prices for the fowls. After picking, the capons should be hung in a cool place until all the animal heat is out of the body before being shipped.

\section{QUESTIONS}

1. What is a capon?

2. Why is a capon a more desirable table fowl than an uncaponized male bird?

3 . What conditions should be the governing factors when producing capons on a large scale?

4. What are the best breeds to caponize?

5. When is the most desirable time to caponize cockerels? Of what importance is early hatching as concerning the production of capons?

6. Why is it so necessary to deprive cockerels of feed and water for at least twenty-four hours before the operation?

7. Name the essential instruments necessary for caponizing.

8. Describe in detail the method of caponizing.

9. What care and provision should be made for the birds after they have been caponized? What are wind puffs and how can they be relieved?

10. Describe the method of dry-picking a capon.

\section{SUGGESTIONS}

1. The idea should not be obtained that the art of caponizing is a difficult one, for such is not the case. Many instances are known where boys and girls of fourteen years of age have become quite expert in carrying on this operation. It is, therefore, recommended that members of boys' and girls' poultry clubs should become proficient in carrying on this operation through actual practice, following the plan as described herein. Knnowledge of the necessary steps, confidence, and practice are the three factors necessary to make the operation successful.

2. During June or July carry on a caponizing demonstration. Such a demonstration held in connection with a farmers' meeting or in a gathering of people interested in poultry always attracts attention and creates interest.

3. Farmers, poultrymen, and often those having smaller flocks should endeavor to caponize at least a few cockerels each year, if for no other pupose than to have them for home consumption.

4. Inquiry should be made at your local market and near-by markets as to the demands for cupons. Should a desirable market exist, other conditions being equal, it will be found that the production of capons will be the source of additional revenue from the poultry flock. 
5. An interesting comparison can be made by weighing a capon and a cockerel, both of which were hatched at the same time, both being of the same breed and variety and in so far as possible both being raised under practically the same conditions. In such cases where the capon does not greatly exceed the cockerel in weight, the superior meat qualities of the capon will more than overbalance the value of the capon as compared with the cockerel.

\section{REFERENCES}

"Capons and Caponizing," Rob R. Slocum, U. S. Department of Agriculture, Farmers' Bulletin, No. 849.

Note:-Caponizing instruments are manufactured and may be secured from either of the following: S. K. Burdin, 120 Stibbard Ave., Toronto, Canada; Geo. Beuoy, Cedar Vale, Kansas; Geo. P. Pilling \& Son Co., Arch \& 23rd sts., Philadelphia, Pa. 


\section{CHAPTER XII}

\section{FEEDING FOR EGG PRODUCTION}

The contents and suggestions given in the preceding chapters have a direct bearing on the object for which most fowls are kept, namely, the profitable production of eggs. The features that are so essential for such production are as follows: (1) Standard-bred poultry increases production and improves quality. (2) Select healthy vigorous breeders so as to produce strong chickens. (3) Hatch early. Early hatched pullets produce fall and winter eggs. Feed and manage the growing stock properly, so that they will mature before winter. (5) Cull the flock and thereby eliminate unprofitable producers. (6) Provide a suitable and comfortable house for the layers. (7) Provide suitable raw material, that is, feed, so as to make profitable egg production possible.

\section{VALUE OF PROPER FEEDING}

When feeding hens for egg production two facts should be kept in mind, namely, that the feed consumed first goes to keep up the body requirements and to furnish heat to the body, and, second, to supply the material that makes the egg. It is only after the body requirements of the hen have been satisfied that the surplus feed is available for the production of eggs. When given certain feeds, hens will thrive and keep in good health; but, in order to produce eggs, well balanced, palatable feeds are necessary to fulfill these requirements.

\section{DEVELOPMENT OF THE EGG}

Before discussing the principles and practices of feeding, it will be well to first obtain an idea as to how the egg is formed.

By referring to the top of Figure 199 the ovary is shown 
as containing round follicles, each one of which is the first stage in the development of the egg, and are called the ova, or yolks. The ovum, or yolk, develops in about two weeks, during which time it is enclosed in a sack composed of membrane. While so enclosed the yolk receives by means of the blood the material that composes it. At the end of two weeks, when the yolk reaches its full development, the membraneous sack is broken and the yolk enters the funnelshaped opening of the oviduct, which will be noted in the center of Figure 199. As soon as the yolk enters, the white of the egg, or albumen, is secreted as the yolk proceeds through the oviduct. After a sufficient amount of the albu-

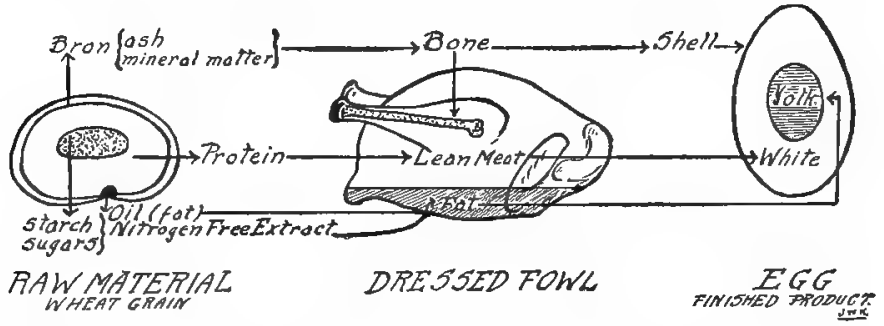

Figure 198.-Chart showing how the elements of the feed go to meet the body requirements and to produce the finished product.

men, or white, is secreted to surround the yolk of the egg the secretion of the membranes and shell begins. This will be noted at the lower end of the oviduct canal. This process is completed by the time the egg leaves the uterus, or shell gland, whereupon it passes out through the vent.

POULTRY FEEDS AND THEIR BY-PRODUCTS

Poultry should have that kind and variety of food which would be natural in the environment of fowls on range. It may be supplemented or modified, however, by such feeds or methods of feeding as experiment and experience may have found productive and profitable.

Grain feeds. The principal feeds fed to poultry consist 


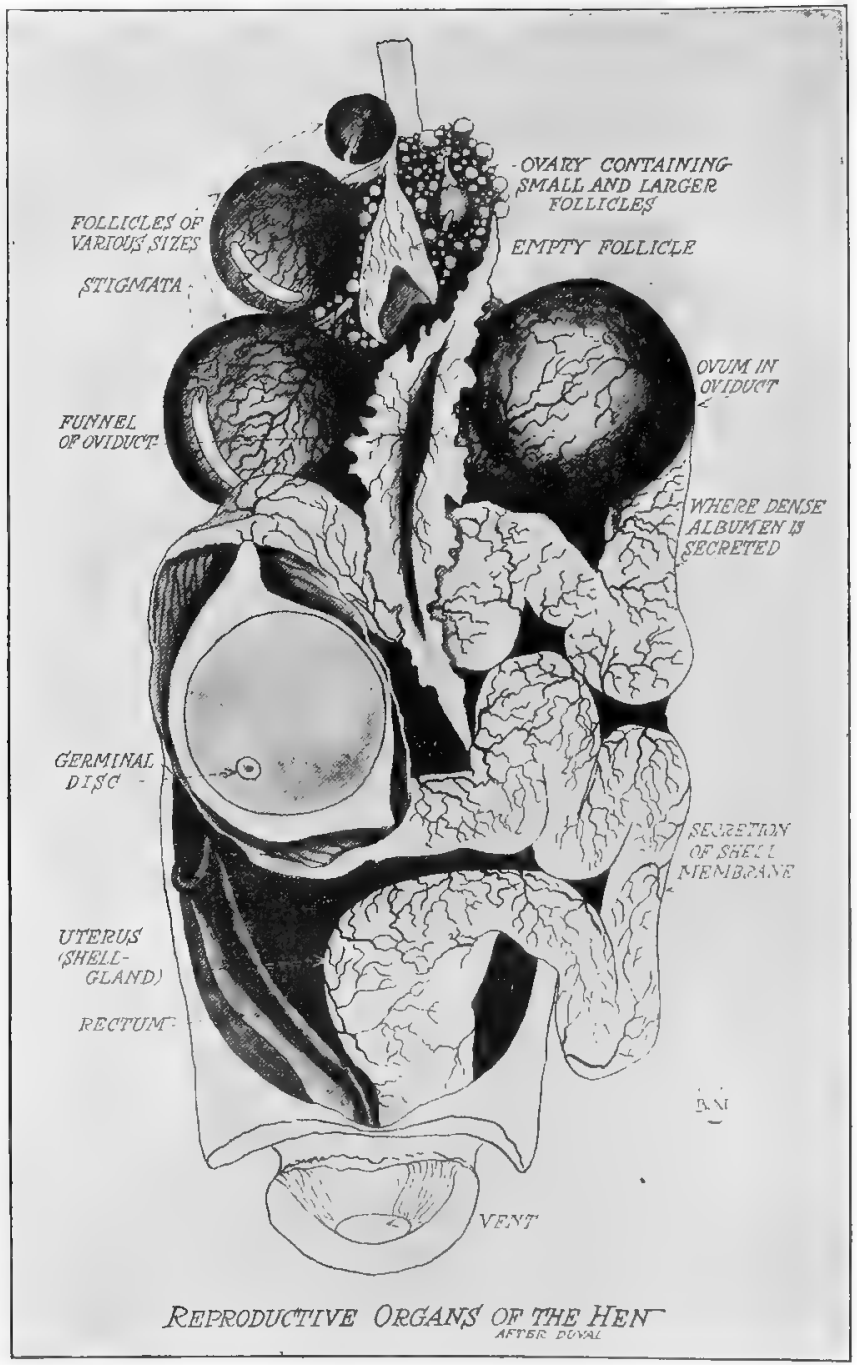

Figure 199.-The egg-producing organs of the hen. (After Duval) 
of corn, wheat, oats, and barley. Kaffir corn and buckwheat are also used, but these are not so generally available or so widely grown as corn, wheat, oats, and barley and usually cost more. Corn and wheat are the two best grains and are similar in value as poultry feeds. On account of the hulls and higher fiber content oats and barley are not as satisfactory as corn or wheat. Rye is not fed to any great extent and does not seem to be relished by fowls. Slightly damaged grains or wheat screenings sometimes can be purchased at a reduced price to an advantage, their value depending entirely upon their quality, condition, and cost. Ordinarily only sound grains in good condition should be fed to poultry and moldy grains or by-products should never be used.

Mash feeds. The most common mill feeds and byproducts fed in mash form are corn meal, wheat bran, wheat middlings, and beef scrap. Corn chop, corn and cob meal, gluten meal, ground oats, and low grade wheat flour may also be added or substituted to advantage. A mash composed of several of these by-products together with meat scrap should be fed in addition to the scratch grains as discussed on page 213. It should be remembered that a highly complicated mash consisting of a large variety of ground grains is not necessary to secure satisfactory results, for such results can be secured from a more simple mash containing 3 or 4 grain by-products together with meat scrap.

Commercial feeds. Quite a variety of commercial mixtures both of scratch grains and of ground grains are prepared for poultry. The value of such commercial feed depends upon its composition and the quality of the grain used in its preparation. When grains can not be grown or when only a comparatively small number of fowls are kept, it is usually better to purchase commercial mixed 
feeds. The average farmer is usually in a position to feed home-grown grains, supplemented with purchased mill feeds and meat scrap or commercial ready-mixed mash feeds. The methods of feeding as practiced by successful poultrymen vary to the extent that some purchase their feeds and mix them, while others depend entirely on commercial mixed feed.

Meat feed. Meat scrap or some other animal feed rich in protein is of most importance in the mash and should not

\begin{tabular}{|c|c|c|}
\hline NATURE PROVIDES: & SCIENTIFIC CLASSIFICATION: & POULTRYMEN FEED: \\
\hline WORMS ANO BUGS & $\begin{array}{l}\text { NITROGENOUS MATEAIAL } \\
\text { OP PROTEN. }\end{array}$ & $\begin{array}{l}\text { EGGS, MEAT (GREEN BONE } \\
\text { OR BEEF SCAAP), MILK } \\
\text { OR COTTAGE CHEESE }\end{array}$ \\
\hline SEEDS & NON-NITAOGENOUS & $\begin{array}{l}\text { WHEAT, OATS, COAN, } \\
\text { BAPLEY, ETC }\end{array}$ \\
\hline GREENS & FAESH AND DRIED. & $\begin{array}{l}\text { LETTUCE, CABBAGE, KALE, } \\
\text { MANGLES, ALFALFA, } \\
\text { CLOVER, ETC }\end{array}$ \\
\hline$G R T$ & MINEPAL MATTEA & GAITANO OYSTER SHELL \\
\hline WATER & WATER & WATEA \\
\hline
\end{tabular}

Figure 200.-Classification of poultry feeds.

be omitted, if a profitable egg production is to be secured. Either fish meal or fish scrap can be used to replace the meat scrap in the mash and compares favorably in results obtained with a good grade of meat scrap containing the same per cent of protein. Skim milk or buttermilk, either sweet or sour, may be used for replacing part or all of the meat scrap. It may be used either in mixing the mash, if a wet mash is fed, or it can be kept before the fowls to drink.

The vegetable protein fceds are not a satisfactory substitute for the meat or animal protein feeds. In sections, however, where they can be obtained cheaply they may be used to replace from one fourth to one half of the meat scrap. 
Of the high vegetable protein feeds cotton-seed meal has given good results, followed by peanut meal, soy-bean meal, and velvet-bean meal, named in the order of their value. Not over one tenth of the mash should consist of cottonseed meal, as the use of a larger amount than this is likely to affect the egg yield considerably and may affect the quality of the eggs.

Green feeds. Green feeds are a necessary part of the hen's rations and should be supplied to her when confined in small yards and also during the winter, when no green feed is available. Free range or large yards kept in grass will furnish ideal green feed. Where smaller yards have to be used, they should be divided, if possible, in to two parts, as discussed in the chap-

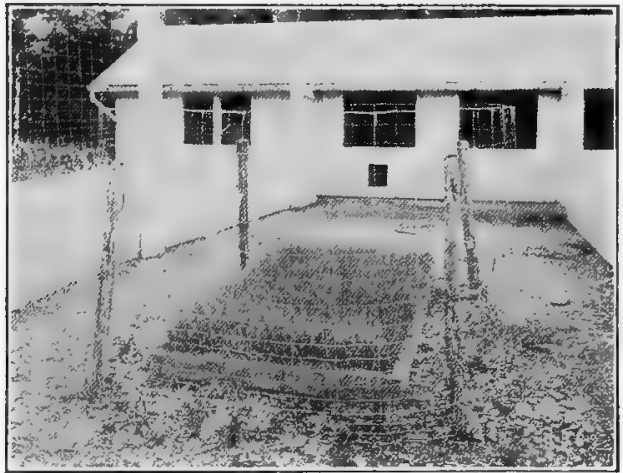

Figure 201.-Green feed can be grown in yards of small size by sowing wheat, oats, or rye in a $2 \times 4$ frame, covering the frame with small mesh wire, and surrounding it with a portable fence to keep the fowls away until the grain is of sufficient size. The fence can then be removed, allowing the fowls to eat the green feed. The wire over the top of the frame keeps the fowls away from the roots of the plants.

ter on poultry houses, and used alternately, planting the vacant yard several times a year with a quick-growing green crop, such as rape, oats, wheat, rye or barley. In this way green feed is supplied and also helps to keep the ground sweet and clean. Other green feeds that can be fed especially in winter are sprouted oats, alfalfa meal, chopped alfalfa, and clover hay, cabbages, and mangel beets. Cabbages are fed 
by suspending them by means of a cord hung up in the poultry house while the beets are usually split and stuck on a nail on the side wall near the floor.

When oats are used for sprouting, they should be of a good grade. Soak them over night in warm water and then spread out $1 / 2$ to 1 inch thick on trays having perforated bottoms. Water the oats thoroughly each day and turn the trays around, so as to bring each side near the light,

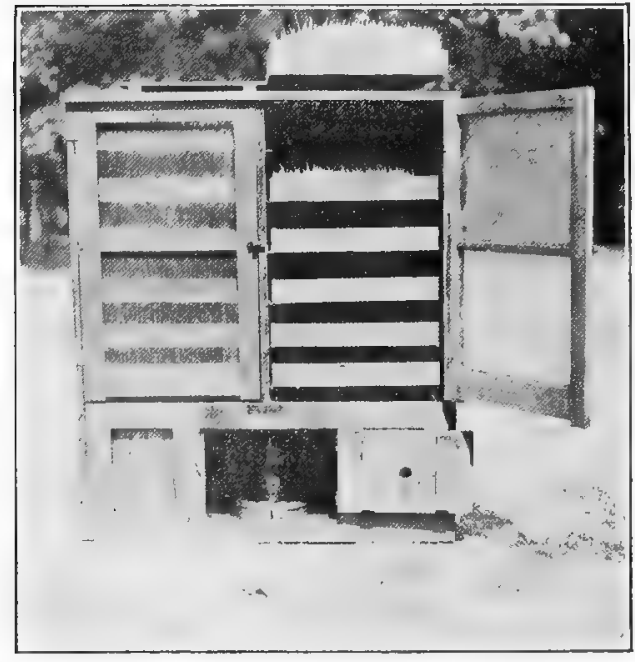

Figure 202.-Oat sprouting cabinet. In cool weather heat is supplied by a kerosene lamp. in order to encourage an even growth. Stir the oats each day until the sprouts begin to form. Artificial heat should be supplied in cool weather usually by means of a kerosene lamp.

Sprouted oats can be fed any time after the sprouts are well started, which usually takes from 5 to 7 days. Clean and spray the trays occasionally with a disinfectant to prevent the growth of mold.

Oyster shell, grit, and charcoal. Oyster shell, grit, and charcoal should be kept in a hopper before the hens constantly. These materials are not expensive and are quite necessary as a part of the ration. Oyster shell supplies lime for bone and egrshell construction, grit is necessary 
for grinding the food, and charcoal tends to absorb gases and poisons. Ordinarily a hen will eat 2 pounds of oyster shell and 1 pound of grit a year.

Water. The body of a hen is said to contain about $55 \%$ water, while the average per cent of water in an egg is $65.5 \%$. Thus it will be seen that water is most essential and a plentiful supply of clean fresh water should always be available. Fifty laying hens will require about 4 to 8 quarts of water daily.

Condiments and egg tonics. The object of so-called egg tonics, or condiments, is to increase the palatability of the ration and stimulate the fowls' appetite, with the result

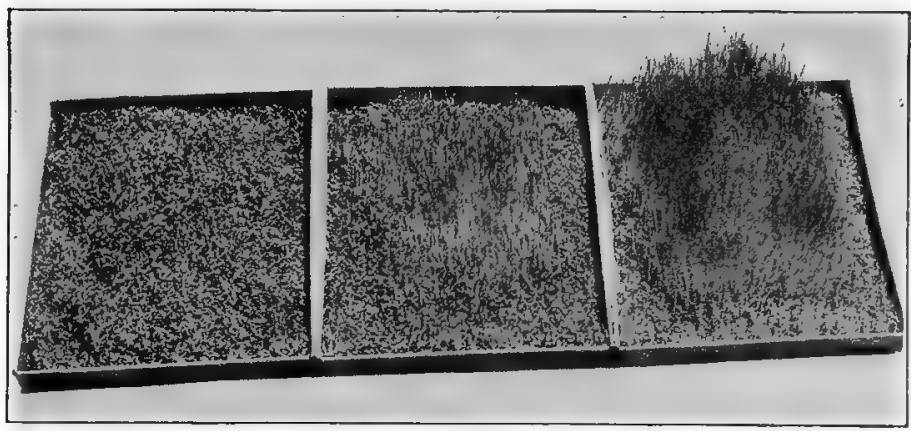

Figure 203.-Oats in the process of sprouting.

that they eat more feed and produce more eggs. Ordinarily fowls that are properly fed and managed do not require a condiment or tonic to produce satisfactory results. Some poultrymen, however, resort to a condiment to stimulate production especially when the fowls are in poor condition. An example of such a tonic may be made as follows: Mix equal parts of capsicum, ground cloves, allspice and ginger. This mixture is fed in the proportion of one teaspoonful to each quart of mash twice weekly. 


\section{COMPOSITION OF THE FEEDS}

It is necessary not only to have the right kind of feeds but that they should be fed at proper intervals and in amounts proportioned to the nutritive and productive requirements of the fowl. In order to feed intelligently, therefore, we must know, first, the composition of feeds.

Feeds and feeding stuffs contain three elements in varying amounts that are essential in the feeding of poultry. They are protein, or nitrogenous material, nitrogen-free extract, or carbohydrates, and fat, together with water and ash. Protein is that part of the food that makes flesh, bone and

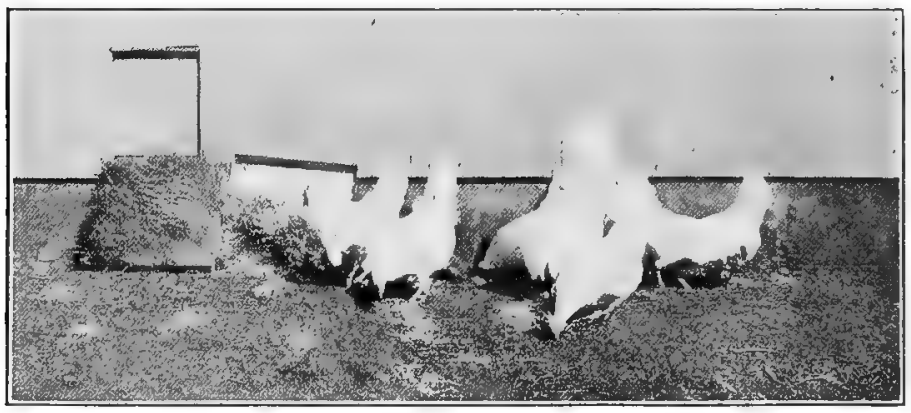

Figure 204.-When feeding sprouted oats allow one square inch per hen daily.

muscle and serves to replace waste material and promote growth. Protein also is the principal ingredient in the white of the egg. It is the element that is apt to be deficient in feeding stuffs and the commercial value of feed depends largely on the amount of protein it contains. Carbohydrates, or nitrogen-free extract, is that part of the feed that goes to make fat, generate heat, and exert energy. The fat content in feeds performs practically the same functions as the carbohydrates. Ash is the mineral material contained in feeds and is largely used in making bone, eggshells, etc., and is just as essential as water or protein. Knowing the 
composition of feeds and the part that they play in maintaining the fowl as well as to produce the product, the question now arises: "How can these essentials be combined in such a proportion that they will supply the necessary requirements?" The question is answered and explained in the balanced ration.

\section{BALANCED RATIONS}

By balanced ration is meant the combination of feeds in such proper proportions as will furnish the necessary amount of nutrients (protein, nitrogen-free extract, and fat) to produce, in the case of poultry, a satisfactory egg production, to fulfill the body requirements, and that can be fed economically. In preparing a ration it is necessary to obtain what is called a nutritive ratio, that is, to obtain the ratio which exists between the amount of the protein in a given feed stuff and the amount of the carbohydrates and fat.

The nutritive ratio. A practical ration for the production of eggs should include a scratch mixture of grains and a mash composed of palatable grain by-products containing some animal feed and sufficient bulk. In general terms

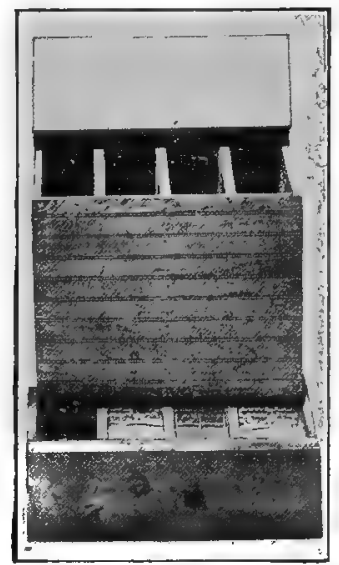

Figure 205.-Homemade hopper containing 4 separate compartments. Such a hopper may be used to feed each of the constituents of the dry mash separately, and a similar hopper containing 3 compartments may be used for charcoal, grit, and oyster shell. the most satisfactory nutritive ratio for poultry should be 1 part of protein to $4 \frac{1}{2}$ or 5 parts of nitrogen-free extract and fat. When computing the nutritive ratio, the fat is changed to terms of nitrogen-free extract, which is done 
by multiplying the fat by $2 \frac{1}{4}$. (Fat has $2 \frac{1}{4}$ times as much heat value as nitrogen-free extract.)

Up to this time sufficient experiments have not been carried on in feeding poultry to determine the amount of various feeds that are actually digested by poultry, as has been done with cattle. The total composition of feed stuffs, therefore, will be used in computing the nutritive ratio rather than the percentage of digestible nutrients. The nutritive ratio, as will be given below, will not include the fiber content, as very little fiber is digested by poultry. The composition of the various poultry feeds is shown in Table II.

How to determine the nutritive ratio. The following

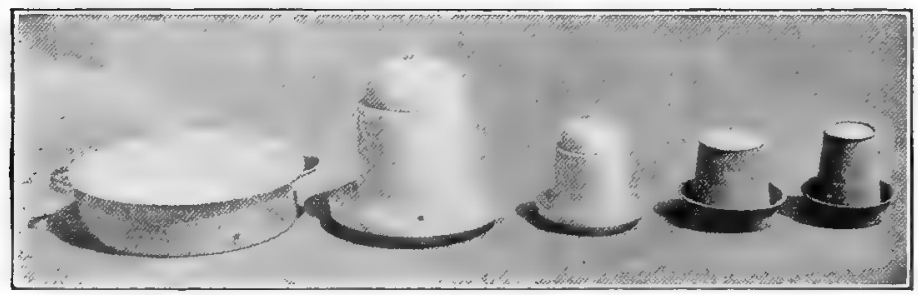

Figure 206.-Various styles of drinking fountains.

will illustrate how a nutritive ratio is determined. Ration No. 3 as found on page 212 will be selected for this purpose, as it consists of but four ingredients, and the simplicity of its make-up will enable one to see how a nutritive ratio is computed more quickly perhaps than a complicated ration. Referring to Table II will be found the number of pounds or per cent of the several feed constituents in $100 \mathrm{lbs}$. of each of the feeds listed. In order to get the number of pounds or per cent of these constituents in 2 lbs. of cracked corn, the per cent of protein, nitrogen-free extract, and fat as given in Table II for cracked corn is divided by 100 to get the amount in $1 \mathrm{lb}$., which is then multiplied by $2 \mathrm{lbs}$. This same procedure is followed out in each of the other 3 in- 
Table II. Composition of Poultry Feed Stuffs.

\begin{tabular}{|c|c|c|c|c|c|c|}
\hline Feed Stuff & 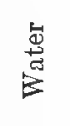 & $\frac{\pi}{2}$ & $\frac{.9}{9}$ & $\frac{0}{0}$ & 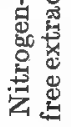 & $\vec{\Phi}$ \\
\hline & $\begin{array}{l}\text { Per } \\
\text { cent }\end{array}$ & $\begin{array}{l}\text { Per } \\
\text { cent }\end{array}$ & $\begin{array}{l}\text { Per } \\
\text { rent }\end{array}$ & $\begin{array}{l}\text { Per } \\
\text { cent }\end{array}$ & $\begin{array}{l}\text { Per } \\
\text { cent }\end{array}$ & $\begin{array}{l}\text { Per } \\
\text { cent }\end{array}$ \\
\hline Corn $\ldots \ldots \ldots \ldots \ldots \ldots \ldots$ & 10.9 & 1.5 & 10.5 & 2.1 & 69.6 & 5.4 \\
\hline$\ldots \ldots \ldots$ & 12.8 & 2.1 & 9.1 & 2.6 & 9.8 & 3.6 \\
\hline Barley...... & 10.9 & 2.4 & 12.4 & 2.7 & 69.8 & 1.8 \\
\hline Oats.. & 11.0 & 3.0 & 11.8 & 9.5 & 59.7 & 5.0 \\
\hline Rye.... & 11.6 & 1.9 & 10.6 & 1.7 & 72.5 & 1.7 \\
\hline$\ldots \ldots \ldots \ldots$ & 10.5 & 1.8 & 11.9 & 1.8 & 71.9 & 2.1 \\
\hline$\ldots \ldots \ldots$ & 12.4 & .4 & 7.4 & .2 & 79.2 & .4 \\
\hline$\ldots \ldots \ldots$ & 12.6 & 2.0 & 10.0 & 8.7 & 64.5 & 2.2 \\
\hline Sunflower seed (whole) . . . . . . . & 8.6 & 2.6 & 15.3 & 29.2 & 21.4 & 21.2 \\
\hline Soy bean $^{1} \ldots \ldots \ldots \ldots \ldots \ldots$ & 8.7 & 5.4 & 36.3 & 3.9 & 27.7 & 18.0 \\
\hline Cowpea $^{1} \ldots$ & 11.9 & 3.4 & 23.5 & 3.8 & 55.7 & 1.7 \\
\hline Canada field pea ${ }^{1}$. & 15.0 & 2.4 & 23.7 & 7.9 & 50.2 & .8 \\
\hline Peas ${ }^{1} \ldots . . . . .$. & 13.4 & 2.4 & 22.4 & 6.4 & 52.6 & 3.0 \\
\hline$\ldots \ldots$ & 12.6 & 1.9 & 9.9 & 1.9 & 69.7 & 3.9 \\
\hline ed. & 8.0 & 2.0 & 10.0 & 14.0 & 45.0 & 21.0 \\
\hline al. . & 15.0 & 1.4 & 9.2 & 1.9 & 68.7 & 3.8 \\
\hline eal..... & 11.9 & 2.6 & 10.5 & 6.5 & 66.3 & 2.2 \\
\hline an meal ${ }^{1}$ & 10.2 & 5.0 & 35.9 & 3.4 & 28.0 & 17.5 \\
\hline neal ${ }^{1} \ldots$ & 8.6 & 6 & 30.0 & 2. & 49.2 & 8.8 \\
\hline feed $^{1} \ldots$ & 8.1 & 1.3 & 23.2 & 6.4 & 54.7 & 6. \\
\hline rs' grains 1 & 8.0 & 3.4 & 24.1 & 13.0 & 44.8 & 6.7 \\
\hline bran... & 11.9 & 5.8 & 15.4 & 9.0 & 53.9 & 4.0 \\
\hline W & 12.1 & 3.3 & 15.6 & 4.6 & 60.4 & 4.0 \\
\hline W & 11.8 & 4.5 & 14.9 & 7.4 & 56.8 & 4.5 \\
\hline & 11.6 & 2.9 & 12.5 & 4.9 & 65.1 & 3. \\
\hline meal $\ldots \ldots \ldots$ & 8.2 & 7.2 & 42.3 & 5.6 & & 13. \\
\hline ed meal, old process ${ }^{1} . .$. & 9.2 & 5.7 & 32.9 & 8.9 & & 7.7 \\
\hline Linseed meal, new process ${ }^{1} . .$. & 9.9 & 5.6 & 35.9 & 8.8 & & 3. \\
\hline Peanut meal ${ }^{1} \ldots \ldots \ldots \ldots \ldots$ & 10.7 & 4.9 & 47.6 & 5.1 & 23.7 & 8.0 \\
\hline Skim milk, cream raised by sep- & & & & & & \\
\hline & 90.6 & .7 & 3.2 & & 5.2 & .3 \\
\hline Butternailk ${ }^{2}$.. & 91.0 & .7 & 3.0 & & 4.8 & \\
\hline Animal meal ${ }^{2}$. & 5.7 & 39.9 & 39.4 & & $\ldots$ & 10.7 \\
\hline Meat scrap ${ }^{2}$. & 7.9 & 17.4 & 49.7 & & & 18.5 \\
\hline Mea & 6.3 & & 48.4 & & & 12.9 \\
\hline sh bone ${ }^{2} \ldots .$. & 34.3 & 22.8 & 20.6 & & 1.9 & 20.5 \\
\hline d lfo $1 \mathrm{f}$ h & 8.1 & 8.8 & 14.6 & 28.9 & 37.4 & 2.1 \\
\hline Mangel beets. . . . . . . & 90.9 & 1.1 & 1.4 & & 5.5 & \\
\hline
\end{tabular}

(1) Contains a high proportion of vegetable protein. high proportion of animal protein.

(2) Contains a 
gredients. The following table will show the per cent of protein, nitrogen-free extract, and fat in each of the ingredients in ration No. 3.

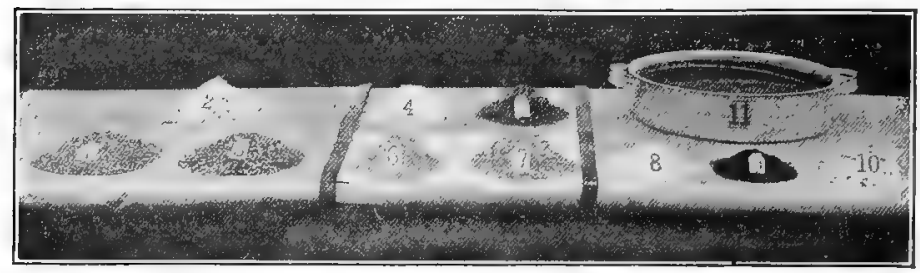

Figure 207.-A balanced ration. 1. Wheat. 2, Cracked corn. 3 Oats. These constitute the grain feeds. 4. Corn meal. 5. Beef scrap. 6. Middlings. 7. Bran. These constitute the mash feed. 8. Grit. 9. Charcoal. 10. Oyster shell. 11. Water. These should be left before the fowls constantly.

Table III. Composition of Ingredients of a Balanced Ration.

\begin{tabular}{|c|c|c|c|}
\hline Feed & Protein & $\begin{array}{l}\text { Nitrogen- } \\
\text { free extract }\end{array}$ & Fat \\
\hline & Per cent & Per cent & Per cent \\
\hline 2 lbs. cracked corn. & .210 & 1.392 & .108 \\
\hline $1 \mathrm{lb}$ oats.......... & .118 & .597 & .050 \\
\hline 3 lbs. cornmeal .......... & .276 & 2.061 & .114 \\
\hline 1 lb. meat meal ........ & .497 & & \\
\hline 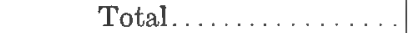 & 1.101 & 4.050 & .457 \\
\hline
\end{tabular}

As will be noted, this ration contains 1.101 pounds of protein, 4.05 pounds of nitrogen-free extract, and .457 of a pound of fat. To determine the nutritive ratio of this ration the total amount of fat, .457 of a pound, is multiplied by $2 \frac{1}{4}$ (fat having $2 \frac{1}{4}$ times the heat value of nitrogen-free extract), which gives $1.028 \mathrm{lbs}$. This amount is then added to the total amount of nitrogen-free extract, 4.05, making a total of $5.078 \mathrm{lbs}$. This total is then divided by the total amount of protein, which is 1.101 , which gives a nutritive ratio of $1: 4.6$ for the ration. The formula for computing 
the nutritive ratio, using the totals from the above table, may be represented as follows:

Table IV. Formula for Determining the Nutritive Ratio.

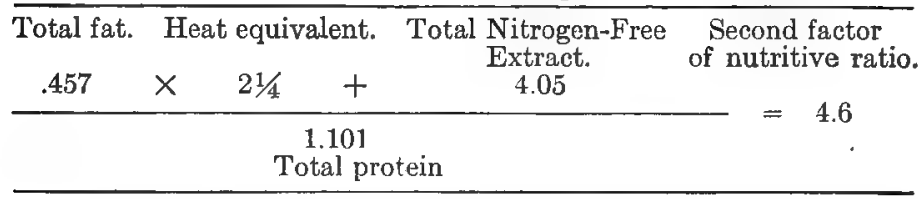

\section{EGG LAYING RATION}

There is no best ration for all conditions, as many grains can be fed interchangeably, depending on their availability,

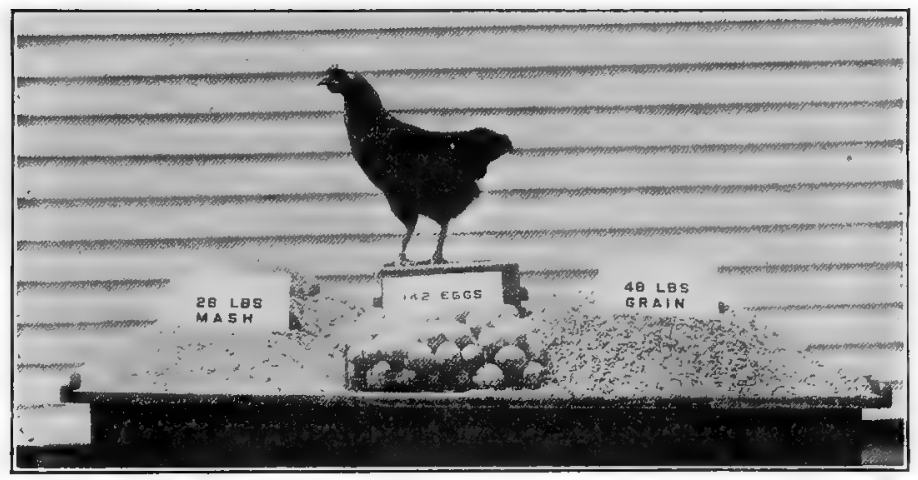

Figure 208. - The amount of feed consumed by a Rhode Island Red and eggs produced.

composition and price. As in the case of mash feeds the more simple grain mixtures, composed of home grown grains, will prove more profitable and produce eggs at less cost than complicated mixtures composed of eight or ten grains. All the following rations have been used with satisfactory results at the Government Experimental Farm at Beltsville, Md. In making a selection one should choose the ration most suitable to local conditions, and one that is most economical. Feeds not given in these rations may 
be substituted on the basis of their comparative analysis, as shown in Table II, provided the meat scrap or animal protein feeds are not entirely replaced by cotton-seed meal or other of the vegetable protein feeds. The change from one feed to another should be made gradually, as sudden changes may decrease the egg production considerably.

\section{Mash}

16 pounds corn meal

$61 / 2$ pounds meat scrap

1 pound bran

1 pound middlings
Ration No. 1

\section{Scratch Mixture}

8 pounds cracked corn

8 pounds wheat

8 pounds oats

\section{Ration No. 2}

2 pounds barley, or corn, meal

1 pound bran

1 pound middlings

1 pound meat or fish serap

2 pounds cracked corn

1 pound oats

1 pound wheat or barley

Ration No. 3

(Wheatless Ration)

3 pounds corn meal

1 pound meat scrap

9 pounds corn meal

5 pounds middlings

4 pounds bran

2 pounds cotton-seed or gluten meal 5 pounds barley

2 pounds meut serap

2 per cent bone meal

1 pound corn meal

1 pound bran

$3 / 4$ pound meat scrap

1 pound middlings

1 pound ground oats

3 pounds corn meal

1 pound bran

1 pound middlings

$1 / 2$ pound meat scrap

Feed with table scraps or cooked vegetables.
Ration No. 5

10 pounds cracked corn

5 pounds wheat

5 pounds wheat

2 pounds cracked corn

1 pound oats

\section{Ration No. 4}

Ration No. 5
2 pounds cracked corn
1 pound wheat
1 pound oats
1 pound barley

Ration No. 6

2 pounds cracked corn

1 pound wheat

1 pound oats 
Ration No. 5 is especially suited for pullets or hens inclined to get too fat, such as the Plymouth Rocks, Orpingtons, and Wyandottes. Corn meal when fed with the meat scrap, is very fattening; consequently these two feeds are cut down in ration No. 5 .

Ration No. 6 should be fed with table scraps or vegetables at the rate of 5 pounds of table scraps daily to 30 hens.

\section{METHODS OF FEEDING}

The scratch, or grain, mixture when fed indoors should

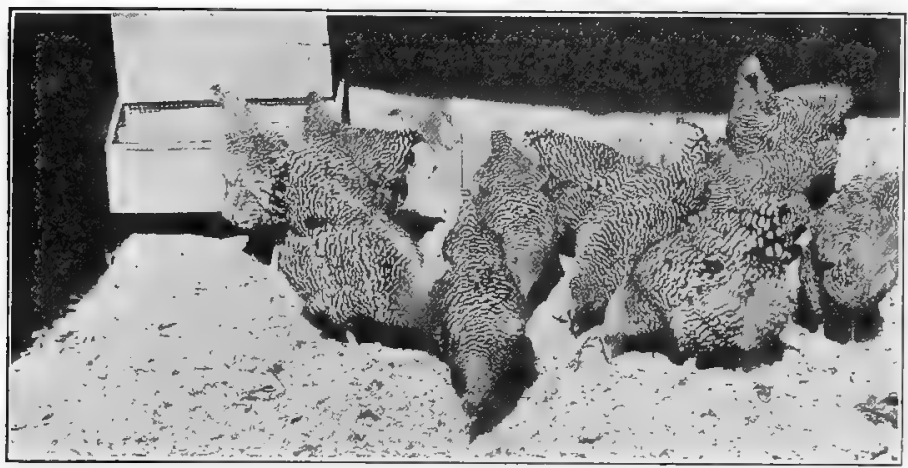

Figure 209.-Hens seratching in the litter for their grain. Such exercise keeps the hens in good condition. Note the two hens to the left in the rear eating mash from the dry mash hopper.

be fed twice daily, in a litter of from 3 to 5 inches deep on the floor of the poultry house.

Feed about one third of the amount of the grain feed in the morning and two thirds in the afternoon, the morning feed consisting of as much as the hens will eat within half an hour, the night feed being enough to fully satisfy them. Feed the mash either dry or as a moist feed in addition to the scratch grains, an effort being made to feed about equal amounts of each. To feed the mash dry is the more 
common method and it should be kept in a hopper! before the fowls constantly.

The wet or moist mash should in no sense be sloppy and when properly fed gives very good results. It should be fed only once a day, preferably in the morning, or at noon, and only as much should be given as the fowls will eat up clean in about half an hour. A moist mash provides a satisfactory way to use up table scraps and cooked vegetables.

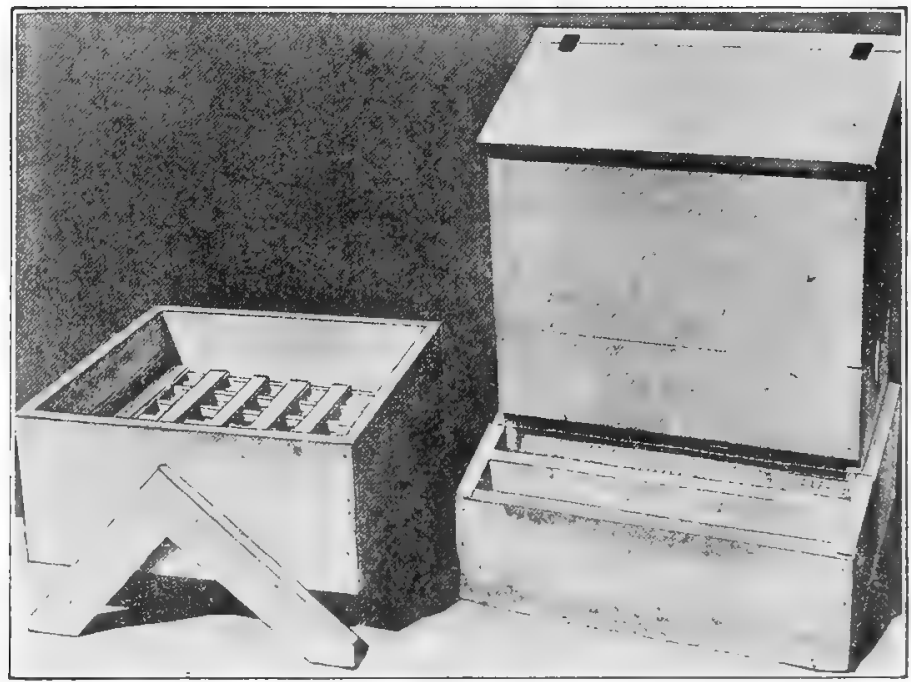

Figure 210.-Two styles of easily constructed homemade feed hoppers. The hopper on the left is very simple and does not waste feed.

Exercise. When hens tend to become too fat, they should be made to exercise more by working harder for their feed, which should be fed in a deep litter. When such is the case reduce the amount of scratch grains and likewise the amount of meat scrap in the mash. At times it becomes necessary to close up the dry mash hopper until noon in order to make the hens work harder for their scratch grains. 
The same feeds or combinations of feeds may be fed throughout the year. During the molting period do not try to foree the molt prematurely by special methods of feeding.

\section{QUANTITY OF GRAIN TO FEED}

Judgment must be used in deciding how much grain to feed as the amount eaten varies with different flocks and at different seasons of the year. For instance fowls will eat more in the spring when laying heavily than in the summer and fall, when production has dropped off. It is advisable to feed approximately at the rate of one quart of scratch grains and an equal amount of mash ( $1 \frac{1}{2}$ quarts) daily to 13 hens of the general-purpose breeds or to 16 hens of the smaller, or egg, breeds. Hens of the general-purpose breeds having free range or large yards containing green feed will eat about 75 pounds of feed in a year, while the hens of the egg breeds such as the Leghorns, will eat about

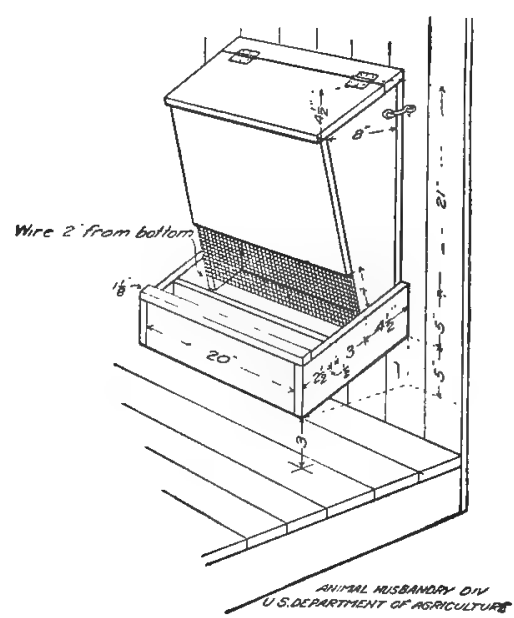

Figure 211.-Working plans for a dry mash hopper.

55 pounds in addition to the green feed consumed.

Relation of the amount of feed to egg production. Concerning the amount of feed consumed at different seasons of the year and the correlation of feed consumption with egg production, the following results from the first Texas National Egg Laying Contest are cited:* During

*Report of the First Texas National Egg Laying Contest, Texas Agricultural Experiment Station. Bulletin 246 by F. W. Kammier. 
the months of February, March, April, and May the birds entered in the contest consumed the greatest amount of feed and also produced the greatest amount of eggs. "In June, July, August, September, and October the birds consumed the smallest amount of feed and also produced the least number of eggs. From this it may be safely concluded that during the period of heaviest feed consumption there is also the greatest egg production."

Experiments. It is interesting to note the results of three years' experimental work on feeding for egg production at the Government Poultry Farm, Beltsville, Maryland. $\dagger$ This report stated that "the amount of feed consumed varies considerably throughout the year, being greatest just preceding the period of highest egg production, but it does not vary absolutely with production either during one year or when one year is compared with another."

Referring again to the results of the Texas Egg Laying Contest it states that "the feed consumption averaged 51/6 pounds for every dozen eggs produced" and that it cost an average price of 22 cents for feed alone (not counting labor and other production costs) to produce a dozen eggs. Further, that on an average it took $31 / 2$ pounds of feed to produce a pound of eggs and that "the birds in the contest produced $31 / 2$ times their own live weight in eggs."

The results of the feeding work at the Government Poultry Farm $†$ showed in this connection that the average feed consumption for each dozen eggs produced was $61 / 2$ pounds. This increased amount as compared to the average of $51 / 6$ pounds for each dozen of eggs at the Texas Contest is due most likely to the fact that the feeding experiments as conducted at the Government Farm covered a longer period and involved a larger number of birds of the general-

†"Feed Cost of Egg Production." U. S. Dept. of Agriculture, Bulletin 561 by Harry M. Lamon and Alfred R. Lee. 
purpose class than was included in the Texas Contest where the majority of the birds were Leghorns.

Further, it is brought out as the result of the feeding work at the Government Poultry Farm that the value of eggs or selling price for the year was greatest in November, while the feed cost to produce a dozen of eggs was greatest in December, owing to the low production at that time. Eggs are produced at the lowest cost during the period of greatest production, which is in the spring, and at the highest cost in the season of lowest production, which is the fall and early winter. This high cost of egg production in the fall and winter increases materially as the fowls become older.

\section{ARTIFICIAL LIGHTS}

Within the past several years the practice known as artificial lighting of poultry houses has come into use. The object of this system is to obtain a greater egg production during the fall and winter months when eggs are high in price, the sole idea being to produce by means of artificial lights a longer working day for the hen. In the fall and winter the period of daylight is comparatively short as contrasted with the spring and summer days. Consequently by the use of lights the short days are made longer, thereby permitting the hens to eat more feed with which to produce more eggs. This practice is ordinarily carried on with the layers rather than with birds that are intended for breeders.

Some poultrymen who have tried artificial lights, however, on their breeding stock, do not report any detrimental results. Another advantage of artificial lighting is that by providing a longer working day, late-hatched and slowdeveloping pullets are given an opportunity to mature more rapidly, and thereby come into egg production sooner than when artificial lights are not provided. Again, when lights 
are used hens will complete their molt sooner than they would otherwise.

The period of artificial lighting. The period during which artificial lights are used in the poultry house ranges from the 1st of September or October to the 1st of March or April, these being the months during which the days are shortest. The three methods that have been used as concerning the period or time of the day during which lights have been turned on are as follows:

1. The lights are turned on an hour or two before day-

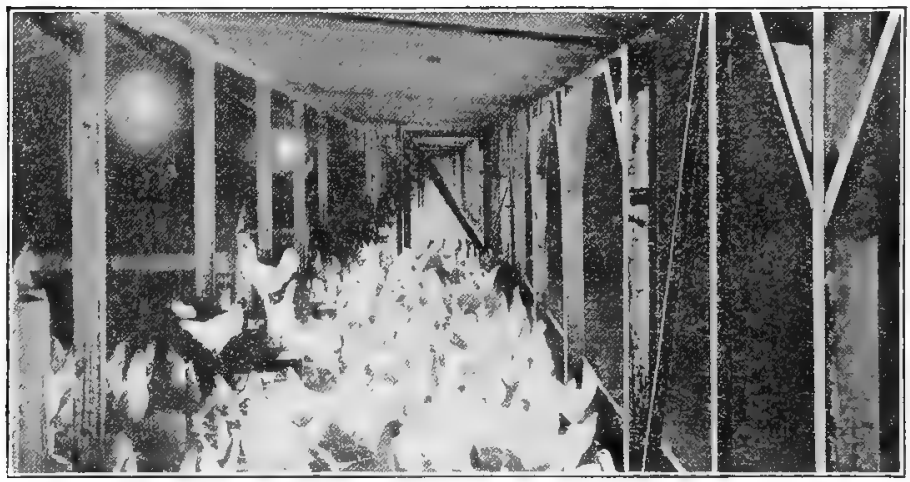

Figure 212.-The interior of a poultry house illuminated with electrio lights.

light in the morning and again in the evening before it gets dark, so as to make a twelve-hour day for the hens.

2. The lights being turned on only in the evening before it gets dark and remain on so as to give the hens the same number of hours as mentioned above.

3. To turn the lights on in the morning only, usually about 4:30 a. m., and turn them off as soon as it becomes sufficiently light in the house for the hens to see. When this plan is used the lights are not turned on in the evening.

Considering all these plans, the latter seems to be the 
most desirable. When the lights are used in the evening it is necessary to provide some way to dim the lights before turning them out completely so that the hens can see their way to the roosts. When the lights are used only in the morning, such a system is not necessary.

Kinds of lights to use. The various means of illuminating the poultry house are by the use of electric lights, gasoline lamps or kerosene lamps. The former is by far the most satisfactory method and less dangerous from the standpoint of fire than the other two methods. Aside from the element of safety, the electric lights can be so arranged that they can be turned on automatically early in the morning by means of an alarm clock. By this arrangement the alarm will go off at a given time and the alarm key in turning will automatically make a contact so as to turn the lights on. When gasoline or kerosene lamps are used, it is necessary to light them at such a time as it is desired to have light. When electric lights are used, it is usually planned to provide one light of from 40 to 80 watts for each 100 hens. One gasoline lamp will usually be sufficient for the same number of fowls. When kerosene lamps are used, a reflector should be provided for each lamp and four such lamps should be arranged for each 100 hens. In other words, sufficient light should be provided to enable the hens to see sufficiently to eat.

Methods of feeding. Methods of feeding fowls in illuminated pens differ little from those suggested in this chapter. Some poultrymen, however, prefer to feed scratch grain three times a day at morning, noon, and night instead of twice daily, believing that the extra grain feed is necessary to keep up the body requirements during the winter months when artificial lights are used. Another plan is that of scattering some grains in the litter after the fowls have gone to roost, so they will have it to eat in the morning. 


\section{QUESTIONS}

1. Name some of the features that are essential for profitable egg production.

2 . What two facts should be kept in mind when feeding for egg production?

3. Describe the development of the egg.

4. What are the most common grain feeds fed to poultry?

5. Mention some of the more common grain by-products usually found in mash feeds.

6. What facts should be kept in mind when purchasing commercial feeds?

7. Discuss the importance of meat food in the ration.

8. Mention several kinds of green feeds that can be fed.

9. Describe the method of sprouting oats. shell.

10. Discuss the necessity of feeding charcoal, grit, and oyster

11. Why is water so essential to hens?

12. What are the three important elements found in feeds? What part do they play in maintaining the body and producing the product?

13. What is a balanced ration?

14. What is the nutritive ratio?

15. How is the nutritive ratio determined?

16. Mention at least three of the rations recommended in this chapter for egg production.

17. How and when should a grain mixture be fed?

18. Discuss two ways of feeding a mash mixture.

19. How should hens be fed that show a tendency to become too fat? What ration would you feed to such hens?

20. About how much feed would you give daily to a pen of fowls consisting of 25 hens and 1 male bird of the general-purpose breed?

21. What is the object and purpose of artificially lighting poultry houses?

22. What are the advantages of artificial lighting?

23. During what time of the year are lights used? Why?

24. What three plans are used as concerning the time lights are turned on? What are the three methods of lighting?

25. How should fowls in illuminated houses be fed?

\section{SUGGESTIONS}

1. As the principal purpose for which most fowls are kept is for the production of eggs, endeavor to so manage your flock as to secure a good egg yield. If fowls are to be kept, make them profitable. The real pleasure in poultry after all is in the profit.

2. By following the suggestions as given on pages 208 to 211 determine the nutritive ration of Rations Nos. 1, 2, and 4. After determining the quantity of feeds that you are now using for your flock, figure out what the nutritive ratio will be. Does this conform to the nutritive ratio as recommended for laying hens as given on page $207 ?$

3. Does your method of feeding differ materially from that described on page 213? If you are not securing as good an egg yield 
as you think you might expect, why not change your method and see if there is an improvement?

4. Secure several samples of commercial grain feeds from various dealers and examine them carefully as to the quality and number of different grains contained.

5. Remember that the animal protein contained in bugs and worms that the fowls get in the spring and summer must be provided in some form by feeding a meat feed in the winter, in order to secure eggs.

6. A feed mixing demonstration carried on before a group of people interested in poultry will be of great value and lead to an interesting discussion as to the principles and practice of feeding.

7. Would it not be possible for you to try artificial lights in your poultry house and thus secure an increased egg production in the fall and winter months?

\section{REFERENCES}

Feeds and Feeding, by Henry and Morrison.

Feed Cost of Egg Production, U. S. Department of Agriculture, Department Bulletin 561, by Harry M. Lamon and Alfred R. Lee.

Feeding Hens for Egg Production, U. S. Department of Agriculture

Farmers' Bulletin 1067, by Harry M. Lamon and Alfred R. Lee. Principles and Practice of Poultry Culture, by John H. Robinson. 


\section{CHAPTER XIII \\ CULLING THE FLOCK}

One of the greatest achievements that has been accomplished in poultry keeping of recent years is that of being able to determine by certain characteristics the egg-producing ability of a hen. No one phase of poultry practice has been of more economic value to the industry than this, for now practically anyone with a little practice and knowledge of the characteristics peculiar to the good and poor producer can cull out unprofitable fowls and thus place the flock on a true business basis.

Object of culling. One of the principal reasons for culling is that it insures that the feed will be consumed by the better-producing hens, thereby increasing the profit. Again such practice makes it possible to save the hens that are best suited for breeders both on account of their egg-producing ability and their superior strength and vitality. These qualities are very essential to layers, if they are to stand up under the strain of heavy production.

If the flock is to be put on a paying basis, the poor producers should be eliminated in order that eggs may be produced profitably and efficiently. Another advantage of removing the poor producers is that of creating more room for those that remain and a better chance to produce desirable results.

Culling the growing stock. Culling should by no means be confined to the layers; for in the young stock as well certain individuals will be found that it would not pay to keep. Young birds that are stunted in growth, unhealthy, or those that do not possess the qualities that go to make up strong, healthy fowls should be removed from the flock and disposed of. Such birds will never pay for the feed and care used in 


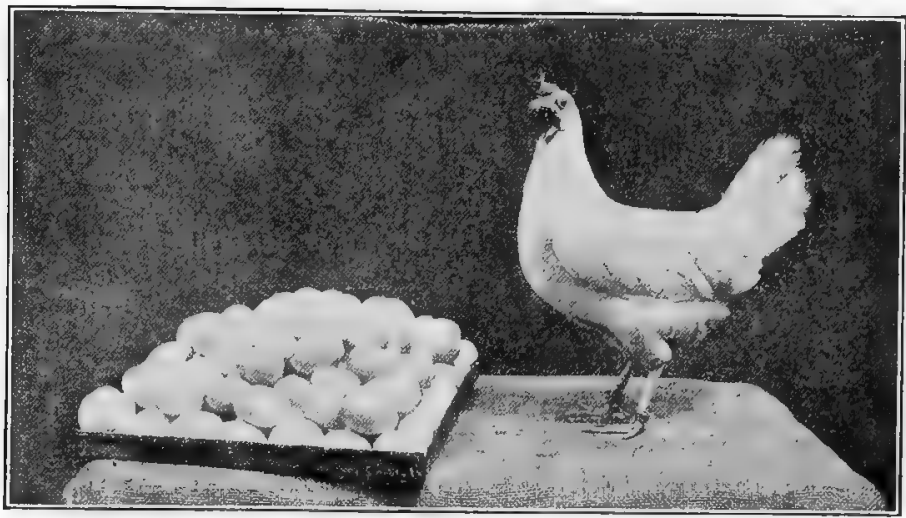

Fig. 213.-This Single-Combed White Leghorn hen, a good producer, laid 160 eggs in a year. Such hens are profitable and should be retained.

trying to raise them. When looking over the growing stock, there will be found certain cockerels that are larger in size and more vigorous than others. On locating such birds they should be leg banded or marked so that they may be retained

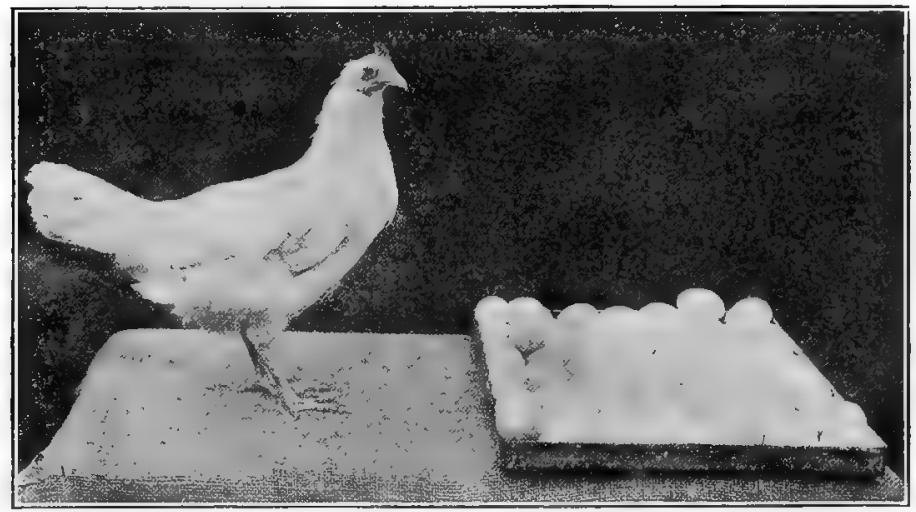

Figure 214,-This Single-Combed White Leghorn hen, a poor producer, laid but 80 eggs in a year. Such hens should be culled as unprofitable. 
as breeders, other conditions being favorable, such as color, type, etc.

When to cull. Culling, generally speaking, should be a continuous process throughout the year. It should include the elimination not only of hens that are non-productive but

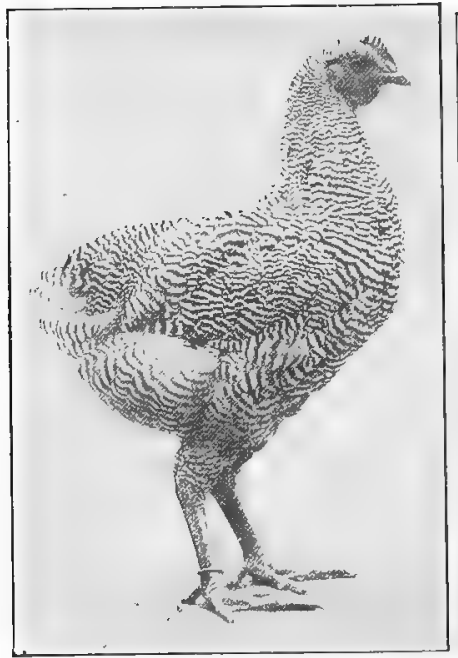

Figure 215.-A Barred Plymouth Rock cockerel well grown and developedthe kind to keep.

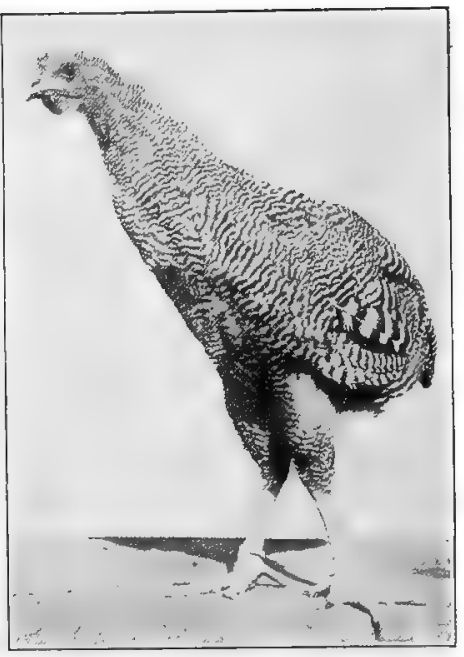

Figure 216.-An extremely poor Barred Plymouth Rock cockerel. Such birds as these should be culled from the flock and marketed.

likewise those that are sick, that are thin or emaciated, as well as those that show poor vitality. At some one time, however, the whole flock should be given a careful and systematic culling. Each hen should be handled and gone over carefully with the object of picking out and retaining the better producers and culling the poor producers. At such a time it is also advisable to pick out from the better producers such hens as will be needed for breeders the following spring. These fowls should be leg banded or other- 
wise marked so that eggs from them will be saved for hatching. The hens culled as poor producers should be marketed as soon as possible, so as to realize an immediate saving on the feed consumed. The best time to cull is during the latter part of August or the first part of September. It is comparatively easy at this time of the year to form a fairly close estimate of the relative value of a hen as to its ability to produce eggs and likewise to cull out the poor producers. Hens that show indications of laying at this time have as a rule been the better producers for the year. The fact should be kept in mind also that hens that have been good layers during their first laying year are usually the ones that will be the better producers in the second and third years. Hens showing positive indications of having been good producers throughout the year should be retained for the next year regardless of their age. Relatively few hens, however, will prove to be profitable producers beyond their second laying year, if they are of the heavier breeds, such as the Plymouth Rock or Wyandotte, or beyond their third laying year, if they are of the lighter breeds, such as the Leghorn. When possible, preliminary culling during July is desirable also in order to eliminate hens which have started to molt and have stopped laying for reasons mentioned under "Molt."

Method of culling. There are several points which require special attention in selecting the good layers. (See Culling Chart in the Appendix.) It is a comparatively easy matter to cull when the different characteristics or several of them agree as indicating good production or poor production. Experience, however, will show that there is not always an agreement of indications. When such characteristics do not agree, one's judgment must be used in deciding which should be given the greatest weight. The following are the principal points to be considered:

Sickness and lack of vigor. Sick fowls can ordinarily ba 


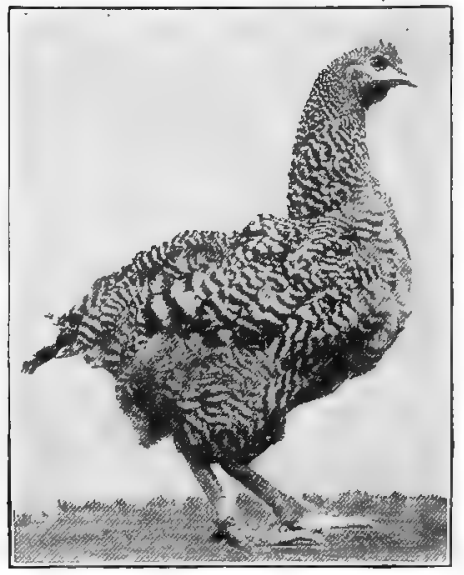

Figure 217.-A Barred Plymouth Rock hen in full molt.

distinguished in that they are usually lifeless, inactive and have a tendency to stay on the roost all or part of the day. Likewise they show but little desire to eat and their comb is usually very pale or of a dark or bluish color. Fowls with long toe nails, a snaky or crow head, and dull sunken eyes can safely be culled as possessing but little vigor or constitutional. strength.

Molt. Molting is the process of shedding the old feathers and the growing of new feathers to take their place. This condition or process is one of the most valuable and easily applied tests as an index of production. Most hens cease laying completely or practicallysoduring the molt, as but few hens can grow feathers and produce eggs at the same time. It will be observed that hens of the general-purpose breeds lay more or less during the molt. This condition is less frequently found in the lighter breeds, such as the Leghorn. The best producers continue laying well into the fall, before molting. The poor producers usually molt early in

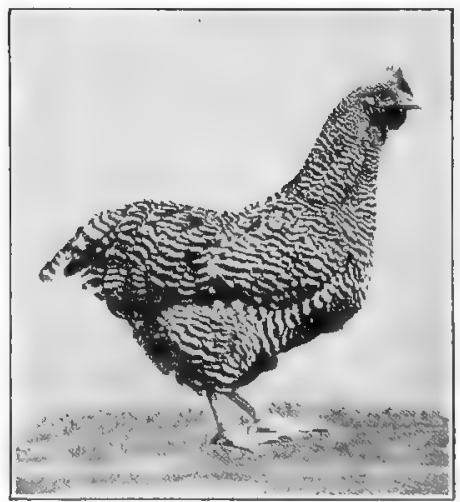

Figure 218.-A Barred Plymouth Rock hen that has not molted. 
the summer, and complete their molt before the better producers begin. Early molters molt slowly while this process is more rapid with the better producers, or late molters.

In considering these facts, therefore, save the hens that have not started to molt by the last of August or are just beginning to molt in September. Some hens molt as late as December. Discard those that have finished molting or are well into the molt by the end of August. The hens that molt last, provided they are otherwise desirable, are the ones that should be saved for the breeding pen.

The hen that has not molted can be told by the fact that the plumage is soiled, worn, or broken, which indications are especially evident in the tail feathers. Those that have

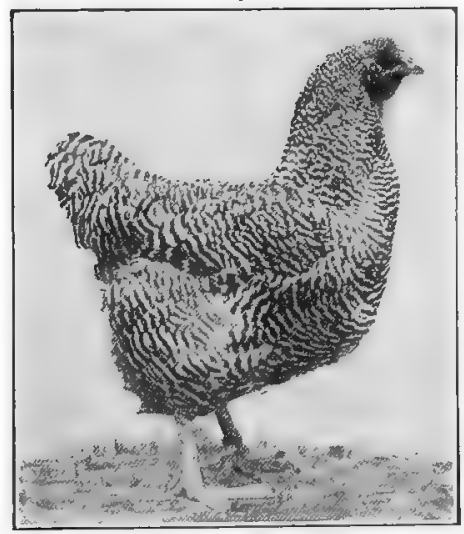

Figure 219.-A Barred Plymouth Rock hen that has completed the molt. molted or are in the process of molting show clean, fresh plumage or are growing new feathers.

Culling out the early molters just as soon as they begin to molt is one of the easiest ways to eliminate the poor layers.

Shank color. The degree of leg or shank color in those breeds or varieties having yellow legs should likewise be considered in culling the flock. In such birds it will be noticed that the color of the shank fades out as the laying season advances and the rapidity and degree of the fading of color depends to a great extent on the heaviness of laying. As the color leaves the legs it fades from the scales on the front of the shanks first, and later from those on the rear. 
Other factors that affect the color of the shanks are the nature of the soil and the extent of grass on the range or yard to which the flocks have access. For instance, some kinds of soil tend to bleach the color out of the shanks and it has also been noticed that fowls on grass range do not lose this color as rapidly as those in bare yards. Hens that show bright or medium-colored shanks are most usually poor layers. Occasionally, however, poor layers may show pale or white shanks. This is especially true with a sick hen or one in poor condition. In breeds where the shanks show a horn color as well as yellow, as in the case of the Rhode Island Reds, the horn color must not be confused with yellow. In such cases the absence of yellow color will be noted on the rear and sides of the shanks. The correct color of the shanks for the standard breeds will be found on pages 348,349 .

Condition of shank. Another characteristic which may be found in some high producers is the flexibility of the skin on the rear of the shanks. As laying progresses the skin becomes loose and pliable and a groove or depression forms on the sides of the shanks. 'This condition is not apparent to such an extent on poor or fair layers.

Beak color. In such breeds as have yellow beaks practically the same principle applies as in the case of the yellow shanks. The beak color, however, is lost from the beak more quickly than from the shanks, as the hen starts laying, and is likewise regained more quickly when she stops laying. The lower half of the beak fades out faster than the upper half. The lower half of the beak may be used as a gaide in this connection in individuals where the upper beak is horn color or black.

Vent color. In breeds having a yellow skin the yellow color immediately surrounding the vent is quickly lost when laying begins and is likewise regained quickly when the bird 
stops laying. White or pinkish vent color usually indicates that the hen is laying, while a yellow vent indicates that the hen is not laying. The condition of the vent other than color should likewise be considered. That is, when a hen is laying, the vent is large, expanded, and moist, and when not laying it is comparatively small and dry.

Comb. The comb of a hen that is laying or about to lay is large, feels waxy to the touch and is bright red in color.

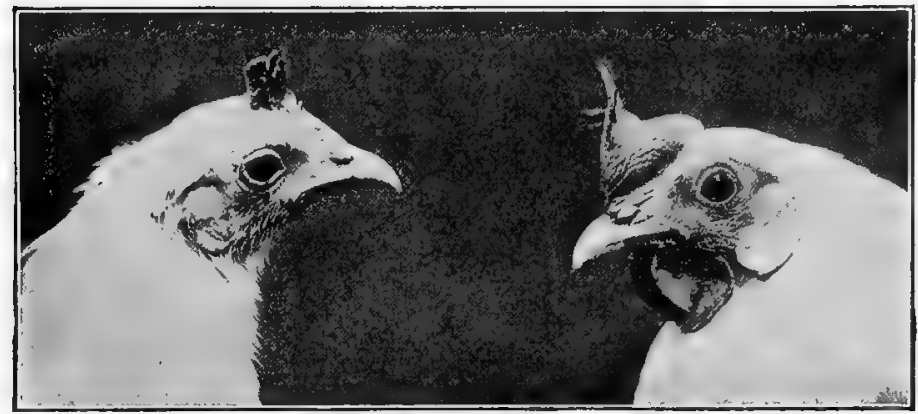

Figure 220.- The head of a good and of a poor producer. Note how the comb and wattles of the poor producer on the left are small and shrunken in size. Likewise note the listless appearance of the eye of the poor producer. The good producer on the right has a fairly large and well developed comb and wattles and a bright, keen eye.

When not laying, the comb is small, shrunken, pale or dull in color, comparatively hard and covered with whitish scales. As previously mentioned a dark or bluish color in the comb usually indicates that the hen is sick. The changes in the wattles and ear lobes are quite similar to those of the comb, but not quite so marked. When considering the size of the comb of the fowl the difference in the size of the combs of the various breeds should likewise be considered.

Pelvic and keel bones. The pelvic bones can be felt as points on each side of the vent. As the hens stoplaying there is a tendency for them to take on fat and this condition is noticeable on these bones. 
Again, when a hen is not laying, these bones feel thick and rigid. When she is laying, these bones are comparatively thin and flexible. A most valuable indication as to whether a hen is laying or not is the spread or distance between these pelvic bones. When laying, the distance between them is greater than when not laying. This distance, or spread, can be measured by determining how many fingers can be placed between the bones.

When the spread measures two fingers or less, it is very

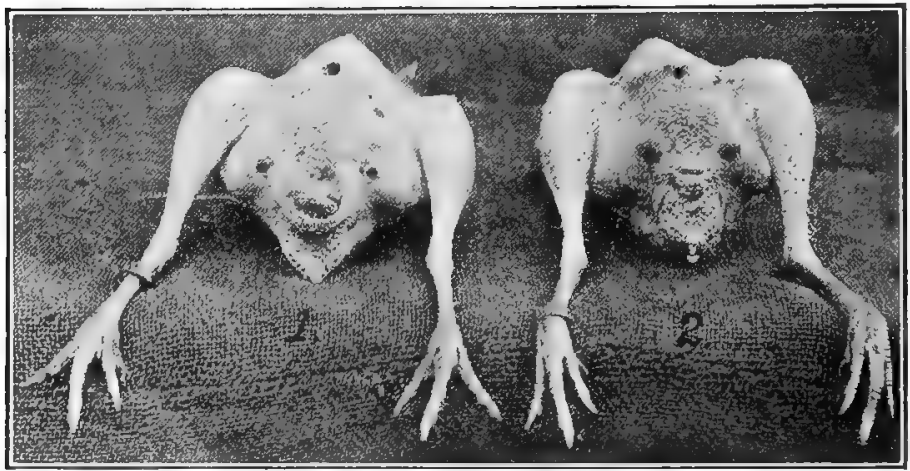

Figure 221.-These fowls have been killed and dressed in order to show the position of the two pelvic bones and of the keel or breast bone. The black dots on either side of the vent in each case show the location of the pelvic bones. The black dots immediately above these in each case show the location of the keel bone. The distance between the pelvic bones and the pelvic bones and the keel bone of the bird on the left being greater indicates that she is the better producer. The closeness of those bones as shown on the bird on the right indicates that she is the poorer producer.

probable that the hen is not laying, while if the spread is greater she is probably in laying condition. When measuring this spread, the difference in the size of hens of different breeds and the corresponding difference in the spread should be kept in mind. It is natural to suppose that a laying hen is a good eater and, therefore, her intestines are more distended and require more room than when she is not laying and not eating so much. It is equilly true that when 
laying the ovary and oviduct are of greater size and require more room. To provide this extra room the distance increases from the end of the keel, or breast bone, to the pelvic bones with a consequent increase in the size of the abdomen.

In the smaller breeds, such as the Leghorn, a spread of three or more fingers indicates that the hen is in a laying condition. In the larger breeds such as the Plymouth Rock, a

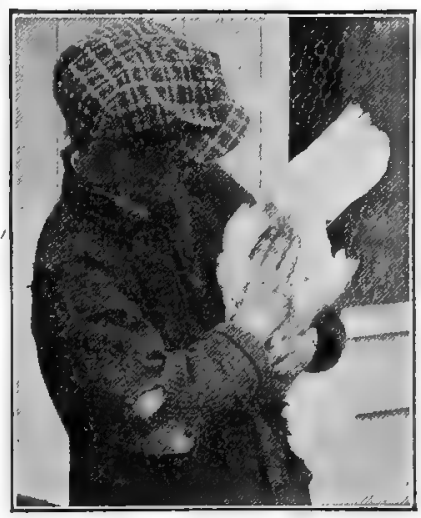

Figure 222.-This hen has a spread of three fingers between the pelvic bones, indicating that she is in laying condition. hen that is in laying condition should have a spread of four or more fingers. A spread of less than this indicates that the hen is not in a laying condition.

Flexibility of abdomen. In a good producer the abdomen is soft and flexible, owing to its increased size, together

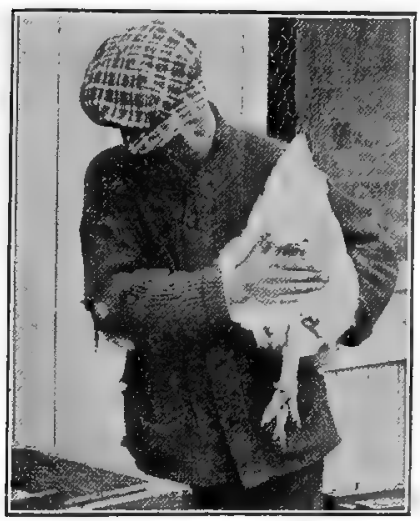

Figure 223.-This hen has a spread of four fingers between the keel and pelvic bones, which indicates good capacity and, therefore, good production. with the fact that there is less tendency at this time to accumulate fat. (Figure 224.)

As laying ceases the abdomen becomes smaller, contracted and feels harder and less flexible. When culling the flock, the fact should be kept in mind that it is safer to depend upon the agreement of a combination of several of the characteristics as mentioned herein rather than to select by any one point alone. 
The kind to cull. Hens possessing the following characteristics or a combination of such characteristics should be culled as poor producers: Those that are sick, weak, lacking vigor, inactive, poor eaters, as well as those that have molted or started to molt early, those with small, dry, puckered vents, with small shriveled, hard, dull colored combs, with thick rigid pelvic bones, with pelvic bones that

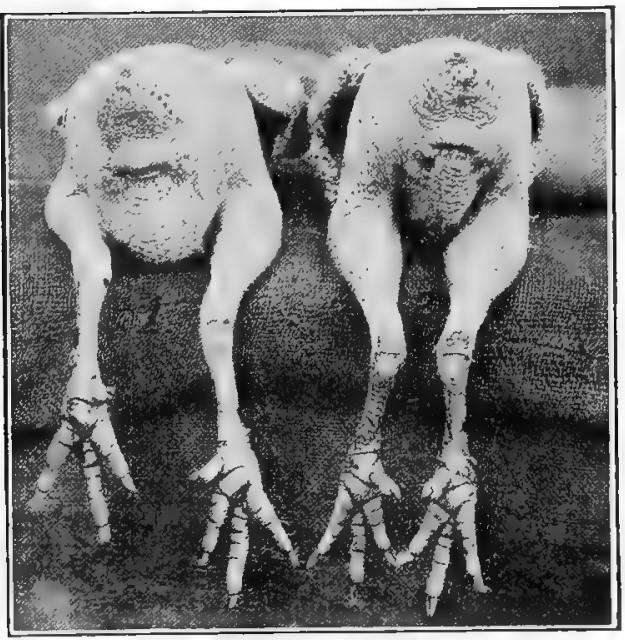

Figure 224,-The hen on the left has a full, flexible, expanded abdomen, indicating that she is laying. The hen on the right shows a hard contracted abdomen, indicating that she is not laying. are close together, small spread between pelvic bones and rear end of keel, and small hard abdomen. In yellowskinned breeds poor producers also should show yellow or mediu m yellow shanks, yellow beaks and vent. See pages 348 , 349 , for the color of the skin, ear lobes, and shanks of the standard breeds.

The kind to save. Such hens that are healthy, strong, vigorous, alert, active, and good eaters should be saved as good producers, that is, those that have not molted or are just beginning to molt by September, having large, moist vents, with large, bright red combs, thin flexible pelvic bones well spread apart, a wide spread between the pelvic bones and rear end of keel, and a large, soft, pliable abdomen. 
Laying hens of yellow-skinned breeds should show pale or white shanks and pale or white beaks and vents.

\section{QUESTIONS}

1. What two purposes does culling the flock accomplish?

2. What points should be observed when culling young stock?

3. Why should continuous culling be carried on in a general way throughout the year?

4. What is the best time of the year when systematic culling of the layers should be practiced?

5. What are the characteristics usually associated with fowls that lack vigor and are sick?

6. Other things being equal, what hens should be retained as good producers, those that molt in July? Those that molt in August? Those that molt during the latter part of September?

7. What effect has egg production on the color of fowls having yellow legs and beak?

8. Describe the appearance and color of the vent in a good and of a poor producer.

9. What is the appearance of the comb and ear lobes in a good and in a poor producer?

10. Where are the pelvic bones located?

11. What should be the distance between the pelvic bones in a good and in a poor producer?

12. What governs the distance of the keel bone from the pelvic bones of a hen?

13. What should be the distance between the keel and pelvic bones in a good and in a poor producer of the smaller breeds, such as the Leghorn, and of the larger breeds, such as the Plymouth Rock?

14. What is the condition of the abdomen when a hen is laying? When not laying?

\section{SUGGESTIONS}

1. Culling the flock is of great importance. Cull systematically at least once a year.

2. Retain the non-producers that have been culled for a week or ten days before sending them to market. These birds should be kept in a separate place from the good producers and careful observation should be made as to the number of eggs they produce, comparing the number produced by the culls with those produced by the hens selected as profitable layers. If this culling is done properly, the eggs laid by the poor producers will be but few as compared with those laid by the hens selected as good layers.

3 . Try to interest others in culling. A demonstration with persons interested will be most beneficial.

4. Remember that the hen that lays is the hen that pays, and the way to determine the hen that lays is to practice systematic culling. Instead of your keeping hens, let the hens keep you.

\section{REFERENCES}

"Culling the Poultry Flock," U. S. Department of Agriculture, Circular No. 31. 


\section{CHAPTER XIV}

\section{TURKEYS, DUCKS, GEESE, GUINEA FOWLS AND PIGEONS}

TURKEYS

Turkeys are ordinarily raised on general farms rather than on an extensive commercial scale. Years ago New England was famous for its turkeys; but, as the country developed, the number produced grew less until at the present time but comparatively few are found throughout that section. The majority of turkeys are now grown in the middle and southwestern states. Plenty of range is the most essential factor for the successful production of turkeys. This, together with the fact that turkeys do best in a semidry climate, is one of the reasons why Texas ranks first as a turkey-producing state.

VARIETIES

All our varieties of domestic turkeys are descended from wild turkeys which are natives of and are found in North America. The six varieties of domestic turkeys as recognized by the American Standard of Perfection are as follows: Bronze, White Holland, Bourbon Red, Black, Narragansett, and Slate.

Bronze. This is by far the most popular and widely known variety and in appearance resembles the wild turkey. In color it is a rich brilliant copperish bronze against a background of black and brown. The tail coverts and main tail feathers have clear white tips. As will be noted from the standard weights, the Bronze is the largest of the several varieties, the standard weights being as follows: Adult cock 36 lbs., yearling cock 33 lbs., cockerel 25 lbs., hen 20 lbs., pullet 16 lbs.

White Holland. As the name would indicate, the plum- 


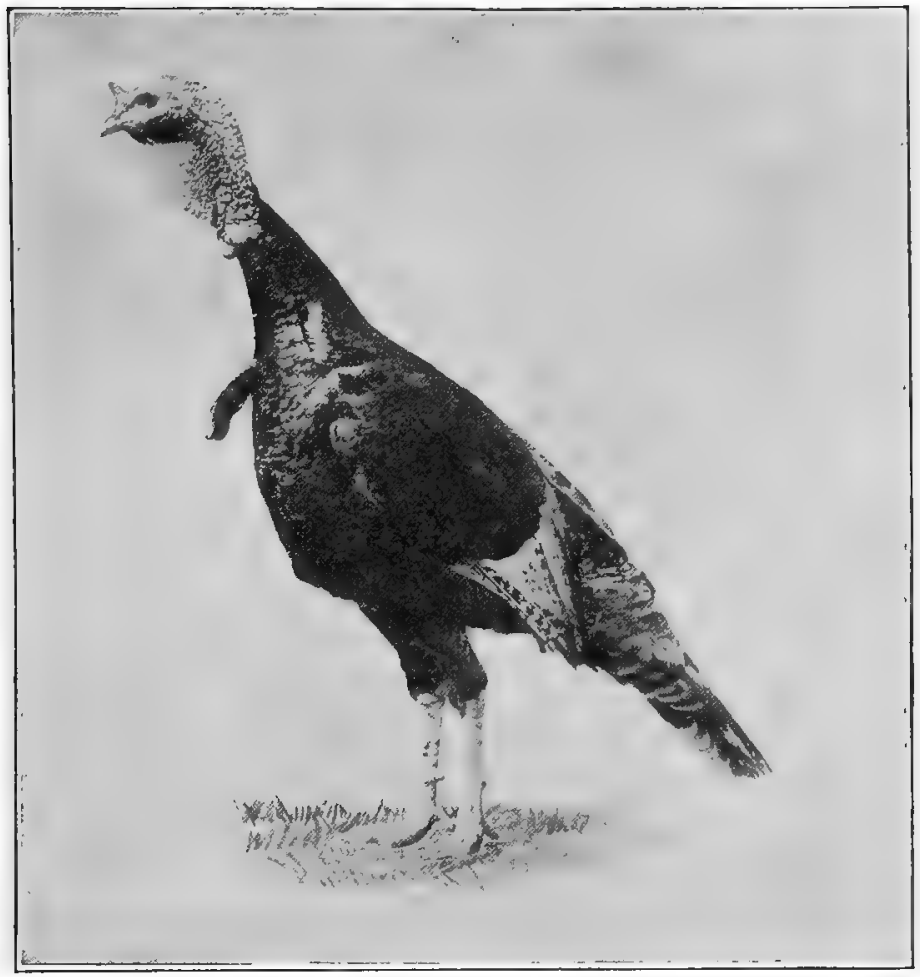

Figure 225.-Wild turkey male.

age of this variety is pure white with the exception of the beard, which is black. The standard weights are: Adult cock $28 \mathrm{lbs}$., yearling cock 24 lbs., cockerel $20 \mathrm{lbs}$, , hen 18 lbs., pullet 14 lbs.

Bourbon Red. This variety is of a deep brownish-red color, with white wings and tail. The standard weights are: Adult cock $30 \mathrm{lbs}$., yearling cock $25 \mathrm{lbs}$., cockerel 20 lbs., hen 18 lbs., pullet 12 lbs.

Black. The plumage color of this variety is of a lus- 


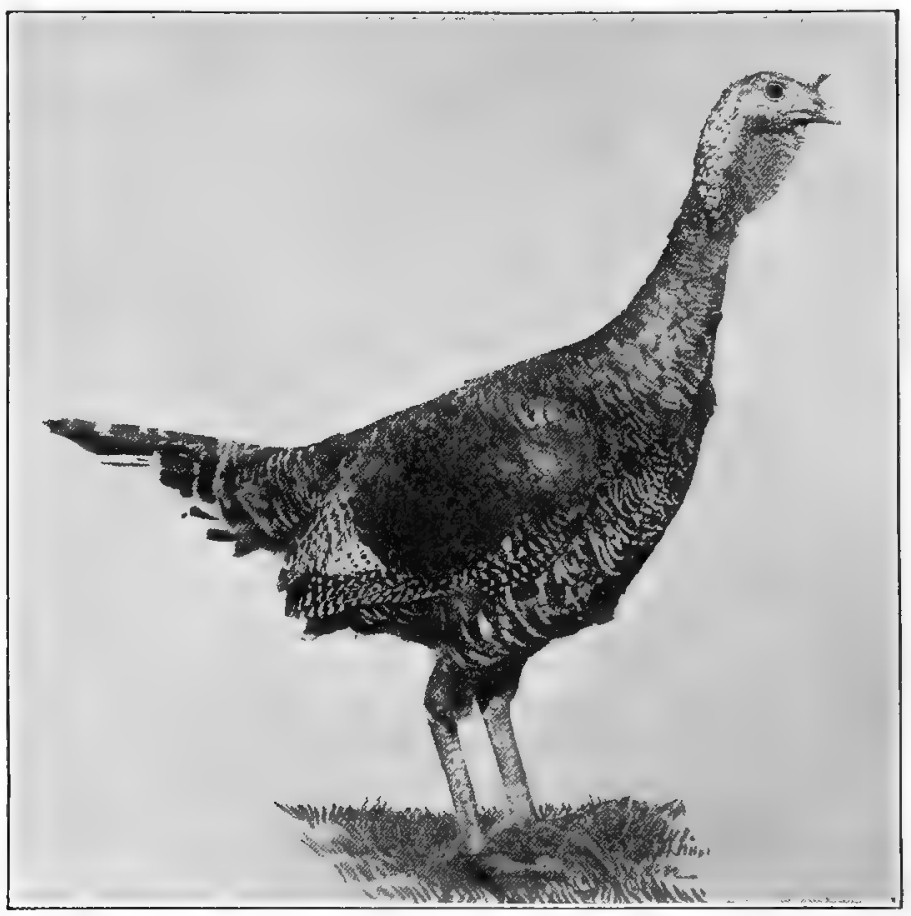

Figure 226.-Bronze turkey hen.

trous glossy black throughout. The standard weights are: Adult cock 27 lbs., yearling cock $22 \mathrm{lbs}$., cockerel $18 \mathrm{lbs}$., hen 18 lbs., pullet 12 lbs.

Narragansett. The color of the Narragansett is a steel gray against a black background. The standard weights are: Adult cock $30 \mathrm{lbs}$, yearling cock 25 lbs., cockerel 20 lbs., hen 18 lbs., pullet 12 lbs.

Slate. The plumage of this variety is of a slaty or ashy blue color more or less dotted with black. The standard weights are: Adult cock 27 lbs., yearling cock 22 lbs., cockerel 18 lbs., hen 18 lbs., pullet 12 lbs. 


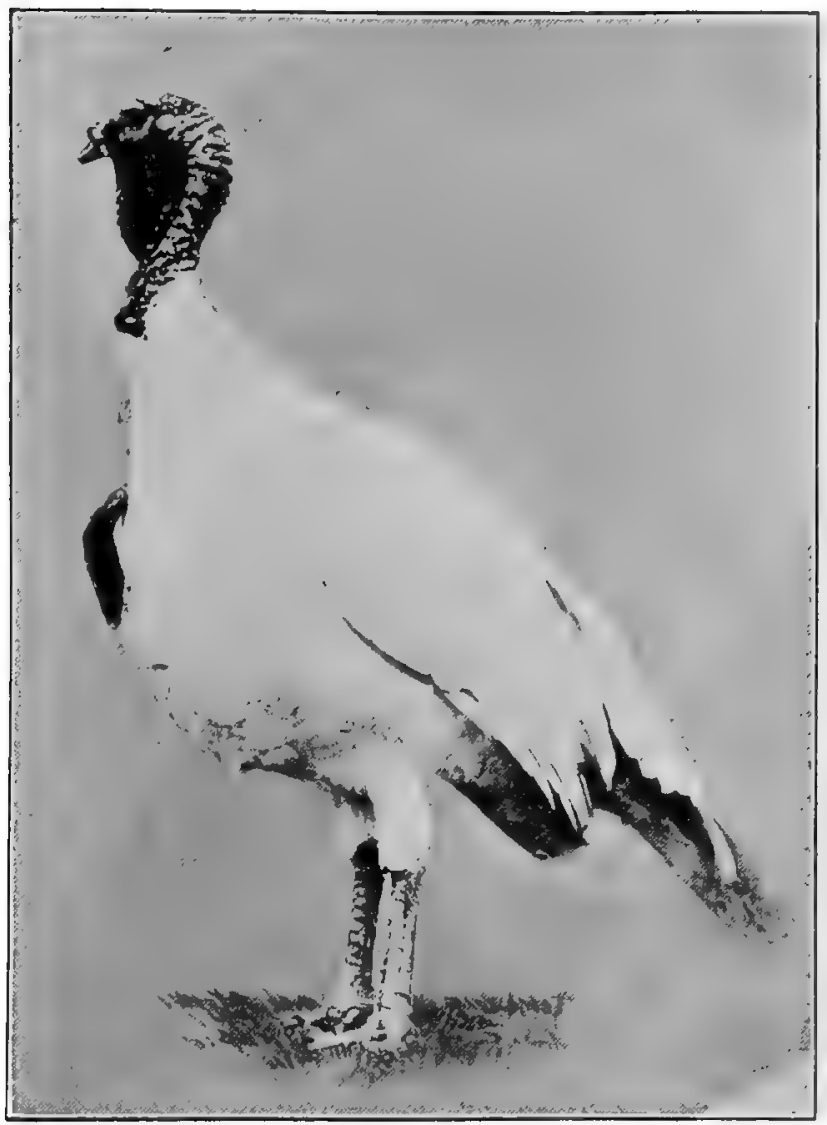

Figure 227, White Holland turkey male.

MANAGEMENT

The production of turkeys is a profitable side line for those so situated that they can give plenty of range to the flock. Experience shows that turkeys do not thrive well on limited range or in confinement. Thus free range is of importance from the standpoint of health, vigor, and. 


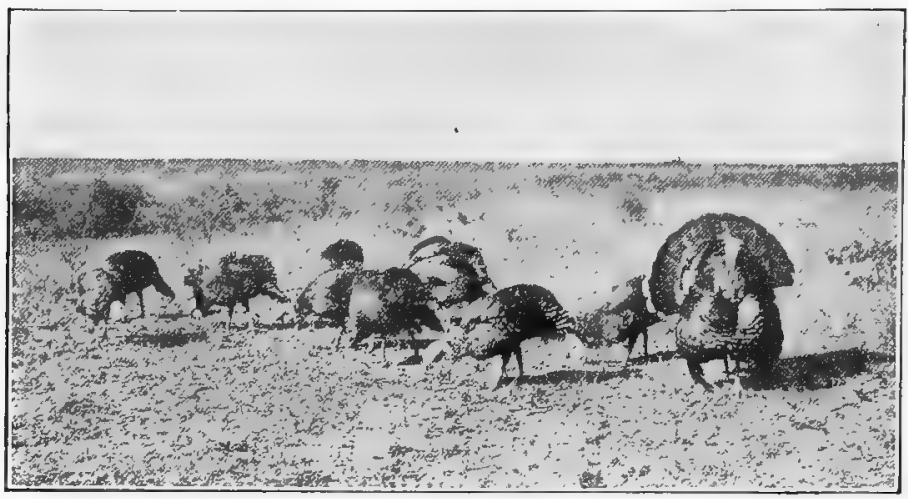

Figure 228.-Flock of Bronze turkeys on range.

growth. Given free range they will readily pick up such food as grasshoppers, insects, green food and waste grains thereby reducing the cost of production.

Breeding. One of the most important factors in order to obtain success in turkey production is the proper selec-

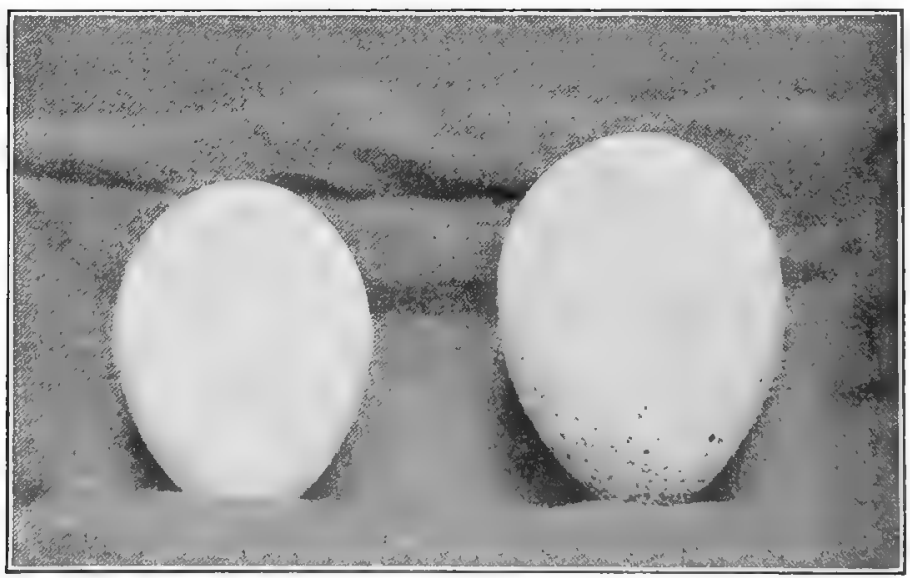

Figure 229.- Turkey eggs. The one on the left was laid by a pullet, the one on the right by a hen. 
tion of breeding stock. The breeders should be selected for vigor, size, shape, strong bone, early maturity, and color of plumage as given in the American Standard of Perfection. Ordinarily 15 turkey hens can be mated to a vigorous tom, or male bird. Turkey hens usually lay about 18 eggs in their first litter. The period of incubation for turkey eggs is 28 days. When it is not desired to have the hens incubate

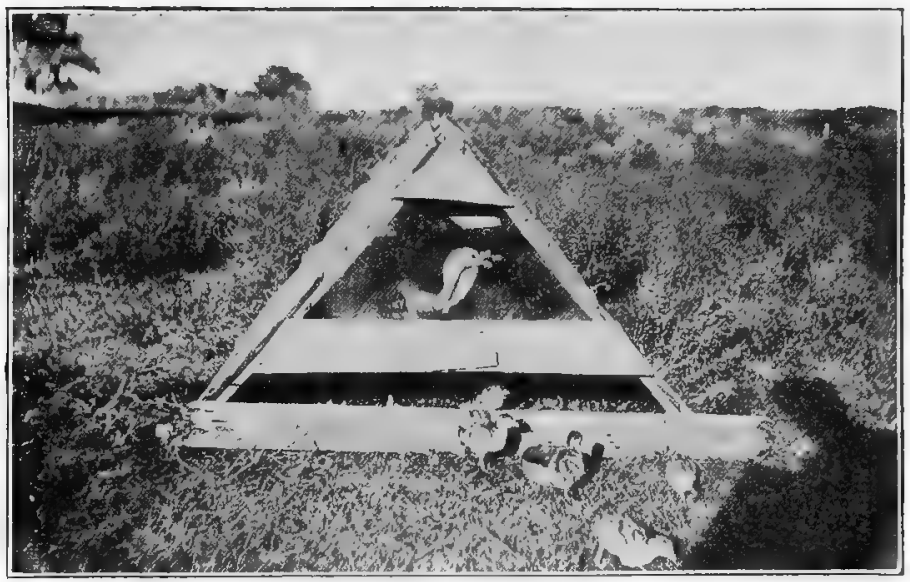

Figure 230.-Turkey hen and brood.

the eggs, they can be broken up as soon as they become broody and made to lay a second and frequently a third litter. Turkey eggs can be incubated either artificially or by natural means.

Mortality. Young turkeys, or poults, are hard to raise unless all conditions are favorable. The high death rate among poults is usually due to one or more of the follow ing causes: Exposure to dampness or cold, improper feed ing, close confinement, lice and weakness in the parent stock.

\section{DUCKS}

The production of ducks is carried on both as a farm side 


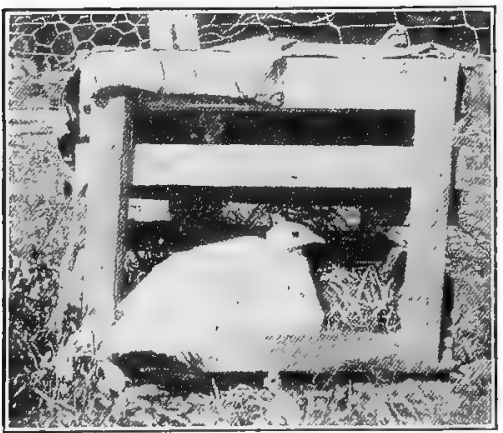

Figure 231.-Coop for turkey hen while sitting.

line on general farms and as an intensive business on a large commercial scale. While ducks are seen in many farm flocks scattered throughout the country, they are found in larger numbers on the general farms of the central western states. The large commercial duck farms are found principalIy in the East near large cities and especially on Long Island. BREEDS

In all there are eleven breeds of ducks recognized by the American Standard of Perfection, these being divided according to their economic usefulness into three classes, namely, the meat, egg, and ornamental classes. Most of these breeds with the exception of the Muscovy are said to have originated from the Mallard, or common wild duck.

THE MEAT CLASS

Pekin. The Pekin duck is one of the most popular breeds both on general farms and on commercial duck farms.

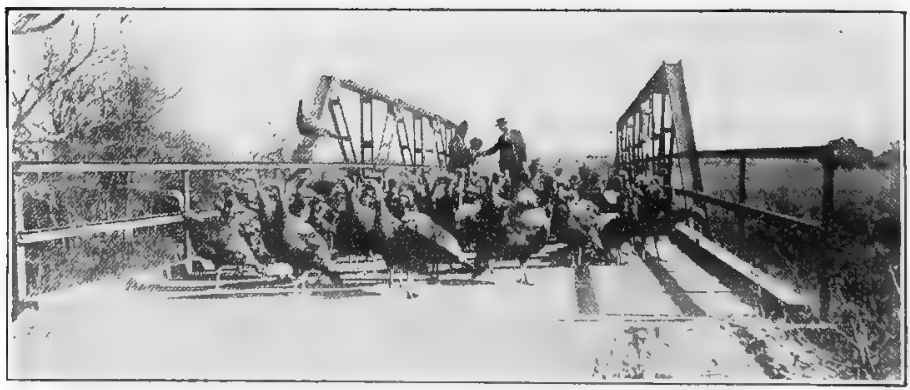

Figure 232.-Driving turkeys to market. 


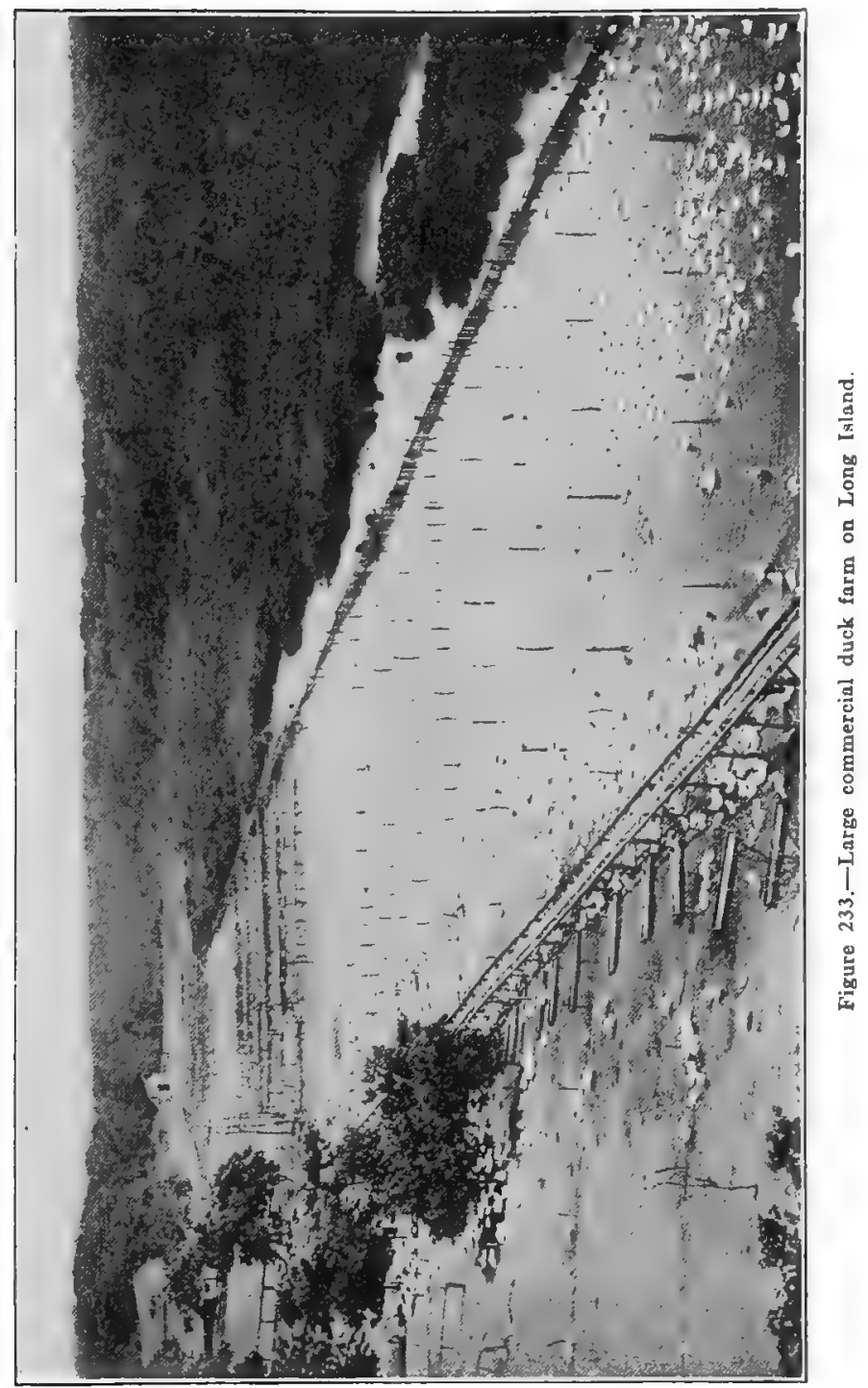


It is most extensively found on commercial duck farms that make a specialty of producing "green" ducks, that is, ducklings which are grown rapidly and marketed when from 8 to 12 weeks old and weigh from $4 \frac{1}{2}$ to 6 pounds apiece.

The White Pekin is the only variety of this breed, it having a yellow skin, and white or creamy-white plumage.

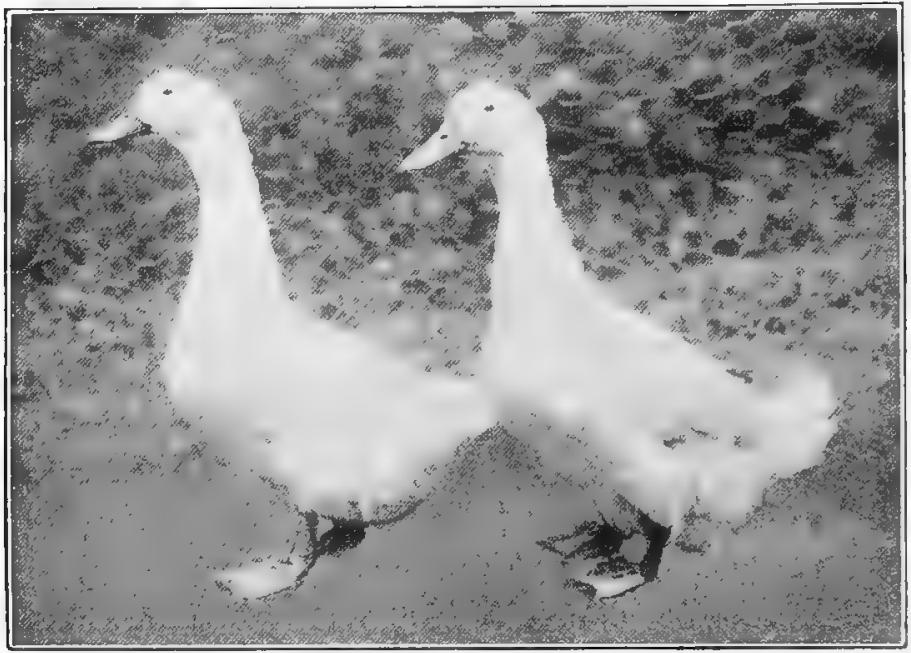

Figure 234.-Pekin drake and duck.

The standard weights for Pekin ducks are:Adult drake 9 lbs., young drake 8 lbs., adult duck 8 lbs., young duck 7 lbs.

Aylesbury. This breed which is likewise white in color is quite similar to the Pekin, the standard weights of both of these breeds being identical. This breed, which is a native of England, is quite popular in that country as a producer of duck meat.

Muscovy. The Muscovy is found more on general farms than on commercial duck farms, owing to the fact that they are not so well suited to highly intensive conditions or to 
the production of market ducks, owing to the variation in size between the male and female. The two varieties of the Muscovy duck are the White and Colored. The White variety is pure white throughout all sections of its plumage. In the colored variety the breast, body, and back are blueblack in color, broken with some white. The wing coverts are similar in color, while the tail is black. The standard weights of this breed are: Adult drake $10 \mathrm{lbs}$, young drake 8 lbs., adult duck 7 lbs., young duck 6 lbs.

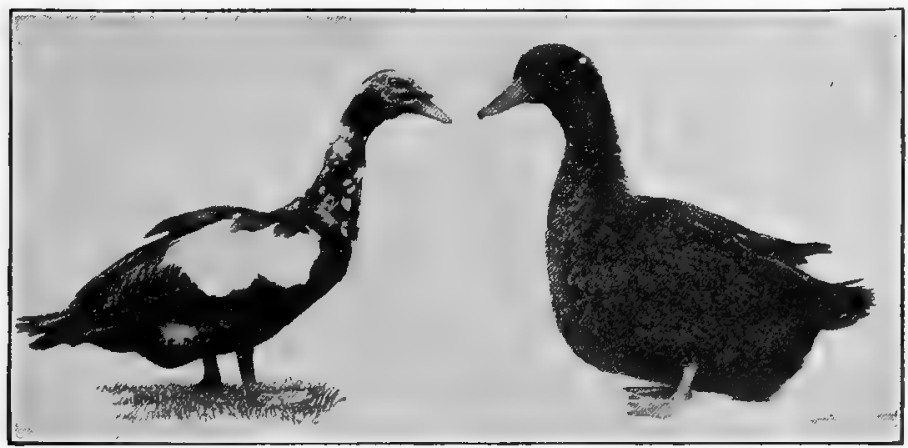

Figure 235.-Colored Muscovy drake. Figure 236.-Cayuga duck.

Rouen. In shape and type this breed is quite similar to the Pekin and has the same standard weights. There is but one variety of this breed, it being colored. The plumage of the male and of the female varies with different colored markings.

Cayuga. This breed likewise resembles the Pekin in shape. It is not quite so desirable as the Pekin as a market duck, owing to the dark plumage. The plumage is greenish black in all sections of the body. The standard weights are: Adult drake 8 lbs., young drake 7 lbs., adult duck 7 lbs., young duck 6 lbs.

Buff. The plumage of this breed, of which there is one 
variety is an even shade of rich fawn buff with the exception of the head and the upper part of the neck in the drake which are of a seal-brown color. The standard weights are one pound lighter in each class than in the Pekin.

Swedish. The Swedish duck, or, as it is sometimes called, the Blue Swedish, is quite similar to the Pekin in type, but smaller. The plumage of the Blue Swedish is a steel blue in all sections except that it has a white bib on the neck

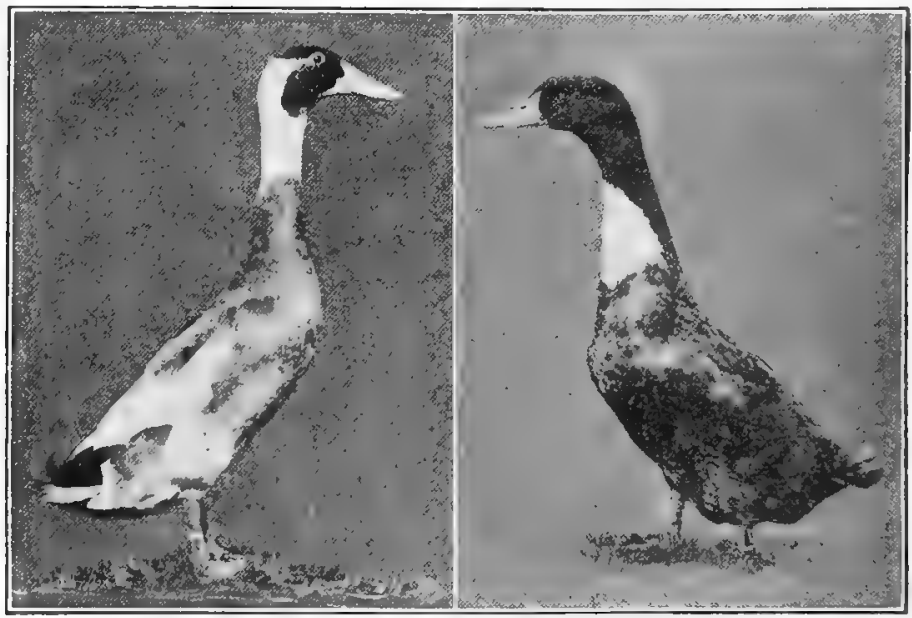

Figure 237.-Fawn and White

Figure 238.-Blue Swedish drake. Runner drake.

and the two main flight feathers are pure white. The standard weights are: Adult drake 8 lbs., young drake $61 / 2$ lbs., adult duck $7 \mathrm{lbs}$, young duck $51 / 2 \mathrm{lbs}$.

\section{THE EGG CLASS}

Indian Runner. There is but one standard variety included in this class, that being the Indian Runner, or, as it is sometimes called, the Runner Duck. While this breed is noted for its high egg production, at the same time, having a yellow skin, it makes good broilers when weighing from 
$2 \frac{1}{2}$ to $3 \mathrm{lbs}$. apiece when about 6 weeks of age. There are three varieties of the Indian Runner duck: the White, Fawn and White, and Penciled, the Fawn and White variety being probably the most popular of the three. As will be noted from the standard weights, this breed of ducks is considerably smaller than those of the meat class, the weights being: Adult drake $4 \frac{1}{2} \mathrm{lbs}$., young drake $4 \mathrm{lbs}$., adult duck 4 lbs., young duck $31 / 2$ lbs.

\section{THE ORNAMENTAL CLASS}

This class includes the following standard varieties: The Call, Crested White, and East India ducks. Each of these is raised primarily for ornamental purposes, the Call being more common in this country than the other two.

MANAGEMENT

The production of ducks will be found practical and profitable both from the standpoint of eggs and meat, when a profitable market can be found. Duck eggs can be hatched successfully by either natural or artificial methods. The period of incubation for duck eggs is 28 days, with the exception of the Muscovy ducks, which is from 35 to 37 days. Matings are usually made in the proportion of one drake to 5 or 6 ducks.

\section{GEESE}

Geese can be raised successfully in practically any part of this country and are found on many general farms. They are more frequently found, however, on the general farms in the South and in the Middle West. Geese are primarily raised as a meat food. The one factor that is against their wider use as a table fowl is the fact that they are too large for the average family.

\section{BREEDS}

There are six breeds of geese recognized by the American Standard of Perfection, namely, the Toulouse, Emden, Chinese, African, Wild, or Canadian, and Egyptian. 
The Toulouse. This is the largest of the standard breeds of geese, the standard weights being: Adult gander $26 \mathrm{lbs}$, young gander $20 \mathrm{lbs}$., adult goose $20 \mathrm{lbs}$., young goose $16 \mathrm{lbs}$. The color of the plumage is dark gray on black, gradually shading to a light gray, edged with white on the breast

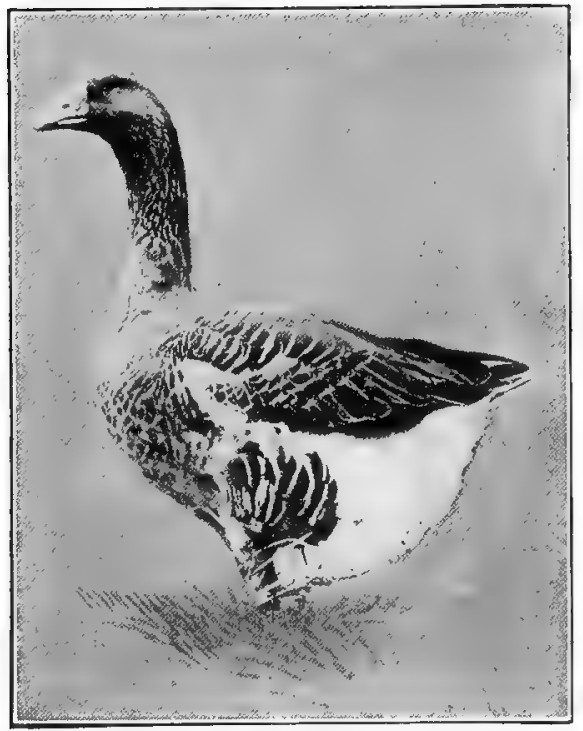

Figure 239.-Toulouse goose.

and to white on the abdomen. The Toulouse is a comparatively good layer, producing from 20 to 35 eggs a year, grows rapidly, and makes a good market fowl.

The Emden. The plumage of this breed is pure white. It is slightly smaller than the Toulouse, the standard weights being: Adult gander 20 lbs., young gander 18 lbs., adult goose 18 lbs., young goose $16 \mathrm{lbs}$. As a table fowl this breed is quite similar to the Toulouse. When picked, however, it makes a better appearance than the Toulouse, owing to the fact that it has white pin feathers. This breed grows rapidly and matures early.

Chinese. There are two varieties of Chinese geese, the Brown and the White. The Brown is of a grayish brown color, somewhat lighter on the under side of the body, with a brown head and dark brown or black knob on top of the head and a black bill. The White Chinese goose 
has pure white plumage with an orange colored bill and knob. Both of these varieties are desirable market fowls, being prolific layers and rapid growers. The standard weights are: Adult gander 12 lbs., young gander $10 \mathrm{lbs}$., adult goose $10 \mathrm{lbs}$., young goose $8 \mathrm{lbs}$.

African. The plumage is dark gray on the wings and back and gray or light gray on the neck, breast, and under side of body. The head is dark gray or black. It is in the same market classas the previously mentioned breeds. The standard weights are the same as for the Emden except that those of the young gander and young goose are 16 and 14 pounds respectively.

Wild, or Canadian. The Canadian geese are not kept

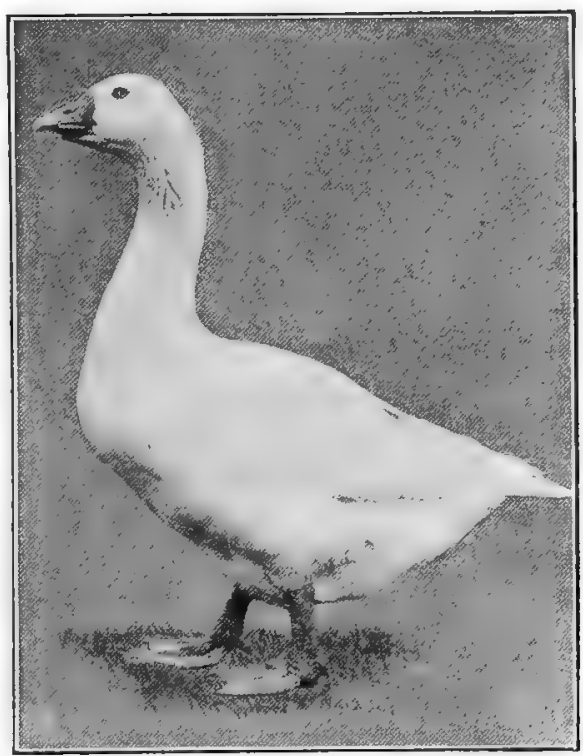

Figure 240.-Emden goose. to any great extent in captivity. When raised under domestic conditions, however, the young geese are usually sold to hunters to use as decoys. The body plumage is gray or dark gray in color, the breast being light gray and the lower part of the body white from the wings to the tail. The standard weights are: Adult gander $12 \mathrm{lbs}$., young gander 10 lbs., adult goose 10 lbs., young goose 8 lbs.

The Egyptian. This breed is kept primarily for orna- 
mental purposes. It resembles the Canadian goose in shape, stands higher, and weighs 2 pounds less in each class. The plumage on the back and body is gray and black with the lower part of the body a pale buff or yellow color, penciled with black. The breast is chestnut and gray and the tail is black. The wings are of a glossy black with white shoulders.

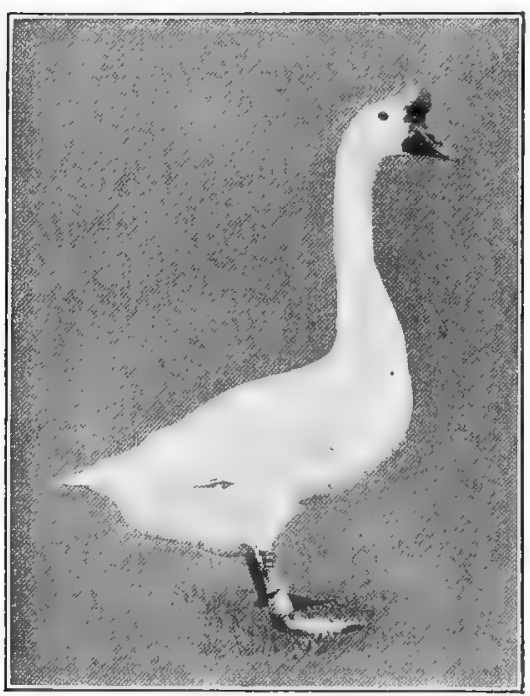

Figure 241.-White Chinese goose.
MANAGEMENT

Geese can be raised in small numbers successfully and at a profit on many farms, especially on low rough pasture land having a supply of water. Geese need a house only during cold or stormy weather during which time an open shed should be provided. The period of incubation of goose eggs varies from 28 to 30 days. Ordinarily goose eggs are set under hens so that the geese will continue laying eggs for a longer period. Geese that become broody can usually be broken up by confining them in a slat-bottomed coop for from 2 to 4 days. During this time water can be provided, but no feed should be given. One gander is usually mated to 1 or 2 geese.

\section{GUINEAS}

Guineas are becoming quite popular as a table fowl and especially as a substitute for partridges, quail, and pheasants. 
Many hotels and restaurants in large cities are eager to secure young guineas to be served at banquets and dinners as a special delicacy. They are usually raised in small flocks on general farms and need a large range for best results.

\section{VARIETIES}

There are three varieties of domesticated guinea fowl, namely, Pearl, White, and Lavender, of which the Pearl is the most popular.

The Pearl. The Pearl guinea has purplish gray plumage regularly dotted or marked with white. In addition to its value as a table fowl the feathers of this variety are frequently used for ornamental purposes.

The White. The White guinea fowl is pure white in color and

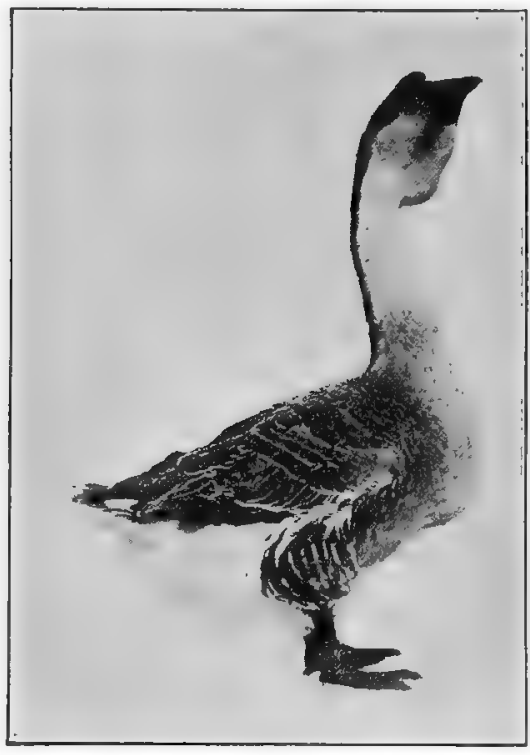

Figure 242.-African gander. the skin is somewhat lighter than that of the Pearl variety.

The Lavender. This variety is quite uncommon and resembles in color markings the Pearl variety except that the plumage is of a light gray or lavender, regularly dotted with white dots.

Guineas have not yet been recognized by the American Standard of Perfection. No standard weights, therefore, are given. On an average, both the male and female weigh from 3 to 4 pounds at maturity. 


\section{MANAGEMENT}

Guinea fowls have a tendency to mate in pairs. One male, however, may be mated successfully with 3 or 4 females. Guinea hens usually begin to lay in April or May and will produce from 20 to 30 eggs before becoming broody. If

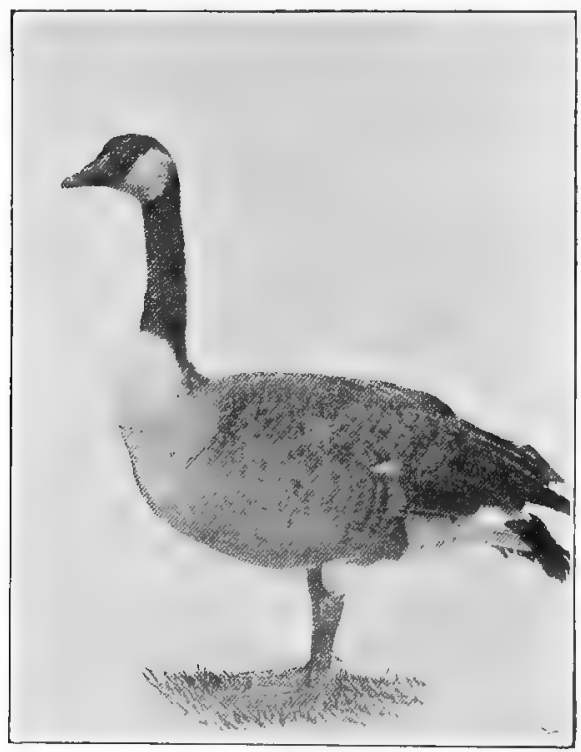

Figure 243.-Wild, or Canadian, goose. not allowed to sit, they will continue to lay throughout the summer, producing from 40 to 60 eggs. Ordinarily hens are used to hatch and rear guinea chickens. The period of incubation is from 26 to 28 days. Guinea hens and turkey hens, however, may be employed successfully. Guineas are usually marketed late in the summer when they weigh from 1 to $11 / 2$ pounds when about $21 / 2$ months of age.

\section{PIGEONS}

Pigeons may be successfully raised and are usually found in practically all sections of the United States, both on farms and in cities. Aside from being raised as pets or for flying purposes, the real economic value of pigeons is for the production of squabs. Squab raising is usually conducted as a special business or as a side line on a small scale in towns, cities and on general farms. An intimate knowledge 
of the business and considerable experience is necessary to insure the greatest success in squab production on a commercial scale.

BREEDS

Among the varieties of pigeons kept for the production of squabs are the Runts, White Kings, Carneaux, Homers, Maltese, Mondaines and

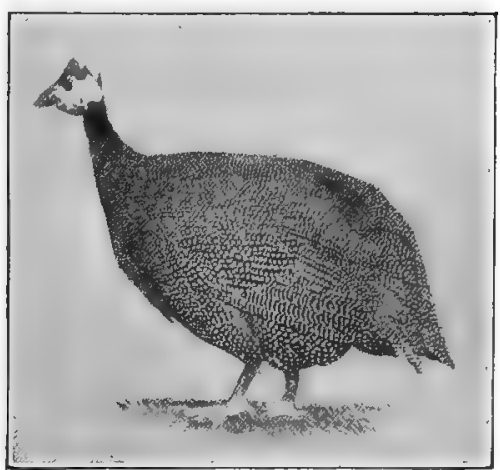

Figure 244.-Pearl Guinea. Hungarians. The White Kings and Carneaux are regarded by many as the better varieties, as they are good breeders and produce a popular-sized squab demanded by most markets. Homers are good breeders, though small; but a RuntHomer cross makes a very good squab-producing pigeon.

Runts. Contrary to their name, Runts are the largest of all varieties of pigeons. The weights range as follows: Old

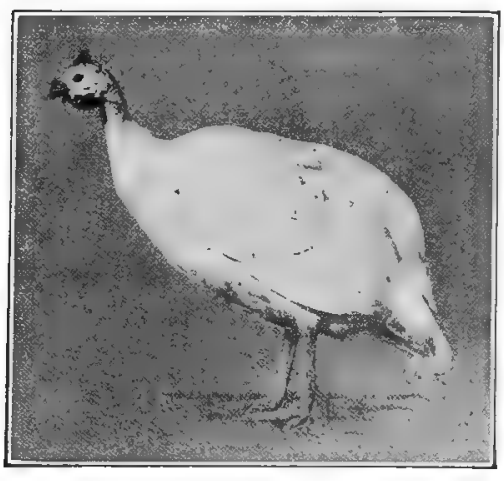

Figure 245.-White Guinea. cocks 28 to 48 ozs., old hens 28 to 40 ozs., young cocks 23 to 40 ozs., young hens from 22 to 36 ozs. There are seven distinct varieties - White, Blue, Black, Yellow, Red, Silver, and Dun. They are bred extensively especially on the Pacific Coast.

White Kings. This breed comes in but one color, white, as the name 
indicates. The standard weights range as follows: Old cocks 22 to 24 ozs., old hens 20 to 22 ozs., young cocks 20 to 22 ozs., young hens 18 to 20 ozs. They are fast breeders of white-meated squabs and are becoming very popular among large commercial squab breeders.

Carneaux. Carneaux are also a very popular squab pigeon. Like the White Kings they are fast breeders of

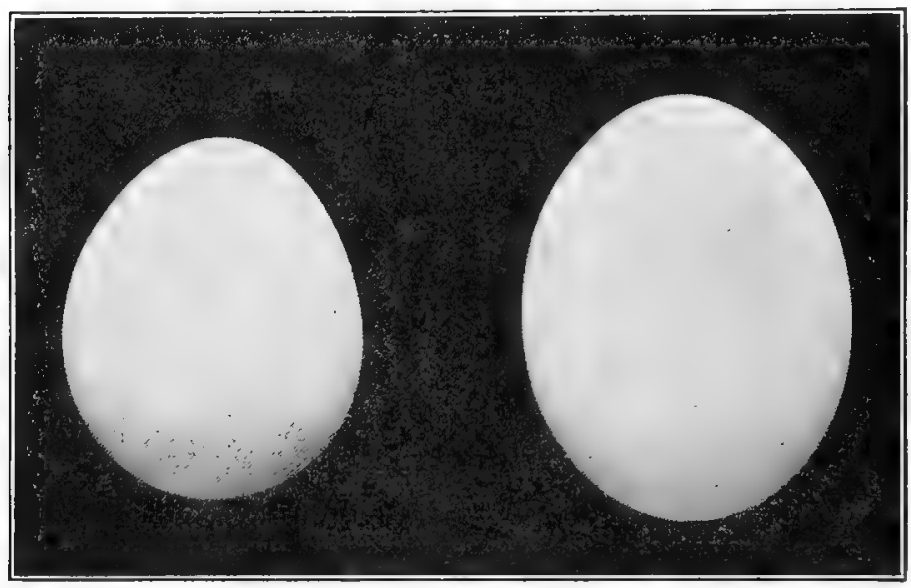

Figure 246.-Showing the relative size and shape of a Guinea egg on the left as compared with a hen's egg on the right. The color of a Guinea egg is dull buff.

popular-sized squabs that dress off nice for market purposes. Their standard weights are: Old cocks 22 to 25 ozs., old hens 20 ozs., young cocks 20 to 23 ozs., young hens 18 ozs. They come in three colors-Red, Yellow, and Splashed, the latter color usually being a mixture of red and white.

Homers. The Homing pigeon derives its name from the fact that, when carried away and released, it will usually return to its home. This trait has led to considerable sport in training such birds to fly long distances. In the recent World War, Homing pigeons played a most important part 
in carrying messages from the Front where other means of communication failed. The Homer is a good breeder; but, owing to its small size, is not as profitable as a squab - producing variety. It comes in a variety of colors, including blue, black, silver and a mixture of these colors.

Maltese. Maltese pigeons at one time were bred quite extensively for squab purposes, but

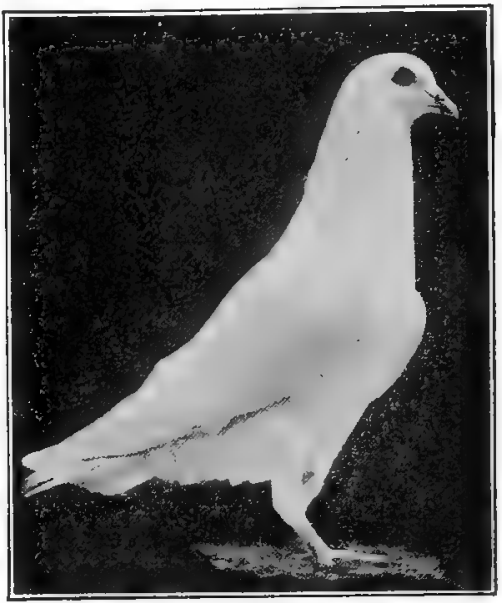

Figure 247.-White King. the standard requirements call for long legs and long necks. Breeders find, therefore, that they are not as profitable for squab breeding as the White Kings and Carneaux.

Mondaines. The Mondaine pigeon is one of the later creations. It is smaller than the Runts, but larger than Kings or Carneaux. They have a rather long, slender body, but some breeders claim that they are good squab pro-

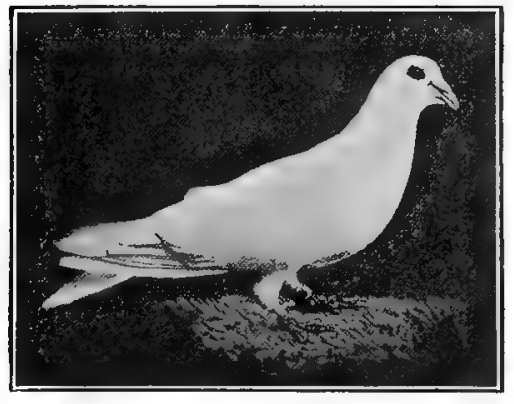

Figure 248 White Runt. ducers. They come in white and blue barred. Their standard weights are: Old cocks 27 ozs., old hens 24 ozs., young cocks 24 ozs., young hens 22 ozs.

Hungarians. Hungarians are a species of the hen pigeon family. They are very similar to 


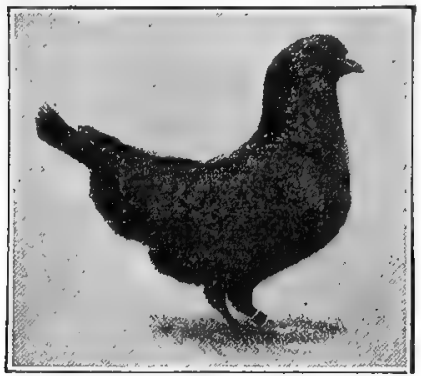

Figure 249.-Maltese pigeon.

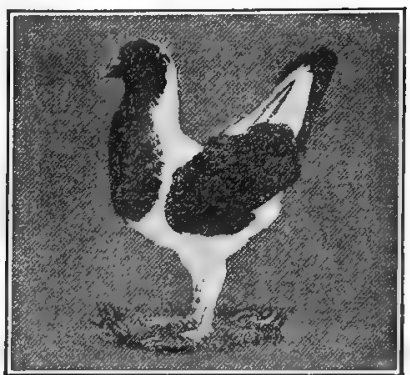

Figure 250.-Hungarian.

the Maltese in type, having rather long legs and long necks, and carry a handsome plumage of black and white and yellow and white. They are not generally kept for squab breeding purposes, but are regarded as very good breeders.

\section{MANAGEMENT}

Pigeons always mate in pairs and usually remain so throughout life, unless one of the birds dies or becomes permanently injured. A mating can be broken up and other birds mated if desired. Pigeons are usually mated at from 4 to 8 months of age. The hen pigeon usually lays two eggs in 3 days before she starts to sit. It is not

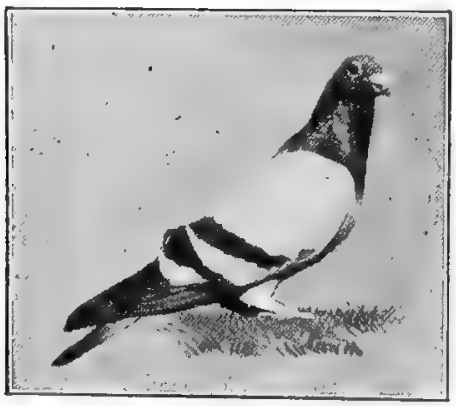

Figure 251,-Homer pigeon.

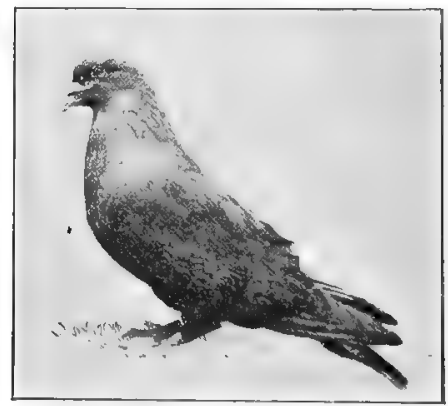

Figure 252.-Carneau pigeon. 


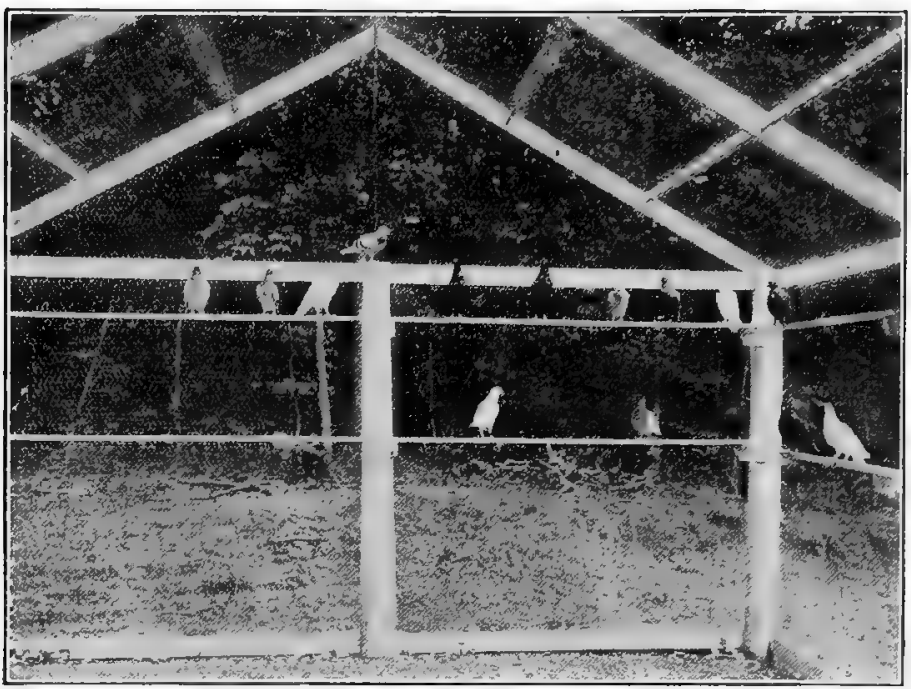

Figure 253,-A well arranged pigeon fly.

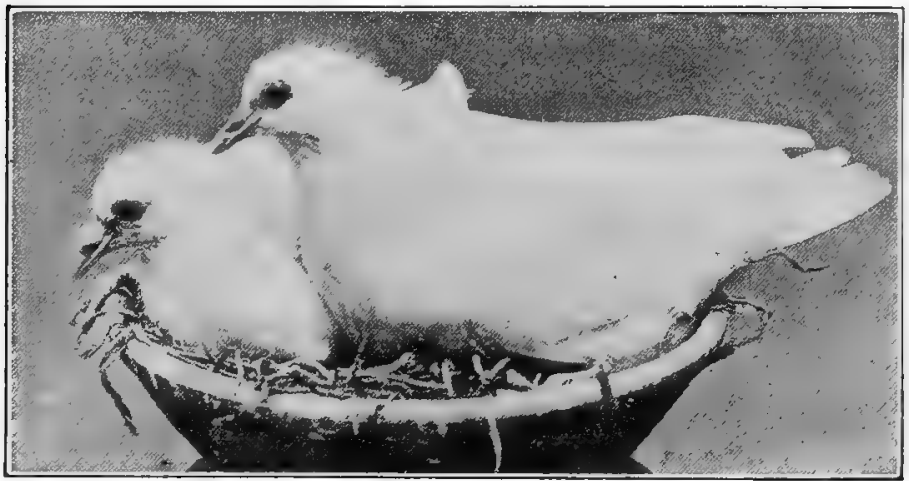

Figure 254.-A pair of White King squabs 4 weeks old. 


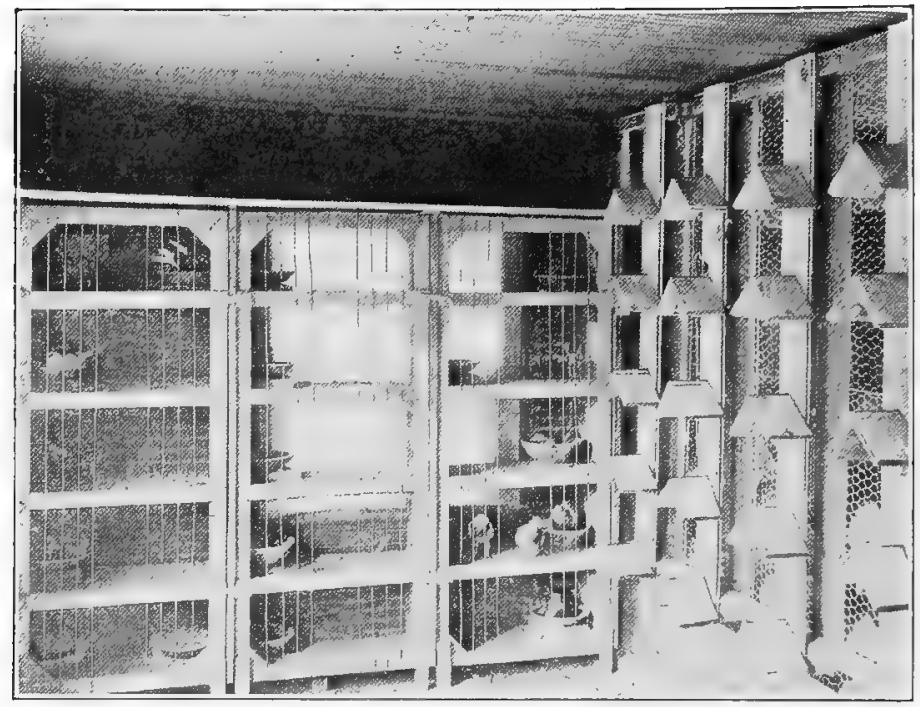

Figure 255.-Interior arrangement of a pigeon loft showing nests, nest pans and roosts on the right.

advisable to place an extra egg or eggs in the nest, as a pair of pigeons can raise only two good squabs at a time. The period of incubation is about 17 days. Squabs are fed by their parents until they are from $3 \frac{1}{2}$ to $4 \frac{1}{2}$ weeks of age.

\section{QUESTIONS}

1. What are the six varieties of domestic turkeys as recogntzed by the American Standard of Perfection?

2. Which is the most popular variety of turkeys? Describe this variety.

3. Under what conditions should turkeys be grown?

4 . What are some of the important factors that should be considered when breeding turkeys? poults?

5. What is the main cause of mortality among young turkeys, or

6. In what three classes are the breeds of ducks divided?

7. Describe the Pelin duck. What are "green" ducks?

8. What are the two varieties of the Muscovy durk?

9. Name the thrce varieties of the Indian Runner duck. 
10. What is the principal value of Indian Runner ducks?

11. Name the three varieties of ducks included in the ornamental class.

12. What is the period of incubation for duck eggs?

13. Name the six standard breeds of geese.

14. Describe the Toulouse goose. How does this variety correspond in weight to the other five standard varieties?

15. Discuss the value of guineas as table fowls.

16. Discuss, the management of guineas.

17. For what purpose are pigeons usually kept?

18. Describe the two more popular varieties of pigeons and their value as producers of squabs.

19. Discuss the management of pigeons.

\section{SUGGESTIONS}

1. In order to familiarize yourself with the extent to which the several kinds of poultry mentioned in this chapter are grown in your community, make a survey, listing the various flocks of turkeys, ducks, geese, etc., found in your nighborhood, together with the varieties grown.

2. Assuming that you were going to raise turkeys, what facts would you first consider as concerning the location, nearness to markets, and variety selected? Compare your conclusions in this respect with the possibility of producing ducks, geese, guineas, and squabs. After considering each of these subjects thoroughly, which do you feel will be the most profitable?

3. Should you be interested particularly in any one of these subjects, that is, as pertaining to the production of turkeys, or ducks, or geese, etc., inquire of your state agricultural college or the U. S. Department of Agriculture for additional information on these phases of poultry keeping.

\section{REFERENCES}

Turkey Raising, U. S. Department of Agriculture Farmers' Bulletin 791 , by $A$. S. Weiant.

Duck Raising, U. S. Department of Agriculture Farmers' Bulletin 679, by Alfred $R$. Lee.

Geese, U. S. Department of Agriculture Farmers' Bulletin 767, by Harry M. Lamon and Alfred R. Lee.

The Guinea Fowl, U. S. Department of Agriculture Farmers' Bulletin 828 , by A. S. Weiant.

Squab Raising, U. S. Department of Agriculture Farmers' Bulletin 684, by Alfred R. Lee. 


\section{CHAPTER XV}

\section{PREPARING BIRDS FOR EXHIBITION}

\section{OBJECT AND VALUE OF EXHIBITING POULTRY}

Since the first exclusive poultry exhibit, was held in Boston in 1849 poultry shows as a class have played a most important part in the development of the industry. A poultry show properly conducted is the final court in determining the merits of a fowl, and in determining the ability of a breeder to produce standard-bred stock. Then, too, "Poultry shows or exhibitions play a most important part in improving the various breeds and varieties. Not only do they serve to foster competition, and create rivalry, thereby increasing interest in breeding, but they also make it possible to compare results. In this way the individual breeders have an opportunity to see what other breeders have accomplished, and to observe where their birds are strong or weak in comparison. Thus they learn where they must seek to improve, if they expect to work their way to the top or if they expect to stay there, when once they have arrived." *

In addition to these advantages the exhibition of fowls provides additional features which should not be overlooked. The best individuals in each class or variety are awarded premiums and ribbons, designating their place as prize winners. While the money prizes in most instances are not of great amounts, at the same time the honor and distinction of winning can not be measured in terms of dollars and cents. The advertising value of such winners is of great importance, and plays a significant part in the affairs of one who produces and has for sale breeding stock and eggs for hatching.

*The Mating and Breeding of Poultry by Harry M. Lamon and Rob $R$. Slocum, published by Orange Judd \& Company. 


\section{KINDS OF POULTRY SHOWS}

Poultry shows may be classified according to their scope and importance, as follows: (1) Community exhibits which consist of school poultry shows and fowls from backyard flocks. (2) County fair poultry exhibits. (3) State fair exhibits. (4) Poultry association shows usually held in towns and cities by the state and local poultry associa-

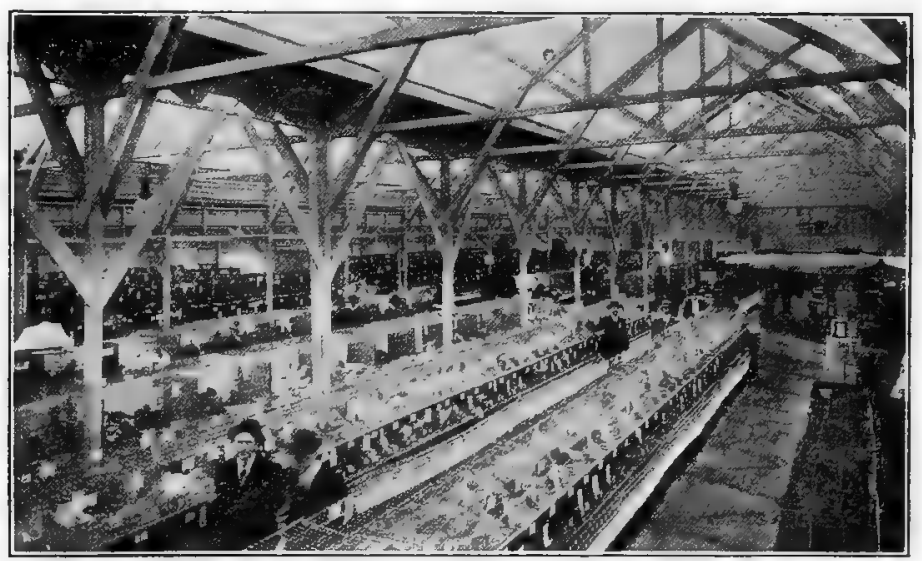

Figure 256.-Poultry shows play a most important part in the development of the industry.

tions. (5) Shows of the larger poultry associations which are usually of national or international importance.

For the beginner just starting with standard-bred poultry it is usually advisable to exhibit first at the local shows and, as his experience as a breeder develops, exhibits can be made at the county and state fairs, and finally at the larger shows.

\section{PREPARING BIRDS FOR THE SHOW}

Selecting the birds. The actual selection of the birds to be shown and the conditions that will determine selection 
practically start soon after the chickens are hatched and continues up until the time the birds are sent to the show. In other words, unless chickens are properly managed and grown so that they will mature into typical representatives of their breed, they will not make a creditable showing. Most frequently chickens from special matings are hatched at such a time that they will be grown and in the pink of condition for a certain show. Again such stock is frequently grown in a separate place from the rest of the flock in order to insure the best of care and attention. Such practice is,

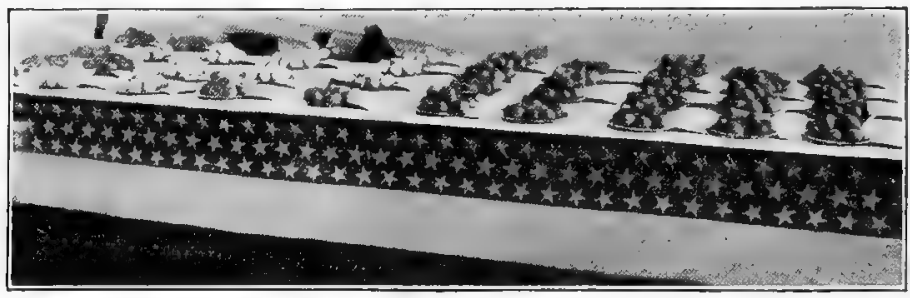

Figure 257.-An egg exhibit is always an interesting attraction at a poultry show.

of course, principally that of specialized poultry breeders, but these facts should be kept in mind by those who hope to attain the highest success in their efforts.

Preliminary selection. The actual preliminary selection of the birds to be shown should take place by observing the fowls as they appear on the range or in the yard at least a month or two before sending them to the show. Attention will then be directed to certain individuals that are outstanding in their appearance, fowls that possess good type and color, and other characteristics that go to make likely candidates. Such birds should be examined carefully in detail for under color and surface color, as well as for defects and desirable points, as called for in the American Standard of Perfection. 
When making the preliminary selection each bird should be carefully examined for such defects as would disqualify it and, therefore, eliminate the possibility of winning a prize. When a defect of such a nature as would be considered a disqualification is discovered by the poultry judge, the fowl is no longer considered as eligible for a place among the winners.

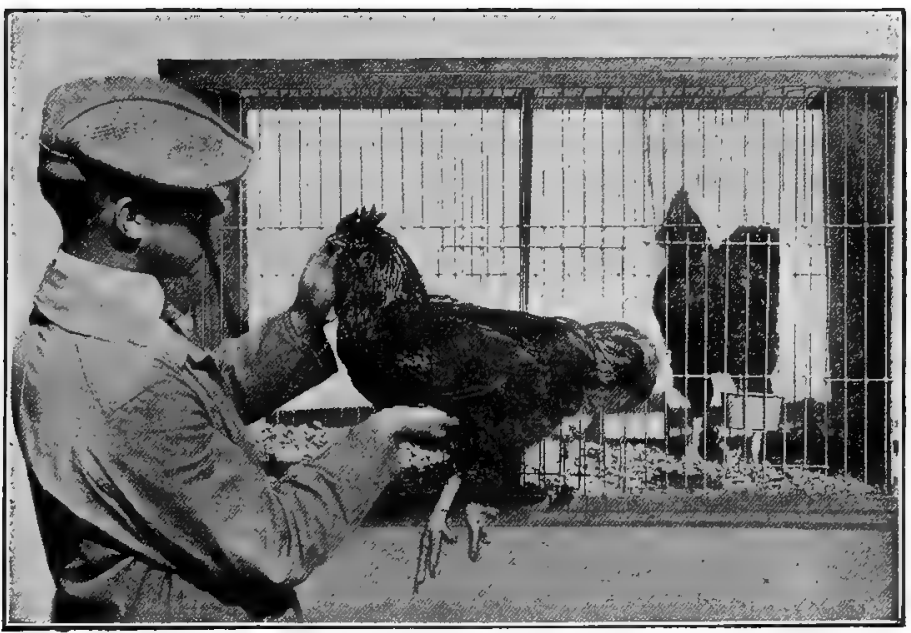

Figure 258.-Examining the head, face, and wattles of the fowl for defects and disqualifications.

General disqualifications. Some of the general disqualifications as given in the American Standard of Perfection that should be carefully guarded against and which are found in some of the more common breeds are as follows:

Comb. A lopped comb in all males or females excepting the females of the egg, or Mediterranean and Continental, classes and Dorkings, (See Figure 61, No. 2.) is a disqualification. The same is true with split combs, side sprigs. (See Figure 61, No.4.) Rose combs that are abnormal in 
size or lopsided (See Figure 61, No. 3.), and the absence of the spike in rose-comb breeds excepting some of the Bantams. A comb foreign to the breed, as, for instance, a rose comb on a Plymouth Rock is also a disqualification.

Face. White on the face of cockerels and pullets of the Mediterranean class, excepting White Faced Black Spanish, is a disqualification.

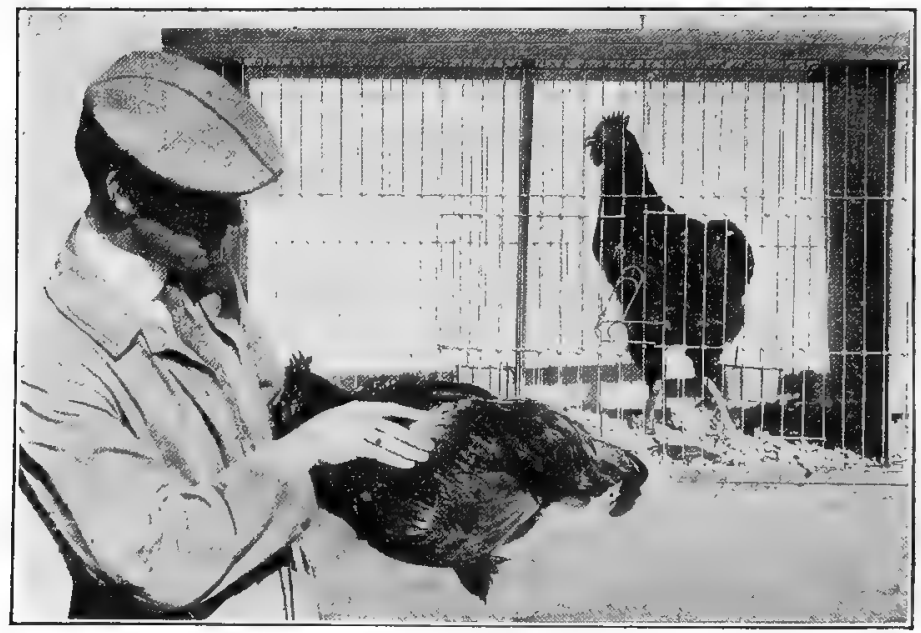

Figure 250.-Examining the under color of a fowl to detect defects.

Back. A deformed or crooked back commonly known as roach back disqualifies.

Wings. Clipped flight feathers or secondary feathers of the wing are a disqualification.

Tail. A decided squirrel tail or wry tail (Figure 62) is a disqualification as is also the absence of the main tail feathers.

Shanks and feet. Disqualifications that should be looked for here are the absence of feathers on the outer sides of the shanks of the Brahmas, Cochins and Langshans; the 
presence of feathers or down on the shanks, feet and toes of all breeds that should have unfeathered shanks and toes. Shanks and feet of a color that is foreign to the breed concerned disqualifies; likewise, the presence of more or fewer than four toes on breeds having four toes and more or fewer than five toes on breeds so characterized.

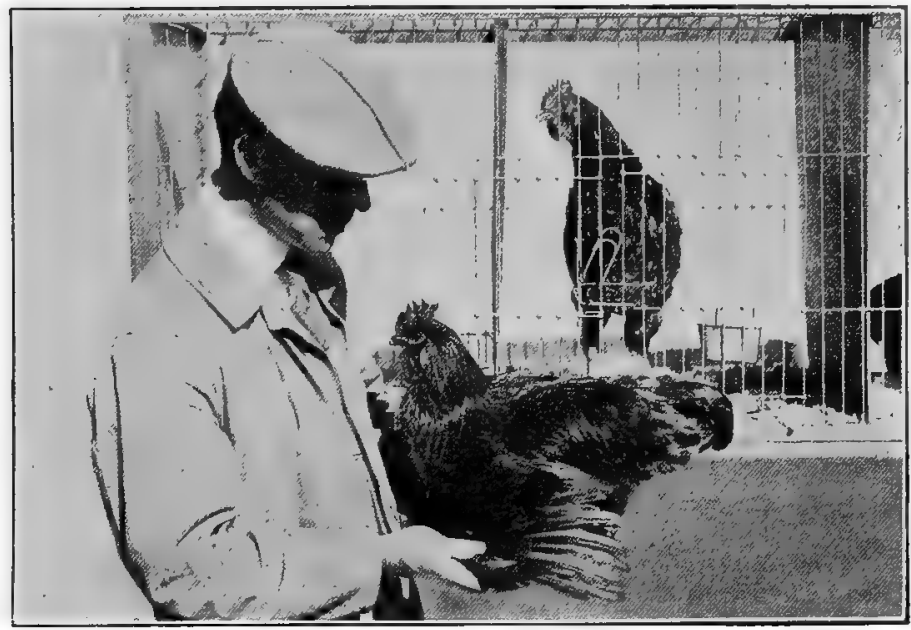

Figure 260.-Examining the wings.

Weight. A fowl that weighs less than two pounds below the standard weight for the breed, excepting turkeys and bantams, is a disqualification.

Any attempt to deceive the judge by faking, that is, to remove or change a disqualifying feature in any manner will disqualify the fowl.

For additional information on the disqualifications of turkeys, ducks, geese and bantams and disqualifications peculiar to the individual breeds refer to the American Standard of Perfection. 
The fact should be realized that no fowl is perfect, no matter how well bred, and that in selecting birds for the show it is a matter of picking those with the fewest defects and the most desirable points, the latter of course being in the majority. The standard requirements as given in the American Standard of Perfection for the breed and

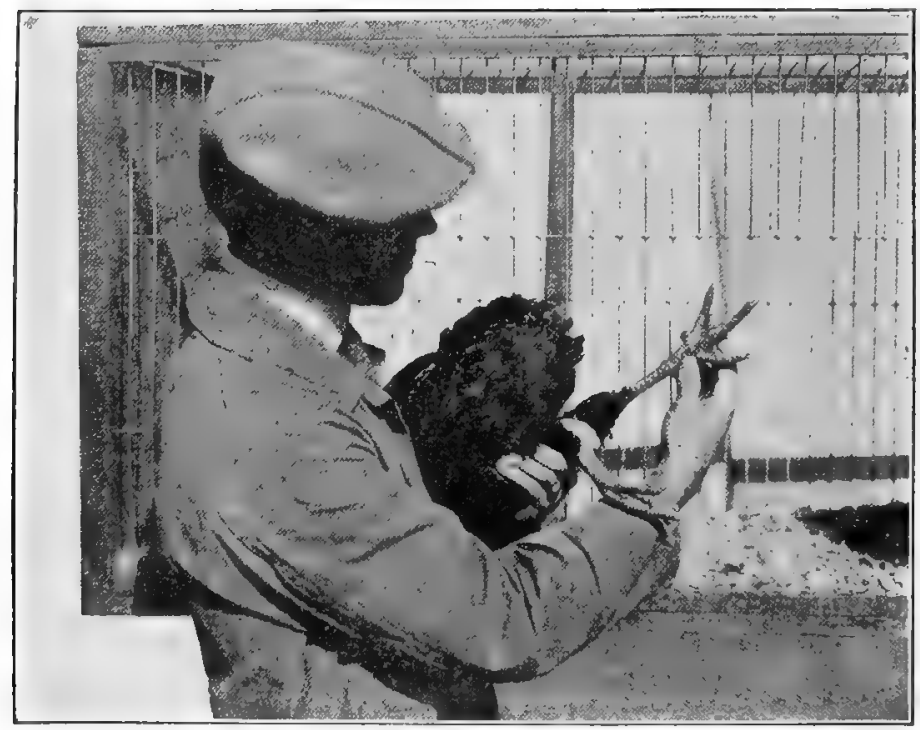

Figure 261.-Examining the feet and shanks for stubs and down.

variety concerned as well as the disqualifications should be kept constantly in mind. These points, together with health, vigor, general appearance, and bearing of the bird should be the deciding factors in selecting the birds that are to be conditioned for the show.

Conditioning birds. Conditioning and training as described herein do not in any sense infer misrepresentation nor should such practices usually known as faking be tol- 
erated. There is no question, however, that a bird should be clean when shown and that a clean fowl with proper training will make a better appearance and impression than one equally as good otherwise but having soiled plumage or one that is easily frightened. Some fowls do not respond to training or conditioning as readily as others. It is well, therefore, to have an extra fowl or two in training before the final selection is made. If possible, the birds selected should be removed from the rest of the flock and the males and females separated. Homemade or purchased exhibition coops should be provided and each fowl kept in the coop for a portion of each day.

Exhibition coops such as shown in Figure 263 can be purchased from most poultry supply houses. Fowls so confined will become accustomed to the coop and the handling of them daily will have the effect of making them tame. In removing and returning

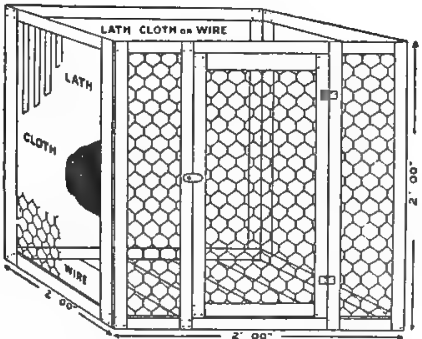

Figure 262.-A homemade exhibition coop suitable for training and conditioning exhibition fowls. the fowls to and from the coops, move quietly and handle the birds gently so as not to frighten them unnecessarily. When handling the birds, hold them as shown in Figures $258,259,260,261$, and examine the plumage so that they will become accustomed to such movements when being handled by the judge.

Fowls intended for exhibition should not be closely confined to the coop for too great a period, as long continuous cooping may cause the bird to lose its appetite and result in a subsequent loss in weight. An effective plan is to allow the birds range every other day and confine them to the coop every other day alternately. This plan should be 
continued up to within a few days before sending them to the show. They should then be confined to their coops for the final training and conditioning.

But little difficulty will be experienced in posing birds after they have become accustomed to being handled by smoothing their wattles as previously described. The ability of a fowl to pose well is of great value and helps to make a favorable impression when being judged.

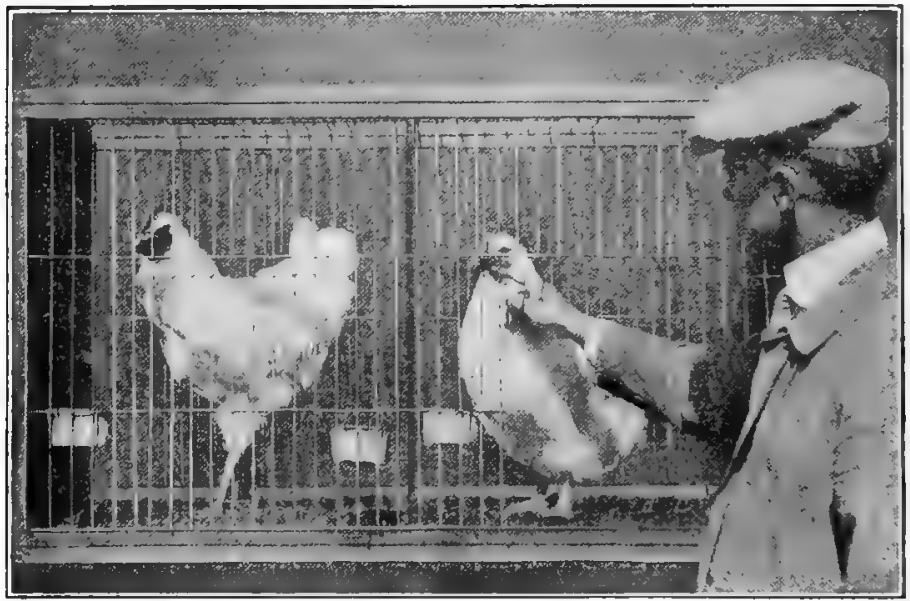

Figure 263.-It is advisable to frequently stroke or gently rub the wattles of the bird with the fingers, as they seem to be very fond of this attention, which, when they are properly handled otherwise, will accomplish much in making them tame.

Washing birds. White varieties and those having considerable white plumage such as the Columbian Plymouth Rocks, Light Brahmas, etc., and occasionally the Buff varieties should be washed, in order to show to a good advantage when exhibiting. Such fowls as Rhode Island Reds, the Partridge varieties, and those having dark-colored plumage need not be washed unless their feathers are considerably 
soiled. The head parts, however, and the shanks of all varieties should be properly cleaned, as described herein. The process of washing fowls is not a difficult one, and fowls that have been properly trained do not seem to object. It is suggested that those not experienced in washing fowls should first practice on a few before washing those that are to be shown. The most desirable place to wash the fowls is in a room where the temperature is about 70 or 80 degrees

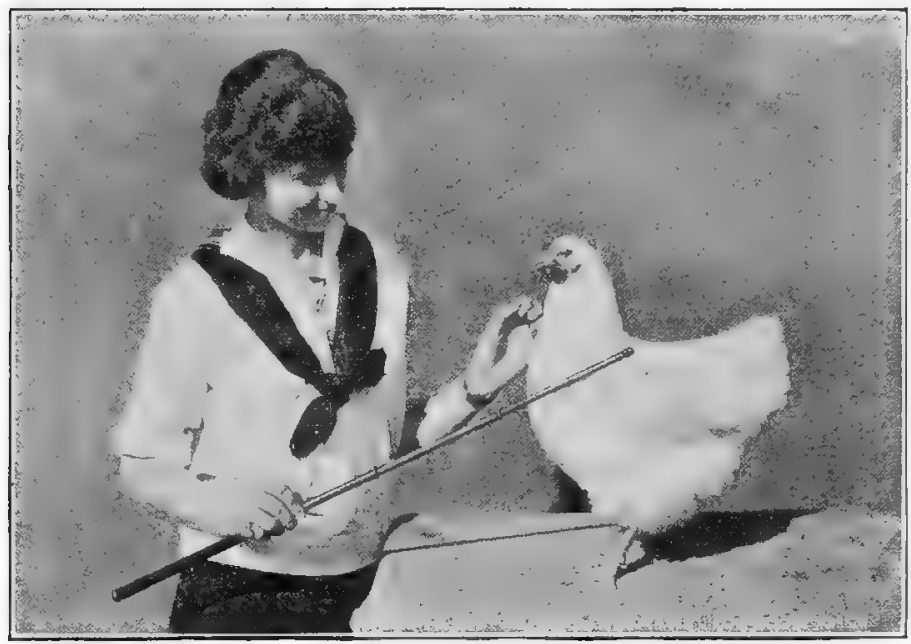

Figure 264.- In addition to handling the birds frequently an attempt should be made to get them to pose.

and one that is free from draft. When possible, the washing should be done in the morning, so that the birds will have sufficient time to dry off completely before evening. Before beginning the operation, place the exhibition coops a short distance from the stove or radiator, so the fowls will dry readily after being washed. Place clean shavings in the coop and cover the top, back, and sides of the coop with cloth or paper to prevent a draft, leaving the front of 
the coop open. Provide three, or better still, four tubs arranged on a bench or platform of convenient height.

The water in the first tub is used for the actual washing. The second and third tubs of water are used to remove all the soap, while the water in the fourth tub may have added a slight amount of blueing, such as is used in washing clothes. The practice of adding blueing is not as widespread as it used to be on account of the danger of coloring the plumage. Each tub should contain sufficient water to cover the body

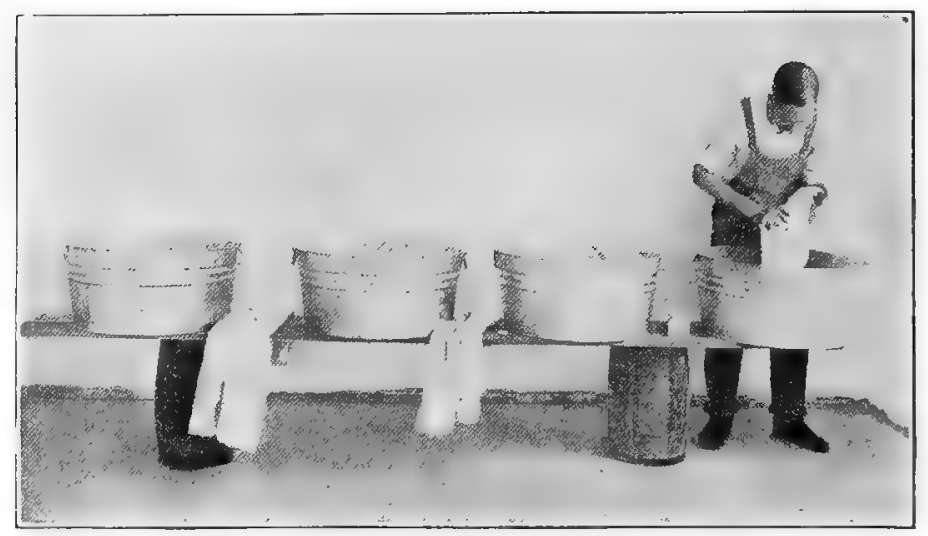

Figure 265.-Washing the fowl.

and neck feathers of the bird when immersed. Clean rain water should be used, if it is possible to obtain it, as hard water or water that contains mineral deposits such as iron will not produce satisfactory results. Pure white soap, such as Ivory or Castile soap, should be used. The water in the first two tubs should be heated to a temperature that will be comfortable to the hand, while the water in the third tub should be slightly cooler and in the fourth tub cooler still. Prior to washing the birds, soap the water well in the first tub, so as to have plenty of suds. 
Before washing the plumage, clean the face, comb, wattles, legs, and feet by scrubbing these parts with a small nail brush and plenty of lather. With the left hand grasp the fowl by the legs, holding the right hand over the back to prevent the wings from flapping, and immerse the bird in the first tub. In doing so be sure to see that the water has penetrated all sections of the plumage until thoroughly soaked to the skin. This is most important. Apply the soap by work-

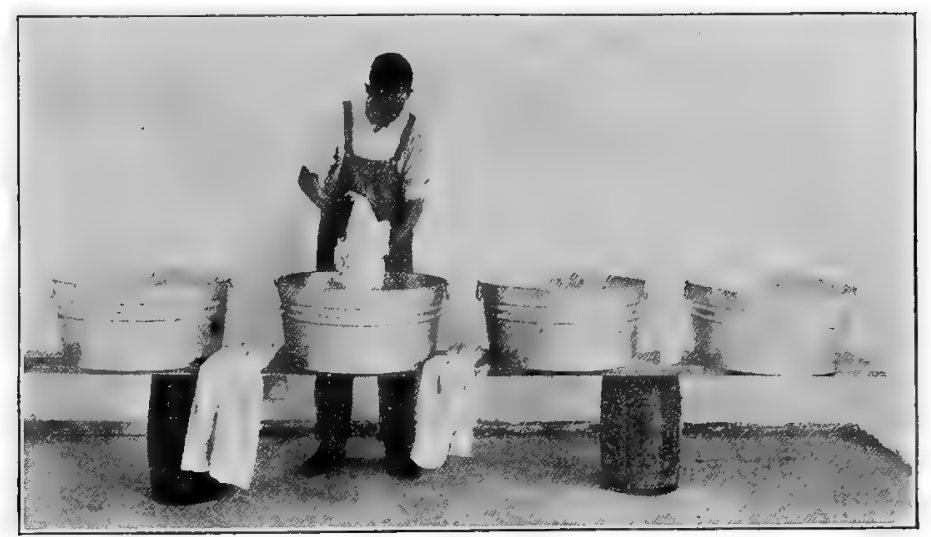

Figure 266.-Rinsing the soap from the feathers.

ing a good lather through all portions of the feathers with the fingers, rubbing the lather with the feathers instead of against them until the bird is clean. A small sponge will help considerably in applying the lather and in cleaning the main tail and wing feathers. If these feathers are very dirty, a small nail brush may be used for this purpose. Remove as much of the soap as possible from the bird in the first tub and the rest in the second and third tubs. It is very important that all the soap be removed completely, as any trace of it will cause the feathers to appear streaked and matted together when dry. When rinsing the feathers in the second 
and third tubs, raise and lower the fowl slowly several times in the water so that all portions of the plumage may be reached. The use of a sponge will likewise assist in removing the soap. After four or five fowls have been washed, change the water in all the tubs before washing additional birds. When blueing is used in the last tub, immerse the fowl completely with the exception of the head and repeat the operation of allowing the water to come in contact with all sections of the plumage.

Drying the birds. On removing the fowl from the tub, and before placing it in the clean coop before the stove or radiator to dry, remove the surplus water from the feathers by blotting the surface feathers with a Turkish towel. Should the fowl seem cold and shiver when placed in the coop, move it closer to the source of heat for a short period. Do not place the coop too close to the stove, however, for, if the feathers dry too quickly they are apt to curl. If, on the other hand, the bird seems too warm, remove the coop a little from the stove. After the feathers are dry, increase the space between the coop and the stove until the temperature around the coop is about $70^{\circ}$. Keep the birds in the room at this temperature for at least 12 hours before shipping them.

Cleaning the head, feet, and shanks. After the fowl is thoroughly dry, examine the shanks and feet to see that no dirt remains under or around the scales. Such particles of dirt can be easily removed with a tooth pick. At this time it is also well to moisten a small cloth with a very little sweet or olive oil or vaseline and rub it on the shanks, wattles, ear lobes, face, and comb. It will tend to bring out the true color of these parts considerably. It is advisable to repeat this operation after the birds reach the show, as a final dressing up. Be careful not to apply too much oil or vaseline, as it may later soil the plumage. 


\section{PREPARING GEESE, DUCKS, TURKEYS AND PIGEONS FOR EXHIBITION}

Geese and ducks. The preparation of geese and ducks for exhibition does not involve as much detail work as in the case of fowls (referring to chickens). The preliminary preparation of geese and ducks for exhibition should be followed along the same lines as previously described for poultry, that is individuals should be selected that conform as closely as possible to the standard requirements for the breed, care being taken not to select those which possess any serious defects or any disqualifications. As to the actual preparation for exhibition, ducks and geese are practically self-prepared. For a period of at least a week or ten days before shipping the birds to the show those intended for exhibition should have access to a grass range and also, if possible, running water. The grass range will keep them in good condition and by having access to a stream of running water they will keep clean themselves.

All breeds of geese with the exception of the Chinese should be fed a grain mixture twice daily, consisting of 1 part corn and 2 parts oats for a period of at least 10 days before exhibiting, to bring them up to standard weight. Oats alone should be fed to Chinese geese, as they are apt to put on too much weight when fed corn. This method of feeding corn and oats likewise applies to all the breeds of ducks, the exception as to the feeding of oats alone applying to the smaller breeds of ducks, as for instance the Indian Runner.

When catching geese and ducks that are to be crated for shipment, care should be taken in handling them, as the method employed in this case differs from that used in catching chickens. 'Grasp the goose firmly with the hand around the neck so as to control its head and prevent its biting. Grasp the body of the goose under the other arm, 
holding the bird securely. In this position the goose can be easily carried. Do not let go of the neck of the goose until the bird is in the shipping coop or otherwise released.

The same method is used in catching and carrying ducks, although one does not have to be cautious as in the case of geese to prevent biting.

Both ducks and geese can be carried short distances by the neck alone without injury. Under no circumstances should either ducks or geese be caught or carried by the legs as they are apt to break very easily.

Turkeys. As in the case of ducks and geese no great amount of preparation for exhibition is required for turkeys other than keeping them up to standard weight by feeding as described under "Marketing of Turkeys" on page 294. In addition to this the head, feet, and shanks of exhibition turkeys should be washed in the same manner as described for chickens on page 266. When washing these parts it is well for one person to hold the bird while another does the washing. This prevents the possibility of the bird's fluttering or struggling and thus injuring the feathers. To catch a turkey grasp it firmly over the shoulders, being careful not to injure the feathers. Next, encircle the body of the turkey with one arm, holding it securely under the arm and with the other hand hold the legs. As turkeys are easily excited, they should be handled carefully.

Pigeons. To prepare pigeons for exhibition it is necessary to provide a pan containing about four inches of water. This will enable the birds to bathe and thus keep themselves clean. The American Poultry Association does not provide a standard for pigeons. Such standards can be secured from the different pigeon associations. In every case pigeons should be selected that conform to the standard for the breed and variety concerned. Pigeons are usually caught with a catching net or bag fastened by means of a 
metal ring about 18 inches in diameter at the end of a pole, the length of which is governed by the size of the loft.

\section{SHIPPING THE BIRDS}

Under no conditions should a makeshift coop or poorly constructed one be used for shipping the fowls. A desirable fowl may be rendered unfit for show, if shipped in a coop that is too small. Coops for this purpose may be purchased for a reasonable amount.

A homemade shipping coop can easily be constructed by following the plans given in Figure 268.

The following dimensions should be used in constructing this coop: For 1 bird, 12 inches wide, 18 inches long, 25 inches high. For 2 birds, 12 inches wide, 24 inches long, 25 inches high. For 3 birds, 18 inches wide, 24 inches long, 25 inches

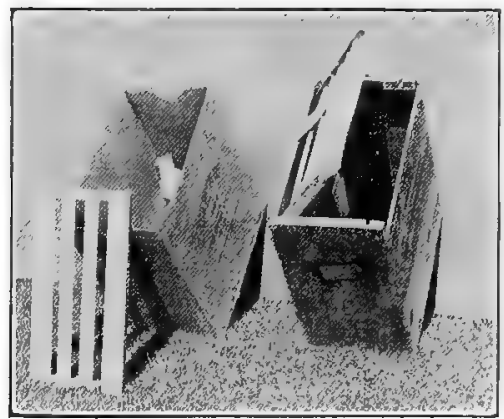

Figure 267.-Ready-made shipping coops for exhibition fowls suitable for one bird each. Larger sized coops may be purchased for from 2 to 5 fowls each.

high. For exhibition pen of 4 females and a male, 24 inches wide, 24 inches long, and 25 inches high. In order to keep the fowl from becoming soiled during the trip, a piece of muslin should be tacked on the inside of the top under the slats, care being taken not to use cloth that is too heavy or thick, so as to cut off ventilation. A small amount of clean hay or straw that is free from dust, or dry shavings should be placed in the bottom of the coop. A cup or can may be provided for feed. Cans for this purpose should be nailed securely about half way between the top and bottom in a corner of the coop. Feed is not nec- 
essary in the coop when fowls are shipped only short distances or when they will not be confined to the coop over 24 hours. When feed is provided, whole grain, such as corn and wheat, are most satisfactory. Water when placed in the shipping coop is liable to spill out and soil the plumage. A mangel tied in the coop which the fowl can pick at will supply sufficient moisture. A tag or card plainly marked showing the destination of the shipment as well as the return address can be tacked or pasted on the outside where

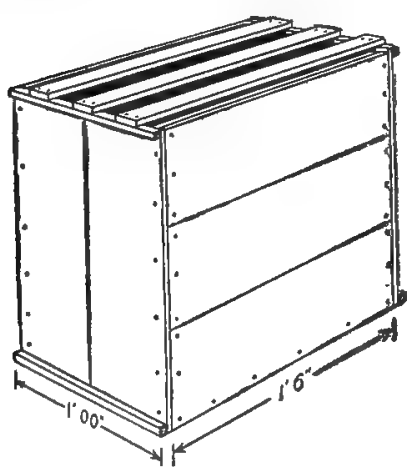

Figure 268.-A homemade coop for shipping exhibition fowls. it can be plainly seen. In fastening a coop it should be made secure, so that it will not come open in transit. Some provision should be made so that the coop can be readily opened on arrival at the show room. Frequently it is found necessary to damage the coop considerably before it can be opened, often rendering it practically unfit for use in returning the fowls.

\section{SHOW RULES AND REGULATIONS}

In order to acquaint those who have never exhibited poultry with the more important rules governing poultry shows and exhibits the following are cited:

1. In judging poultry only fowls of the same breed and variety compete. That is, for instance, White Plymouth Rocks do not compete against Barred Plymouth Rocks. This holds true in every other breed and variety, except where prizes are offered for the best bird or birds, all varities competing.

2. The units of classification in judging are as follows: 
cocks, cockerels, hens, pullets, young pens, and old pens. By this is meant that cockerels do not usually compete against cocks, hens against pullets, or young pens against old pens. A cockerel is a male bird under one year old, a cock over one year old. A hen is a female over one year old and a pullet under one year old. This distinction likewise

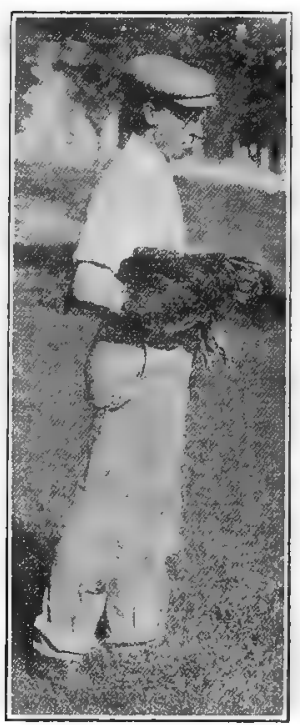

Figure 269.

The correct way to carry a fowl.

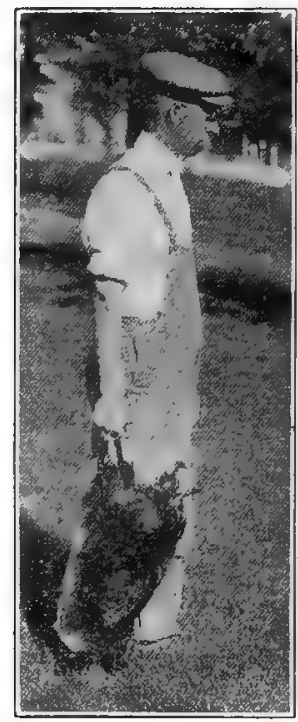

Figure 270.

The incorrect way.

applies to the age of the individuals in a young or old pen. A pen consists of one male and four females.

Cash and ribbon prizes are usually offered as the first, second and third premiums and ribbons only offered for the fourth and fifth premiums. Cash prizes for pens usually exceed those in value of single bird entries. Usually it takes 3 or 4 entries in a class to win first money. When there are fewer than 3 entries in a class, the first premium 
may be awarded, but the second money paid. Prizes are not usually awarded to birds impaired in value for breeding purposes. The American Standard of Perfection should be and usually is the guide and authority in judging. * Unhealthy specimens are not allowed to be exhibited. Fowls intended for exhibition should be banded and the band numbers properly entered on the entry blank.

*See page 346 for the Scale of Points of the American, Mediterranean, and Asiatic Classes.

\section{QUESTIONS}

1. What is the object and value of poultry exhibitions?

2. Name five kinds of poultry shows.

3. What fact should be kept in mind when selecting the birds for the show?

4. Describe the preliminary selection of the birds to be shown.

5. Name a disqualification as concerning the comb, face, back, wings, tail, shanks, weight.

6. Describe the method of training an exhibition bird.

7. Discuss the arrangements that should be made prior to actually washing the birds.

8. Describe the method of washing an exhibition fowl.

9. Why is it so necessary to remove every particle of soap from the plumage?

10. Describe the method of drying the birds.

11. How should the head, feet, and shanks be cleaned? Why before the bird is washed?

12. Discuss the method of preparing geese and ducks for exhibition; turkeys; pigeons.

13. Discuss the method of shipping fowls to the show.

14. Mention some of the important rules and regulations governing poultry exhibits.

\section{SUGGESTIONS}

1. The real value of poultry shows can not be fully appreciated until you have actually taken part in one. Hold a poultry show in your community. Such a show may be held either in connection with a school poultry club or local poultry association. Through your efforts endeavor to stimulate enough interest among those in your community who raise poultry to exhibit their fowls at some one time during the year.

2 . Should there be no school poultry association or local poultry association in your community, endeavor to organize one, having for one of its objects the holding of an annual poultry show. Suggestions and information concerning the holding of poultry shows may be obtained from the secretaries of such poultry organizations as exist in near-by towns and cities. Secure a copy of the premium list of your 
state fair. This will contain many useful suggestions as to the rules and regulations relating to a poultry exhibit.

3. When holding a poultry show, endeavor to get as many interested as possible by advertising it thoroughly and inviting the people from the country as well as the townspeople to take part and attend. Endeavor to make it especially attractive by having such demonstrations and talks on poultry as are suggested in other chapters. No doubt the poultry department located at your state agricultural college or experiment station will be able to render you considerable assistance.

4. In making plans for the holding of a poultry show undoubtedly the local Chamber of Commerce will not only endorse your plan but will likewise be able to be of considerable as istance to you.

5. In addition to a display of fowls arrange to hold an egg exhibit consisting of eggs produced by the exhibitors' birds. Prizes should be offered for the best eggs based on their quality, condition of shell, uniformity, etc. Usually two classes are provided, one for white and another for brown-shelled eggs. Score cards such as are used in judging eggs, a copy of which will be found on page 343 , can be secured from the Secretary of the American Poultry Association.

\section{REFERENCES}

The Mating and Breeding of Poultry, by Harry M. Lamon and Rob R. Slocum.

Barred Plymouth Rock Standard and Breed Book, published by the American Poultry Association. 


\section{CHAPTER XVI}

\section{MARKETING THE PRODUCT}

To the farmer or poultryman who plans on securing part or all of his income from poultry the marketing of the product is of considerable importance. As with other food commodities, the marketing of poultry and eggs has made great strides in recent years and as a result has developed into a most essential branch of the industry. In order to secure the best returns for his product the poultryman or farmer must know the market demands as well as how, where, and when to sell such products. Not only is the quality of the product essential, but an attractive appearance is of equal importance. In like manner the requirements as to the manner of dressing and packing vary in different markets, so that such facts should be considered in order to secure the best returns.

There are several different methods or combinations of methods through which poultry products are marketed. In general these methods can be classified as follows: From the producer to any of the following agencies: the country buyer or huckster, the country store, the wholesaler, commission merchant, retail store, hotel, restaurant, or to the consumer direct. It frequently happens, especially in remote sections of the country, that the producer sells to the huckster, or to the country store, from which place they are sent to the wholesaler, commission merchant, or jobber, in the city, and finally disposed of through the retail store to the consumer. The advisability of the producer's selling direct to the consumer or through the various mediums as given should be decided in individual cases, depending on market conditions and extent of the product to be sold. 


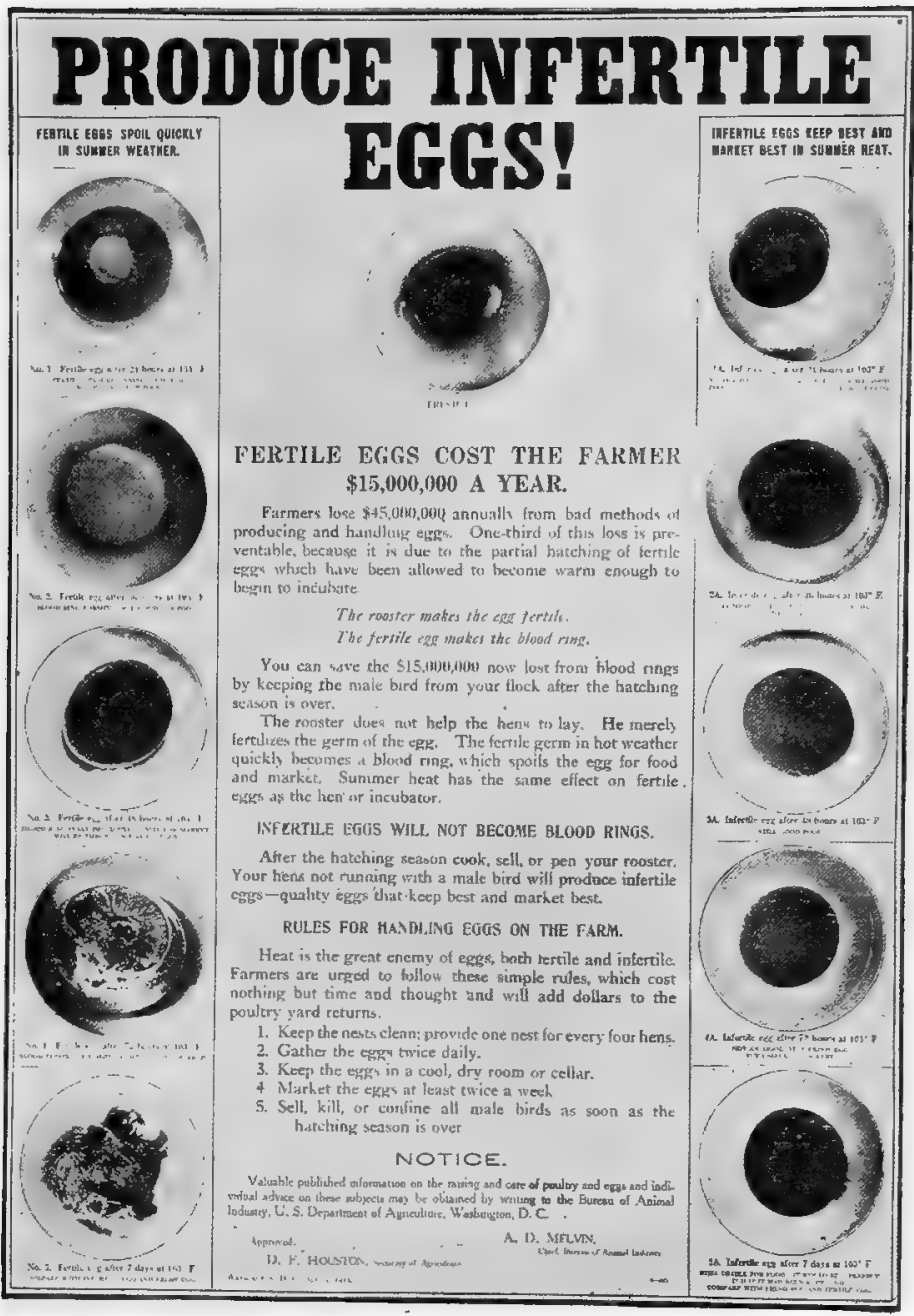

Figure 271.-Infertile egg placard. 


\section{EGGS}

Eggs are by far the most important poultry product marketed and the sale of them amounts to hundreds of millions of dollars annually. The revenue received from this product by the farmer or poultryman could in most instances be substantially increased by putting into practice the principles suggested herein as concerning the proper handling of eggs to be marketed.

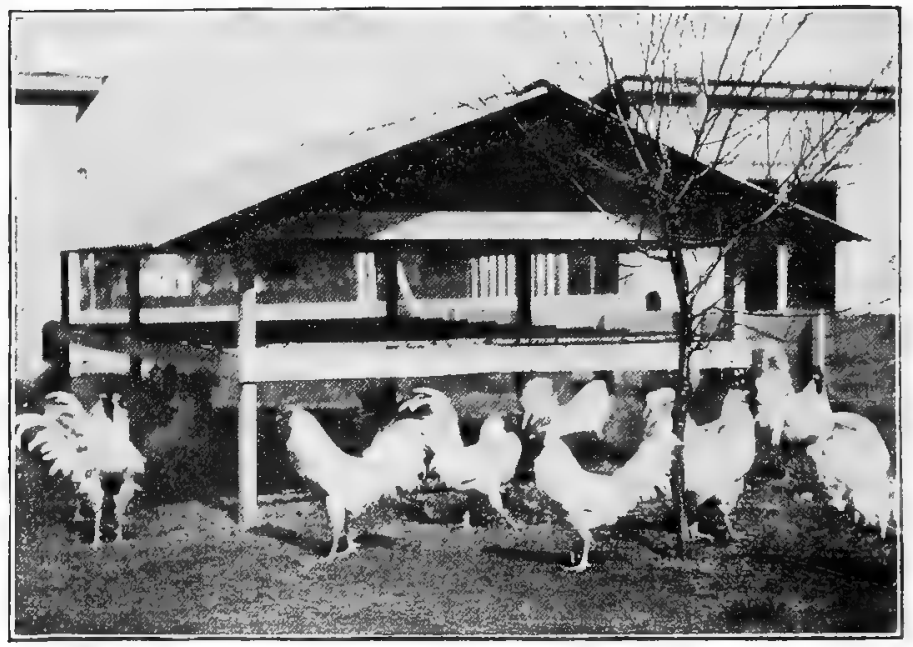

Figure 272.-Male birds confined to a yard by themselves after the breeding season is over.

CARE AND PREPARATION FOR MARKET

Infertile eggs. The first and most important suggestion that can be given relating to the production of eggs for market is to "PRODUCE INFERTILE EGGS." As stated on page 279 , an infertile egg is one that is laid by a hen that has not been allowed to run with a male bird. In most cases 14 days is sufficient time for eggs to become infertile after the male bird has been removed from the flock. 
Table V. Relative Losses of Fertile Compared with Infertile Eggs

\begin{tabular}{|c|c|c|}
\hline & $\begin{array}{c}\text { Fertile } \\
\text { eggs }\end{array}$ & $\begin{array}{c}\text { Infertile } \\
\text { eggs }\end{array}$ \\
\hline 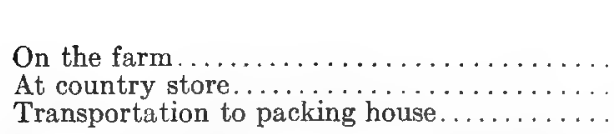 & $\begin{array}{c}\text { Per cent } \\
29.0 \\
7.1 \\
6.4\end{array}$ & $\begin{array}{l}\text { Per cent } \\
15.5 \\
4.0 \\
4.7\end{array}$ \\
\hline Total. & 42.5 & 24.2 \\
\hline
\end{tabular}

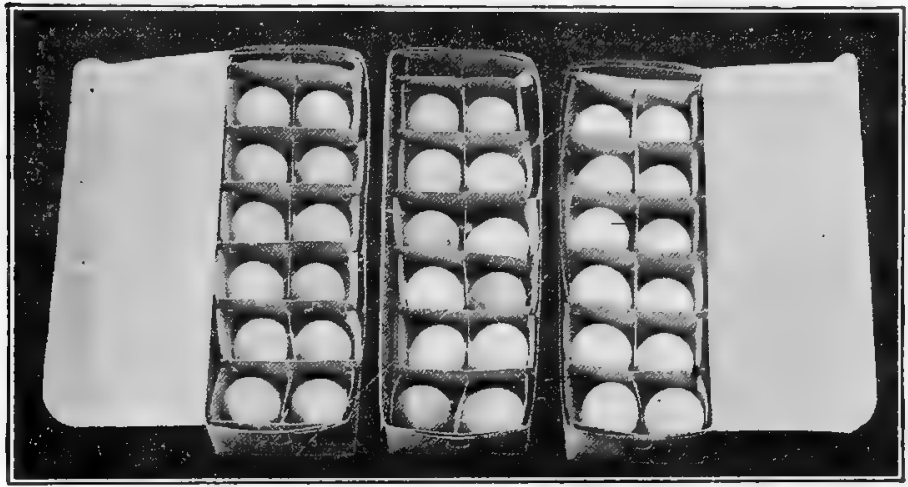

Figure 273.-Brown and white-shelled eggs in separate cartons. Mixed eggs, as will be noted in the middle carton, present an unattractive appearance.

The male bird in the flock has no influence on the number of eggs laid by the hens. He merely fertilizes the germ of the egg which is not necessary when the egg is to be sent to market or used for table purposes. It is impossible for a germ to develop or a blood ring to form in an infertile egg. It keeps in better condition, therefore, at temperatures that would cause fertile eggs to become unfit for food.

Hens in a flock wherein there is no male bird will produce infertile eggs, which keep best and market best.

Nests. Provide one clean, dry, vermin-free nest for every 4 or 5 hens. Eggs will not remain clean very long in 


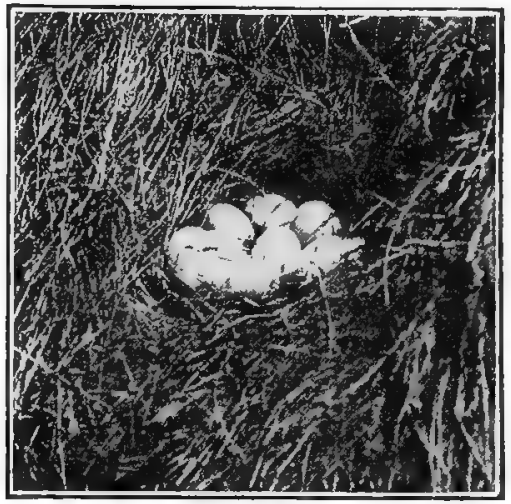

Figure 274.-A stolen nest in the hay loft.

dirty nests, and only clean eggs should be marketed.

Gathering eggs. Gather eggs at least once a day in cool weather and twice daily in hot, freezing, or rainy weather. Eggs from stolen nests should not be marketed, as they are of unknown age and quality, and should be used at home.

Uniformity of product. Uniform products usually command the best price. Eggs of a uniform color and size can be produced by keeping one breed or variety of standard-bred fowls. (See Figure 273.)

When catering to a market that prefers white-shelled eggs, keep some one of the varieties of the egg breeds, such as the Leghorns, etc. If, on the other hand, the market prefers and pays a premium for brown-shelled eggs, keep some one variety of the general-purpose breeds, such as the Plymouth Rocks, Wyandottes, etc.

Storing. After the eggs are collected, store them in a cool dry place beforesending them to market. When storing eggs, be c aref ul to keep them away from onions, kerosene, or other substances having an odor, as this odor is apt to be absorbed by the eggs.

Grading. Market

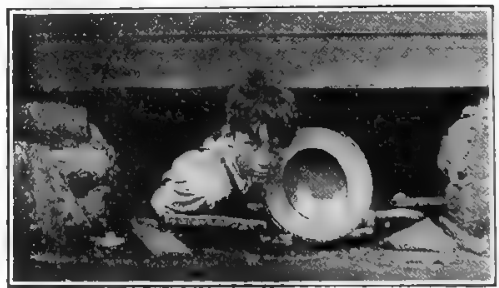

Figure 275.-Eggs from a stolen nest under the corn crib. Use such eggs at home. 
white-shelled and brownshelled eggs in separate packages. Eggs irregular in shape, unusually large or small eggs, those having thin shells, or that have shells otherwise defective should be kept for home use, so that breakage in transit may be reduced as much as possible.

Eggs are divided into several classes for different markets. There is no uniform grade or standard that applies to all markets and to all kinds of eggs. Fresh gathered eggs, however, are usually divided in the following classes:-Specials, Extras, Number Ones and Number Twos.

Specials. Eggs that come within this class are of uniform size, weighing over 24 ounces to the dozen or over 45 pounds to the thirty-dozen case. They should be absolutely clean, strong and sound in shell with a small air cell not over

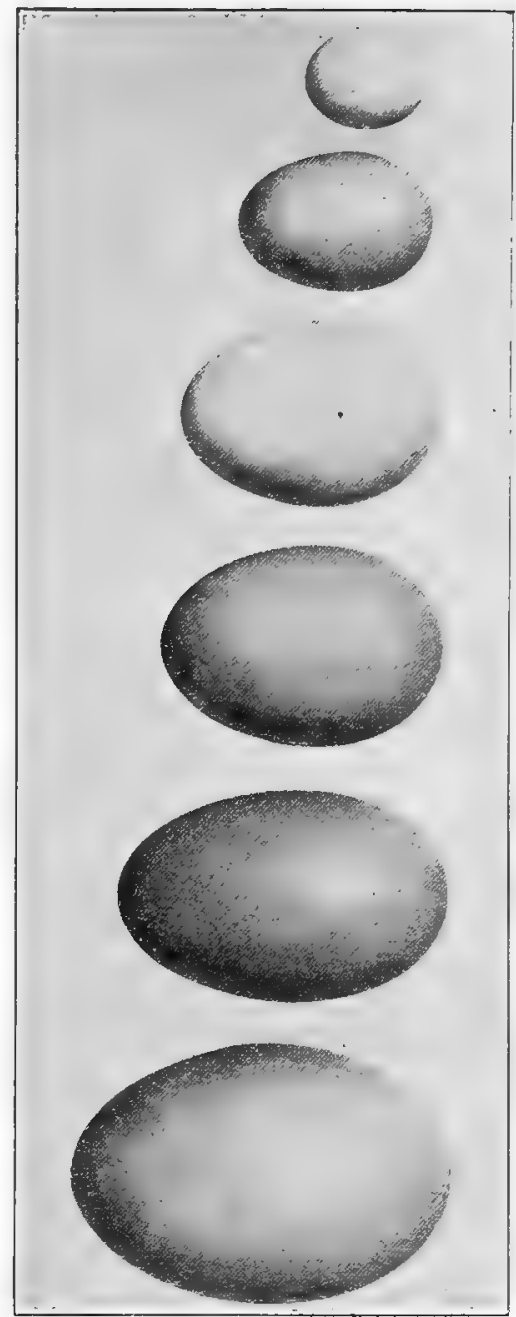

Figure 276. - Extremely large, small, and soiled eggs should not be marketed. All the eggs in this picture were produced by a farm flock of mongrel fowls. 
3-16 of an inch in depth. The white of the egg should be firm and clear and the yolk hardly visible and free from blood clots or blood rings or any form of decomposition.

Extras. This class of eggs consists of those of good size weighing at least 24 ounces to the dozen or 45 pounds net to the thirtydozen case. They should be clean, sound in shell with

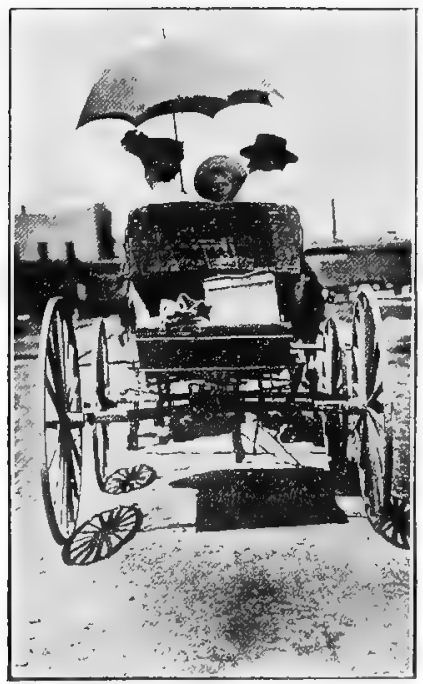

Figure 278. - When taking eggs to market, protect them from the sun's rays.

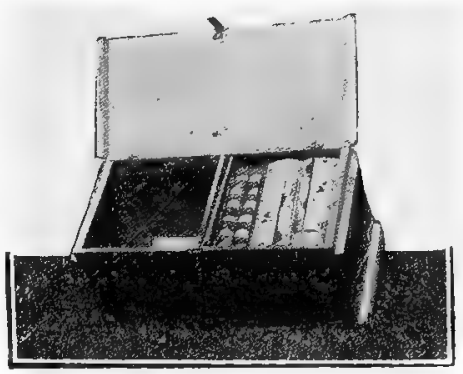

Figure 277.-Egg crate with hinged top holding 30 dozen eggs. The egrs here shown are not packed in regular pasteboard fillers but in individual one-dozensize cartons.

an air cell not more than $3 / 8$ of an inch in depth and the white firm and yolk only slightly visible.

Number Ones. This class of eggs should weigh at least 23 ounces to the dozen or 43 pounds net to the thirty-dozen case. They should be clean, sound in shell, air cell not more than one half an inch in depth, white of the egg reasonably firm and yolk visible but mobile. The yolks should likewise not be stuck to the shell or seriously out of place. The air cell need not necessarily be stationary.

Number Twos. These should be clean, sound in shell, but sometimes consist of weak 
watery eggs, eggs with heavy yolks and all other eggs sound in shell but fit for food. The several classes of eggs which go to make up this grade are defined as follows:-

(1) Heated egg. This term is applied to an egg in which the embryo has developed to the point that corresponds toabout 18 to 24 hours of incubation. In the infertile egg this condition may be recognized by the in-

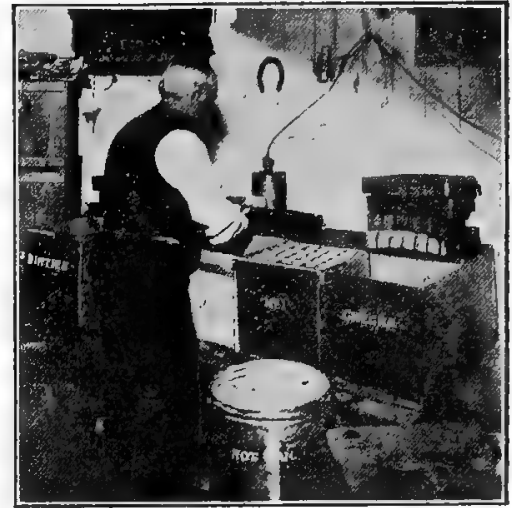

Figure 279.-Candling eggs for quality. Notice the candler has separate boxes for the good eggs as well as the checks, cracked eggs, dirty eggs, and rots. When selling eggs insist that they be bought on a quality basis.

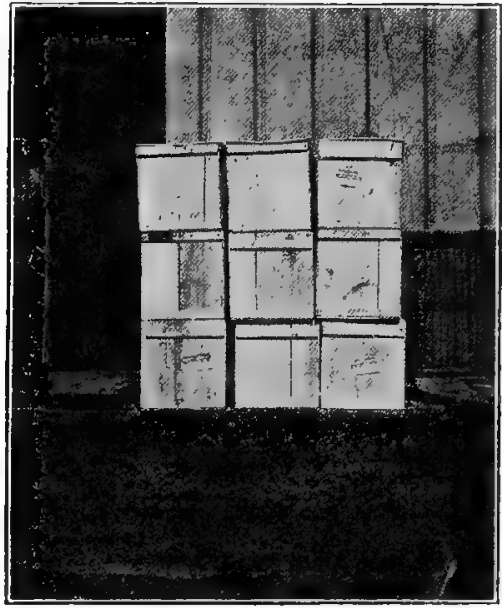

Figure 280. -A shipment of eggs on the railroad station platform exposed to the sun. Infertile eggs will withstand such conditions much better than fertile eggs. creased color of the yolk and when held before the candle it will appear heavier and slightly darker than in the fertile egg.

(2) Shrunken egg. This class of Seconds may be easily distinguished by the increased size of the air cell. As previously stated in the chapter on incubation, the size of the air cell increases in proportion to the evaporation of the water in the egg.
(3) Small eggs. 
(4) Dirty eggs.

(5) Watery eggs. This term applies to eggs in which the inner membrane of the air cell has been punctured or ruptured, thereby allowing the air to escape into the contents of the egg giving it a watery or frothy appearance.

(6) Eggs containing foreign matter.

(7) Badly mis-shaped eggs.

Other terms used in grading eggs:

Cracks. This term applies to eggs which have been cracked but have not started to leak.

Leakers. As the name would imply, this term refers to eggs which have been cracked sufficiently to lose part of their contents.

Spots. This refers to eggs in which the bacteria or mold growth has developed locally or in spots and causes the formation of a lumpy adhesion on the inside of the shell. There are three recognized classes of mold spots, namely: white, brown and black.

Blood rings. Eggs in which the embryo has developed to such an extent that it can be quickly recognized when held before the candle. The development of blood rings cannot take place nor are they found in infertile eggs.

Rots. Eggs graded as rots are absolutely unfit for food. The several classes of rots are defined as follows:

Black rot. This stage of decomposition is most easily recognized and when held before the candle the contents have a blackish appearance and in most cases the air cell is very prominent.

White rot. These eggs have a very characteristic sour smell. The contents are watery, the yolk and white mixed, and the egg offensive to both the sight and smell.

Spot rot. In eggs so designated the bacteria or mold growth has not contaminated the entire egg but, as its name would imply, has remained in one spot. Such eggs are easily 
recognized when held before the candle, and when broken show a lumpy adherence to the inside of the shell.

Packing. Eggs marketed in quantity for shipment should be packed in a standard egg crate, which holds thirty dozen eggs. Place a layer of clean excelsior or straw evenly distributed over the bottom of the crate before packing the eggs. Use clean fillers and pasteboard flats and place the eggs with the small end down. When the case is full, cover the top layer with excelsior or straw evenly distributed over the top. Nail the lid on securely at each end but not in the center of the case, thus allowing room for a slight movement of the eggs, and reducing the breakage. When marketing to private trade or direct to the consumer, pasteboard cartons holding a dozen eggs each may be used, as shown in Figure 277.

\section{MARKETING}

Precaution. Market the eggs frequently; twice a week, if possible, during the summer.

When selling eggs, insist that they be purchased on a "loss-off" basis, that is, that they be candled and purchased on the basis of quality rather than by the case irrespective of quality. Thus the price received for eggs so purchased will be based on the actual quality. It is obvious, therefore, that infertile eggs of good quality sold on a "loss-off" plan will bring a greater return than those sold on a "case-count" basis, irrespective of quality or condition. It necessarily follows that the dealer who purchases eggs on a "case-count" plan is compelled to pay less per dozen than when bought on a quality basis in order to protect himself from possible loss in reselling the eggs, a per cent of which may be unfit for sale or consumption.

By parcel post. Many farmers and poultrymen especially those in the more thickly settled sections of the country have taken advantage of the parcel post to market their 
eggs direct to the consumer. When satisfactory prices can be obtained for a high grade fresh product, this system will prove practical. There are several factors, however, that must be considered when this method is used, namely, when the distance between the producer and consumer is too great, the postage required may prove prohibitive. Another factor that should be considered and definitely agreed upon when this system of marketing is employed is that the consumer shall make prompt settlement and return the cartons, which,

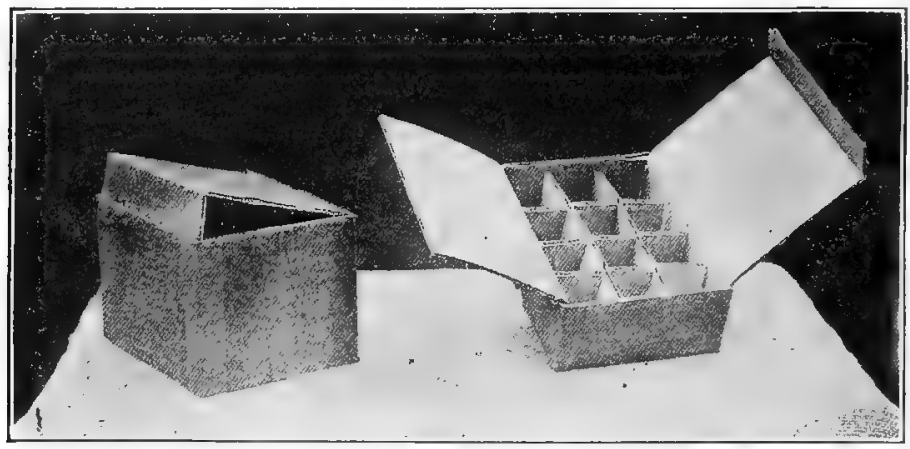

Figure 231.-A satisfactory type of egg carton for shipping by parcel post, showing one and two dozen sizes.

in most cases, can be used several times. In order to secure the best prices for eggs so marketed, fresh, clean, infertile eggs should be furnished as suggested above.

Containers. There are several makes and styles of containers of various sizes ranging from one-dozen-egg capacity up. These containers are usually constructed of corrugated cardboard or of a light metal. In selecting a container consideration should be given to the cost, simplicity, strength, weight, and durability, as all these factors will influence either directly or indirectly the cost of marketing by this method. The containers as shown in Figure 281 are commonly used with good results. 
Packing for shipment. Eggs packed for shipment, should be graded for color and size, and only fresh, clean eggs used.

When using a carton similar to that shown in Figure 282, each egg should be carefully wrapped in wrapping paper or newspaper. After packing, wrap the container with a good grade of wrapping paper and tie securely. Address the package plainly to the party for whom it is intended, adding your name and address in the upper left-hand corner.

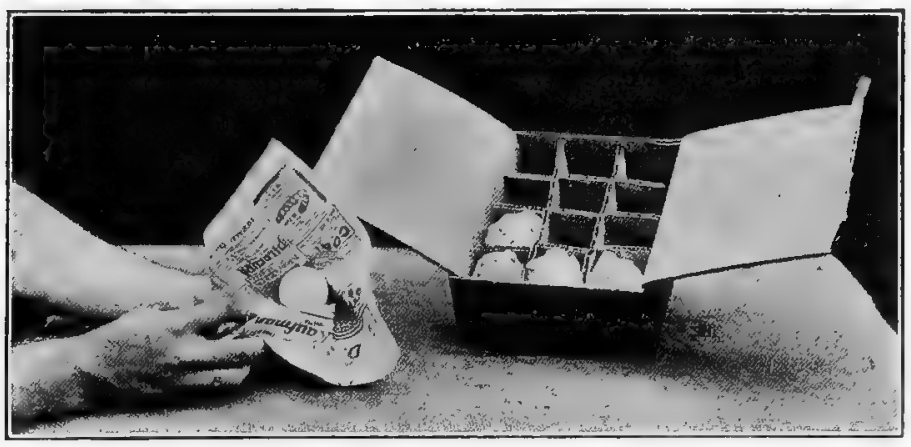

Figure 282.-Each egg should be wrapped separately in paper.

Weight of parcel. On an average, hen eggs will weigh about $1 \frac{1}{2}$ pounds to the dozen or 2 ounces apiece. The weight of a dozen eggs in a carton of sufficient weight to carry the shipment safely, properly packed and wrapped, will usually run from 2 to 3 pounds in weight. As most parcels containing a dozen eggs will weigh over 2 pounds but not reach 3 pounds the postage on them will be seven cents within the first and second zones. When possible, therefore, it is recommended that two dozen, or more, eggs be shipped at one time, as each extra dozen will add but two cents to the postage to carry it the same distance, depending on the nature of the container. Postage can thus be saved.

By express. When eggs are shipped by express, they 
are packed in crates as described under "packing" on page 287. Care should be taken to protect them as much as possible from the sun while en route to stores or stations or while they may remain on station platforms.

\section{TABLE POULTRY}

While the production and marketing of broilers, fowls, or capons for table use is secondary to the production of eggs, at the same time it is a branch of poultry keeping from which considerable revenue is derived. This revenue as

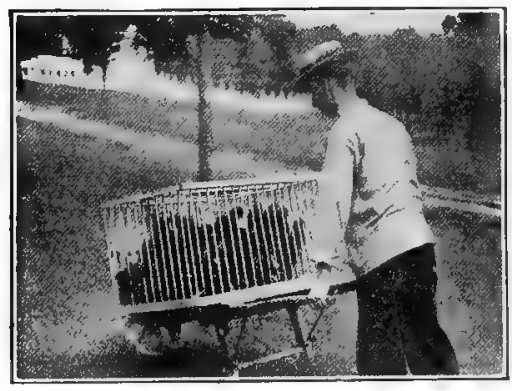

Figure 283.-A crate of cockerels being taken from the range to be fattened for market.

well as that for eggs, can in most instances be considerably increased, if the birds are properly prepared for market.

\section{BROILERS}

As previously suggested in the chapter on brooding, an effort should be made to dispose of all cockerels other than those to be kept for breeding purposes or to be caponized.

Pullets should not be marketed as broilers unless they are deformed or poorly developed.

Market classification. Broilers are divided into three classes: Squab broilers, broilers, and fryers. Squab broilers range in size from $3 / 4$ of a pound to 1 pound in weight, broilers from 1 to 2 pounds in weight, and fryers, or, as they are sometimes called, "large broilers" or "small roasters," from 2 to 3 pounds. Usually it is more profitable to dispose of the cockerels when they range from 1 to $21 / 2$ pounds in weight.

Time to market. The time to market broilers is in the early spring, as the prices are highest during that period. 
Fattening broilers. Broilers that are to be shipped alive as well as those that are to be killed before shipping should be fed a special ration before they are sent to market. Broilers may be fattened either by confining them to a coop, such as is shown in Figure 284, for 10 days or 2 weeks or pen fattened by keeping them in their house for the same period, and feeding a ration that will increase their weight and improve their condition. A good fattening ration for broilers is as follows:

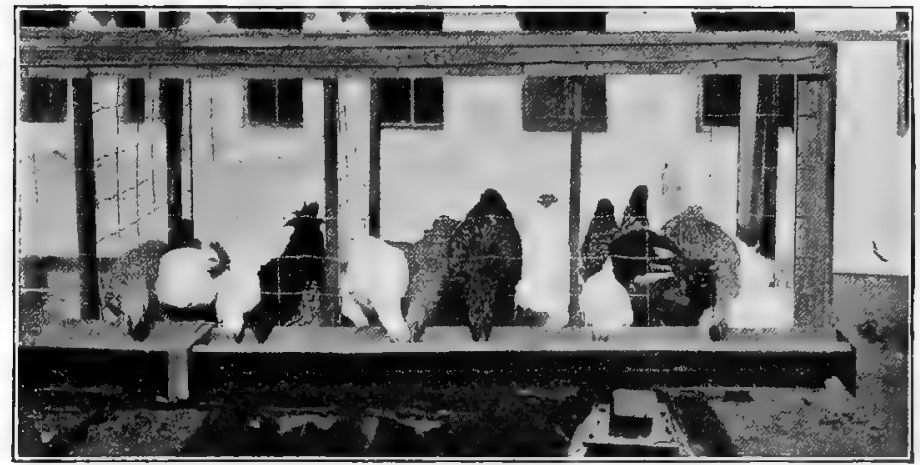

Figure 284.- Surplus cockerels being fattened for market.

3 pounds of corn meal

1 pound of middlings

1 pound of bran

1 pound ground oats

When chickens are confined to a fattening coop, this mixture should be fed twice daily in a trough such as is shown in Figure 284. Birds fed on this mixture should not be given water to drink. When skim milk or buttermilk is not available, add to the above mixture one pound of beef scrap, using water to moisten the mixture. Likewise, when skim or buttermilk is not fed, green feed, such as sprouted oats, cut clover or alfalfa, should be given to the fowls, in order to keep them in good condition. Broilers 
that are fattened by confining them to their pen or house should be fed a mash composed of 3 pounds of corn meal, 1 pound of middlings, 1 pound of bran, and 1 pound of ground oats, slightly moistened with skim milk or water, in the morning and at noon. In addition to this, feed a grain mixture of equal parts of cracked corn and wheat for the evening meal, keeping a pan of skim milk when available or water before the birds constantly to drink. Chickens fattened by this method of feeding are called "milk-fed."

\section{HENS}

As the majority of hens after reaching a certain age do not lay enough eggs to pay for their feed, care, and attention, they should be marketed. As a rule hens of the heavier breeds, such as the Plymouth Rocks, cease to produce a profitable number of eggs after they are two years old. Consequently fowls of this class should be marketed as soon after this time as possible, so that the feed may be fed more profitably to the pullets and younger hens. It will be found, when culling, that many fowls of the lighter breeds, as the Leghorns, can be kept profitably for three years or longer.

Time to market. Usually the best time to market old hens, especially those that molt early, is during July and August. The number of eggs produced by hens while they are molting is very small and in the majority of cases no eggs are produced during this time. Hens culled from the flock as non-producers should be marketed soon after culling, in order to save feed.

How to market. Ordinarily it is not advisable to attempt to fatten hens for market that are two years old or over, for in the majority of instances they are fat enough. Hens that are not in good flesh, however, such as the smaller breeds, should be placed in a coop, as shown in Figure 284, and fed a fattening ration for a week or ten days before killing. By doing so, such fowls, when placed on the mar- 
ket, will be in a better condition and probably bring a better price. A good fattening ration for fowls is:
10 pounds of corn meal
5 pounds of middlings
Mix with 2 gallons of skim
milk or buttermilk.

This mixture should be fed morning and noon, and cracked corn fed for the evening meal. When skim milk or buttermilk is not available, add $1 / 2$ pound of beef scrap to the above mixture. Such green feed as previously mentioned under broilersshould likewise be fed when milk is not available. In most cases it is not advisable or profitable to attempt to fatten fowls that are to be shipped to market alive unless they are in very poor condition, when such special feeding as just given may help to improve them.

\section{CAPONS}

In addition to the information given in Chapter XI on marketing capons, the following suggestions are given

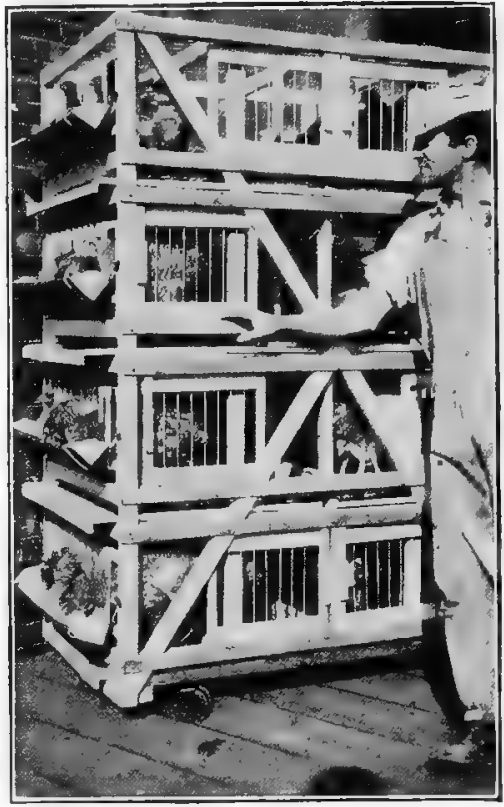

Figure 285. - Portable fattening battery as used by large commercial fattening plants.

concerning the preparation of capons for market. About two or three weeks before shipping the capons to market confine them to small yards and feed from 3 to 4 times a day a grain mixture of equal parts of corn and wheat, together with a dry mash, to which they will have access constantly, 
composed of equal parts of corn meal, middlings, wheat bran, and $10 \%$ beef scrap.

\section{TURKEYS}

The period of fattening turkeys for market usually begins about the first of October so as to have them in the best

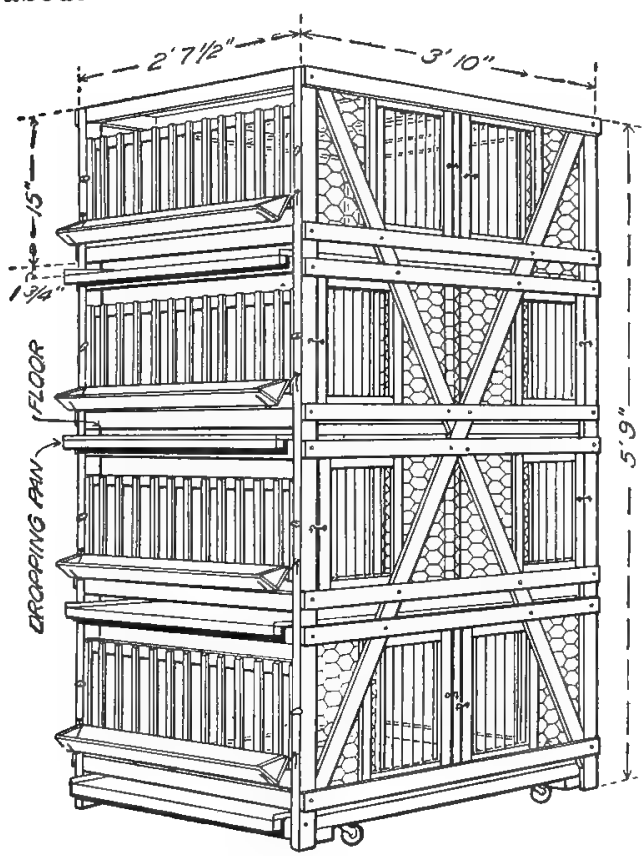

Figure 286.-Working plans of a portable fattening battery. condition for the Thanksgiving and Christmas trade.

\section{The method of} fattening that is commonly practiced consists of feeding a grain mixture of wheat and oats morning and evening during the first part of the fattening period gradually changing the feed to corn as the weather becomes colder and as the period of marketing approaches. It is advisable at first to feed sparingly morning and evening, and gradually increasing the amount until about a week before marketed they are fed three times a day and are given all they will eat. Corn and especially new corn should not be fed to turkeys in any quantity during the first part of the fattening process, as it is apt to cause a 
form of diarrhea. The addition of corn to the ration should be very gradual.

Marketing. The most satisfactory method of feeding turkeys for market is on range. Attempts to confine turkeys during the fattening period in an effort to secure a more rapid development has not proven satisfactory or practical. When confined they will eat well for the first few days after which they lose their appetite and consequently lose in weight.

The majority of turkey raisers sell their birds alive to dealers who either kill and dress them for market or ship them alive to other dealers in the larger markets. The method of killing, picking and preparing for market as given for chickens applies in like manner to turkeys.

\section{DUCKS}

As stated in Chapter XIV, ducks are usually marketed as "green" ducks. In preparing ducks for market the aim is to secure a good growth and development of flesh in a short period. To secure this result the ducklings to be marketed should be fattened for a period of two weeks before being sent to market on a ration consisting of three parts by weight, of corn meal, two parts of low grade flour or middlings, one part of bran, one half part of beef scrap, with three per cent grit and ten per cent green feed. This mash should be fed three times a day during this period. The green feed is sometimes eliminated from the above feed during the latter part of the feeding period, as it has a tendency to color the meat and affect the firmness of the flesh.

Ducks are dressed either by dry picking, scalding, or steaming. Owing to the commercial value of duck feathers (Page 302), it is advisable when possible and practical to employ the dry picking method. Thus it will not be necessary to dry the feathers artificially, as is the case when ducks are scalded and picked. This difficulty is 
overcome on large commercial duck farms where thousands of ducks are marketed by steaming the ducks before picking. The method used in dry-picking poultry is also used with ducks, although the latter are more difficult to pick clean.

\section{GEESE}

One of the more common methods of fattening young geese for market is that of confining them to pens protected by a shed-like structure for a period of from three to five weeks before marketing. During this time they are fed whole corn in hoppers to which they have access at all times. When this method is used, oat straw is provided as litter or bedding. Considerable of the oat straw is eaten by the geese and serves as a roughage. Corn silage may also be used as a roughage.

Geese are usually killed and picked in the same manner as other kinds of poultry.

\section{GUINEAS}

Guineas are usually marketed most profitably during the summer and fall, when they should weigh from 1 to $11 / 2$ pounds during the first part of the season. As the season advances the demand is for heavier birds. The common method of marketing guineas is with the feathers on, for when the feathers are removed the small size of the carcass and the dark appearance of the meat detracts from their value from the standpoint of sales. When selling to hotel or restaurant trade, it is usually preferable to ship them dressed. Guineas should be killed and dry-picked in the manner as described for poultry on page 297.

\section{SQUABS}

Squabs are in good market condition when they are about 4 weeks old and fully feathered under the wings, usually just before they are ready to leave the nest. (See page 255.) Squabs are fed by their parents up to this period. The usual practice of killing squabs is the same as that employed 
with other varieties of poultry. After killing all the feathers are plucked with the exception of those of the head; and the crop cut open and all feed removed.

A more satisfactory price can usually be secured if the dressed squabs are graded according to size and quality. Dark-colored and small-size squabs are apt to lower the price of an entire shipment of mixed squabs. They are usually packed for shipment in cracked ice with paraffin paper between each layer of ice and squabs.

KILLING, PICKING, AND SCALDING

Killing. Fowls that are to be killed before being sent to market should be deprived of feed for a period of at least 12 hours before killing.

Best method of killing. The old method of killing by removing the head with an ax or hatchet is to be discouraged in that it detracts considerably from the appearance and affects the keeping qualities to a certain extent. By far the most satisfactory method of killing is that described as follows: Suspend the fowl by means of a cord around the feet. Grasp the head of the fowl with the left hand, force the mouth open, and with a knife having a sharp point make a diagonal cut, severing the arteries in the back of the throat, which are back of the base of the jaw. (See Figure 287.) The point of the knife is then plunged through the groove in the roof of the mouth to the brain. This causes paralysis, loosens the feathers, and allows them to be easily picked. The cutting of the arteries causes the fowl to bleed freely from the mouth.

Dry-picking. To make the best appearance when placed on the market, the feathers should be dry-picked in such a manner that the skin will not be torn. Immediately after killing and while the bird is still bleeding the feathers should be removed. The method of plucking the feathers is to first remove the tail feathers, then the large wing feathers 
followed by those from the breast, fluff, and sides, then the hock feathers, the back and thigh, those from the neck and finally the small wing feathers. Care should be taken in each case not to tear or bruise the skin. In pulling the feathers, hold them just tight enough to pull them out without tearing the skin. With a little practice one can become quite expert in this method of picking.
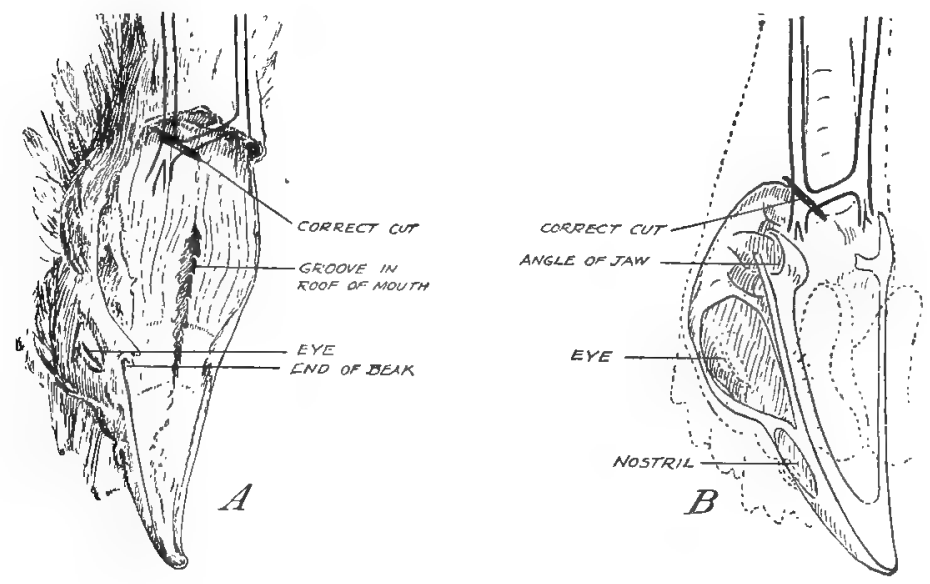

Figure 287.-The lower jaw removed, showing the position of the arteries, the anatomy of the head, and the location of the proper cut.

Scalding. This method of removing feathers is not advisable in that most markets prefer dry-picked birds. For home consumption, however, or when dry-picking is not employed, the birds are scalded by being immersed in hot water, which should be a little below the boiling point. The birds should be so immersed two or three times and then picked clean, care being taken not to tear or break the skin, as injury to the skin detracts from the appearance.

Drawing. It is not advisable to draw or clean poultry that is to be shipped, even though the fowls are packed in 
ice. Drawn poultry deteriorates more quickly than undrawn poultry. When the fowl is drawn, the work should be done before the bird is cool. Make a slit with a knife from near the end of the keel bone down to the vent of sufficient size to admit the hand. Cut carefully around the vent and pull out the intestines together with the other organs, unless the market requirements specify otherwise.

Packing. After the fowls have been thoroughly cooled by being placed in a refrigerator or in cold water they are ready for packing. When the birds are cooled by the latter method, allow them to dry before packing. The inside of the box or barrel should be well lined with clean parchment or wrapping paper. Pack the birds solidly,

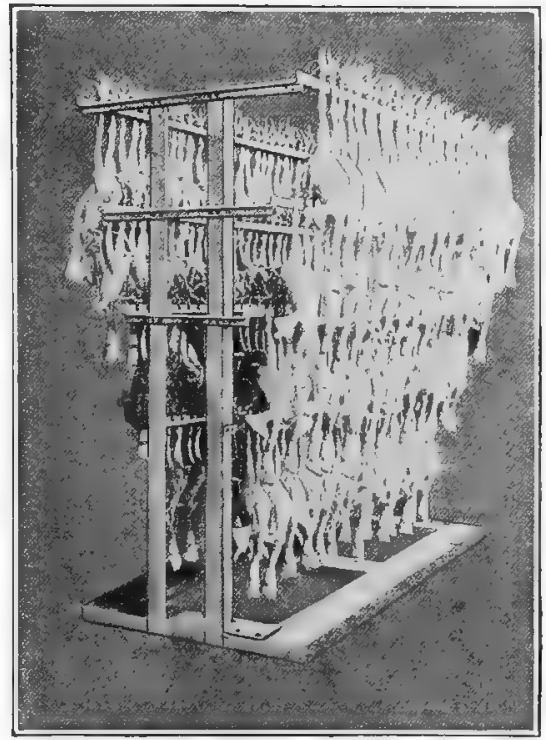

Figure 288. - A metal rack holding 180 fowls as used in large fattening and killing plants. The fowls are hung on this rack and placed in the refrigerator to cool.

so that they will not shift about in shipment and become bruised. When poultry is to be packed in ice, which method should be the only one employed in hot or warm weather, they are usually placed in barrels with layers of ice between each layer of birds, the ice forming the top and bottom layers.

SHIPPING LIVE POULTRY

Fowls of all kinds can be shipped alive and will some- 
times net the shipper as much as when dressed. When shipping live poultry to market, well constructed slatted crates, as shown in Figure 283, should be used in order to provide for sufficient ventilation, especially when shipped in express cars. Do not place too many fowls in one crate so that they will be crowded. When shipping a quantity of live fowls to market, they should be graded according

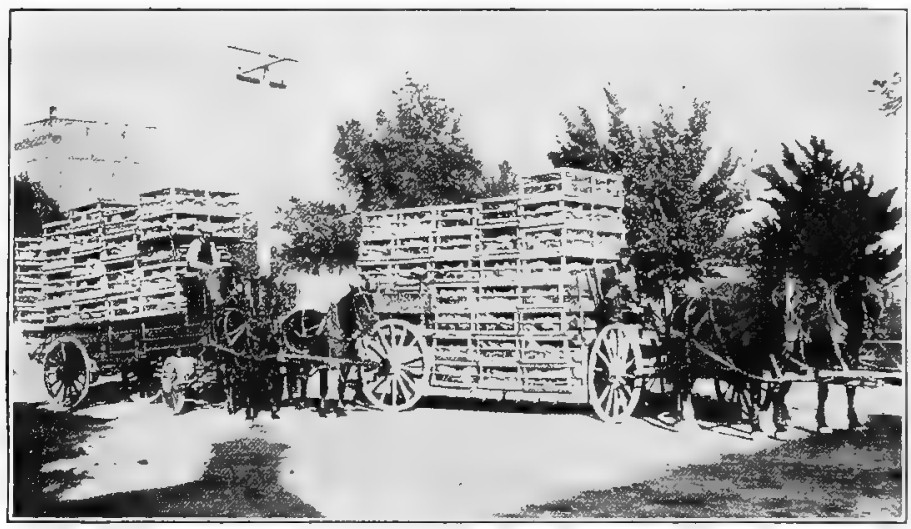

Figure 289.-A large shipment of live fowls to market.

to size and color, and placed in separate coops or in divisions of the same coop according to the variety and size.

POULTRY MANURE

Poultry manure is a valuable by-product, as the average night droppings of a hen amount to 25 to 35 pounds per year. A conservative estimate indicates that this amount of manure contains fertilizing constituents which would cost 20 to 25 cents if bought in the form of commercial fertilizers at ordinary prices. Unless the manure is properly cared for, as much as one half of its fertilizing value is likely to be lost. To prevent loss, frequent cleaning of the dropping boards is necessary, and some sort of absorbent should be 
used daily. The use in moderate quantities of sand, sawdust, fine dry loam or road dust, or, preferably, mixtures of these with a small quantity of land plaster, acid phosphate or potash salts, is recommended. Sifted coal ashes may also be used as an absorbent, but wood ashes or lime should not be mixed with the manure, as they are likely to cause the loss of its most valuable fertilizing constituents: namely, nitrogen (ammonia). The litter from the poultry

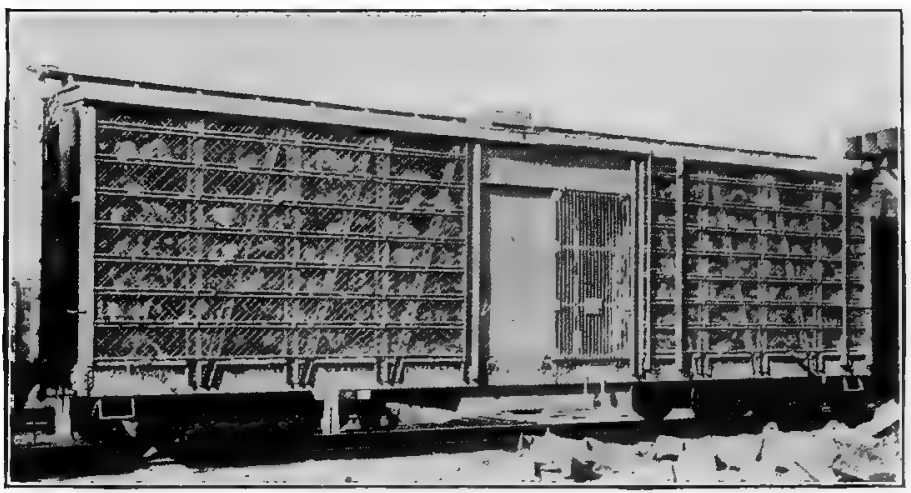

Figure 290.-A specially constructed car for shipping live fowls to market.

house may be mixed with the manure, which increases the bulk, but reduces the value per pound of the manure and makes it more difficult to apply to the soil, except where it is to be broadcasted and plowed in. The litter, however, is of much value to the land.

Poultry manure is more valuable than the manure of any other common farm animal. A ton of poultry manure contains from 0.80 to 2.00 per cent nitrogen; 0.50 to 2.00 per cent phosphoric acid, and from 0.80 to 0.90 per cent potash, depending upon the dryness of the manure, and is valued at from $\$ 10.00$ to $\$ 15.00$. It is particularly well adapted to gardening, and poultry raisers should either use it on 
their own gardens or dispose of it at a good price, thus increasing the profits of their flocks. Market gardeners and orange growers are big buyers of poultry manure and it also makes a fine fertilizer for top-dressing grass lands.

CARE AND VALUE OF POULTRY FEATHERS

Poultry feathers, if properly cared for, will bring fair returns, especially white feathers and feathers from ducks, geese, and turkeys. The feathers from ten chickens will make about one pound of cured feathers. If any considerable quantity of feathers is produced, keep the wing and tail feathers separate from the body feathers and white feathers separate from the colored, if you have any white birds. The feathers must be partly cured before they are sacked for shipment. They may be cured by spreading them not over two to three feet deep in a loft or bin. Work the feathers over occasionally with a fork until the moisture has thoroughly dried out. If only a small number of feathers are produced, they can be placed in. small quantities in loosely woven burlap sacks and hung up in the loft of a building where they get good circulation on all sides, but should not be laid on the floor or packed on top of each other until thoroughly dry.

Dirty feathers may be washed, put through a wringer and dried in the sun, if one has enough feathers to pay for this operation. Ordinarily it is better to try to keep the feathers clean and to throw the dirty feathers in with the poultry manure. The following prices were quoted on different kinds of poultry feathers in the summer of 1919 and clearly show the higher prices paid for white feathers and for geese and duck feathers: Geese feathers, pure white $80 \mathrm{c}$ per pound; average white $65 \mathrm{c}$ to $70 \mathrm{c}$; gray $55 \mathrm{c}$. Duck feathers, pure white $55 \mathrm{c}$; dirty or scalded white $40 \mathrm{c}$ to $50 \mathrm{c}$; dark feathers 40c. Chicken body feathers white $14 \mathrm{c}$ to 16c; dark 6c; damp or scalded feathers $3 \mathrm{c}$ to $5 \mathrm{c}$; hackles 
(no quills) 10c; long fancy rooster tails free from stiff feathers $\$ 1.50$. Turkey feathers, white $45 \mathrm{c}$; dark 15c. Prices for turkey feathers from other parts of the body such as wings, tails, pointers, etc., vary from $1 \mathrm{c}$ to $25 \mathrm{c}$. These prices are for good dry feathers. Those freshly packed and damp are discounted according to their condition.

\section{QUESTIONS}

1. What are the essential factors as concerning the marketing of poultry products?

2. Discuss the methods of marketing.

3. What is an infertile egg? Why should infertile eggs be produced for market?

4. Why should eggs of uniform color and size be produced for market?

5. How often should eggs be gathered?

6. Discuss the storing of eggs before being sent to market.

7. How should eggs be graded? What are "Specials," "Extras," "No. 1's," "No. 2's"?

8. Describe the method of packing eggs in a standard size crate.

9. On what basis should eggs be sold?

10. Describe the method of packing eggs for shipment by parcel post.

11. What is the market classification for broilers?

12. Describe the method of fattening broilers.

13. When should hens of the heavier breeds be marketed? Of the lighter breeds? Why?

14. Describe the method of fattening hens for market.

15. How should capons be fed before they are marketed?

16. Discuss in a general way the method of preparing turkeys for market, ducks, geese, guineas, squabs.

17. Describe a satisfactory method for killing.

18. Describe the method of dry-picking fowls.

19. Describe in detail the method of packing fowls for shipment. Describe the method of shipping live fowls.

20. Discuss the value of poultry manure as a fertilizer.

21. How should poultry feathers be handled to obtain the best price when sold?

\section{SUGGESTIONS}

1. By what method are you now marketing your eggs, that is, direct to the consumer, to a retail store, or to some one of the other agencies mentioned herein? If you are marketing to a retail store or commission merchant, why not try to work up a retail trade direct to the consumer, providing your time and facilities will permit.

2. Should you market to a commission merchant, wholesaler; or to a country store, insist that your eggs be purchased on a "loss-off," or quality, basis. 
3. Immediately after the breeding season sell, confine, or kill such male birds as you do not desire to retain as breeders. Those retained should be confined to a yard or a place separate from the rest of the flock. In other words, produce infertile eggs and try to get your neighbors and fellow club members to do the same. The importance of doing so can not be overestimated.

4. A simple and at the same time convincing demonstration can be carried on by grading eggs according to size, color and cleanliness. Place all white-shelled eggs in one carton, brown-shelled eggs in another, and in the third carton place a mixture of white and brown-shelled eggs, together with those that are large, small, and having dirty shells. The comparison and contrast will be most marked. In addition to this demonstration conduct one showing the method of packing eggs for shipment, both in standard egg crates and for parcel post. Such demonstrations should be held at poultry association or club meetings or general farmers' meetings and will always create interest and attention.

5. In order to determine the advisability of fattening broilers, select about a dozen as nearly the same size as possible, and fatten six of them, following the suggestions as given herein and feeding the fattening ration as given under broilers. Continue feeding this ration for a period of ten days or two weeks. In the meantime allow the other six broilers to range as they have been accustomed. At the end of two weeks weigh both lots of broilers and see which are in the better condition, and which are heaviest.

6. With a little practice the method of killing and dry-picking as given in this chapter can be easily carried on. A demonstration showing the method of killing and dry-picking should be carried on at an appropriate time in connection with a club or farmers' meeting. Should there be a packing plant near-by, endeavor to secure one of their men to carry on this demonstration. In all events endeavor to put into practice this method when marketing fowls of your own.

\section{REFERENCES}

Fattening Poultry, U. S. Department of Agriculture, Bureau of Animal Industry Bulletin 140 , by Alfred $R$. Lee.

Marketing Eggs through the Creamery, U. S. Department of Agriculture Farmers' Bulletin 445 , by Rob. R. Slocum.

Commercial Fattening of Poultry, U. S. Department of Agriculture Department Bulletin 21, by Alfred R. Lee.

The Community Egg Circle, U. S. Department of Agriculture Farmers' Bulletin 656 , by C. E. Bassett and W. H. Kerr.

Marketing Eggs by Parcel Post, U. S. Department of Agriculture, Farmers' Bulletin 830, by L. B. Flohr. 


\section{CHAPTER XVII}

\section{ORGANIZATION}

\section{JUNIOR CLUBS}

In view of the work that is carried on in many of the states along the lines of organizing boys' and girls' poultry clubs, the following is suggested with a view of assisting those who are desirous of organizing such clubs or acting in the capacity of a community leader in carrying on such club work.

Object of organization. Primarily the principal object of organizing poultry clubs among boys and girls is to give a better knowledge of the value and importance of the poultry industry, to teach better methods of caring for poultry and eggs, to show the increased revenue that can be derived from standard-bred poultry when proper methods of management are pursued, and to gratify the desire on the part of most boys and girls to possess live pets.

Advantages. When an effort is made to organize a poultry club, it has usually been found advisable to regard the school as a medium and unit through which the organization can be carried on and perfected. When the plan is first presented, the parents of the children should be invited, so that they will have a better understanding of the work and thus be able to assist in carrying out the plans. The purpose of the organization and the importance of the poultry industry should be explained. The boys and girls should be told that by carrying on this work they can establish for themselves a profitable and permanent business which will enable them to make money without interfering with their regular school work. Prizes and exhibits are arranged in this form of club work, in order to enable the members 
to compete among themselves, and thus secure the benefit of prizes and the honor of winning such awards. The members should be told that they will not be required to purchase extensive equipment or necessarily to build separate houses and yards. the idea being that they should do the best they can by improving such buildings and equipment as

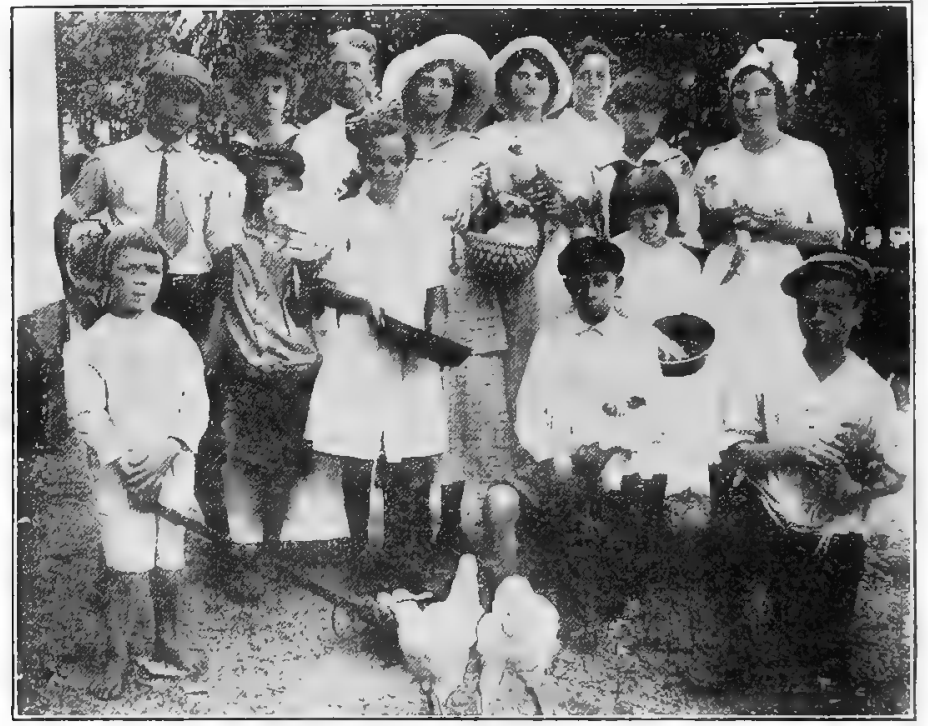

Figure 291,-A typical boys' and girls' poultry club.

they have at home until they are well established in the work. In most cases the only requirement necessary is that of purchasing standard-bred stock in the form of hatching eggs or fowls.

Organization. After allowing a little time for the boys and girls to think over the matter, a second meeting should be called with the idea of enrolling those who desire to become members. After the club is organized, there should 
be an election of officers, consisting of a president, one or more vice-presidents, and a secretary and treasurer. It is advisable for the teacher in charge to be designated as the honorary president of the club. A simple constitution and by-laws should be adopted. The following are suggested as some of the rules that should be considered in the organization of the club: (1) Boys and girls joining the club must be between ten and eighteen years of age. Special classes may be organized for older boys or girls. (2) No

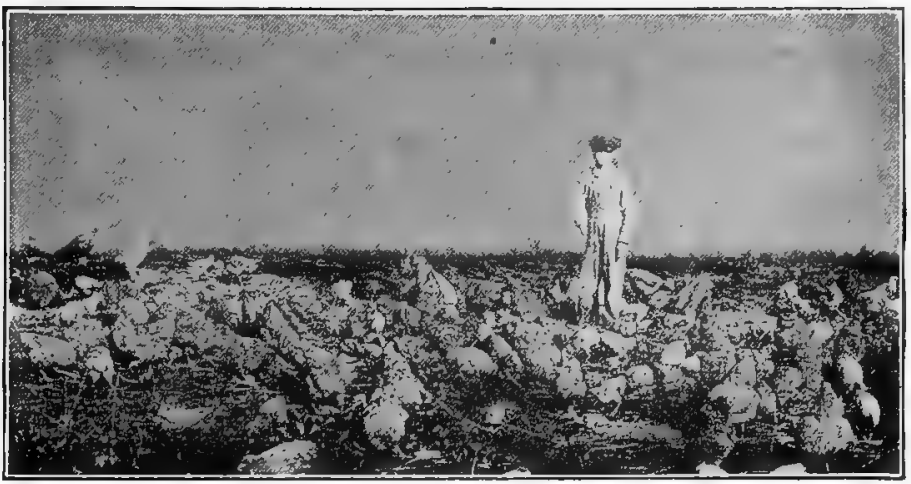

Figure 292.-A poultry club nember and his flock.

boy or girl shall be eligible to receive a prize unless he or she becomes a member of the club and sets at least one setting of eggs from standard-bred stock. (3) Each club member must agree to study the instructions given by the club organizer and write a composition on some phase of poultry keeping. Suggested outlines for this purpose will be found on pages 339, 340, 341 in the Appendix. Each member must plan to do his or her own work and keep a complete record of all transactions including labor, purchase of supplies, and sale of stock. A suggested report for this purpose will be found on page 330 . 


\section{SUGGESTED CONSTITUTION AND BY-LAWS}

Article I. This club shall be known as the...........Boys' and Girls' Poultry Club.

Article II. The objects of the club shall be: (1) To obtain a greater knowledge of the value of raising and breeding standard-bred poultry. (2) To teach better methods of marketing first-class poultry and eggs of uniform quality, and, (3) To learn how to carry on hatching, rearing, feeding, and housing of fowls.

Article III. Any boy or girl between the ages of ten and eighteen years can become a member of the club on signing the membership roll and on agreeing to set at least one setting of eggs from standardbred stock during the hatching season, and following instructions.

Article IV. Members shall not pay any dues or assessments other than those actually necessary to carry on the club activities. Such dues or assessments shall not exceed............... year.

Article V. The club as an organization agrees to hold a meeting at least once a month and all members of the organization are expected to attend.

Article VI. Each member must study the instructions sent out by the club organizer and agree to furnish reports when requested to do so. The officers of the club shall be a president, a vice-president, and a secretary and treasurer.

Article VII. The president or secretary has a right to call a meeting of the club at any time. The annual meeting shall take place as soon after November lst of each year as possible. The officers for the ensuing year shall be elected at that meeting and shall hold office until their successors are elected.

Article VIII. Each member is expected to exhibit every fall or winter several fowls of his or her own raising, and one dozen of eggs at the state or county fair or some other suitable place, such as a school or community show.

Article IX. All prizes on live poultry must be decided in accordance with the standards of the breeds described in the American Standard of Perfection, published by the American Poultry Association.

Plans for starting the actual work. One of the most important phases of this work is that of providing ways and means by which the members can get their start. When this problem is solved, the club can be considered well under way. Generally speaking, there are two methods that can be followed. The first and least expensive one is that of hatching chickens from eggs purchased from a reliable breeder of standard-bred stock. The second plan is that of buying several hens and a male bird. This method, although presenting a larger money investment, ordinarily brings immediate returns through the production of eggs. In either 
case an effort should be made to have all the members agree to adopt the same breed and variety of standard-bred fowls. The advantages of such a plan will be found under the heading of "Community

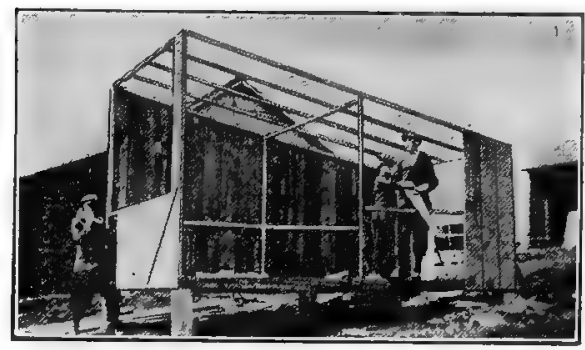

Figure 293.-A poultry house being built by club members.

Breeding Associations." In any case the members should agree to raise only standard-bred poultry. The advantages of standard-bred fowls over mongrels will be found in Chapter II.

The following suggested plans could assist club members in getting started, when financially unable to purchase stock or eggs outright:

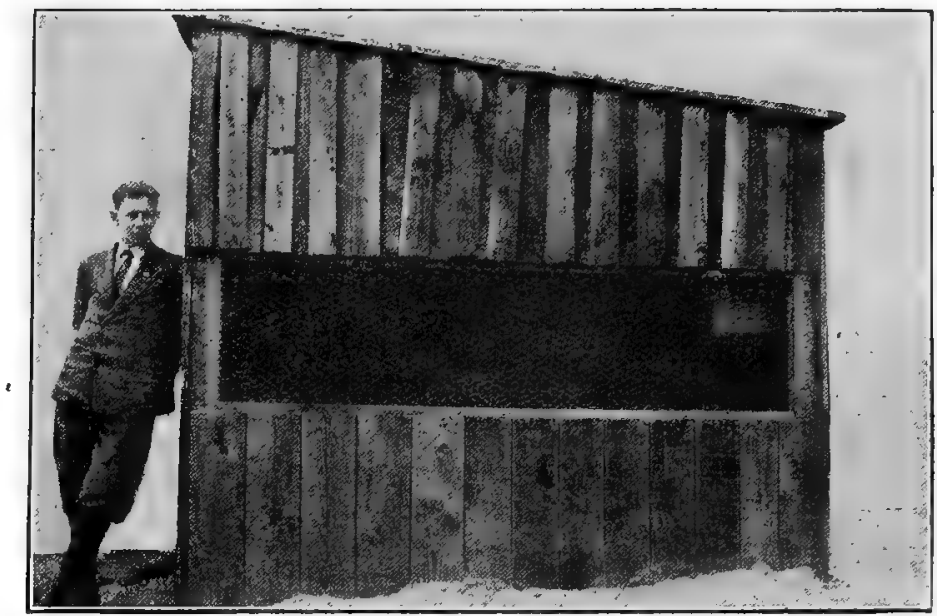

Figure 294,-A poultry house built by a club member. 
1. Winning a prize of a setting of eggs or a pen of fowls offered by a local poultryman to the members writing the best compositions on some phase of poultry work.

2. Have the members take charge of the home flock, and, as a reward for the attention given, receive a portion of the eggs produced. From the sale of these eggs the member can secure enough money to purchase several settings of eggs from a standard-bred flock, or a pen of standard-bred fowls.

3 . In numerous instances poultrymen have co-operated with members in supplying them without cost 50 to 100 eggs, with the understanding that the poultry breeder is to receive in return two matured fowls hatched from each lot of 50 eggs given to the members.

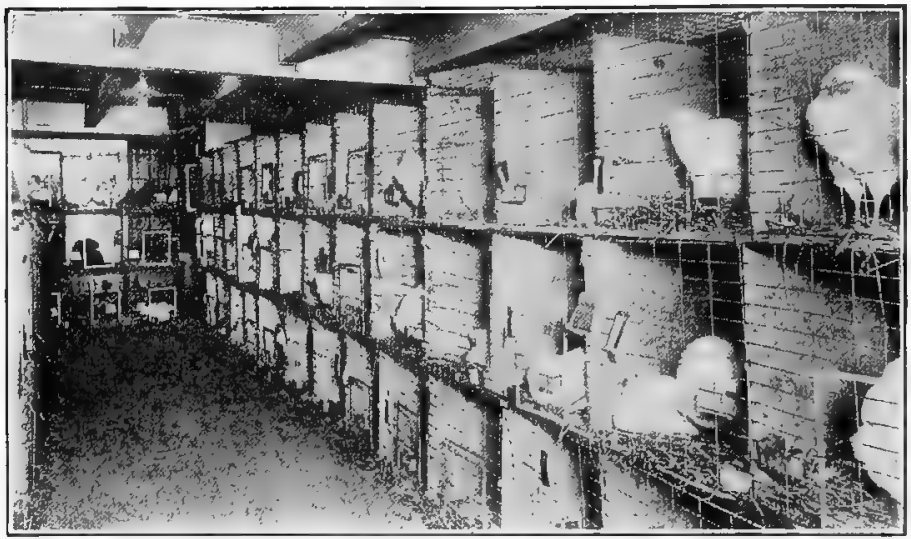

Figure 295.-A poultry club exhibit held in connection with a regular poultry show.

4. A similar plan is that of a poultryman's lending to a member a pen of fowls during the breeding season, the eggs from which are to be used for hatching. Upon reaching maturity, 3 to 5 birds hatched from these eggs are to be returned to the breeder, together with the original pen.

5. A progressive club might have in connection with its school a poultry plant planned and built by the members. Several pens of fowls could then be purchased or donated by a public-spirited poultryman, and these fowls taken care of by the members. Thus the club would not only have an opportunity of carrying out a community object lesson, but the eggs produced could be taken to their respective homes to serve as a foundation for a standard-bred flock of their own.

6. Plans may be arranged whereby the merchants of the town would donate several hundred eggs from standard-bred stock, and the 
members compete for them by writing essays on some poultry subject, or as the result of an examination given to the members on ins principles of poultry culture.

Monthly meetings. After the club has been organized and the work actually under way, one of the most important factors to stimulate and maintain interest and add to the members' knowledge of the subject is that of holding monthly meetings. Clubs should embody in their constitution the clause of holding monthly meetings, and the members should agree, when signing their application cards, to at.tend them. During the school session the meetings should be held at the schoolhouse. During the summer they can be held at the different members' homes. On all occasions the patrons and public should be invited to attend. The program for such a meeting should constitute as far as possible the following parts:

(1) Business meeting of fifteen minutes.

(a) Roll call.

(b) Examination of members' records by club leader.

(c) Questions and discussion of individual problems.

(2) Seasonable questions to members, embracing phases of work done by them during the previous month. Fifteen minutes.

(3) One or two talks by members, farmers or their wives, local poultrymen, county leader or poultry specialist on seasonable poultry topics. Thirty minutes.

(4) Actual demonstration by members of some timely phase of poultry work. Suggestions for such demonstrations will be found at the end of each chapter under the heading of "Suggestions." Twenty minutes.

(5) Open period for questions, plans, entertainment, refreshments, etc.

Club exhibits. The exhibiting of fowls and eggs by the members of a club is a very important feature of the work that should be encouraged. These exhibits afford an excellent opportunity for the members to display their stock and to show the public what they have accomplished. Such exhibits may be held either as a club or community exhibit in connection with the county or local fair or poultry association or in connection with the state fair or state poultry association show. When a community poultry 
show is held, prizes can usually be secured through donation by public-spirited individuals and merchants. Members showing their fowls at poultry shows or fairs should compete in a separate class by themselves, arrangements being first made with the fair officials to provide such a class. Suggestions for preparing the birds for the show and the

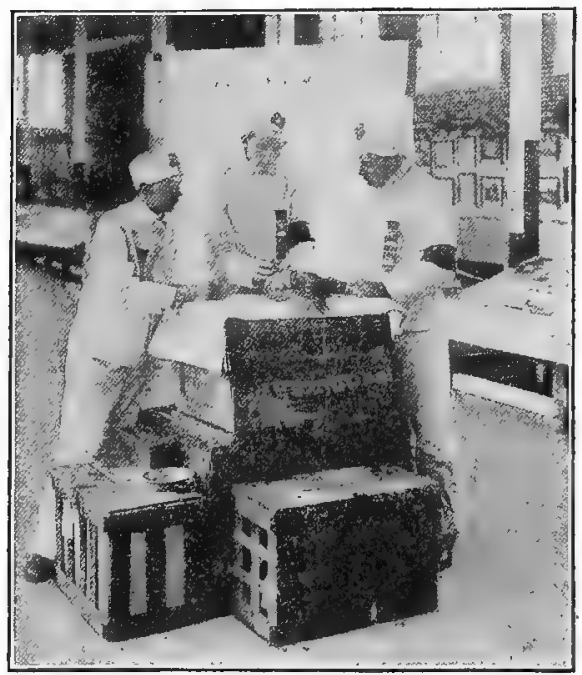

Figure 296.-Members of a poultry club carrying on a caponizing demonstraion. rules that usually govern poultry shows and exhibits will be found in Chapter XV.

\section{A complete ex-} hibit. Besides the display of the members' fowls and eggs, arrangements should be made for some of the members to take part in judging and demonstration teams, carrying on actual poultry work. The selection of the members for such teams can be arranged on a competitive basis. This plan will stimulate individual interest and cause the members to become proficient when judging their fowls and demonstrating the various phases of poultry work. If possible, arrangements should be made to offer prizes to the teams making the best demonstrators and the best showing as to their ability to judge. Suggestions for such demonstrations can be found at the end of the preceding chapters under the heading of "Suggestions." 
Awarding prizes on poultry work. In many instances it may be advisable to award prizes to members on their practical work as well as on their exhibits. When such a plan is followed, the members should be acquainted with the scale of points and the value of such items as will enter into the final awards. A suggested scale is as follows:

Total number of standard-bred fowls raised to maturity Points

in proportion to number of eggs set................. 40 Exhibit, including fowls and eggs.................... 25

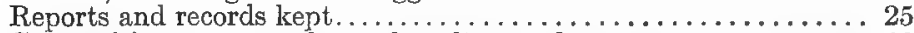
Composition on some phase of poultry work............. 10

Perfect score............... 100

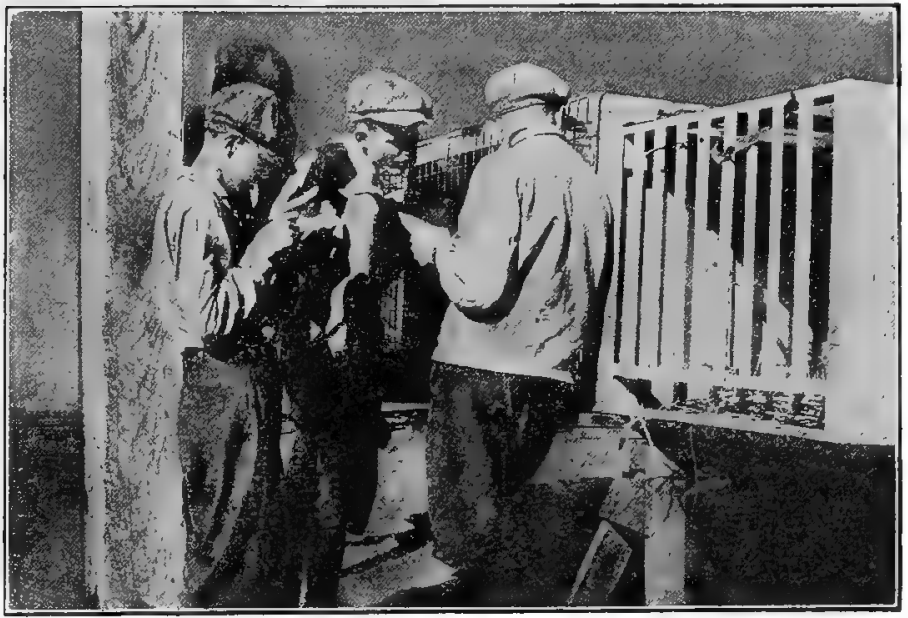

Figure 297.-Members of a poultry olub preparing for a judging contest.

\section{ADULT COMMUNITY BREEDING CLUBS}

A community interest in any one type, breed, or variety of live stock in any form is one of the greatest steps in advance toward progressive agriculture that any section can inaugurate. The organization of a community breeding association often is and should be the outgrowth of previous efforts 
in boys' and girls' poultry-club work. Before trying to organize such an association, the opinion of those in the community who are interested in poultry should be sought. Should enough poultrymen be favorably inclined to lend their support, the preliminary steps should be taken to effect such an organization. When possible, the co-operation of the business men should be obtained, for the reason that such men in towns are often owners of farms and consequently interested in the advancement of agriculture, which in turn

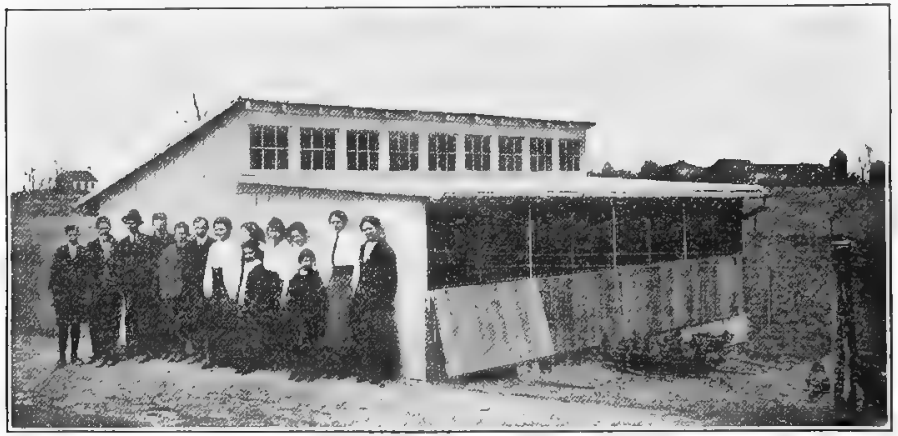

Figure 298,-A school community poultry breeding association and poultry house located on the school grounds.

will benefit their various branches of business. Likewise their assistance should be sought in helping to finance such an association, if necessary. This is usually done by having the business men's associations take the initiative and agree to contribute a reasonable amount of money for the purchase of eggs from standard-bred stock to be distributed among the farmers or poultrymen that join the organization. Should this method not be advisable, it is sometimes possible for the organization to secure a loan from the bank to finance the members in the purchase of standardbred stock or eggs. This plan as well as the former has been carried out with success in several sections of the country. 
Advantages of such an association. The advantages of such an association are as follows:

1. Aside from the establishment of an association that will be interested in poultry, the fact that-it is centering all its efforts on one breed or variety of fowls will add considerably to the interest of all concerned. Under such an arrangement all members will be interested in the same variety of fowls and thus the interest will be mutual.

2. The methods of handling and breeding the accepted breed will be common knowledge so far as the association is concerned and each member's experience, when related, will be a help to the other members. Such an association, devoting all its efforts to one breed

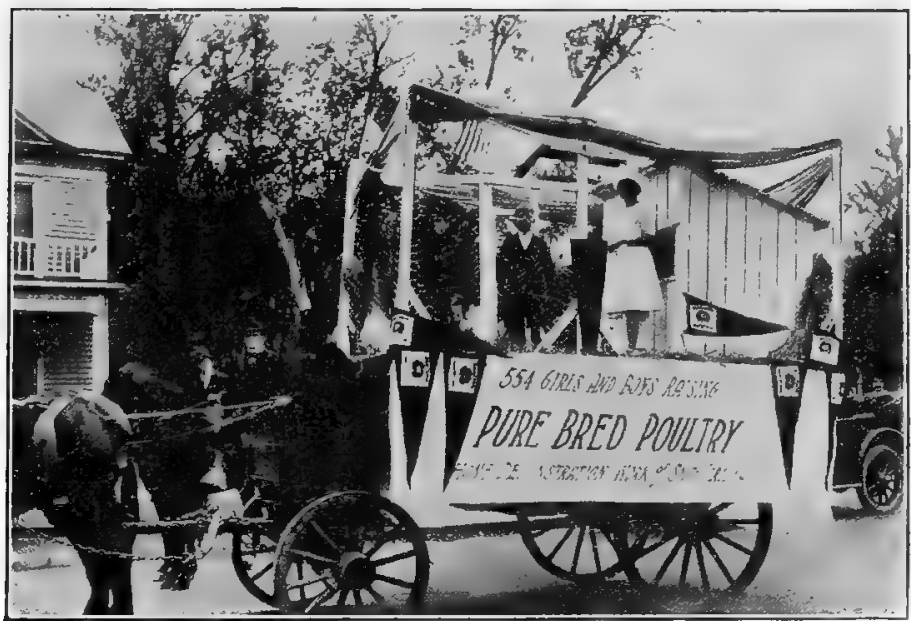

Figure 299.-A poultry club float in an agricultural parade.

of poultry, may be able to establish for itself a center that will become known as a source of supply for quantities of fowls and eggs for market, eggs for hatching, breeding stock, and day-old chicks.

3. When one breed is generally adopted by a community, the chances of cross-breeding are reduced to a minimum.

Selecting the community breed. The selection of the community breed and variety should be left entirely with the association as the result of a vote of the members. In a given class of fowls more depends on the way they are treated and managed than on the breed and variety itself. 
Organization. Other than the usual election of officers and the adoption of a constitution and by-laws a board of directors should be appointed or elected. The duties of such a board will be to consider such problems and phases of work as may arise and submit their recommendations to the association at the monthly meeting for discussion. In perfecting the organization an agreement should be drawn up and

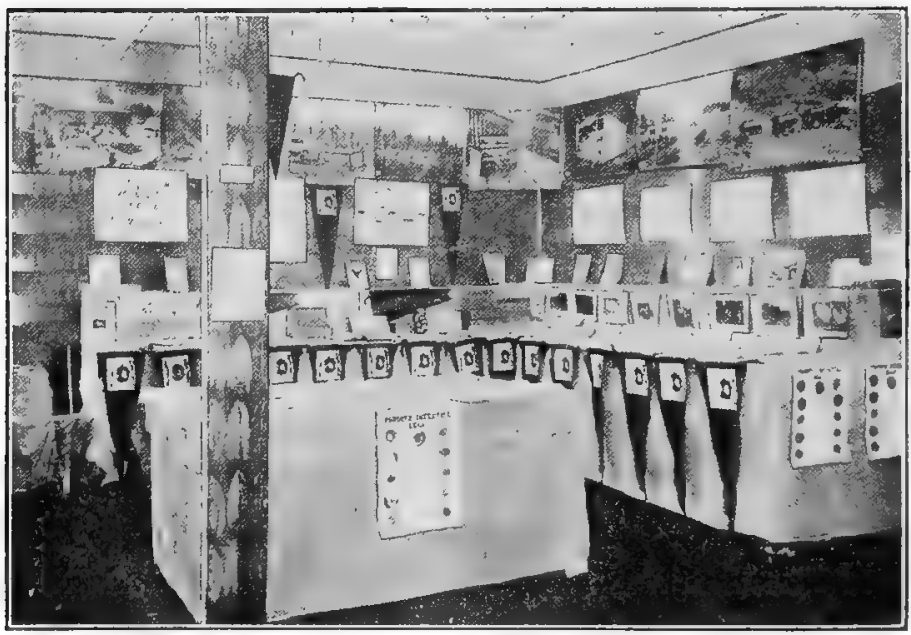

Figure 300.-A poultry educational exhibit.

signed by each member of the association agreeing to do specific things which will have to do with the welfare, success, and future growth of the organization. This agreement should embody such clauses as agreeing to dispose of all their stock through the association, to raise none other than the community breed and variety, and to adhere strictly to the rules and regulations, constitution, and bylaws of the association.

The following agreement which was used in the or- 
ganization of the Farmville Barred Plymouth Rock Association may serve as a guide in drafting similar agreements.

AGREEMENT

Being a member of the Farmville Barred Plymouth Rock Association, the object of which is to improve poultry practices by the establishment of one variety of standard-bred fowls, I hereby agree to abide by the terms of this agreement as well as the constitution and by-laws of the association.

I agree to accept the eggs furnished by the association without obligating myself in any way except by adhering to this agreement.

To accept these eggs for incubation and so manage them as to produce the maximum results and likewise to consider such suggestions and practical advice as given by the poultry adviser of the association so as to produce the best quality of eggs and poultry for market.

The standard variety of this association being the Barred Plymouth Rock, I agree to dispose of all chickens I possess prior to October 1, except standard-bred Barred Plymouth Rocks.

To attend the meetings of this association as often as possible, so as to receive the benefits of hearing poultry topics discussed as well as the business transactions of the association.

At all seasons of the year except during the breeding season when eggs are produced exclusively for breeding purposes, I agree to produce infertile eggs by disposing of or isolating all male birds from my flock.

I agree to market all my poultry and poultry products through this association. In the event that this is not done $I$ agree to pay the association such a percentage as might be decided upon by the board of directors of the value of all products marketed outside of this association.

I agree to furnish next year at a price not to exceed....per dozen twice the number of eggs that I have received this year or such prorata part as the association may require to new members of the association.

I furthermore agree to uphold the reputation of this association at all times and realize that carelessness on my part will reflect a discredit to the association and all of its members, including myself.

Should I fail to comply with this agreement I agree to return the value (not over $\$ 5.00$ ) of the eggs received to the Farmville Barred Plymouth Rock Association on demand.

Meetings. Periodic meetings should be arranged to stimulate interest and improve the members' knowledge of handling poultry by the exchange of ideas and by lectures in addition to carrying on the business of the association.

Possibilities for development. After the work is well under way and the association is in a position to market some of the products produced, arrangements should be 
made by the secretary or manager to find a good market for eggs produced by the association, together with broilers, surplus fowls, and capons. By marketing as an association but little difficulty should be experienced in obtaining a suitable market, for the reason, that if the members are adhering to their agreement, the quality and quantity of the fowls and eggs produced will be readily accepted. To take advantage of every source of revenue afforded by an association of this kind, an effort should be made to advertise the fact that they have breeding stock for sale. In doing so special mention should be made that the association is in position to fill orders for eggs for hatching, and, when possible, day-old chicks and breeders. When conditions seem to warrant it, the association should consider the erection of a community hatchery. Such a plan would not only afford the usual benefits of increasing their incubator capacity and enable them to do custom hatching, but also open a profitable field for selling day-old chicks. When there is a creamery operating in the community, the association should have in mind the possible field of fattening fowls by utilizing the skim milk or buttermilk from the creamery as a supplement to other feeds. In this way the surplus stock of the members can be marketed at an increased profit, together with the stock purchased from other farmers and poultrymen in the neighborhood.

Exhibits. As the principal event in the year's work definite plans should be made for holding an annual exhibit of fowls raised by the members of the association. Lectures, illustrated and otherwise, should be planned, so as to make the event complete. An educational display showing what has been accomplished and the advantages of such an association should be arranged with the idea of interesting others to join.

\section{QUESTIONS}

1. What are the objects of organizing boys' and girls' poultry clubs? 
2. What are the advantages of such organizations?

3. Discuss briefly the organization of such a club, together with some of the rules which should be adopted.

4. Mention some of the more important articles that should be included in the constitution and by-laws.

5. Describe several plans whereby members of the club can get started in their actual work.

6. Discuss the importance and value of holding monthly meetings.

7. Discuss the factors that should be considered when arranging for poultry-club exhibits.

8. Discusss the value of holding a club demonstration in connection with an exhibit.

9. What is a community poultry breeding club?

10. What are the advantages of such an association?

11. How should the community breed be selected? club.

12. Describe the organization of a community poultry-breeding

13. Of what value are meetings of such an association?

14. Mention some of the possibilities for development of a community breeding association.

15. Describe some of the features that should be included in an exhibit held by a community breeding association.

\section{SUGGESTIONS}

1. Reference has been made several times in the preceding chapters to the importance of organizing boys or girls or adults in a community interested in poultry into an association or club. With this thought in mind, the suggestions contained in this chapter have been offered. There is no question that those interested in poultry keeping would be considerably benefited by organizing themselves into a club or association. This applies to boys and girls as well as owners of back-yard flocks, poultrymen, and farmers. Boys and girls should secure the help of their teacher, who in most cases will be only too glad to assist in the organization. Owners of back-yard flocks, poultrymen, or farmers, should seek the co-operation of their county agricultural agent, who in turn will render every possible assistance in perfecting such an organization as it might be desirable to form.

2 . Consider carefully the advantages of a community poultry breeding association, realizing what can be accomplished when one breed and variety of standard-bred fowls is produced by a number of people in one community. Such an organization, properly organized and conducted, will be most instrumental in developing interest in poultry among the members and in the community, to say nothing of the financial benefits that can be derived.

3. In the case of the boys' and girls' poultry club or a poultry association formed among adults, the advantages of an annual exhibit should not be overlooked. The suggestions as given in Chapter XV will be of considerable help in this connection.

\section{REFERENCES}

Better Poultry Through Community Breeding Associations, U. S. Department of Agriculture Yearbook, 1918, separate No. 778, by Jos. Wm. Kinghorne. 


\section{CHAPTER XVIII \\ BUSINESS MANAGEMENT}

One of the most neglected phases of poultry keeping is that of maintaining a record of all business transactions, together with such records as will show whether or not the flock is paying a profit. Such a system is important and of value to those who are keeping poultry only in a small way as well as to farmers and poultrymen with larger flocks, if the business is to be conducted successfully. Aside from these facts, one can frequently determine from such records the cause of loss, should there be any, and, therefore, prevent further loss. Again, even when a profit is shown, it may be possible to determine a way to obtain a still greater profit by reducing the cost of production or eliminating unnecessary expenditures. The records and forms used to keep such accounts and transactions need not be complicated, in order to determine the standing of the business. As a matter of fact, such records should be simple, so as to eliminate any great clerical work, and also to present the standing of the business clearly and quickly.

The records given herein may be used as presented or they may be changed to meet the requirements of a particular flock or the manner in which the business is conducted. In either case the forms can be copied in a suitable blank book so as to keep them intact. The several forms that are necessary are as follows: Hatching and brooding record, monthly statement sheet, feed record, egg record, yearly summary, inventory, and balance sheet.

Hatching and brooding record. Under "Number of eggs" indicate the number in each setting or the number placed in the incubator at one time. With each setting or each lot 
of eggs indicate in the second column the date set. This will serve as a record in determining when the chicks will hatch. Under "Eggs tested out" indicate on the 7th and 14th days of incubation the number of infertile and deadgerm eggs. Before doing this, read again what is said on testing eggs, in the chapter on Incubation, page 86. After the eggs are tescied and the infertile and dead-germ eggs

\section{HATCHING AND BROODING RECORD}

\begin{tabular}{|c|c|c|c|c|c|c|c|c|c|}
\hline \multirow{3}{*}{ Lot } & \multirow{3}{*}{ 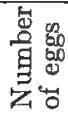 } & \multirow{3}{*}{ 离 } & \multicolumn{3}{|c|}{ Eggs tested out } & \multirow{3}{*}{ 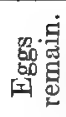 } & \multirow{3}{*}{ 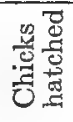 } & \multirow{3}{*}{ 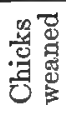 } & \multirow{3}{*}{ 总总 } \\
\hline & & & \multicolumn{3}{|c|}{ On 7th day |On 14th day } & & & & \\
\hline & & & Infer. | Dead | & Infer. & Dead & & & & \\
\hline 1 & & & & & & & & & \\
\hline 2 & & & & & & & & & \\
\hline 3 & & & & & & & & & \\
\hline 4 & & & & & & & & & \\
\hline 5 & & & & & & & & & \\
\hline 6 & & & & & & & & & \\
\hline 7 & & & & & & & & & \\
\hline 8 & & & & & & & & & \\
\hline 9 & & & & & & & & & \\
\hline 10 & & & & & & & & & \\
\hline Total & & & & & & & & & \\
\hline
\end{tabular}

taken out, place in the next column, the number of eggs remaining. The number of chicks hatched from each lot should be placed in the next column. After the chicks are weaned, it would be well to count them, placing the information in the 9th column. The number of chicks that die should be placed in the last column. 
MONTHLY STATEMENT SHEET

Month of ............

Dr. (Money spent)

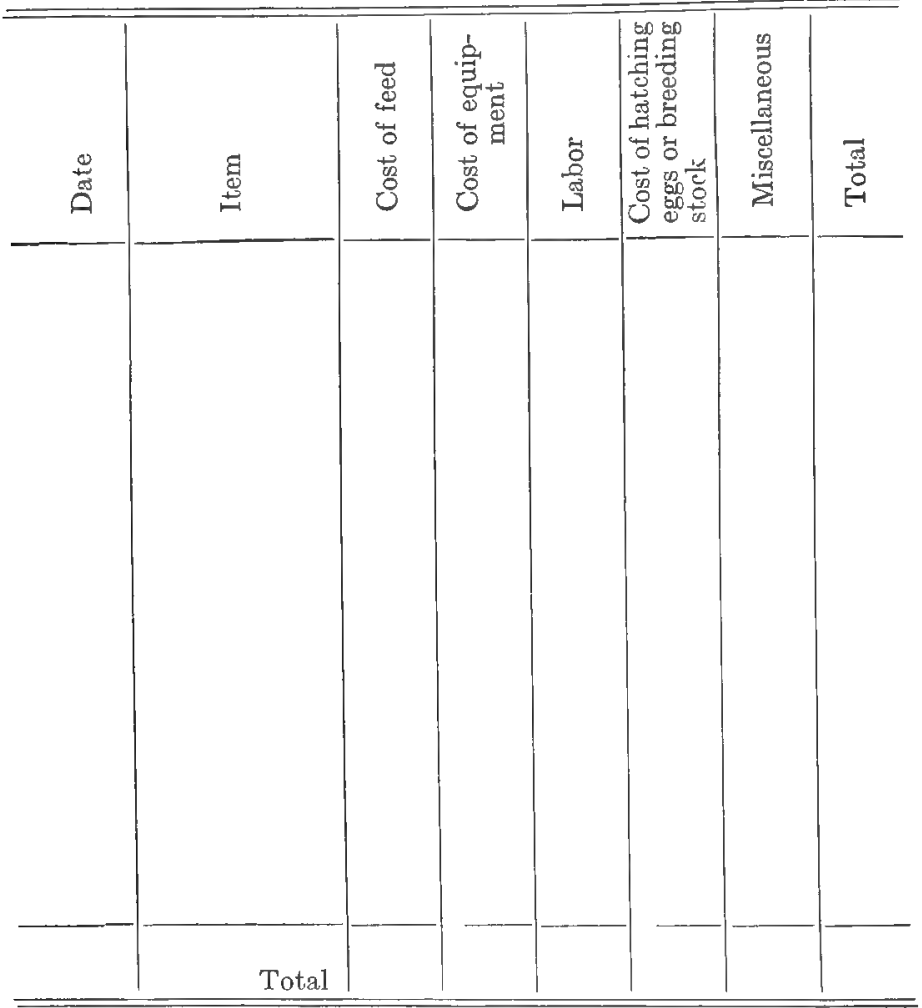

Monthly statement. This form, of which there should be twelve copies, one for each month, is self-explanatory and provides for expenditures and receipts during the month. On the debit side of this sheet in the first column indicate the day of the month that an expenditure is made. 


\section{MONTHLY STATEMENT SHEET}

Month of .............

Cr. (Money receiver)

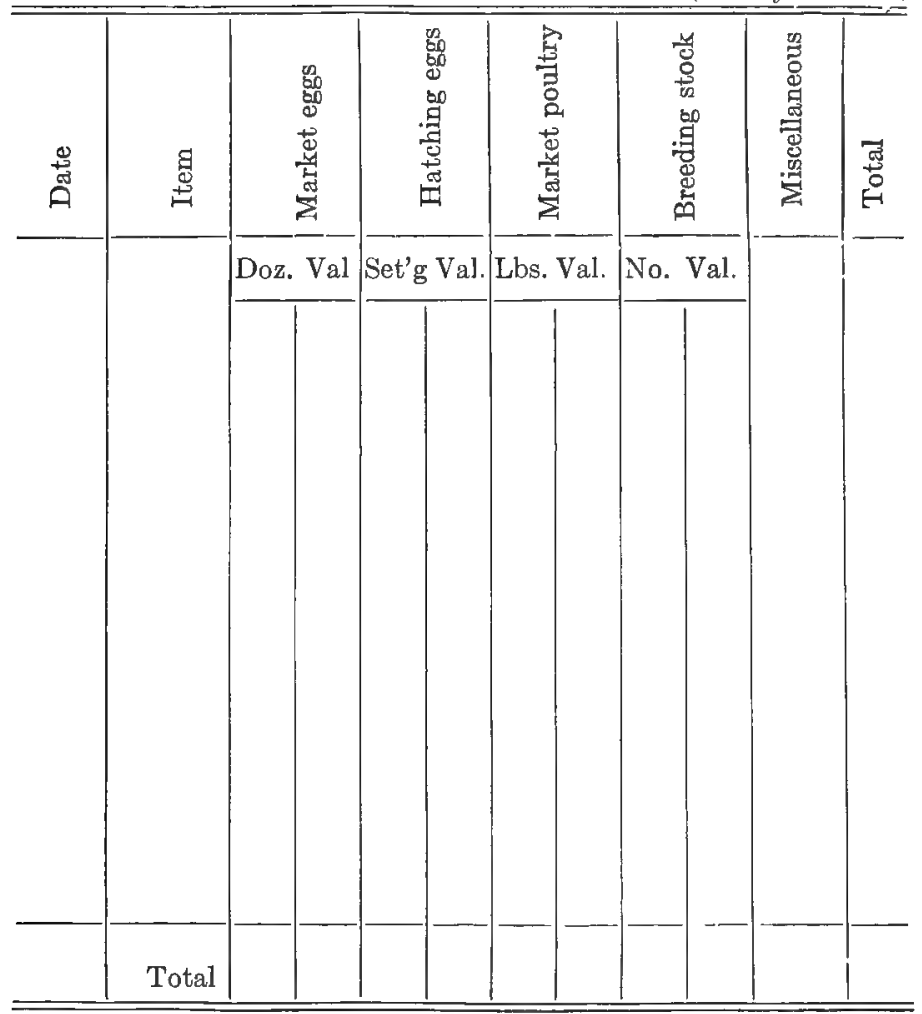

In the second column under "Item" place the kind and amount of the article purchased. For example, should beef scrap be purchased on the first day of January, indicate the amount and nature of the item as, for instance, $100 \mathrm{lbs}$. of beef scrap. Then, on the same line, under the heading of "Feed," place the cost of this beef scrap. The same principle holds true 
with all items purchased. The last column on the debit side should contain the total amount expended on each day for all items, which, when added together at the end of the month, should give the total amount expended during that period. The total line at the bottom of this form will indicate the amount spent during the month for feed, for equip-

\section{YEARLY FEED RECORD}

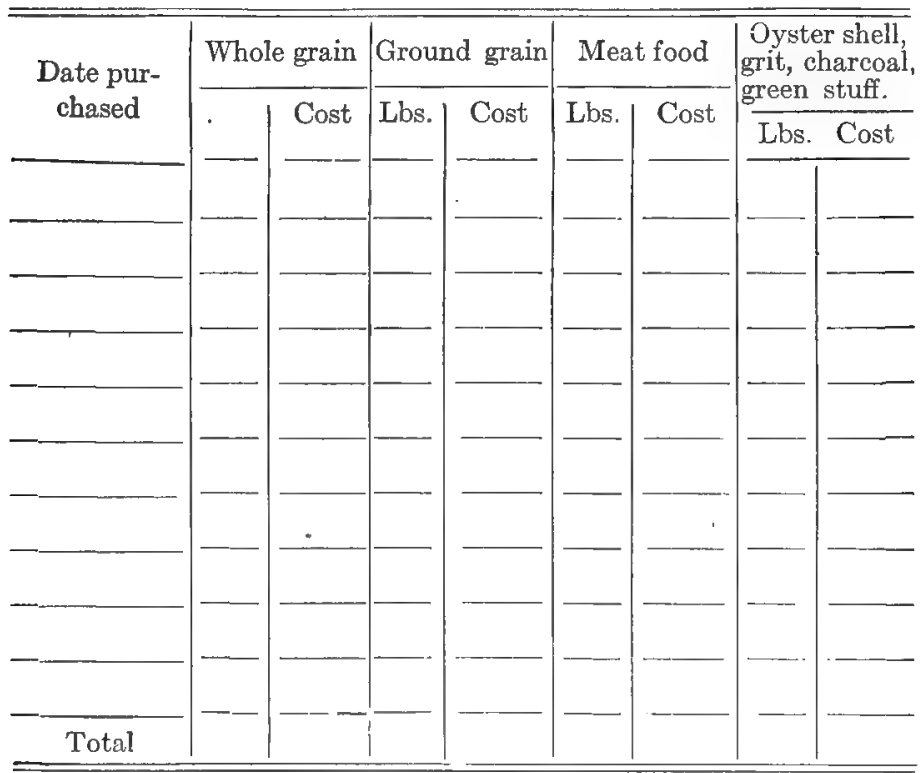

ment, etc., which, when added together, should agree with the total amount spent.

On the credit side of this sheet indicate, as will be noted, the various receipts for each day, totaling the daily receipts at the extreme right-hand side of this form. Likewise at the bottom of the form total the amount of money received 
for market eggs, eggs for hatching, etc., as well as the quantity sold during that period. The totals as obtained at the bottom of the debit and credit side of this monthly statement should be carried over to the yearly record which is shown on page 324 .

The yearly feed record is not regarded as absolutely necessary, for the information may be secured from each of the monthly statement sheets. If a feed record is desired separate from the information given in the monthly statement, however, this form may be used, enabling one to tell at a glance the time, quantity, and cost of feeds purchased and used. Such information may be of considerable value when laying in a supply of feed for the year. In the event that feed is not purchased and in its stead home-grown feed is used, measure out a quantity at a time and place it where it will not be used for any purpose other than for the fowls, charging this feed to yourself at current prices. When this amount of feed is used, repeat the operation. In this way a more accurate record of feed costs can be kept.

The yearly egg record provides a space for each day in the month wherein the number of eggs produced may be recorded. At the end of the month the monthly column should be totaled to determine the number of eggs produced during that time. At the end of the year the number of eggs produced during each of the 12 months may be added to secure the yearly egg record. The average number of eggs per hen each month may be obtained by adding the number of hens in the flock at the beginning of the month to the number of hens in the flock at the end of the month and dividing this total by 2 , which will give approximately the average number of hens during the month. The average production per hen is the total number of eggs divided by the average number of hens. 


\section{YEARLY EGG RECORD}

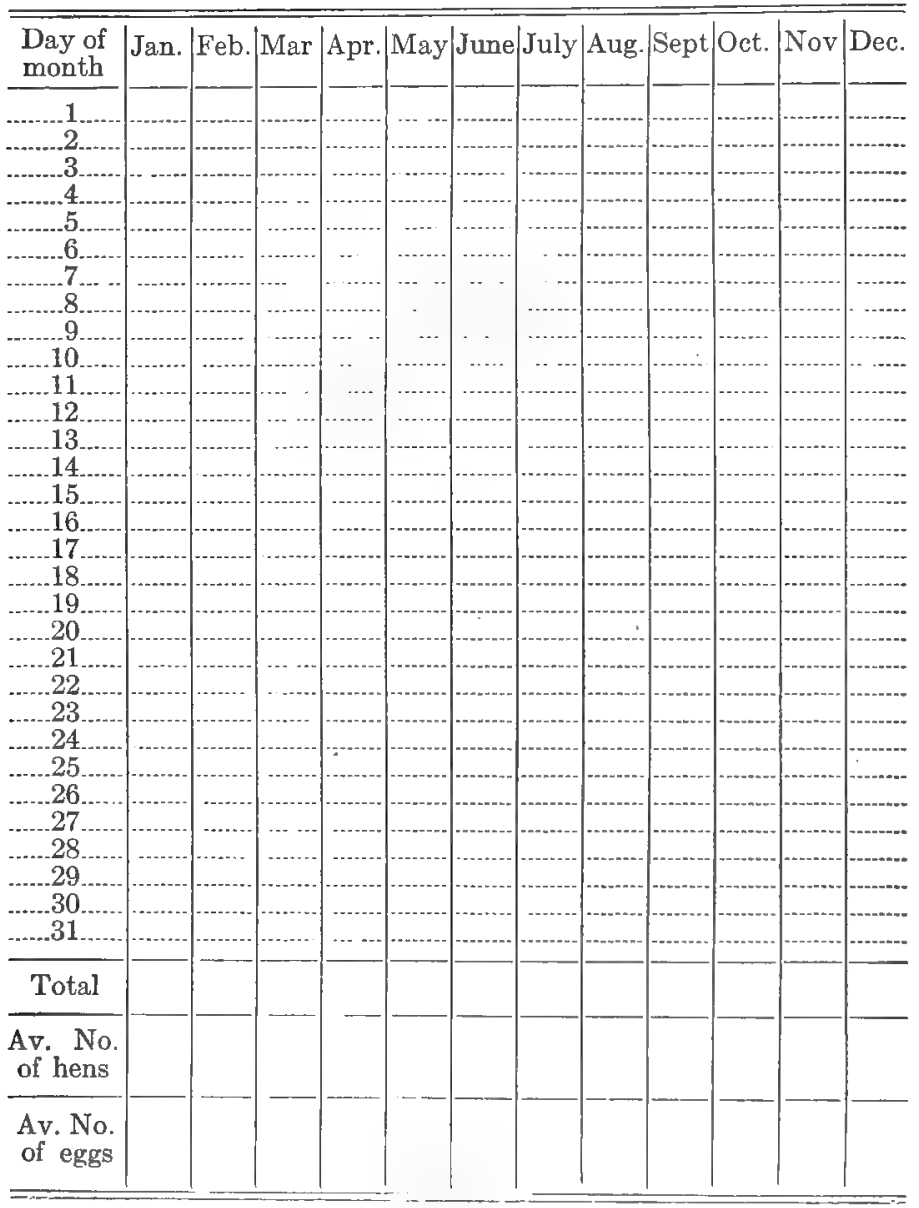




\section{YEARLY SUMMARY}

\begin{tabular}{|c|c|c|c|c|c|c|c|c|c|c|c|c|c|c|}
\hline \multicolumn{7}{|c|}{ Dr. (Money spent) } & \multicolumn{8}{|c|}{ Cr. (Money received) } \\
\hline $\begin{array}{l}\text { Year } \\
19-\end{array}$ & 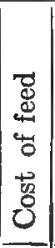 & 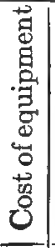 & : & 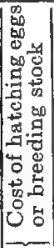 & 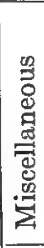 & 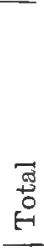 & 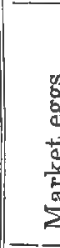 & 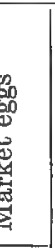 & 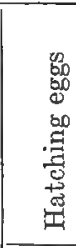 & & 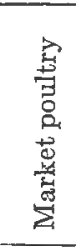 & 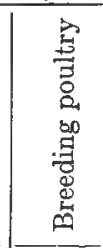 & 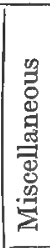 & 吾 \\
\hline Month & & & & & & & Dz. & Val. & Set. V & & Lb.Va & No.Val & & \\
\hline Jan. & & & & & & & & & & & & & & \\
\hline Feb. & & & & & & & & & & & & & & \\
\hline March & & & & & & & & & & & & & & \\
\hline April & & & & & & & & & & & & & & \\
\hline May & & & & & & & & & & & & & & \\
\hline June & & & & & & & & & & & & & & \\
\hline July & & & & & & & & & & & & & & \\
\hline Aug. & & & & & & & & & & & & & & \\
\hline Sept. & & & & & & & & & & & & & & \\
\hline Oct. & & & & & & & & & & & & & & \\
\hline Nov. & & & & & & & & & & & & & & \\
\hline Dec. & & & & & & & & & & & & & & \\
\hline Total & & & & & & & & & & & & & & \\
\hline
\end{tabular}

Explanation. This record should be filled in at the end of each month so that at the end of the year or at the end of any given number of months the total receipts and expenditures can be determined by adding the total amounts spent and received. This record is practically self-explanatory and is quite similar to the monthly statement. 


\section{YEARLY INVENTORY}

INVENTORY JANUARY I.

Stock: No. of cocks......., Value, $\$$..... . No. of hens..... . . Value, \$.... . ; No. of pullets........, Value, \$.....; No. of Cockerels........, Value, \$......; Total value of stock, \$.

Equipment: Value of poultry houses, $\$ \ldots . . \ldots$; Value of Feed hoppers; $\$ \ldots \ldots$. Value of drinking vessels, $\$ \ldots \ldots \ldots$; Value of brood coops, $\$ \ldots . . \ldots$; Value of poultry fences, $\$ \ldots . . \ldots$; No. of incubators.......; Make. .

Value, \$......; No. of brooders......; Make

Value, $\$ \ldots . . \ldots$; Value of grain on hand, $\$ \ldots . . \ldots \ldots \ldots$; Total value of equipment, $\$ \ldots \ldots \ldots \ldots$

Explanation. The inventory should be taken in order to determine the value of stock and equipment on hand and to assist in making up a yearly balance sheet, which follows. It should contain a summary and total both of the number and value of all fowls and such equipment as one may possess. Ordinarily, unless improvements are made on equipment such as poultry houses, hoppers, etc., $10 \%$ of the value of the equipment should be deducted from the total value for depreciation. Judgment should be used in each case when buildings are repaired or when new equipment has been purchased. In some cases repaired buildings or buildings that have been painted are of greater value than they were formerly, so that this fact should be taken into consideration when making an inventory.

The time to take the inventory need not necessarily be January 1. Some other time may be chosen, if found more desirable, to meet individual needs and conditions. Many poultrymen regard October 1 or November 1 more suitable as representing the beginning of the poultry year, and consequently take their inventory at that time. 
YEARLY BALANCE SHEET

\begin{tabular}{|c|c|c|c|}
\hline & Dr. & $\mathrm{Cr}$. & Bal. \\
\hline $\begin{array}{l}\text { Value of inventory Jan. } 1,1920 \ldots \ldots \ldots \\
\text { Interest at } 6 \text { per cent on capital in- } \\
\text { vested, as represented by value of } \\
\text { inventory above................ } \\
\text { Expenditures during } 1920 \ldots \ldots \\
\text { Value of inventory Jan. } 1,1921 \ldots \ldots \ldots \\
\text { Receipts during } 1920 \ldots \ldots \ldots \ldots\end{array}$ & $\begin{array}{r}30.00 \\
250.00 \\
\ldots \ldots\end{array}$ & $\$ \$ 600.00$ & $\begin{array}{l}\cdots \cdots \\
\cdots \\
\cdots \\
\ldots\end{array}$ \\
\hline 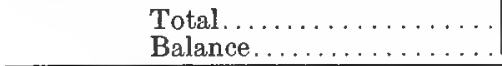 & $\$ 780.00$ & $\begin{array}{l}\$ 1,100.00 \ldots \\
\ldots \ldots \ldots\end{array}$ & $\$ 320.00$ \\
\hline
\end{tabular}

Explanation. As will be seen, this form is used to determine the total profit or loss, as the case may be, for the year. The years 1920 and 1921, together with the amounts as shown on this form have been used by way of illustration to indicate the proper column wherein such amounts should be placed, in order to secure the yearly balance. It will be readily seen that by keeping an account by the use of the preceding forms that this yearly balance sheet can be summarized and totaled with but little effort and will enable one to obtain a true statement as to the financial standing of the business.

January 1 has been indicated as the date of the inventory. Should any other date, such as October 1 or November 1, be used as the beginning of the poultry year, the yearly balance and the inventory should be made at that time. When the returns from the flock are included in the income tax statement, such returns must be made not later than tro and a half months after the close of the year. If a period of 12 months, ending October 31, for instance, is regarded as the end of the poultry year, the income tax statement must be filed not later than the following January 15. 


\section{POULTRY CLUB RECORD}

Name

Age.

Name of club

Address.

Breed and variety of fowls

No. of eggs set.

No. of chicks hatched.

No. of chicks raised... No. of males.... No. of femaless.

No. fowls sold for market

Value

No. fowls used at home

Value

Breeders sold.

Value

Doz. of eggs used at home.

Value

Doz. of eggs sold.

Value

Settings sold

Value

Value of fowls on hand.

Value of prizes won.

Total amount of money received.

Cost of eggs for hatching.

Cost of breeding stock bought.

Cost of equipment.

Cost of feed.

Value of labor at $15 \mathrm{c}$ an hour.

Total amount of money spent.

Profit.

Explanation. This form has been designed for boys and girls who are members of poultry clubs. As will be noted, this blank is quite simple and, when properly filled out, will present a brief and complete record of the year's work. When desired, this form can be supplemented with some of the forms given previously in this chapter. 


\section{ADVERTISING}

Many of the most successful poultrymen have built up their business as the result of consistent advertising in some form or another. There is no question that advertising, when properly planned and carried on, is of considerable value and a good investment. When planning to advertise such products as are for sale, these facts should be considered. The advertisement should be attractive, so as to catch the eye, should be brief and to the point, stating facts in simple language, and should in no way misrepresent the products offered for sale. The fact should also be kept in mind that the advertisement should be so placed as to be seen by persons that are interested or desirous of purchasing that which is for sale.

What and when to advertise. Ordinarily the only products offered for sale by those keeping poultry are breeding stock, eggs for hatching, and day-old chicks. It is advisable to advertise such stock just preceding and during the period of greatest demand, which is usually during the late fall, winter, and early spring. In the fall some poultrymen endeavor to dispose of surplus cockerels that are suitable for breeding purposes. A special advertisement stating this fact might prove profitable and enable one to secure better prices for desirable cockerels as breeders than when sold as broilers earlier in the season. It is not usual to advertise table fowls or eggs for consumption, as such products can ordinarily be disposed of through the regular commercial channels at satisfactory prices, and, therefore, nothing is gained by advertising, unless it is desired to build up a special retail trade. Again, many poultrymen and farmers make a practice of advertising table fowls and eggs as well as breeding stock and eggs for hatching on a neat attractive bulletin board so placed that it can be seen by those passing on the public road in front of their farms. 
Methods of advertising. Persistent or continuous advertising even in a small way is usually a better investment and will bring greater results than advertising at stated periods. This practice, however, would depend upon the quantity of stock for sale, as it would not be advisable to advertise a product and then be compelled to tell those inquiring that such product was not available. A well managed poultry plant of sufficient size will usually have breeding stock for sale at practically any time throughout the year. Many poultrymen and farmers fail to realize the advantages of advertising in their local papers. Such a medium offers satisfactory results at rates that are usually most reasonable. Larger poultry plants and those making a specialty of high grade standard-bred poultry and exhibition stock will usually find it to their advantage to advertise in farm papers and poultry magazines. In these instances also it will usually be found that the rates asked for advertising space are quite reasonable. Whenever possible, advertisements should be illustrated with a neat cut or photograph of one or two fowls preferably those from your own flock. A well designed trade-mark or trade name will also add to the attractiveness of the advertisement. Many such periodicals have classified columns where small advertisements may be placed by those not desiring to invest in a larger display advertisement. Advertisements should be placed in papers of good circulation, so as to reach a large number of people.

Answering inquiries. On receiving inquiries as the result of your advertisement, make every effort to answer them all ats promptly as may be possible. Make the replies brief and to the point, but at the same time courteous, stating the quality and kind of stock you have for sale and the price asked. It is needless to say that printed stationery is more business-like and creates a better impression than 
plain stationery. Likewise typewritten letters make a better impression than those written in longhand. A record should be kept of all inquiries and a second and third follow-up letter written within a reasonable length of time, if you do not hear again from the party making the inquiry. In your reply do not appear unduly persistent, but state such facts as will stimulate confidence on the part of the purchaser. In such letters inquire if the party received your first letter and if there is any additional information that you can furnish him. Likewise inquiry might be made as to the reason, if any, why the order was not placed with you, as it is your desire to please prospective purchasers. When advertising in two or more papers, a record should be kept, if possible, as to the number of inquiries received from the advertisement in each paper. This will assist you in determining which paper is the best advertising medium for your purposes. Key each advertisement.

Making shipments. As soon as an order is received, acknowledge it and thank the purchaser for it, notifying the party as to the date that the shipment will be made, so that some idea may be obtained as to the time of arrival. When shipping live birds, make every effort to so plan the shipment that it will not be held in the express office over Sunday. For instance, shipment should not be made on Saturday, if there is any possibility of its arriving at its destination on Sunday, and consequently being held in the express office until Monday morning.

\section{QUESTIONS}

1. Of what importance and value is the keeping of accounts and records?

2 What is the value of keeping a monthly statement sheet for each month in the year, showing the amount of money spent and the amount received.

3. For what purpose primarily should the feed record form as given herein be used?

4. How can one determine the average egg production per hen during the month? 
5. Of what value is the yearly inventory record?

6. What are the essentials of good advertising?

7. How and when should poultry products be advertised?

8. Discuss the methods of advertising.

9. How can advertisements be made attractive?

10. What facts should be kept in mind when answering inquiries?

\section{SUGGESTIONS.}

1. It is a recognized fact that practically every successful business endeavors to keep a record of all of its transactions. This same principle as brought out in this chapter should apply to the poultry business. With this idea in mind, resolve to keep such records of your flock as will enable you to determine whether or not it is paying.

2. Keeping records and accounts is largely a matter of habit, and when once cultivated and the true value realized, it is a hard one to break. Usually the most successful poultrymen are the ones that keep definite information and records as to their receipts and expenditures.

3. Members of boys' and girls' poultry clubs are particularly urged to keep records and accounts of their poultry work. Besides the advantages mentioned herein, the keeping of such records will enable them to put into practice many of the principles and facts learned in mathematics.

4. Assuming that you had some breeding stock and eggs for hatching for sale, prepare an attractive advertisement stating these facts and such additional information as you believe will assist in selling your products.

5. Try advertising in your local papers, should you have any surplus stock for sale. The advertising manager of such papers will be only too glad to assist you in preparing advertisements. Vary some part of your name or address, so as to furnish a key to the advertisements that brought inquiries.

\section{REFERENCES}

A Simple System of Poultry Accounting, by Rob R. Slocum, Bureau of Animal Industry Circular No. 176, U. S. Department of Agriculture.

Farm Management, Andrew Boss.

Farm Management, George E. Warren. 
APPENDIX 


\section{IIST OF STATE AGRICULTURAL INSTITUTIONS}

Alabama Polytechnic Institute and the Agricultural Experiment Station, Auburn, Ala.

Arizona State College of Agriculture and the Agricultural Experiment Station, Tuscon, Arizona.

Arkansas State College of Agriculture and the Agricultural Experiment Station, Fayetteville, Ark.

California State College of Agriculture and the Agricultural Experiment Station, of the University of California, Berkeley, California. Poultry Experiment Plant, Davis, Cal.

Colorado State College of Agriculture and the Agricultural Experiment Station, Fort Collins, Colo.

Connecticut Agricultural College and the Storrs Agricultural Experiment Station, Storrs, Conn.

Delaware College and Agricultural Experiment Station, Newark, Del. Florida State College of Agriculture and the Agricultural Experiment Station of the University of Florida, Gainesville, Fla.

Georgia State College of Agriculture, Athens, Ga. Georgia Experiment Station, Experiment, Ga.

Idaho College of Agriculture and the Agricultural Experiment Station of the University of Idaho, Moscow, Idaho.

Illinois College of Agriculture and the Agricultural Experiment Station of the University of Illinois, Urbana, Ill.

Indiana-Purdue University (School of Agriculture, the Agricultural Experiment Station), La Fayette, Ind.

Iowa State College of Agriculture and Mechanic Arts and the Agricultural Experiment Station, Ames, Iowa.

Kansas State Agricultural College and the Agricultural Experiment Station, Manhattan, Kansas.

Kentucky College of Agriculture and the Agricultural Experiment Station of the University of Kentucky, Lexington, Ky.

Louisiana State University and Agricultural and Mechanical College and the State Experiment Station, Baton Rouge, La.

Maine College of Agriculture and the Agricultural Experiment Station of the University of Maine, Orono, Maine.

Maryland State College of Agriculture and the Agricultural Experiment Station, College Park, Md.

Massachusetts Agricultural College and the Agricultural Experiment Station, Amherst, Mass.

Michigan Agricultural College and the Agricultural Experiment Station, East Lansing, Mich.

Minnesota State School of Agriculture and the Agricultural Experiment Station, University Farm, St. Paul, Minn.

Mississippi Agricultural and Mechanical College and Agricultural Experiment Station, Agricultural College, Miss.

Missouri College of Agriculture and the Agricultural Experiment Station of the University of Missouri, Columbia, Mo. State Poultry Experiment Station, Mountain Grove, Mo.

Montana State College of Agriculture and Mechanic Arts and the Agricultural Experiment Station, Bozeman, Montana. 
Nebraska College of Agriculture and the Agricultural Experiment Station of the University of Nebraska, Lincoln, Nebr.

Nevada College of Agriculture and the Agricultural Experiment Station of the University of Nevada, Reno, Nevada.

New Hampshire College of Agriculture and the Mechanic Arts and the Agricultural Experiment Station, Durham, N. H.

New Jersey State College of Agriculture and Mechanic Arts and the Agricultural Experiment Station of Rutgers College, New Brunswick, N. J.

New Mexico College of Agriculture and Mechanics Arts and the Agricultural Experiment Station, State College, N. M.

New York State College of Agriculture and the Agricultural Experiment Station of Cornell University, Ithaca, N. Y.

North Carolina State College of Agriculture and Engineering and the Agricultural Experiment Station, West Raleigh, N. C.

North Dakota Agricultural College and the Agricultural Experiment Station, Agricultural College, N. D.

Ohio College of Agriculture, Columbus, Ohio. Ohio Agricultural Experiment Station, Wooster, Ohio.

Oklahoma Agricultural and Mechanical College and the Agricultural Experiment Station, Stillwater, Okla.

Oregon Agricultural Colleges and the Agricultural Experiment Station, Corvallis, Ore.

Pennsylvania School of Agriculture and Agricultural Experiment Station of the Pennsylvania State College, State College, $\mathrm{Pa}$.

Rhode Island State College and the Agricultural Experiment Station, Kingston, R. I.

South Carolina-Clemson Agricultural College, and the Agricultural Experiment Station, Clemson College, S. C.

South Dakota State College of Agriculture and Mechanic Arts and the Agricultural Experiment Station, Brookings, S. D.

T'ennessee College of Agriculture and the Agricultural Experiment Station of the University of Tennessee, Knoxville, Tenn.

Texas Agricultural and Mechanical College and the Agricultural Experiment Station, College Station, Texas.

Utah College of Agriculture and the Agricultural Experiment Station, Logan, Utah.

Vermont College of Agriculture and the Agricultural Experiment Station of the University of Vermont, Burlington, Vt.

Virginia Agricultural and Mechanical College and Polytechnic Institute! and the Agricultural Experiment Station, Blacksburg, Va.

Washington State College of Agriculture and the Agricultural Experiment Station, Pullman, Washington.

West Virginia College of Agriculture and the Agricultural Experiment Station of West Virginia University, Morgantown, W. Va.

Wisconsin College of Agricultrue and the Agricultural Experiment Station of the University of Wisconsin, Madison, Wis.

Wyoming College of Agriculture and the Agricultural Experiment Station of the University of Wyoming, Laramie, Wyo.

United States Department of Agriculture, Bureau of Animal Industry, Washington, D. C., Experimental Station, Beltsville, Md. 


\section{OUTLINE FOR A COMPOSITION ON "POULTRY MAN- AGEMENT"}

To Be Written by First-Year Poultry Club Members.

\section{Introduction:}

What is the best way to start in the poultry business?

\section{Discussion:}

(a) Name the three leading classes of poultry:

(b) Name three breeds of each of the three classes.

(c) Which in your opinion is the best breed for the farm? Why?

\section{Housing:}

(a) What are the two systems used?

(b) Which is the best system for the farm? Why?

(c) Where and how should the house be located?

(d) When should yards be used?

\section{Feeding:}

(a) How soon would you feed little chicks' after they are hatched?

Why? What should you feed them?

(b) What would you feed them after they are weaned?

(c) What would you feed the laying hens?

Management:

(a) Explain why the mother hen should be kept up in a coop while the chicks are small.

(b) Tell how and why the brood coops and houses should be cleaned often.

\section{Marketing:}

(a) Tell how eggs should be marketed, so as to get the highest prices.

(b) What is an infertile egg? Tell how it is produced.

(c) Does the infertile egg keep longer than the fertile egg?

\section{Conclusion:}

Why should girls and boys be active members of Poultry Clubs?

\section{OUTLINE FOR A COMPOSITION ON "MY EXPERIENCES WITH POULTRY"}

To Be Written by Second-Year Poultry Club Members

\section{Introduction:}

How I started in the poultry business.

Discussion:

(a) "The breed which I selected and why I selected it."

(b) Tell how the eggs were set, and how you managed and fed the sitting hen during the period of incubation.

(c) Tell how the chicks were managed and fed during the brooding period.

\section{Housing:}

(a) If you have built a house, tell about the kind, where it is located, with reference to the direction which it faces, and the cost and time required to build it, if possible. 
(b) In case an old poultry house was remodeled for your chickens, describe the alterations you have made.

(c) In either instance, give a little drawing of the house, showing the floor plan and front view.

Feeding:

(a) Give a general discussion of the way you feed and the grains the chickens have been fed since they were weaned.

(b) Tell how often you give the chickens water.

General management:

(a) Tell how often you clean the house, and any other thing which may be of interest concerning the methods which you use.

Conclusion:

(a) Give an account of how the poultry-club work has benefited you.

(b) State what benefit, if any, you have received from the poultryclub work, and tell why the boys and girls of your state should join the poultry clubs.

OUTLINE FOR A COMPOSITION ON "MARKETING AND EXHIBITING POULTRY AND EGGS"

To Be Written by Third-Year Poultry Club Members

Subject "A":

"How I marketed my poultry products."

\section{Discussion:}

What the markets require in order to grade an egg as a first.

Infertile eggs for market:

(a) Give a general discussion of infertile eggs.

Gathering eggs:

(a) Tell about the attention you give to the hens' nests.

(b) How often you gather your eggs in summer and in winter.

(c) How and where you store your eggs.

Grading and packing eggs:

(a) Tell how many grades of eggs you get from your flock and how you grade them.

(b) Tell how you pack them for shipment.

(c) Why should eggs for market not be washed?

Marketing eggs:

(a) Tell how and where you sold your eggs, how you found a customer, and how often you market them.

(b) Give the largest and the smallest price per dozen that you received for eggs for table use.

Marketing live and dressed poultry:

(a) Give a general discussion of the manner in which you marketed your surplus cockerels and old hens, and tell the results obtained.

Subject "B":

"Exhibiting poultry."

(a) Tell what you think of the advantages of exhibiting poultry 
and eggs, and give a history of your experience as an exhibitor at the poultry shows.

(b) Tell what the poultry shows taught you.

\section{OUTLINE FOR A COMPOSITION ON "HISTORY OF MY POUL- TRY CLUB WORK"}

To Be Written by Fourth-Year Poultry Club Members

\section{Discussion:}

(a) Tell how you joined the Poultry Club and the object of the Poultry-Club Work.

\section{History:}

(a) Tell what breed you selected and why you selected this breed. Tell how many eggs you set and give an outline of your first year's work.

(b) Tell what improvements you made in the handling of the poultry at home after you joined the Poultry Club, and what results you obtained (housing, feeding, etc.) and how the home poultry flock has been improved.

(c) Tell what problems you came in contact with and how you met them.

(d) Tell what the Poultry Club has done for you in interest, instruction, and money value.

(e) Give an account of any interesting experiences you may havc had in your Poultry Club work, such as trips, fairs, ete.

\section{Note:}

Use drawings and photographs, if possible, to illustrate this composition.

\section{SCORE CARD FOR BREEDING STOCK SUITABLE FOR THE PRODUCTION OF TABLE FOWLS}

This card is designed as a guide in selecting breeding stock of a type especially suited for producing desirable table fowls. It is arranged in the form of a score card so that it can be used, if desired, for the scoring of such fowls when exhibited in competition. In applying this scale of points, due consideration must be given to breed characteristics. Other points being equal, preference must be given to those birds most nearly approaching the standard weights for each breed, as given in the American Standard of Perfection. Other points being equal, preference should be given to those birds showing greatest indication of standard breeding. In judging the excellence of the fowls, it will be found helpful, if not actually necessary, to handle them and not depend upon observation alone.

Weight

Sex

Exhibitor Entry No.

Band No..... Class....... Breed Variety. 


\section{.}

Disqualifications.-Decidedly crooked breasts, crooked backs, or wry tails.

Health and Vigor. ....................

The bird must be free from disease or from any indication of having been affected with disease. It must also show strong constitution and great vigor as indicated by bright red comb and wattles, and by full, prominent bright eyes, by general alertness, and by bright, lustrous plumage.* Males should be decidedly masculine. Avoid females showing masculine appearance.

\section{Head, $\mathbf{b}$.}

Shape of Head.

Should be short, deep, and broad.

Face, comb, and wattles.

Should be bright red.* (Dark red approaching black indicates poor condition.) Wattles medium size. Comb small to medium, firmly set on head. Avoid lopped combs in those breeds where they are supposed to be upright.

Eye.

Large, full, bright. (Sunken or dull eye denotes lack of vigor and poor vitality.)

Beak.

Short, strong, curved.

Neck. body.

Medium short and stout in proportion to the Wings.

Strong, medium size, neatly folded, and held firmly in place. (Avoid breeding from slipped or twisted winged birds.)

Body, 60. General Shape--Body should show good length, breadth, and depth, and be well fleshed throughout.

Breadth of Body.

Should be broad at shoulders, breadth extending downward well back to hips.

Depth of Body

Should be deep from shoulder to front of keel and extending well back.

Back.

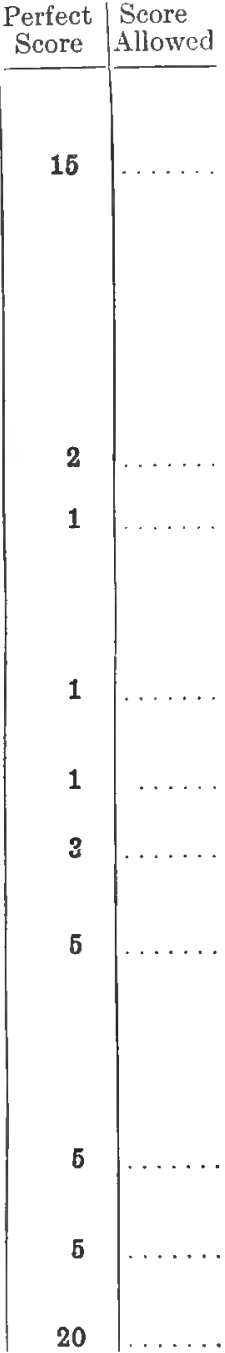

*Allowance should be made for fowls in molt. (Swe Chapter XIII.) 
Back of good length, broad throughout, and fairly level on top, from side to side, throughout its entire length and ending in a broad full tail. Breast.

Deep, broad, full, corresponding with breadth of shoulders. Keel or breast bone should be long, straight, and well fleshed.

Thinness and texture of skin.

Skin should be thin and smooth; free from roughness or scaliness.

Legs, 10. Medium length and set well apart. (Knock-kneed individuals are undesirable.)

Thighs and second joints.

Short, thick, and heavily fleshed.

Shanks.

Short, strong

Toes.

Strong, straight, short, well spread.

TOTAL.

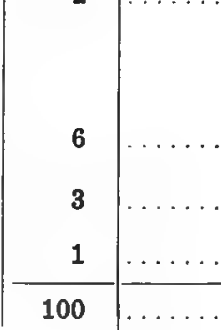

Score Card used by the Bureau of Animal Industry, U. S. Department of Agriculture.

\section{OFFICIAL SCORE CARD FOR EGGS}

(Copyright 1915 by the American Poultry Association.)

(Name of Show or Association)

(Date, Month, Days and Year of Show.)

EXHIBITOR

\section{ADDRESS}

CLASS ENTRY NO

COLOR WEIGHT.

SCORE CARD FOR EXHIBITION AND FOR COMMERCIAL EGGS

When judging an exhibit of eggs, the scores of the eggs forming each individual entry are to be added together; the total then being divided by the number of eggs comprising the entry; and the average so obtained shall be the score of the entry.

\section{DISQUALIFICATIONS}

Exhibition Egg: Cracked shell; extremely dirty or stained shell; foreign shell-color; pronounced irregularity of shape; sign of incubation; decay, rot, mold, or mustiness; blood-rings; foreign odor; or any condition that renders it unfit for food.

Commercial Egg: Sign of incubation or germ growth; decay, rot, mold, or mustiness; blood-ring; or any condition that renders it unfit for food. 


\begin{tabular}{|c|c|c|c|}
\hline $\begin{array}{l}\text { DIVISIONS AND SCORE OF A PER- } \\
\text { FECT EGG }\end{array}$ & $\begin{array}{l}\text { Points } \\
\text { scored }\end{array}$ & $\begin{array}{l}\text { Score } \\
\text { of entry }\end{array}$ & Remarks \\
\hline 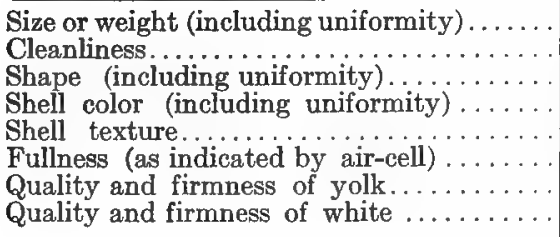 & $\begin{array}{r}15 \\
15 \\
5 \\
5 \\
5 \\
15 \\
20 \\
20\end{array}$ & & \\
\hline Total value... & 100 & & \\
\hline
\end{tabular}

JUDGE

SECRETARY

SUPPLEMENTARY SCORE CARD FOR CASE LOTS

(For Values in detail see Score Card for Exhibition and for Commercial Eggs.)

(Name of Show or Association)

EXHIBITOR

(Date, Month, Days and Year Show Is Held)

\section{ADDRESS}

CLASS

COLOR

ENTRY NO

WEIGHT

OZ

\section{CASE-LOT SCORE CARD}

When judging eggs in Case Lots the same values are allotted as in smaller lots, as shown on Score Card for Exhibition and for Commercial Eggs; but in order to lessen the detail a number of the items have been added together to meet the requirements of Graders and Inspectors of Commercial Eggs.

\section{DIVISIONS AND SCORE OF A PERFECT EGG}

Size or weight (including uniformity)

Exterior condition (Cleanliness, shape, color and texture of shell)

Contents (fullness, yolk, white).........

Total value.

\begin{tabular}{|c|c|c}
$\begin{array}{c}\text { Points } \\
\text { scored }\end{array}$ & $\begin{array}{c}\text { Score of } \\
\text { entry }\end{array}$ & Remarks \\
\hline 15 & $\ldots \ldots \ldots$ & $\ldots \ldots \ldots$ \\
30 & $\ldots \ldots \ldots$ & $\ldots \ldots \ldots$ \\
55 & $\ldots \ldots \ldots$ & $\cdots \ldots \ldots$ \\
\hline 100 & &
\end{tabular}

JUDGE

SECRETARY

Notice:-The score cards as given herein for exhibition and commercial eggs as well as for eggs in case lots are copyrighted by the American Poultry Association. Permission for their publication has been granted by this Association. Copies of these score cards may be obtained from the Secretary of the American Poultry Association. 


\section{EXPLANATION OF SCALE OF POINTS}

Each entry should consist of one dozen eggs.

Size or Weight.-One dozen eggs should weigh from 24 to 26 ounces. Deduct one point for each ounce under 24 ounces and one half point for each ounce over 26 ounces, except Langshan, Brahma and Minorca eggs, in which case an entry should weigh from 26 to 28 ounces, and the same deductions as mentioned above made for under or over weight. Exceptionally large eggs are undesirable for shipment especially if they project too high in the filler and thus are liable to be broken. All eggs within the dozen should be uniform in size and weight.

Cleanliness.-Each egg should be clean, free from dirt or blood stains. Under no circumstances should eggs be washed, as this removes the natural bloom from the egg and will cause it to spoil more quickly than when it is unwashed. Deduct one point for each soiled egg and each egg that shows signs of being washed.

Shape:-There should be a uniformity in the shape of each of the eggs in the entry. An idea as to the correct shape of the egg will be found in Figure 67, page 69. Eggs from different breeds vary somewhat in shape, some being slightly longer and others more round. These points should be considered in forming an ideal as to the correct shape for the entry being judged. Deduct one third of a point for each egg which varies from the average shape of the eggs in the entry.

Shell Color:- Uniformity of color and the presence of the natural bloom or luster of each egg is very important. White eggs should be pure white and brown eggs should be the same shade of brown throughout; other points being equal, preference should be given to dark brown eggs over light brown. White eggs of a tinted or creamy color is a defect. Deduct one third of a point for each egg that is off color.

Shell Texture:-The shell should be uniformly smooth and free from corrugations or wrinkles, pebbling or rough places, spots and cracks. Eggs with thin shells are undesirable. Cut one third of a point for each thin-shelled egg or egg possessing any of the above defects in shell texture.

Fullness:- The fullness of an egg is determined by the size of the air cell, which is one of the indications of a fresh egg. When held before a candle, see Figure 84, page 86, with the large end of the egg up, the air cell in a fresh egg should be about the size of a ten-cent piece or about one eighth of an inch in depth. Deduct three points for each egg having air cell larger than that of a fresh egg.

Quality and Firmness of Yolk:-In determining the condition of the yolk and white it is necessary to candle each egg, see Figure 85, page 87 , For a description of the various grades of eggs as concerning quality see page 284 . When held before the candle the egg should appear opaque, the yolk free from dark color and scarcely visible. Cut three points for each egg containing a dark colored yolk. Eggs showing germ development, decay, rot, mold or blood rings disqualifies the entire entry.

Quality and Firmness of White:- When candled the white should appear thick. Deduct three points for each egg wherein the white appears watery. Any egg showing any indication of decomposition or incubation as mentioned above disqualifies the entire entry. 
SCALE OF POINTS FOR JUDGING BREEDS OF THE AMERICAN, MEDITERRANEAN, AND ASIATIC CLASSES

EXHIBITOR.

ENTRY NO.......

CLASS.

BREED

. VARIETY . .

Cock, Cockerel, Hen or Pullet

BAND NO

\begin{tabular}{|c|c|c|c|c|}
\hline & $\begin{array}{l}\text { Amer- } \\
\text { ican } \\
\text { Class }\end{array}$ & $\begin{array}{c}\text { Medi- } \\
\text { ter'n } \\
\text { Class } \\
\end{array}$ & $\begin{array}{l}\text { Asiatic } \\
\text { Class }\end{array}$ & $\begin{array}{c}\text { Score } \\
\text { Allowed }\end{array}$ \\
\hline & 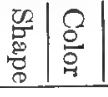 & 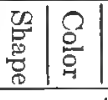 & 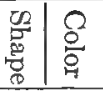 & \\
\hline Symmetry. & 4 & 4 & 4 & \\
\hline Weight..... & 4 & 4 & 4 & $\ldots$ \\
\hline Condition............. & 4 & 4 & 4 & $\ldots$. \\
\hline Comb..... & 8 & 10 & 8 & $\ldots \ldots$ \\
\hline Head.... & $2 \mid 2$ & $2 \mid 4$ & $2 \mid 2$ & $\ldots \mid \ldots$ \\
\hline Beak. . & $2 \mid 2$ & $2 \mid 2$ & $2 \mid 2$ & $\ldots \mid \ldots$ \\
\hline Eyes.... & $2 \mid 2$ & $2 \mid 2$ & $2 \mid 2$ & $\ldots \mid \ldots$ \\
\hline Wattles and ear lobes... & $2 \mid 2$ & $4 \mid 6$ & $2 \mid 2$ & $\ldots 1 \ldots$ \\
\hline Neck. & $4 \mid 6$ & $3 \mid 5$ & $4 \mid 6$ & $\ldots \mid \ldots$ \\
\hline Wings...... & $4 \mid 6$ & $4 \mid 6$ & $4 \mid 6$ & $\ldots \mid \ldots$ \\
\hline Back. . & $5 \mid 5$ & $5 \mid 5$ & $6 \mid 4$ & $\ldots \mid \ldots$ \\
\hline Tail..... & $5 \mid 5$ & $5 \mid 4$ & $5 \mid 5$ & $\ldots \mid \ldots$ \\
\hline Breast.... & $5 \mid 5$ & $4 \mid 4$ & $6 \mid 4$ & $\ldots \mid \ldots$ \\
\hline Body and fluff.. & \begin{tabular}{l|l}
5 & 3
\end{tabular} & $3 \mid 2$ & $5 \mid 3$ & $\ldots 1 \ldots$ \\
\hline Legs and toes.... & $3 \mid 3$ & $2 \mid 2$ & $3 \mid 3$ & $\ldots \mid \ldots$ \\
\hline Perfect score.... & 100 & 100 & 100 & \\
\hline
\end{tabular}


Explanation-This consolidated score card for exhibition stock was compiled from the American Standard of Perfection, permission being granted by the American Poultry Association. Any further information as to the scale of points for breeds in other classes, as well as definition and description of the points given above, refer to the American Standard of Perfection. The breeds that can be judged from this combined scale of points are as follows: American Class, all standard varieties of Plymouth Rocks, Wyandottes, Javas, Dominiques, Rhode Island Reds and Buckeyes; Mediterranean Class, all varieties of Leghorn, Minorcas, Spanish, Blue Andalusian and Anconas; Asiatic Class, all varieties of Brahamas, Cochins, and Langshans.

The Average Weight and Volume of Poultry Feeds.

KINDS OF FEED

One qt. One lb.

weighs measures

(pounds) (quarts)

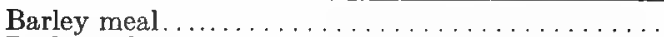

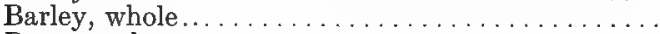

$1.1 \ldots \ldots .9$

Bone meal.

$1.5 \ldots \ldots 0.7$

Brewer's dried grains. . . ...................

$2.0 \ldots \ldots .0 .5$

Beef $\operatorname{scrap} . . . \ldots \ldots \ldots \ldots \ldots \ldots \ldots \ldots . \ldots \ldots$

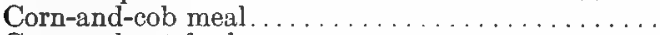

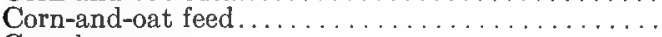

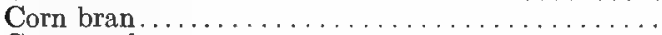

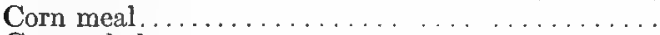

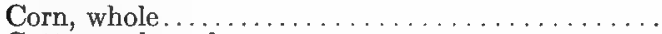

Cottonseed meal.

$0.6 \ldots \ldots 1.7$

$1.3 \ldots \ldots .8$

$1.4 \ldots \ldots .0 .7$

$0.7 \ldots \ldots 1.4$

$0.5 \ldots \ldots 2.0$

$1.5 \ldots \ldots .0 .7$

$1.7 \ldots \ldots .6$

Distiller's dried grains.

$1.5 \ldots \ldots .0 .7$

Germ oil meal. ...........................

$0.5-0.7 \ldots 1.0-1.4$

Gluten feed.

$1.4 \ldots \ldots .0 .7$

Gluten meal.

$1.3 \ldots \ldots .0 .8$

Hominy meal.

$1.7 \ldots \ldots .6$

Linseed meal, new process...................

$1.1 \ldots \ldots .0 .9$

Linseed meal, old process..................

$0.9 \ldots \ldots .1 .1$

Malt sprouts.

$1.1 \ldots \ldots 0.9$

$0.6 \ldots \ldots 1.7$

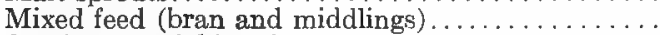

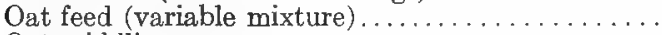

$0.6 \ldots \ldots 1.7$

$0.8 \ldots \ldots 1.3$

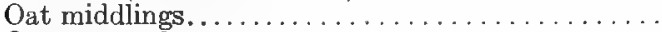

Oats, ground.

$1.5 \ldots \ldots 0.7$

$0.7 \ldots \ldots .1 .4$

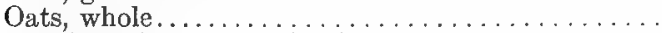

Rye feed (bran and middlings)...............

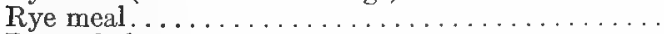

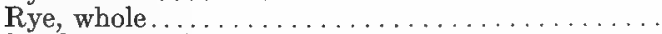

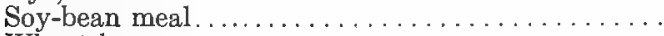

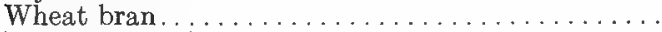

$1.0 \ldots \ldots .1 .0$

$1.3 \ldots \ldots .8$

$1.5 \ldots \ldots 0.7$

$1.6 \ldots \ldots .6$

$1.3 \ldots \ldots .8$

$0.5 \ldots \ldots .0$

Wheat, ground $\ldots \ldots \ldots \ldots \ldots \ldots \ldots \ldots \ldots \ldots .6 \ldots \ldots$

Wheat middlings (flour) $\ldots \ldots \ldots \ldots \ldots \ldots \ldots \ldots . . .6 \ldots$

Wheat middlings. . . . . . . . . . . . . . . .

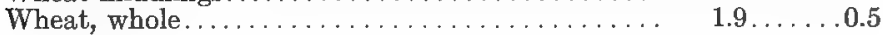




\section{A Guide for the Selection of Good Producing Hens and the Culling of Poor Producers}

Laying-Therefore Keep.
HEALTH.
Good health, Good or fair condi-
tion of flesh. Active. Alert.
MOLT.
Not molting or just beginning to
molt by the last of September or in
October.
COMB.
Waxy, full of blood, red in color.
OVW
Prominent, bright, full of life.
PELVIC BONES.*
Thin, flexible, spread apart more
than the width of two fingers.
SIZE OF ABDoMEN.
Spread of three or more fingers in
the smaller breeds and four or more
in the larger breeds from pelvic bones
to end of keel. Length of keel should
also be considered. A hen with a
long keel may have greater capacity
than one with a short keel but greater
spread between pelvic bones and end
of keel.

\section{FLEXIBIITY OF ABDOMEN. \\ Soft, flexible.}

APPEARANCE OF VENT.

Large, expanded, moist.

\section{SHANK COLOR.}

(Applies only to yellow-shanked breeds.) Pale yellow or white. Broody hens or those just recovered from broodiness may have yellow shanks, but should be kept if they have not begun to molt. A flock on good grass range will retain yellow shank color to a greater extent than those in bare yards.

\section{BEAK COLOR.}

(Applies only to yellow-beaked breeds.) Pale or white.

\section{VENT COLOR.}

(Applies only to yellow-skinned breeds.) White or pink.

Not Laying-Therelore Cull.
HEALTH.
Poor health, poor or thin condition
of flesh, overfat, broken down behind,
listless, dumpy.

MOLT.

Molted or beginning to molt early in August.

\section{COMB.}

Shrunken, paler or duller red in color, comparatively hard, covered with whitish scales.

\section{EYE.}

Sunken, dull, listless in appearance

\section{PELVIC BONES.}

Thicker, less flexible, spread apart two fingers or less.

\section{SIZE OF ABDOMEN.}

Spread of less than three fingers in the smaller breeds and less than four in the larger breeds.

FLEXIBIIITY OF ABDOMEN.

Smaller, harder, less flexible.

\section{APPEARANCE OF VENT. \\ Comparatively small, hard, dry puckered.}

\section{SHANK COLOR.}

(Applies only to yellow-shanked breeds.) Deep or medium yellow.

\section{BEAK COLOR.}

(Applies only to yellow-beaked breeds.) Yellow or partly yellow.

\section{VENT COLOR.}

(Applies only to yellow-skinned breeds.) Yellow.

* Pelvic bones are the two bones which can be felt as points on each side of the vent.

Form A. H. 260 issued by Animal Fusbandry Division, Buregu of Animal Industry, U. S. Department of

Agriculture. Washington, D. C. 


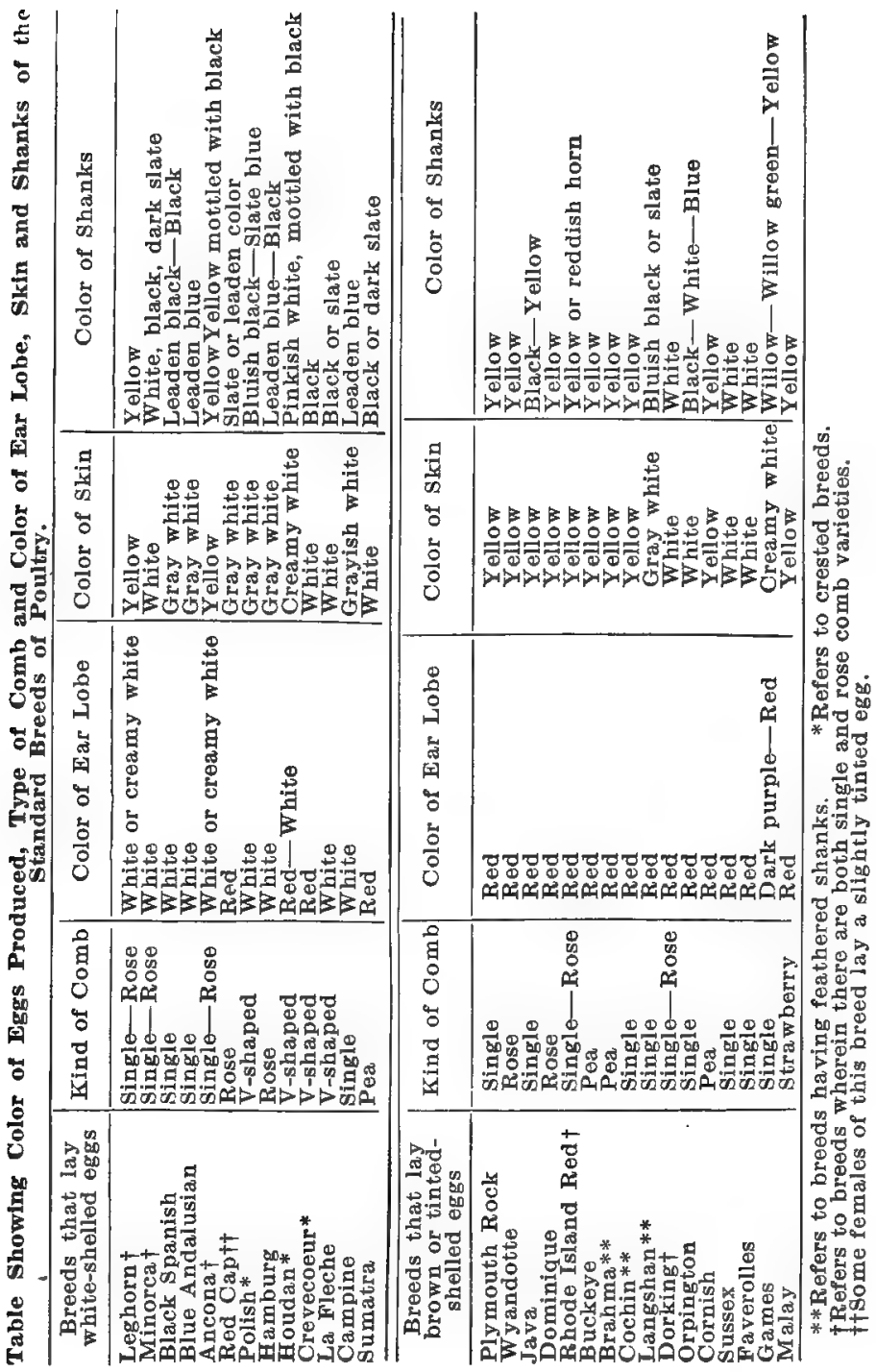




\section{FARM POULTRY SURVEY}

\section{Name}

Address.

Date

Character of farm:

Size.

Crops raised.

Stock kept

Poultry accommodations:

Houses:

Kind

Number.

Location.

Nests:

Kind.

Number

Location

Runs:

Size

Number.

Do fowls have free range?

Poultry kept:

Breed and variety.

Number:

Males.

Females

Approximate ages 


\section{Incubation:}

Is natural or artificial incubation practiced?

Between what dates is most of the hatching done?

\section{Brooding:}

Is natural or artificial brooding practiced?

\section{Egg production:}

Method of feeding.

Rations.

Are infertile eggs produced?

\section{Gathering eggs:}

Frequency.

By whom.

In what

\section{Marketing:}

Where kept for marketing?

How long kept?

How marketed?

Distance from market?

If standard-bred poultry is kept, do you sell eggs for hatching?

Breeding stock? Day-old chicks?.

Note to the Teacher: Have the members of the poultry class or club use this form in making a survey of the farms in the community when they start their poultry work and again at the end of the year. This will enable you to note such changes or improvements as have been made during this time. 



\section{INDEX}

Abdomen, condition of, 231.

Acid phosphate, 301.

Action and appearance, 55

Advertising-

methods of, 332 .

value of poultry shows, 258 .

what and when to advertise, 331 .

African geese, 247.

Agglutination test, 169 .

Age of breeding stock, 62 .

Agricultural Colleges and Experiment Stations, 17, 337.

Air cell of egg, 67, 86, 345 .

Albumen of egg, 68, 199.

Alfalfa, 115, 291. meal, 203.

American breeds: See Generalpurpose class.

American Standard of Perfection, $32,263,347$.

Anconacharacteristics of, 31 . standard weights of, 31 .

Andalusian, Blue, 32.

Animal protein feeds, 202, 212.

Appearance and action, 55.

Appliances, 144.

Artificial and natural incubation, 67.

brooding, 98.

incubation, 78.

lights, 217.

methods of feeding with, 219 . period of, 218.

Asiatic breeds: See Meat class.

Ash, 206.

Atavism, or reversion, 46.

Aylesbury duck, 242.

Back of breeders, 57.

Back, disqualifications of, 262 .

Back-yard flocks, 11, 19.

Balance sheet-yearly, 329 .

Balanced ration-how determined, 207.
Banding: See Wing banding.

Bantams-Game, 39, 40. value of, 41 . varieties of, 41 .

Barley, 201, 203, 212. meal, 212.

rolled or hulled, 109, 112.

Beak-

color as influencing production, 228.

shape of, 56 .

Beef scrap: See Meat scrap.

Black turkey, 235.

Blackhead, 166.

Blastoderm, 68, 86 .

Blood ring, 87, 121, 286, 343.

Bloom of egg, 69.

Blue Andalusiancharacteristics of, 32 . standard weights of, 33 .

Blue bugs, 182.

Blue ointment, 180 .

Blueing water for washing birds, 268.

Board floors, 136.

Body of breeders, 57.

Bone meal, 212.

Borax, 162.

Boric acid, 162.

Bourbon Red turkey, 235.

Brahma-

as capons, 187.

standard weights of, 34 . varieties of, 34 .

Bran, 109, 110, 201, 212, 291 , 295.

Bread for chicks, 109.

Breast, of breeders, 57 .

Breastbone: See keel bone.

Breed definition of, 23 . selecting the, 23,315 .

Breeder, the poultry, 20, 44 .

Breedersage of, 62 , 
Breeders, (continued)

defects in, 59.

feeding the, 64 .

management of, 62 .

range for, 62 .

selecting the, 55 .

Breeding-

and mating, 45, 60 .

cross, 50.

essentials of, 54 .

importance of, 44 .

in, 48 .

line, 48 .

out, 48.

pen, demonstration on selecting, 66 .

principles and practices of, 45 .

purpose of, 59.

stock, age of, 62 .

turkeys, 238.

Breeds and varieties-

egg, 30 .

for natural incubation, 75 .

Game and Game Bantam, 39.

general-purpose, 26.

meat, 33 .

miscellaneous, 41

origin and classification, 22 .

suitable for capons, 187.

Brick construction, 134 .

Broilers-

fattening, 291.

market classification of, 290.

marketing of, 290.

Bronze turkey, 234.

Brood coop-

care of, 93.

construction of, 95,96 .

litter for, 94.

Brooder-

capacity of, $100,101$.

coal-burning, 102.

colony, 102 .

continuous, 103.

fireless, 103, 104.

hot-air, 100.

hot-water, 100 .

hot-water-pipe, 102, 103.

house, proper size of, 102 .

individual, 100.

kerosene-heated, 100.

kinds of, 100 .
Brooder, (continued)

litter for, 94, 105.

location of, 94.

management of, 105.

requirements of, 99 .

stoves, 101.

Brooding and hatching-

artificial, 92, 98.

correct temperature for, 104.

importance of, 92 .

natural, 92.

record, 321.

Broody coops, 150

Broody hens, 69 .

breaking up, 150.

indications of, 75 .

Brown-shelled eggs-

breeds that lay, 26, 349 .

example of correlation, 47 :

testing, 86.

Buckwheat, 201,

Buff duck, 243.

Build, time to, 132.

Building materials, 133 .

Buildings: See Houses.

Bumble foot, 174.

Business management, 320 .

Buttermilk: See Milk.

By-products, 201.

Cabbage, 115, 203.

Campinecharacteristics of, 33 . standard weights of, 33 . varieties of, 33.

Canadian, or wild, geese, 247.

Candling eggs, 86, 285.

Canker, 162.

Capacity of brooder, 100. of incubators, 79 .

\section{Capon-}

care of after operation, 194.

center of industry, 186.

fattening, 293.

feeding, 194.

killing and dressing, 195.

killing of during operation, 193.

marketing of, 293. production of, 1.6 .

Caponizing-

advisability of, 186 . 
Caponizing, (continued)

care after, 194.

demonstration, 196.

instruments, 188.

operation, 189.

suitable breeds for, 187. time for, 187.

Carbohydrates, 206.

Carbolated vaseline, 161, 165.

Carbolic acid, 160, 163, 177, 184.

Carneau pigeons, 252.

"Case count" plan of marketing eggs, 287.

Case-lot score card, 344.

Castor oil, 164, 168.

Cayuga duck, 243.

Cement construction, 134, 136.

Chalazae, 68.

Charcoal, 65, 111, 113, 205.

Chicken pox, 165 .

Chicks-

brooding, 92, 98 .

day-old, purchasing, 106.

feeding, 108.

first feed of, 108.

management of, 118.

toe-punching, 95.

Chiggers, 183.

Chinese geese, 246.

Chlorate of potash, 162.

Cholera, 162.

Class, definition of, 22.

Classification of poultry, 22

Cleanliness of growing quarters, 117. of eggs, $283,345$.

Clipping the wing, 154.

Clover hay, 203. cut, 115, 291.

Clubs: See Community Breeding Clubs.

See Junior Clubs.

Coal-burning brooders, 102 .

Coal-tar products, 89, 160, 163, 177.

Cochin-

description of, 38 .

standard weights of, 38 .

varieties of, 38 .

Cockerel, definition of, 275.

Cockerel mating, 61.

Cockerels, separating of, 118.
Cock, definition of, 275.

Cock-fighting, 14.

Cold storage, 15.

Colony house-

advantages of, 129 .

disadvantages of, 129 .

floor of, 136.

for growing stock, 114, 115.

framework of, 136, 143.

plan of, 142.

Color-

of beak, 228 .

breeders, 55 .

comb, 56, 229.

ear lobe, 349 .

face, 56 .

shanks, 227, 349.

skin, 59,349 .

vent, 228.

Comb-

as concerning production, 229 .

disqualifications of, 261.

frozen, 63, 167.

of capon, 185.

of breeders, 56 .

white, 166.

Combs-

defective, 56,58 .

types of, $51,53,54,349$.

Commercial chick grain, 109, 110.

feeds, 201.

poultry farms, 16.

poultrymen, 44 .

Community breeding clubs-

advantages of, 315 .

development of, 317

exhibits, 317

meetings of, 316 .

organization of, 316.

selecting community breed, 315.

Composition of poultry feeds; 206, 209.

on "History of my Poultry Club Work," 340.

on "Marketing and Exhibiting," 340.

on "My Experiences with Poultry," 339.

on "Poultry Management," 339. 
Concrete floor, 135. foundation, 134.

Condiments, 205.

Conditioning birds, 264.

Constitution and by-laws of Junior Clubs, 308.

Constructioncost of, 130 economy of, 127, 130 . of houses, 132.

Containers for Parcel Post marketing, 288.

Continental Class, 30.

Continuous house planadvantages of, 130 . disadvantages of, 131. framework of, 136 . plan of, 145, 146.

Cooling eggs, 84.

Cooping exhibition fowls, 265.

Copulation, 61.

Corn, 109, 112, 201, 294. and cob meal, 201. chop, 201. cracked, 109, 112, 212, 292. Kaffir, 109, 112, 201. meal, 109, 110, 112, 201, 212, $291,293,295$. silage, 296.

Cornish-

as capons, 187.

description of, 38 .

standarcl weights of, 39 . varieties of, 39 .

Correlation, 47.

Cost of producing eggs, 216.

Cottonseed meal, 203, 212.

Cracks (eggs), 286.

Crating eggs, 287.

Creolin, 163, 177.

Creosote, 163, 177.

Crested breeds, 349 . head, $51,53,55$.

Crop bound, 171.

Crossbreeding, 50.

Crossing-out, 48.

Crowding chicks, 116.

Crow-head, 56.

Crude oil, 177. petroleum, 183.

Cullingchart, 348.
Culling, (continued)

demonstration, 233.

growing stock, 222.

hens, $225,292$.

kind to cull, 232.

method of, 225.

object of, 222 .

time to cull, 224.

Curing of feathers, 302.

Dampness in poultry houses, 132, 134.

Day-old chicks, care of, 106.

Dead germ, 87, 88.

Defects in breeders, 59 .

Defective combs, 56, 58 .

Demonstrationcaponizing, 196.

contests, 312 .

culling, 233.

egg grading, 304.

feed mixing, 119, 221.

preserving eggs, 126.

selecting the breeders, 66 .

testing eggs, 91.

Department of Agriculture, Federal, 16.

Diarrhea as symptom of cholera, 162.

as symptom of tuberculosis, 163.

in hens, 167.

white in chicks, 168.

Dimensions of houses, 134.

Diseases and treatment, 159. possibilities of spreading, 1.59 .

Disinfecting and storing incubators, 89 .

Disqualifications for commercial eggs, 343 .

for exhibition eggs, 343 .

for poultry, 261 .

Domestication of fowls, 14 .

Double mating, 60.

Doublc-pitched roof, 140.

Drafts, prevention of, 142,151 . 267.

Drawing the fowl, 298 .

Dressing capons, 195.

Dressing: See Dry-picking.

Drinking fountains, 150. as source of spreading disense, 159. 
Dropping board, 147.

Dry-picking, 297.

Drying washed birds, 270.

Ducks-

Aylesbury, 242.

Buff, 243.

Cayuga, 243.

Egg class of, 244.

eggs, 69.

feeding for exhibition, 271 .

feeding for market, 295.

Indian Runner, 244.

management of, 245.

marketing of, 295.

meat class, 240 .

Muscovy, 242.

Ornamental class, 245.

Pekin, 240.

preparing for exhibition, 271 .

Rouen, 243.

Swedish, 244.

Dust boxes, 150.

Dusting for lice, 93, 179, 180. sitting hen, 77.

Ear lobe, color of, 349 .

Education, poultry, 16.

Egg-

albumen of, 68 .

breeds, 30 .

development of, 198.

eating, 173.

laying rations, 211.

membranes, 67.

nest, 76, 281.

producing organs, 199, 231 .

record, 325.

study of, 67 .

tonics, 205.

turning cabinet, 69,70 .

yolk of, $68,108,345$.

anormal, 70 .

and poultry, value of, 11 .

blood ring of, 286 .

bloom of, 69 .

breeding for, 59 .

candling of, 86 .

cleaning, 69, 121.

cooling in incubator, 84 .

cost of producing, 216 .

cracked, 286.

crate for, 287 ,

culling hens for, 222 .
Eggs-

dead-germ, 87, 88.

dirty, 286 .

duck, 69 .

essentials for production of, 198.

exhibits of, 277.

"extras," 284.

feeding for, $211,215$.

fertile, $68,87,88$.

fresh, 69 .

gathering, 69, 282.

grading, 282.

heated, 285.

high production of, 26,30 .

incubation of, 67 .

infertile, $87,88,280$.

kind to preserve, 120.

"leaker," 286.

market grades of, 283.

marketing, 280, 287.

mixing of during incubation, 69.

packing, 70, 287, 289.

preserving, 120.

production, feeding for, 211.

"rots," 286.

score card for, $343,344$.

shape of, 345 .

shell color, 345 .

shell texture, 345 .

shrunken, 285.

selected for incubation, 68 .

size of, 345 .

small, 285.

soiled, 69 .

"special," 283.

"spots," 286.

storing, 282.

thin-shelled, 70.

testing, 86 .

tester, 87.

turning of in incubation, 84 .

uniformity of, 282.

variation in production of, 216.

watery, 286.

weight of, $283,284,285,345$.

Egyptian geese, 247.

Electric incubator, 79.

lights, 219.

Emden geese, 246. 
English breeds: See Generalpurpose and Meat classes.

Epsom salts, 170.

Exhibition-

breed for, 59 .

coops, 265.

first poultry, 258.

object and value of, 258 .

preparing birds for, 258 .

selecting birds for, 260 .

shipping coop for, fowls, 273.

Exhibits, of community breeding clubs, 317 .

junior clubs, 311.

Experimental stations, 337.

"Extras" (Referring to eggs) 284.

Eyes of breeders, 57 .

Face, disqualifications of, 262.

Faking, 263.

Fancier, 44.

Fat, 206, 207.

Fattening battery, 294.

broilers, 291.

capons, 293.

ducks, 295.

geese, 296.

hens, 292.

rations, 291, 293, 294, 295.

turkeys, 294.

Favus, or white comb, 166.

Feather pulling, 172.

Feathered shanks, 34, 51, 52, 263,349 .

Feathers, curing of, 302 .

drying of washed birds, 270 .

market grades and prices, 302 . market value of, 302 .

Fecundity, 48.

Feed and water for growing stock, 111.

cost of, 131.

cost of, for eggs, 216.

for sitting hen, 78 .

mixing demonstrations, 119, 221.

quantity of grain to, 213,215 . record-yearly, 324.

Feeding -

hreeders, 64 .

capons, 194, 293.

chickens, 108.
Feeding, (continued)

condiments and egg tonics, 205.

exhibition birds, 274 .

experiments, 216.

for egg production, 198.

forced, 64 .

growing stock, 108, 111.

methods of, for eggs, 211, 213.

methods of, for chicks, 108.

on range, 215.

stuffs, composition of, 209.

value of, for eggs, 198.

Feeds and by-products-

classification of, 202.

commercial, 201.

composition of, 206, 209.

for fattening: See fattening rations.

grain, 199, 212.

green, 64, 110, 113, 203.

mash, 201.

meat, 202.

quality of, 201.

quantity consumed, 213, 214, $215,216$.

weight and volume of, 347

Feet-

cleaning of, 267, 270 .

disqualifications of, 262 .

Fences, 152.

Fertile eggs, 68, 87.

Fertilizer, value of poultry manure, 301.

Fiber, 208.

Fireless brooder, 103.

Fish scrap, 202, 212.

Fleas-"Stick-tight," 181.

Flock, culling, 222.

breeding of, 61 .

Floors-

board, 136, 137.

concrete, 136.

earth, 136.

kind of, 136.

space of, 134 .

Foundations and floors, 134, $135,136$. concrete, $135,136$.

Framework of building, 136.

French class, 42.

Frozen comb, 63, 167. 
Gable-roof house, 139.

Game and Game Bantam class, 39. varieties of, 40 .

Gapes, 170.

Gates, 155.

Geese--

African, 247.

Chinese, 246.

Egyptian, 247.

Emden, 246.

feeding for weight, 271

management of, 248.

marketing of, 296.

method of catching and carrying, 271.

preparing for exhibition, 271 .

Toulouse, 246.

Wild, or Canadian, 247.

General-purpose class-

breeds of, 26 .

characteristics of, 26.

feeds consumed by, 215

Germ, dead, 86, 87.

spot, $68,86$.

Glass windows, 141.

Gluten meal, 201, 212.

Grading eggs, 282.

"Grading up," 49, 50.

Grain feed for growing stock, 112.

for layers, 212, 213.

growing of, 201.

quantity of to feed, 213, 215.

"Green ducks," 242, 295.

Green feed-

for breeders, 64 .

for chickens, 110 .

for ducks, 295.

for growing stock, 113.

for layers, 203.

growing of in yards, 152, 203.

Grit, 64, 111, 113, 204.

Growing stock-

care of, 115.

culling, 222 .

Growth of chickens, 73.

Guineas-

Lavender, 249.

management of, 250.

marketing of, 296.

Pearl, 249.
Guineas, (continued)

White, 249.

Hamburg class, 42.

Hatch-

early, 73 .

experiments on, 91 .

length of, 71 .

proportion of sex in, 71 .

time of year to, 73,74 .

Hatching and brooding record, 321.

Head-

cleaning of, 270.

crow, 56 .

disqualifications of, 261.

in selecting breeders, 56 .

lice on chickens, 93, 180.

Health and vigor, 54.

Heated eggs, 285.

Hens-

brooding chickens with, 92 .

confining mother hen, 97 .

culling, 225, 292.

definition of, 275 .

fattening, 293.

marketing, 292.

time of year to market, 292.

Heredity, 45.

Hollow tile construction, 134.

Homer pigeons, 252.

Hopper, feeding dry mash, 110 , $113,214$.

Houses and appliances-

colony, 116, 128.

construction of, 132.

continuous, 128.

essentials of, 127.

foundation and floors, 134, $135,136$.

framework of, 136.

front of, 141.

interior of, 144.

kind to build, 128.

location of, 132 .

monitor, 139.

roof of, 138, 139 .

size and dimensions of, 134 .

systems of, 128 .

time to build, 132 .

two-story, 130

walls of, 142 .

Housing growing stock, 115. 
Hovers-

capacity of, $100,101$.

individual, 100.

Hungarian pigeons, 253.

Hydrogen peroxide, 162, 175.

Identifying chickens, 95 .

Inbreeding, 48.

Income tax return, 329.

Incubation-

artificial, 78.

natural, 67,74 .

periods of, 71 .

progress of, 67.

temperature of, 83.

Incubator-

capacity of, 79 .

care of at hatching, 88.

cellar, 80,81 .

disinfecting and storing, 88.

electric, 79 .

hatched chickens brooded by hens, 93.

hot-air, 79.

hot-water, 79.

mammoth, 79 .

operation of, 81,82 .

place to operate, 80 .

selecting, 79 .

types of, 78 .

Indian Runner ducks, 244.

Infertile eggs, 87.

for market, 280 .

Inquiries answered, 332.

Interior fixtures, 144.

Intestinal worms, 170.

Inventory-yearly, 328.

Iodine, tincture of, 165, 166.

Johnnycake, 109.

Jungle fowl, 22.

Junior clubs-

advantages of, 305 .

constitution and by-laws of, 308.

exhibits, 311.

meetings of, 311.

object of organizing, 305.

organization of, 306 .

plans for starting work, 308 .

record, 330.

rules for, 307 .

Kaffir corn, 109, 112, 201.
Keel bone, 230 .

Kerosene oil, 174, 177, 183.

Killingcapons, 195.

methods of, 297.

squabs, 296.

Labor, 130.

Lamp, care of in incubator, 84 .

Land plaster, 301.

Langshanas capons, 187.

description of, 34 .

standard weights of, 34 .

varieties of, 34 .

Lavender guinea, 249.

Layers, characteristics of, 232.

"Leakers" (eggs), 286.

Leghorn-

as capon, 187.

characteristics of, 31 .

standard weights of, 31 .

varieties of, 30,31 .

Leg banding, 95, 223.

Legs and toes of breeders, 58 . disqualifications of, 262.

Lice, 150, 178.

and mites on breeders, 63 .

head, on chickens, 93, 180.

Lights-

artificial, 217.

effect on egg production, 217 , kind of to use, 219.

Limberneck, 164.

Lime, 301.

Limewater for preserving eggs, 123.

Line breeding, 48.

Linseed oil, 174.

Litter, 117, 301. feeding in, 213, 214. for brooders, 94.

Location of houses, 132.

"Loss off" plan of marketing eggs, 287.

Louse powder, 179.

Lumber as building material, $133,134$.

Maltese pigeons, 253.

Mammoth incubator, 79 .

Managementbusiness, 320 . 
Management, (continued) of breeders, 63.

of growing stock, 118. of sitting hen, 77 .

Mangel beets, 115, 203.

\section{Manure-}

amount per bird per year, 300 . analysis of, 301 .

fertilizer value of, 301 . value of, 300 .

Market classification for broilers, 290.

for grades of eggs, 283.

Marketing-

case count method of, 287.

co-operative, 317.

ducks, 295.

frequency of, 287.

geese, 296.

guineas, 296.

importance of, 278.

"loss off" methods of, 287.

methods of, $278,287$.

of broilers, 290 .

of capons, 293.

of eggs, $280,287$.

of hens, 292.

of table fowls, 290 .

of turkeys, 294, 295.

of squabs, 296.

Mash-

dry, for growing stock, 113.

feeding, 213.

feeds, 201 .

for fattening, 291, 293, 295.

for growing chicks, 110 .

hopper, 110, 113, 214.

wet, $110,214$.

Mate, time to, 61.

Mating and breeding, 45 .

Matings-

double, 60 .

flock or mass, 61 .

kinds of, 60 .

single, 60 .

size of, 62 .

stud, 61 .

Meat breeds of ducks, 240 .

Meat class-

breeds of, 33 .

characteristics of, 34 .
Meat scrap, 110, 201, 202, 212, 291.

for breeders, 64 .

importance of, 202.

Mediterranean class, 30.

Meetings of community breeding clubs, 316.

junior clubs, 311 .

Membrane of egg, 67.

Mercurial ointment, 180.

Middlings, 110, 201, 212, 291, 293, 295.

Mill feeds, 201.

Milk-

butter, 291, 293.

skim, 202, 291, 293.

sour, for chickens, 109, 111, 113.

whole, 113.

Minorca-

characteri itics of, 32 .

standard weights of, 32 .

varieties of, 31 .

Miscellaneous class, 41.

varieties of, 42 .

Mites, 176.

Harvest, 183.

Moisture during incubation, 85. type of incubator, 78 .

Molt as influencing production, $74,226$.

feeding during the, 215 .

Mondaine pigeons, 253.

Mongrels, breeding from, 50. vs. standard-bred fowls, 25 .

Monthly statement sheet, 322 .

Muscovy duck, $2 \pm 2$.

Mutations, or sports, 46.

Narragansett turkey, 236.

Neck of breeders, 57 .

Nest eggs, 76.

Nests -

for sitting hens, 76 .

material for, 76 .

proper number of, 149, 281. trap, 149.

Nitrogen-free extract, 206, 207.

Nitrogenous material, 206.

Nomenclature of the fowl, 51, 52.

Non-moisture type incubator, 78 . 
Non-producers, culling, 222.

Non-sitters, 30.

Nutritive ratio, 207.

formula for, 211.

how to determine, 208.

Oats-

as green feed, 203.

ground, 201, 212, 291.

hulled, 109, 112.

neal, 109, 110.

pinhead, 109,

rolled, 109.

sprouted, 110, 115, 203, 204, 291.

Organization of clubs, 305, 306, 316.

of poultry associations, 276 .

Origin of domestic fowls, 22.

Ornamental breeds of ducks, 245.

class of fowls, 42 .

Orpington-

characteristics of, 29.

standard weight of, 29.

varieties of, 29.

Out-breeding, 48.

Out-crossing, 48.

Oviduct, 199, 231.

Ovary, 199, 231.

Oyster shell, 64, 111, 113, 204.

Packing-

dressed fowls, 299.

eggs, 287, 289.

hatching eggs for shipment, 70.

squabs for market, 297.

Painting houses, 155.

Parcel post-

containers, for use by, 288 .

marketing eggs by, 287.

packing for shipment, 289. shipments, weight of, 289 .

Partitions in the house, 142, 141 .

Peanut meal, 203.

Pearl guinea, 249.

Pekin duck, 240.

Pelvic: bones, spread of, 229, 230.

Permanganate of potash: See Potassium permanganate.

Picking ducks, 295.

PigeonsCarneau, 252.
Pigeons, (continued)

Homer, 252.

Hungarian, 253.

Maltese, 253.

management of, 254 .

marketing of, 296.

method of catching, 272.

Mondaine, 253.

preparing for exhibition, 272.

Runt, 251.

squab breeds, 251.

White King, 251.

Pinhead oat meal, 109.

Plumage-

condition of, 55 .

washing of, 266.

Plymouth Rock-

as a capon, 187.

standard weights of, 27.

varieties of, 27.

Polish class, 42.

Posing birds, 266.

Potash salts, 301.

Potassium chlorate: See Chlorate of potash.

Potassium permanganate, 160, 162, 163, 170.

Poultry and eggs-

back-yard, 11, 19.

breeders, 20 .

club record, 330 .

clubs, 305.

development of industry, 14.

distribution of in U. S., 12, 13.

farmers, commercial, 16 .

industry, development of, 14.

industry, size and extent of, 11.

keeping on the farm, 15.

sections, intensive, 17 .

shows, 16, 259.

standard-bred, 25.

value of, 11 .

Premiums for exhibition fowls, $258,275$.

Preparing birds for exhibition, $258,259$.

Prepotency, 48.

Preserved eggs-

keeping qualities of, 120 .

selling, 125.

using, 124 . 
Preserving eggs-

demonstration of, 126.

methods of, 122 .

necessity of, 120 .

time for, 120.

Prevention of poultry diseases, 159.

Principles of breeding, 45 .

Prizes awarded for junior club work, 313.

for exhibition fowls, 275 .

Progression, 47.

Proportion of males to females, 62.

Protein, 206, 207.

Pullet, definition of, 275.

Pullet mating, 61.

Pullets as breeders, 62, 118.

Quality of feed, 110, 201.

Quantity of feed consumed, 216. of feed for chickens, 109 . of grain to feed, $213,215$. of mash to feed, $213,215$.

Range-

as affecting feed consumed, 215.

for breeding stock, 63 .

Rape, 203.

Rations-

balanced, 207.

egg-laying, 212.

fattening, 291, 292, 293, 294, $295,296$.

for chickens, 109, 110.

for growing stock, 112, 113.

Records-

balance, yearly, 329 .

egg, yearly, 325 .

feed, yearly, 324 .

hatching and brooding, 321 .

inventory, yearly, 328 .

monthly statement, 322 .

poultry club, 330 .

summary, yearly, 327 .

Red bugs, or chiggers, 183.

Regression, 47.

Reversion, or atavism, 46.

Rheumatism, 173.

Rhode Island Redsstandard weights of, 29 .

varieties of, 29 .
Roasters, small, 290. soft, 186.

Rolled barley, 109, 112. oats, 109.

Roof and roofing material, 139. types of, 138, 139 .

Roofing paper, 115, 139, 142.

Roost, teaching chickens to, 118.

Roosts, 144.

Rose Comb breeds, 349 .

"Rots" (eggs), 286.

Rouen duck, 243.

Roup, 160.

Rules and regulations for shows 274.

for junior clubs, 307 .

Runt pigeons, 251.

Rye, as green feed, 203.

Salicylic acid, 171.

Salt spray for fleas, 182.

Scalding to pick, 298 .

Scale of points-

for eggs, 343, 344 .

for exhibition fowls, 346 .

for table fowls, 341 .

Scaly leg, 173.

Score card-

for different classes, 346 .

for eggs, 343, 344 .

for table fowls, 341 .

Scraps-table, 213.

Scratch feed-

for chickens, 109.

for growing stock, 112.

for layers, 212.

Selecting birds for the show, $259,260$.

the breed, 23.

the community breed, 315 .

Selection of the breeders, 55 .

Setting a hen, 75 . management of, 77 .

Sex, predetermining, 73 . proportion of, secured, 71 .

Shade for chicks, 116.

Shank-

color as influencing production, 227.

condition of in layers, 228 .

Shanks-

cleaning of, 267, 270 . 
Shanks, (continued)

color of, 349 .

disqualifications of, 262.

effect of soil on, 228.

Shed-roof houses, 139.

Shell-

color, 345 .

description, 67.

gland, 199.

oyster, 204.

texture, 345.

Shipping coops for exhibition fowls, 273 .

for live poultry, 299.

Shows-

kinds of, 259.

organization for holding, 276.

poultry, 16, 259 .

preparing birds for, 258.

rules and regulations, 274.

Sick fowls as breeders, 55, 63 .

Sickness and lack of vigor, 225 .

Side sprigs, example of prepotency, 48 .

Single comb breeds, 349 .

Single mating, 60 .

Size -

of breeders, 55 .

of eggs, 345 .

of house, 134 .

of matings, 62 .

Skin, color of, 59,349 .

Skim milk: See Milk.

Slate turkeys, 236.

"Slip," 194.

Soap for washing fowls, 268 .

Sodium fluoride, 179.

Sodium silicate, or water glass, 122.

Soft roasters, 186.

Soil desirable for fowls, 132 . effect of on shank color, 22x.

Soiled eggs, 69.

Sore head: See chicken pox.

Soy-bean meal, 203.

"Specials" (Referring to eggs), 283.

Sports, or mutations, 46.

"Spots" (Referring to eggs), 286.

Spraying for fleas, 181.

for mites, 177
Sprouted oats, 110, 115, 203, 291.

method for, 204.

Squabs, 251, 256, 296.

Standard-bred, definition of, 25. poultry, 20.

vs. mongrels, 25 .

Standard weights of breeders, 55 .

"Stick-tight" fleas, 181.

Storing eggs, 282.

Strain, definition of, 23.

Stubs, examples of reversion, 47.

Stud mating, 61 .

Sulphur, 162, 165. ointment, 166, 184.

Summary, yearly record, 327.

Survey of farm poultry, 2.50.

Sweet oil, 270.

Swedish duck, 244.

Table forvls, $26,33,60$. score card for judging, 341 .

Table scraps, 212, 214.

Tails-

defective, 57,59 .

disqualifications of, 262.

of breeders, 57 .

Temperature-

correct for brooding, 104.

for storing hatching eggs, 69 .

normal of the hen, 75 .

of incubation, 83.

Testing eggs, 78,86 .

Testicles removed, 193 .

Thermometer, 81 .

Thermostat, 81 .

Ticks, or blue bugs, 182 .

Tinted-shelled eggs, 349 .

Tobacco stems, 170 .

Toe-5th, 53, 55 . picking, 172.

Toe punching chicks, 94, 95.

Toes and legs of breeders, 58 .

Tonics-egg, 205.

Toulouse geese, 246.

Transportation facilities, 14 .

Trap nests, 149 .

Tuberculosis, 163.

Turning eggs, 84 .

rack for, 69 . 
Turkeys-

Black, 235.

breeding of, 238 .

Bronze, 234.

Bourbon Red, 235.

management of, 237.

marketing of, 295.

method of catching and holding, 272.

mortality and disease of, 239.

Narragansett, 236.

preparing for exhibition, 272.

Slate, 236.

White Holland, 234.

Turpentine, oil of, 168.

Uniformity of eggs, 282.

Uterus, or shell gland, 199.

Variation, 46.

Varieties and breeds, 22.

Variety, definition of, 23.

Vaseline, 161, 165, 167.

Vegetable protein feeds, 202, 212.

Vegetables, cooked, 212, 214.

Velvet-bean meal, 203.

Vent color as influencing production, 228 . condition of, in hens, 229 .

Ventilation, 151 during incubation, 81,85 .

Vigor and health, 54 . lack of, 225.

Volume and weight of feeds, 347.

Walls, 142.

Washing birds, 266.

Water-

for chickens, 111, 115.

for layers, 205.

for the breeding pen, 64 .

for washing birds, 268.

fountains, 150 .

glass, 122 .

in feeds, 206.

lime for preserving eggs, 123. percentage of in eggs, 205. percentage of in fowls, 205.

Watery eggs, 286.
Weight-

disqualifying, of breeders, 55 , 263.

of eggs, 345 .

of parcel post shipments, 289.

Weights and volume of feeds, 347.

Wheat-

as green feed, 203.

bran, 109, 110, 201, 212, 291, 295.

flour, 201, 295.

middlings, 110, 201, 212, 291, 295.

screenings, 201.

White Comb, or favus, 166.

White diarrhea, 168.

White guinea, 249.

White Holland turkey, 234.

White King pigeons, 251.

White of egg-quality of, 345 .

White-shelled eggs-breeds that lay, 30,349 . testing, 86 .

Whitewash, 155, 177.

Wild, or Canadian, geese, 247.

Windows, 141.

"Wind puffs", 194.

Wing clipping, 154. disqualifications of, 262.

Wing banding chickens, 95 .

Wings, defective, 57 . of breeders, 57 .

Worms, gape, 170. intestinal, 170.

Wry tail, 58, 59.

Wyandotte-

as capons, 187.

characteristics of, 27.

standard weights of, 27.

varieties of, 27 .

Yards and fences, 152.

Yearly balance sheet, 329 .

egg record, 325 .

feed record, 324 .

inventory, 328 .

summary record, 327.

Yolk of egg, 68, 199.

absorption of, 108.

quality of, 345 . 


\title{
SPECIAL BOOKS for SPECIAL PURPOSES
}

7 N ADDITION TO OUR OWN PUBLICATIONS WE CARRY AN EXTENSIVE 1 STOCK OF THE BEST BOOKS ON ALL SPECIAL PHASES OF THE POULTRY INDUSTRY, ANIMAL HUSBANDRY, GENERAL FARM CROPS, VEGETABLE GARDENING, FRUIT RAISING, SOILS AND THEIR MANAGEMENT, FARM BUSINESS, ETC.

WHENEVER A BOOK THAT GIVES EXPLICIT INFORMATION ON A PARTICULAR SUBJECT IS WANTED, WE INVITE YOU TO ADVISE WITH OUR SERVICE DEPARTMENT.

WE WILL TRY TO HELP YOU.

GENERAL CATALOG SENT ON APPLICATION.

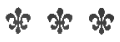

\section{WEBB PUBLISHING COMPANY}

55.79 EAST TENTH STREET

ST. PAUL, MINNESOTA 

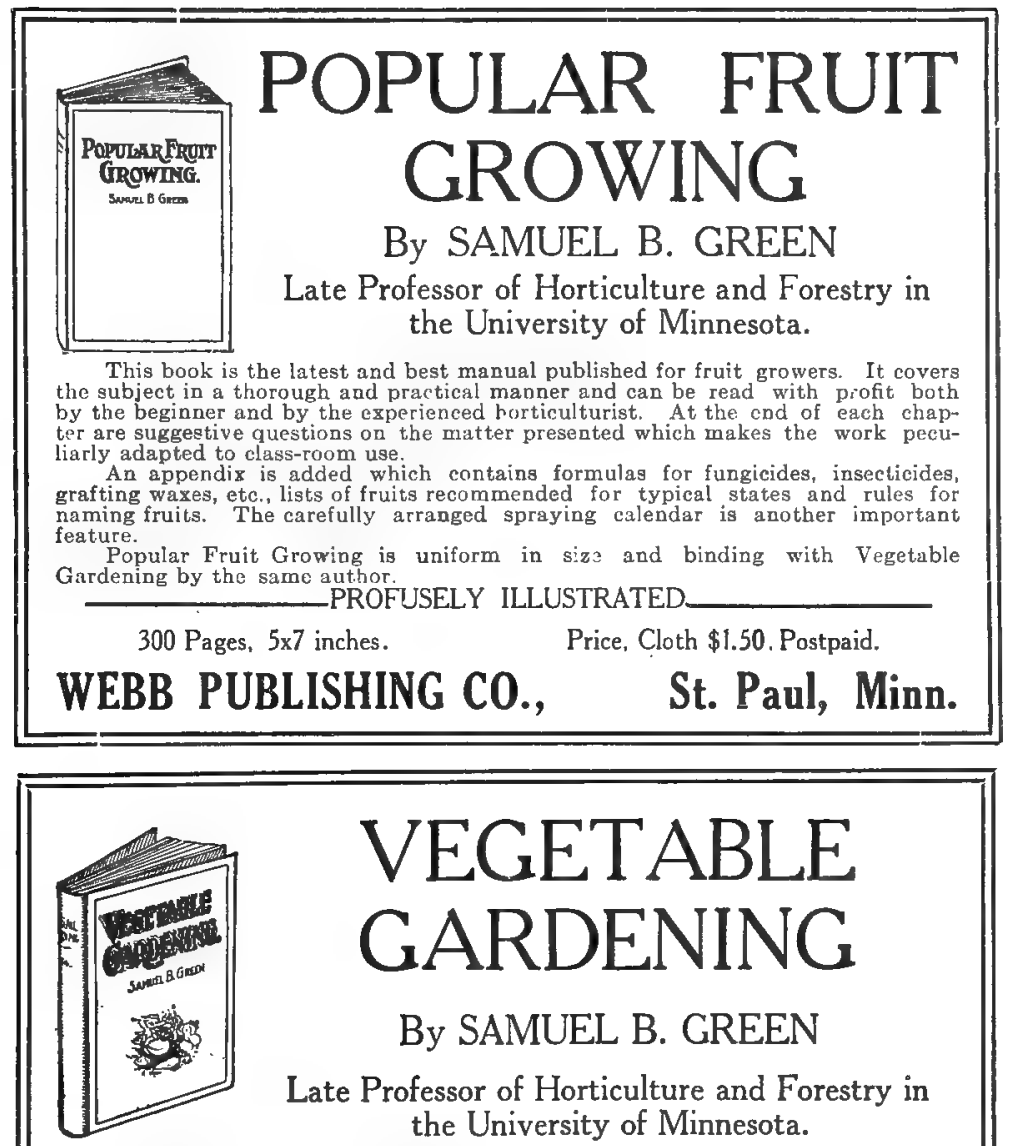

Late Professor of Horticulture and Forestry in the University of Minnesota.

A manual on the growing of vegetables for home use and for the market. The immense sale of tlus book to farmers and gardeners and its wide recognition in agricultural schools and colleges prove it to be a standard work on this subject. This is the fourteenth revised edition.

It sets forth the principles of plant growth, of soil management, of the individual peculiarities of plants, etc., as well as specific instructions for the culture of all the popular vegetables.

The book is set in large, clear type, printed on high class paper, and is strongly and neatly bound.

PROFUSELY ILLUSTRATED
336 Pages, 51/2x71/2 inches.
Price, Cloth, \$1.50 Postpaid.

\section{WEBB PUBLISHING C0., St. Paul, Minn.}




\section{STANDARD BOOKS FOR FARMS AND FARM SCHOOLS}

We can supply any book published on General Farming, Gardening, Dairy, Live Stock, Horticulture, Forestry, Soils, Poultry, Bees, etc. All inquiries and orders for Farm Books will receive prompt attention.

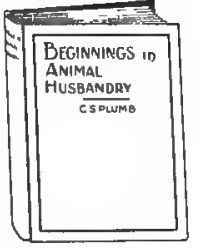

Beginnings in Animal Husbandry

By Prof. C. S. Plumb, of the Ohio State University College of Agriculture. Author of "Types and Breeds," etc. It teaches in a very interesting way what every farmer and farm boy ought to know about types and breeds, judging, breeding, feeding and care of farm animals and poultry. No bock like it has ever been published. 393 pages; 216 illustrations. Cloth bound, $\$ 160$; postage 12c extra.

Field Crops A new standard bonk by A. Agr., and C. W. Warburton, U.S. Dept. of Agr., on the best metheds of growing, harvesting and marketing farm crops; seed selection; fertilizers; cost of production; rotations; and weeds. Handsomely bound; 544 pages; 160 illustrations. A practical book by practical men. Cloth bound, $\$ 1.80$; postage $17 \mathrm{c}$ extra.

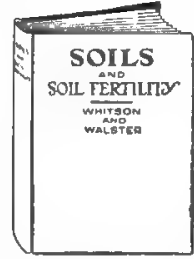

Soils and Soil Fertility A clear, Soils and Soil Fertility non - technical discussion, by Profs. A. R. Whitson and H. L. Walster, of the Wis. College of Agr., presenting the foundation principles of soil management. It tells clearly how to make simple tests of soils to discover their needs; how to fertilize, till, and otherwise handle different types of soil, as sandy, marsh and clay soil. It will answer your perplexing soil questions. 315 pages; well illustrated; nicely bound. Cloth, $\$ 1.60$; postage $12 \mathrm{c}$ extra.

Make all Remittances by Postoffice or Express Orders, or New York, Chicago, or St. Paul Drafts.

\section{Webb Publishing Co., St. Paul, Minn.}





